\title{
Pratiques de la médiation des savoirs
}

\section{Michel Sot (dir.)}

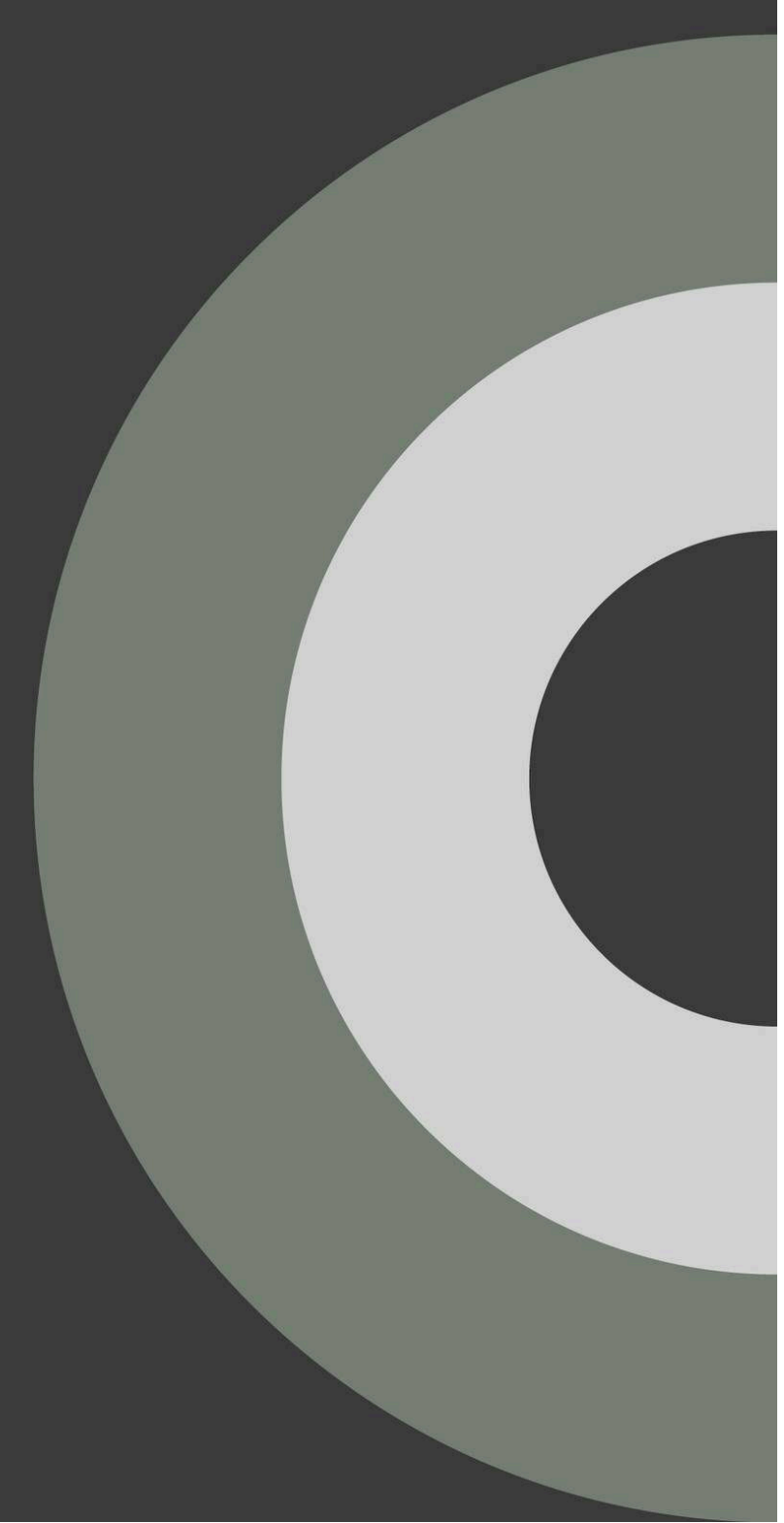




\section{Pratiques de la médiation des savoirs}

\section{Michel Sot (dir.)}

DOI : $10.4000 /$ books.cths. 5280

Éditeur : Éditions du Comité des travaux historiques et scientifiques Année d'édition : 2019

Date de mise en ligne : 5 juin 2019

Collection : Actes des congrès nationaux des sociétés historiques et scientifiques

ISBN électronique : 9782735508983

\section{Sbooks}

http://books.openedition.org

\section{Référence électronique}

SOT, Michel (dir.). Pratiques de la médiation des savoirs. Nouvelle édition [en ligne]. Paris : Éditions du Comité des travaux historiques et scientifiques, 2019 (généré le 20 novembre 2020). Disponible sur Internet : <http://books.openedition.org/cths/5280>. ISBN : 9782735508983. DOI : https://doi.org/ 10.4000/books.cths.5280.

Ce document a été généré automatiquement le 20 novembre 2020.

(C) Éditions du Comité des travaux historiques et scientifiques, 2019 Conditions d'utilisation :

http://www.openedition.org/6540 
D'une personne à une autre, d'une génération à une autre, d'une culture à une autre, les savoirs et les savoir-faire se transmettent. Cette transmission peut être privée ou publique, officielle ou informelle, orale ou écrite. Elle peut avoir lieu dans la sphère familiale, dans le milieu éducatif, dans un cercle professionnel ou encore au sein d'une communauté scientifique. À partir d'exemples de l'Antiquité à nos jours, en France et au-delà de ses frontières, cet ouvrage collectif souligne la diversité des acteurs, des modèles et des canaux de la médiation des savoirs.

Le Congrès national des sociétés historiques et scientifiques rassemble chaque année universitaires, membres de sociétés savantes et jeunes chercheurs. Ce recueil est issu de travaux présentés lors du $143^{\mathrm{e}}$ Congrès sur le thème « La transmission des savoirs ».

\section{MICHEL SOT}

Professeur émérite à Sorbonne Université, membre de la section Histoire et philologie des civilisations médiévales du CTHS 
SOMMAIRE

Introduction

Michel Sot

\section{Apprentissages et savoir-faire}

Apprentissage et apprentis à Lyon au XVII ${ }^{e}$ siècle

Françoise Bayard

Apprentissages et apprentis dans les règlements

Maîtres et familles d'apprentis

Les ratés de l'apprentissage

La transmission de savoir-faire dans la grande entreprise : étude d'une relation éducative expert-novice

Jean-Louis Boutte

La relation de transmission

Méthode

Résultats

Analyse

Discussion

La transmission du savoir au sein de deux coopératives au Gabon Nina-Marinette Makouatsa Boupo

Définition des concepts

Les principaux acteurs de la transmission de la culture coopérative moderne

La transmission de la culture coopérative et l'influence des savoirs exogènes

\section{Rôle historique des sociétés savantes et des savants de terrain}

L'érudition normande dans la France du XIX siècle : le rôle d'Arcisse de Caumont François Guillet

Le rassemblement de la France provinciale savante

Les activités savantes

La diffusion des connaissances : une ambition pédagogique

Le rôle d'enseignant du conservateur de musée de province membre de sociétés savantes sous la III République

Géraldine Masson

Les musées de la III République et la transmission des savoirs

Les conservateurs des musées de province et la transmission des savoirs : une noble mission vers la voie de la professionnalisation

Les conservateurs de musées membres des sociétés savantes très impliqués dans la transmission des savoirs

L'excursion archéologique, outil de construction et vecteur de diffusion des savoirs antiquaires en France au XIX siècle

Odile Parsis-Barubé

Un préalable à la construction des savoirs antiquaires

Une propédeutique du regard

La diffusion d'une poétique et d'une esthétique du paysage archéologique 
Interruption dans le processus de transmission du savoir : exemple des grottes préhistoriques de Montmaurin (Haute-Garonne) fouillées par Louis Méroc (1904-1970) Amélie Vialet

Les grottes préhistoriques de Montmaurin

Montmaurin aujourd'hui

L'organisation de l'archéologie préhistorique dans la deuxième moitié du xx siècle

Louis Méroc, le « bon élève »

La portée scientifique des sites de Montmaurin

Montmaurin « oublié »

Le rôle des sociétés de publication de documents dans la transmission des savoirs : l'exemple de la Société des archives historiques de la Saintonge et de l'Aunis Pascal Even

Un rouage de l'érudition saintongeaise au tournant du $\mathrm{xx}^{\mathrm{e}}$ siècle

La renaissance de la Société des archives historiques

\section{Savoirs oraux, savoirs écrits, archives}

Entre l'oral et l'écrit : la transmission des contes et récits populaires en Alsace Marie-Noële Denis

La tradition orale des contes et récits populaires

Un nouveau genre littéraire : les contes alsaciens

Des formes modernes de transmission au $\mathrm{Xx}^{\mathrm{e}}$ siècle

Mémoires orales du canal de Suez

Philippe Joutard

Les conditions de l'enquête

« Une jolie mémoire »

Un cosmopolitisme totalement assumé

Le Panthéon et la transmission des savoirs sur Marie Curie : enjeux et apports d'une nouvelle forme de médiation

Ginette Gablot

Le Quartier latin et la mémoire du couple Curie

Enjeux et apports d'une célébration

Un quartier qui requiert une médiation

Transmission des savoirs et pratiques des archives dans les familles nobles du Portugal d'Ancien Régime

Filipa Lopes

Savoirs archivistiques et pratiques d'archivage : une brève contextualisation

Autour des premières pratiques d'archivage familial au Portugal

Entre l'influence des modèles rationalistes et les besoins familiaux dans un monde en mutation

La double médiation archivistique des savoirs

Jean-Marie Yante

Fabriquer de l'archive

L'archivage 


\section{Les savoirs à l'épreuve de l'interculturel}

Transmettre l'art de transmettre : la grammaire latine entre Antiquité et Moyen Âge (IV -IX siècle)

Michel Sot

Renaissance carolingienne et grammaire

Les deux phares de la grammaire latine entre Antiquité et Moyen Âge : Donat et Priscien

Donat et son Ars grammatica (apr. 350)

Transmission et évolution de la grammaire latine du IV ${ }^{\mathrm{e}}$ au IX ${ }^{\mathrm{e}}$ siècle : de la Méditerranée aux îles

Britanniques et au royaume puis Empire franc

Le détour par les îles Britanniques (VII ${ }^{\mathrm{e}}-\mathrm{VIII}^{\mathrm{e}}$ siècles)

Astronomes voyageurs du XVII ${ }^{e}$ siècle : Cassini et les missions lointaines

Monique Gros

Le contexte scientifique

Les missions astronomiques et géographiques

Les jésuites mathématiciens astronomes de Louis XIV en Chine

Transmettre le savoir à travers la traduction : interprètes européens et chinois auprès de la main-d'œuvre chinoise employée en France pendant la Première Guerre mondiale

Yuan Hua Liu-Honvault

Un nécessaire recrutement de personnel bilingue pour accompagner la main-d'œuvre chinoise Une première solution : les « officiers interprètes » européens

Une solution complémentaire : le recrutement d'interprètes chinois

Entre transmission des savoirs et propagande politique : Jules Patouillet et l'Institut français de Pétrograd à l'époque de la Grande Guerre

Manuel Geist

Un acteur de « l'expansion intellectuelle de la France »? L'Institut français de Saint-Pétersbourg avant la guerre (1910-1914)

«Ce propagateur de pensée française en Russie » : l'Institut français de Pétrograd pendant la Grande Guerre (1914-1918) 
NOTE DE L'ÉDITEUR

Les articles de cet ouvrage ont été validés par le comité de lecture des Éditions du Comité des travaux historiques et scientifiques dans le cadre de la publication des actes du $143^{e}$ Congrès national des sociétés historiques et scientifiques tenu à Paris en 2018. 


\title{
Introduction
}

\author{
Michel Sot
}

1 Des nombreuses contributions au $143^{\mathrm{e}}$ Congrès national des sociétés historiques et scientifiques tenu à Paris en 2018 et consacré à la transmission des savoirs, on a retenu pour ce volume, organisé en quatre parties, un certain nombre d'articles consacrés aux pratiques de la médiation des savoirs. On s'intéresse d'abord à l'acte social de transmission, chez l'artisan, dans la grande entreprise européenne et dans la coopérative en Afrique. Puis on en vient au rôle des savants de terrain et des sociétés savantes, dont nous sommes les héritiers, dans la recherche et dans la diffusion des connaissances qu'ils ont élaborées aux $\mathrm{XIX}^{\mathrm{e}}$ et $\mathrm{XX}^{\mathrm{e}}$ siècles en France. Notre attention est ensuite attirée sur la mémoire orale, jusqu'à aujourd'hui, pour recueillir et fixer des savoirs avant qu'ils s'effacent, tandis que les écrits deviennent archives, méthodiquement classés et analysés. Enfin il a paru opportun de rappeler que la transmission des savoirs ne s'opère pas seulement à l'intérieur d'une même culture, mais aussi d'une culture à l'autre, que ce soit dans le temps long du passage de l'Antiquité au Moyen Âge ou dans l'espace large des contacts entre l'Europe et la Chine au XVII ${ }^{\mathrm{e}}$ ou au XX ${ }^{\mathrm{e}}$ siècle, ou entre la France et la Russie de 1911 à 1918.

On peut donc voir ici comment à Lyon, au $\mathrm{XVII}^{\mathrm{e}}$ siècle, l'apprentissage est soigneusement régi par des textes précis et comment les nombreuses difficultés d'applications sont portées en justice ou réglées à l'amiable. Dans les grandes entreprises d'aujourd'hui, on a préféré parler de professionnalisation plutôt que d'apprentissage, cultivant une relation de transmission entre un professionnel expérimenté et son successeur. Au Gabon, les coopératives apportent aux paysans des savoir-faire techniques et organisationnels qui sont reçus en partie de l'intérieur et en partie de l'extérieur, et qui contribuent au développement.

3 Avec l'archéologue Arcisse de Caumont, on pénètre ensuite dans l'érudition normande et dans la France savante du $\mathrm{XIX}^{\mathrm{e}}$ siècle, qui entend bien n'être pas seulement parisienne et fait ce qu'il faut pour cela, publiant des guides et des ouvrages de vulgarisation, organisant des manifestations culturelles à l'influence considérable sur la bourgeoisie et les intellectuels. Parmi les animateurs de ce grand mouvement, les conservateurs de musées de province, très souvent membres de sociétés savantes, jouent un rôle capital, parallèle à celui de l'école sous la Troisième République. Dès la 
monarchie de Juillet, l'excursion archéologique était devenue la déclinaison scientifique du "voyage pittoresque et romantique", avec des comptes rendus qui constituent un véritable genre littéraire, alliant la description archéologique à l'émotion poétique. Les pratiques des sociétés savantes des $\mathrm{xx}^{\mathrm{e}}$ et $\mathrm{xxl}^{\mathrm{e}}$ siècles s'inscrivent dans cette filiation, tandis que les normes scientifiques officielles évoluent, ce qui peut amener des difficultés comme dans le cas des grottes préhistoriques de Montmaurin, mais aussi une renaissance, comme pour les publications de la Société des archives historiques de la Saintonge et de l'Aunis.

4 Il est trop souvent admis que la transmission de la littérature populaire, ici alsacienne, a été orale. De fait, elle est tout autant écrite, dès le XIV siècle en partie, et systématiquement avec les folkloristes du $\mathrm{xIX}^{\mathrm{e}}$. Mais on assiste aujourd'hui au renouveau d'une oralité populaire, par la télévision en particulier. Il n'est pas sans intérêt de constater l'acuité de la transmission orale en Égypte contemporaine des souvenirs de l'inauguration du canal de Suez. La mémoire est souvent liée à des lieux. L'expérience de la visite commentée "Marie Curie, le Panthéon et le quartier ", à laquelle un nombreux public curieux de science a pris part, est, à cet égard, significative. Mais pour cultiver la mémoire et passer à l'histoire, il faut des archives, et les archives posent des problèmes de gestion : c'est ce qu'on peut observer avec les familles nobles sous l'Ancien régime au Portugal, quand la diplomatique et la paléographie deviennent des disciplines universitaires, à la fin du XvIII ${ }^{e}$ siècle. Une réflexion méthodique sur la double médiation des archives conclut cette troisième partie.

5 La grammaire latine a été codifiée à Rome au IV ${ }^{\mathrm{e}}$ siècle par un Africain, dont l'œuvre est reprise par les savants carolingiens au $\mathrm{IX}^{\mathrm{e}}$ siècle. Elle leur a été transmise via l'Italie et l'Espagne, mais surtout via l'Angleterre et l'Irlande, où le latin était une «langue étrangère ». La transmission des savoirs pose donc des questions internationales et interculturelles. Les savants astronomes du xVII siècle, Cassini en particulier, s'impliquent dans de nombreuses expéditions lointaines, et des jésuites mathématiciens et astronomes sont envoyés par Louis XIV en Chine : le but est d'établir la carte du monde. De façon plus prosaïque, on retrouve des Chinois en France entre 1917 et 1919: 140000 d'entre eux travaillent au service de l'armée française et de l'armée anglaise, ce qui pose la question des interprètes pour la transmission des ordres et donc pour l'efficacité, mais aussi celle d'une rencontre possible des cultures. C'est pour promouvoir une coopération scientifique franco-russe qu'un Institut français avait été fondé à Pétrograd en 1911. Pendant la Première Guerre mondiale, sous l'impulsion de Jean Patouillet, son directeur, il devient un organe de propagande politique, forme évidemment particulière de transmission du savoir. 


\section{AUTEUR}

\section{MICHEL SOT}

Professeur émérite à Sorbonne Université, membre de la section Histoire et philologie des civilisations médiévales du CTHS 
Apprentissages et savoir-faire 


\title{
Apprentissage et apprentis à Lyon au XVII ${ }^{\mathrm{e}}$ siècle
}

\author{
Françoise Bayard
}

1 À Lyon, au XVII ${ }^{e}$ siècle, les 68 métiers sont régis par 134 règlements déposés à la municipalité, vérifiés par la sénéchaussée avant d'être approuvés par la monarchie. 110 d'entre eux mentionnent l'apprentissage. Les contrats d'apprentissage et les plaintes portées en justice montrent la manière dont ils sont appliqués ${ }^{1}$.

\section{Apprentissages et apprentis dans les règlements}

Concernant l'apprentissage, les règlements expliquent les formalités à accomplir, les conditions d'accès, sa durée et les devoirs des maitres et des apprentis. La mise en apprentissage et sa sortie nécessitent des formalités administratives et financières. 43 règlements, dont celui des maîtres bâtiers de 1669, mentionnent la nécessité de "passer un contrat devant notaire ${ }^{2}$ » et avec témoins ${ }^{3} .69$ y ajoutent l'enregistrement obligatoire sur le livre du métier, soit en avertissant les maîtres gardes "pour se trouver lors de la passation de l'acte d'apprentissage devant notaire ${ }^{4}$, soit que l'opération se fasse ultérieurement en faisant «enregistrer les noms et surnoms des apprentis dans les livres de la communauté qui seront en l'hôtel de ville, au greffe de la sénéchaussée et entre les mains des maîtres ${ }^{5}$ ».

68 règlements mentionnent le paiement d'une somme d'argent pour la signature du contrat, allant de 5 sous en 1599 pour les fabricants de canetilles, de cordons de chapeaux et de guimpes en or et en argent à 20 livres chez les orfèvres en 1686, la valeur la plus courante ( 32 cas) étant de 3 livres, ainsi chez les cordonniers en $1671^{6}$. Pour les 64 règlements mentionnant la destination de cette somme, elle va tantôt aux pauvres de l'hôtel-Dieu de Lyon, pour les apothicaires; tantôt à la location d'une chambre, pour les chapeliers ; tantôt à l'enregistrement de l'acte d'apprentissage, pour les corroyeurs ; mais elle est surtout destinée à la communauté de métier (15), ainsi chez les bouchers en 1700 ; à la réparation de la chapelle et au service divin (39), comme chez les benniers en 1674 ; ou conjointement à la communauté et à la confrérie 
(3, dont les guimpiers), ou encore à la chapelle et à l'enregistrement du contrat (2, dont les tapissiers $\left.{ }^{7}\right)$. Certains règlements, dont ceux des cordiers ${ }^{8}$, précisent que le maître est responsable de ce paiement si l'apprenti est défaillant. D'autres, comme celui des libraires en 1675, indiquent que le versement de cette somme s'effectue "sans qu'ils soient tenus de faire aucun festin ni dépense de bouche aux entrées et sorties dudit apprentissage 9 ", ce qui tend à prouver que ces réjouissances étaient autrefois de règle.

L'apprentissage terminé, le maître délivre un brevet d'apprentissage (63 règlements y font référence), passé devant notaire et témoins, sinon il serait nul, dit le règlement des pâtissiers et oublieurs ${ }^{10}$. Les apprentis ne peuvent en effet travailler comme maîtres " qu'après l'avoir fait apparaître aux maîtres gardes ${ }^{11}$ ». 44 règlements, dont ceux des gantiers parfumeurs ${ }^{12}$, ajoutent la nécessité de « le faire savoir aux maîtres gardes pour faire inscrire sur un livre leur nom et surnom pour travailler comme compagnon ${ }^{13} »$.

5 L'accès à l'apprentissage est soigneusement réglementé. À certaines périodes, aucun apprenti n'y a accès. C'est le cas de 7 métiers, parmi lesquels les barbiers-chirurgiens en $1688^{14}$. Le trop grand nombre d'ouvriers qui ne peuvent vivre de leur activité est mis alors en avant, comme chez les emballeurs en 1679 :

«Attendu le nombre excessif des apprentis, compagnons et maîtres du dit art qui se sont faits depuis les derniers règlements de 1564, auquel temps il n'y avait que 62 maîtres dans la ville au lieu qu'à présent ils sont au nombre de plus de 110 et les fils de maîtres compagnons et apprentis encore en plus grand nombre, ce qui fait qu'une partie desdits maîtres sont réduits à prendre le pain de l'aumône ${ }^{15}$."

6 «Ce qui pourrait les faire tomber dans les désordres et les lâchetés que l'oisiveté cause ordinairement ${ }^{16} "$, renchérissent les selliers. Quant aux guimpiers, ils déplorent la fuite des maîtres et de leurs techniques à l'étranger :

«La plupart, étant sans occupation, ont été obligés pour pouvoir subsister de se retirer dans les pays étrangers, où ils ont porté le secret de cette manufacture qui était florissante en cette ville, et qu'ils ont eu le malheur de voir diminuer tous les jours si considérablement que même la plupart des fils et filles de maîtres sont contraints d'apprendre d'autres professions ${ }^{17}$.»

7 Les temps d'arrêt varient de deux ans, pour les emballeurs, à vingt ans pour les orfèvres.

8 Le nombre des apprentis est limité soit globalement - ainsi les barbiers, étuvistes et perruquiers doivent-ils être « 200 à Paris, 20 dans les autres villes et 6 dans chacune des autres villes choisies par ceux qui font la profession ${ }^{18}$ »-, soit par atelier. Sur les 93 règlements pour lesquels on dispose de ce renseignement, 37, comme les cardeurs de soie $^{19}$, ne peuvent en prendre qu'un à la fois. Toutefois, 43 règlements prévoient que, quelque temps avant la fin du contrat d'un premier apprenti, les maîtres, ainsi les pelletiers ${ }^{20}$, puissent en prendre un second. Les cordiers peuvent en instruire deux ; les maitres doreurs, trois ; les bossetiers, six et les fondeurs, huit ${ }^{21}$. Dans 7 professions, l'importance de la fabrique conditionne le nombre d'apprentis : chez les futainiers, les propriétaires de douze métiers peuvent embaucher trois apprentis, et quatre s'ils ont dix-huit métiers ${ }^{22}$. Une exception est faite chez les fabricants de canetilles en 1599 ainsi que chez les marchands de futaines en 1670 et $1676^{23}$ pour les filles de l'Aumône générale ${ }^{24}$, qui peuvent être embauchées en supplément.

Des exigences particulières de sexe, d'âge, d'état civil, de religion et d'instruction s'ajoutent dans certains règlements. Les fabricants de canetilles et les cardeurs ne veulent "aucune apprentisse " alors que les libraires et les passementiers ${ }^{25}$ les acceptent si le maître est marié. L'âge minimum des apprentis est mentionné 8 fois. 
Chez les balanciers ${ }^{26}$ et les passementiers, il est de douze ans ; chez les ouvriers en soie, de treize ; chez les teinturiers, de quatorze à quinze ans ; chez les tapissiers, de quinze ans; chez les tondeurs de drap, de seize ans et chez les imprimeurs, de vingt ans ${ }^{27}$. L'état civil des apprentis figure dans 12 règlements. Ils peuvent être mariés chez les futainiers mais 6 corps de métier, dont les chapeliers, les veulent célibataires ${ }^{28}$. La religion est inscrite dans 13 règlements. 9 règlements, à l'instar de celui des bouchers, souhaitent des apprentis catholiques. Les fourbisseurs et les peintres et sculpteurs ${ }^{29}$ refusent les apprentis de la "religion prétendue réformée ». Enfin, les apothicaires souhaitent qu'ils «soient instruits aux premières lettres ", les imprimeurs en 1659 et 1661, ainsi que les libraires en 1675 et $1681^{30}$, qu'ils sachent lire et écrire, et, en 1675 et 1676 , qu'ils connaissent la langue latine jusqu'aux humanités, les imprimeurs y ajoutant la lecture du grec en 1695.

La durée de l'apprentissage est variable. En 1588, les aiguilletiers prennent un apprenti tous les ans "pour le temps et terme qu'il plaira au maitre ${ }^{31}$ ", mais dans les 95 autres règlements, le temps est fixé. Il est de deux ans pour les boutonniers en 1659 ; de trois ans pour 32 règlements, dont celui des cardeurs de soie; de quatre ans pour 39 règlements, dont celui des fondeurs; de cinq ans pour 20 règlements, à l'instar de celui des plieurs de soie; de six ans pour les horlogers et de huit ans pour les orfèvres ${ }^{32}$. Les uns et les autres justifient la durée de l'apprentissage « à cause du long travail et expérience nécessaire qu'il faut pour être capable audit $\operatorname{art}^{33}$ » (horlogers) ou " attendu que l'art est très difficile et très pénible ${ }^{34}$ » (teinturiers) et, de manière générale, " pour établir la perfection et fidélité requise ${ }^{35}$ » (tonneliers), « pour obvier aux grands abus et désordres qui se commettent audit métier au désavantage de leur réputation et au préjudice du public ${ }^{36}$ » (fileurs et mouliniers de soie) et pour maintenir la qualité de la production, comme chez les boulangers :

«le principal désordre ne venant que de la facilité de certains maitres boulangers qui donnent des quittances à leurs apprentis par anticipation du temps où ils reconnaissent d'en avoir été servis quoiqu'effectivement ils n'aient pas satisfait à l'article 5 desdits règlement qui les engagent à faire leur apprentissage pendant trois ans pour devenir maitre et leur ôtent par ce moyen l'occasion d'apprendre leur métier, par conséquent de faire du bon pain ${ }^{37}$.»

11 C'est pourquoi la durée de l'apprentissage ne peut être réduite : 22 règlements, dont celui des chandeliers ${ }^{38}$, mentionnent cette nécessité.

Les fils de maîtres sont, en général, dispensés d'apprentissage, ce qu'exprime le règlement des selliers en 1629 : « auxquels il sera permis de lever boutique étant d'âge compétent, payant les droits sans faire apparaître aucun apprentissage pourvu qu'ils aient servi audit art leurs pères ou autres maitres ${ }^{39}$ ". Ils sont même les seuls à pouvoir apprendre un métier quand l'activité se ferme, ainsi pour les orfèvres en 1686. Dans 66 règlements, comme chez les forgeurs, ils voient également leur contribution diminuer : un fils de maître doit payer 10 livres pour accéder à la maîtrise quand « les compagnons ayant fait leur apprentissage à Lyon doivent 30 livres et les compagnons étrangers $40^{40} »$. Des conditions techniques sont allégées. Chez les apothicaires, ils ne doivent passer qu'un examen et ne faire qu'un seul chef-d'œuvre au lieu de quatre, payer 30 livres au lieu de 50 et avoir exercé deux ans comme compagnon au lieu de quatre. Un âge minimum est cependant requis pour leur installation : au moins vingt ans pour prendre des apprentis et des compagnons chez les emballeurs en 1679 et les forgeurs en 1698 ; quinze ans chez les guimpiers, vingt-cinq ans chez les plieurs de soie en 1668 , puis vingt ans en 1688 ; seize ans chez les tondeurs de draps. 

libraires relieurs : «On ne prendra qu'une apprentie à la fois, non compris les veuves et les filles de maitres ${ }^{41}$.» Mais leur cas est plus compliqué, car elles sont susceptibles d'épouser des hommes d'une profession différente. "Les filles qui ont fait leur apprentissage et se marient avec quelqu'un qui n'est pas passementier ne peuvent pas former des apprentis", disent les passementiers en 1637. En revanche, «si elles se marient avec un compagnon de l'état, elles pourront tenir une boutique et former des apprentis $^{42}$ ».

14 Une fois placés, les apprentis doivent observer un certain nombre de règles. En premier lieu, et bien que seulement quatre règlements en parlent expressément, ils « demeureront annuellement en la maison et service de leurs maitres et non hors de ladite maison ${ }^{43}$ ", comme le disent les guimpiers. Par conséquent, ils ne doivent pas s'absenter, ce qui est dénoncé dans 43 règlements. C'est pourquoi, disent les cartiers, «pour obvier aux plaintes et procès qui naissent journellement par la fuite des apprentis des maisons et service de leurs maitres et contenir cette jeunesse en son devoir ${ }^{44}$ ", des sanctions sont prévues. Les selliers en 1681 et les ouvriers en soie envisagent « de faire arrêter [l'apprenti] partout où il sera ${ }^{45}$ ». S'il revient, la plupart du temps, l'apprenti est tenu de finir son temps, ainsi chez les charrons ${ }^{46}$. Mais d'autres métiers sont plus rigoureux. En 1661, les imprimeurs font accomplir aux apprentis fugueurs le double du temps de leur absence, ainsi chez les libraires relieurs en 1619, 1675 et 1689. En 1696, ce tarif n'est valable qu'une fois chez les imprimeurs. En cas de récidive, l'apprenti est déchu définitivement de l'apprentissage, avec inscription sur le livre par le syndic et son adjoint. L'apprenti est exclu au bout d'un temps variable. Chez les bouchers en 1675, «après quinze jours d'absence, le maître pourra en affermer un autre après avoir fait rompre et biffer du livre l'interruption. De retour, l'apprenti ne pourra pas continuer le temps de l'apprentissage mais sera tenu de recommencer le temps ${ }^{47} »$; en 1700 , le temps d'absence s'allonge à un mois avant de faire rayer les apprentis, comme chez les tapissiers. Les passementiers leur donnent deux mois ; les cartiers, trois mois. Par ailleurs, les apprentis ne doivent pas se mettre au service d'un autre maitre sans le consentement du premier, ce que rappellent les tailleurs d'habits par deux fois.

Outre leur conduite au travail, les apprentis sont tenus d'avoir une vie irréprochable En 1668, les guimpiers les empêchent « d'aller au cabaret pendant le service divin ${ }^{48}$ ". 12 règlements précisent qu'ils ne doivent commettre ni larcins ni crimes. Si tel était le cas, leur brevet serait cassé (chapeliers); ils ne seraient pas reçus à la maitrise (chapeliers, menuisiers, vitriers) ; ils seraient remis aux maîtres gardes qui leur feraient faire un procès par le prévôt des marchands (emballeurs, plieurs de soie, tanneurs); n'auraient pas de travail (libraires-relieurs) ou seraient chassés de la profession (emballeurs) ${ }^{49}$. De manière générale, «aucune personne de mauvaise vie ou repris de justice de quelque note d'infamie ne sera recevable audit métier ${ }^{50} »$ (selliers). Enfin, ils ne doivent pas s'assembler sans la permission du prévôt des marchands (emballeurs, forgeurs) sous peine d'être considérés comme "perturbateurs du repos public ${ }^{51}$ ", condamnés à la prison et à une punition exemplaire (chez les imprimeurs, qui condamnent même les confréries).

De leur côté, les maîtres ont également des devoirs. Ils sont solidaires financièrement de leurs apprentis si ces derniers ne peuvent payer ce qu'ils doivent à la communauté ou à la confrérie. 4 règlements rappellent que les maitres ne doivent pas congédier les 
apprentis sans cause légitime, validée par les maîtres gardes ; 24 qu'ils ne doivent pas prendre à leur service les apprentis de leurs collègues ; 7 insistent sur la nécessité de leur apprendre le métier, dont les tapissiers, qui signalent que certains maîtres obligent des apprentis en bas âge à étudier le temps de leur apprentissage au lieu d'apprendre leur future profession; chez les passementiers :

« [...] Plusieurs maîtres résidant ès lieux circonvoisins de cette ville, au lieu de faire travailler leurs apprentis et apprendre ledit art et métier de tissotier, les envoient les uns aider à labourer la terre et les autres à garder le bétail ou en d'autres œuvres différentes et non dépendantes dudit art, et par ce moyen ne vivent ni demeurent en la maison du maitre et font couler ainsi le temps à leurs apprentis au grand détriment et ruine dudit art ${ }^{52}$. »

D'où les recommandations des fileurs : « Ils ne prétendront rien desdits apprentis pour leur apprentissage à la charge de vaquer continuellement par ledit apprentissage à apprendre le métier ${ }^{53}$ »; des imprimeurs : «Les compagnons ne peuvent détourner ou interrompre leur travail ou envoyer les apprentis en ville pour leurs affaires particulières ou s'en servir en aucune manière que ce soit pour leur usage sans le consentement de leur maître ${ }^{54} »$; et des pâtissiers :

« [Les maitres] ne peuvent envoyer leur apprenti vendre et débiter par la ville des petits pâtés, échaudés, casse-museaux, gâteaux ou autres, à cause des inconvénients et maladies qui en peuvent arriver et de la perdition des apprentis qui ne peuvent apprendre leur métier et ne peuvent à la fin de leur temps être bon ouvrier ${ }^{55}$. »

Deux cas particuliers sont envisagés dans 7 règlements. Le premier concerne l'absence de travail : tant les cartiers que les guimpiers ou les tanneurs recommandent alors de voir avec les maîtres gardes si un autre maître peut employer les apprentis. Le second cas a trait à l'absence ou au décès du maître. 52 règlements précisent que les veuves peuvent alors mener l'apprentissage jusqu'à son terme, mais qu'elles ne sont pas autorisées à prendre de nouveaux apprentis. Cependant, si elles ne veulent pas le faire, on en référera aux maîtres gardes, de même si les veuves laissent l'apprenti sans travail pendant un mois (forgeurs) ou trois mois (plieurs de soie). Le recours à la veuve n'est pas systématique : chez les cardeurs de soie, les apprentis peuvent terminer leur temps chez les héritiers ; chez les peintres-sculpteurs-vitriers, aller chez un autre maître, avec l'accord des maîtres gardes ; de même chez les toiliers, à moins que le maître ait déjà un autre apprenti.

Les règlements de métier organisent donc clairement l'apprentissage au sein de la profession. Leur application n'est cependant pas toujours aussi nette, comme l'attestent les contrats d'apprentissage.

\section{Maîtres et familles d'apprentis}

Comme prévu dans les règlements, les contrats sont signés devant notaire. Trois études lyonnaises (Chappelu, Magdinier, Couchard) ont été dépouillées pour les années 1600, 1650,1700 . Y ont été ajoutés les actes de Favard père, notaire de l'Aumône générale. Au total, 82 contrats ont été répertoriés : 18 en $1600 ; 4$ entre 1636 et $1654 ; 11$ en 1650 ; 19 en 1700 et 30 passés par l'Aumône générale entre 1632 et 1674 . Seuls 2 actes mentionnent les maitres gardes, qui en théorie doivent être présents lors de la signature $^{56}$. Tous les contrats comportent les mêmes éléments : le nom et la profession de ceux qui placent quelqu'un en apprentissage auprès d'un maître, dont le nom et le métier sont précisés, la durée de l'apprentissage, les obligations de chacune des parties 
et le prix de l'apprentissage, l'acte se terminant par les signatures éventuelles des contractants. Les documents signés par les recteurs de l'Aumône générale pour leurs enfants adoptifs sont identiques, mis à part les noms de leurs familles.

L'examen de l'ensemble de ces données permet de cerner les profils des apprentis et des personnes qui les placent, les prix et les conditions globales des apprentissages ainsi que leur évolution au cours du siècle.

Ce sont essentiellement des garçons $(66: 80,5 \%)$ qui sont ainsi remis. Il n'y a que 16 filles (19,5\%), dont 13 sont issues de l'Aumône générale. Leur âge n'est pas indiqué. Cependant, l'un d'eux est marié ${ }^{57}$.

Dans la majorité des cas, ce sont les pères ( 22 cas : $42 \%$ ), les mères quand elles sont veuves ( 9 cas : 17,3\%), voire les deux parents $(2$ cas) ou un père et une grand-mère ( 1 cas) qui confient leurs enfants. Mais 5 garçons $(9,6 \%)$, dont Jacques Chabaud ${ }^{58}$, se mettent seuls en apprentissage. Il peut aussi s'agir d'un oncle (4 cas : 7,6\%), d'une tante ( 1 cas), ou de ces deux ascendants ( 1 cas), d'un frère ( 1 cas), accompagné de son épouse (1 cas), d'un ami agissant par procuration, comme Louis Bachelier actant pour le fils d'Antoine Croiset, habitant en Dauphiné ( 4 cas) ${ }^{59}$. Un cas particulier concerne un maître désirant donner un métier à une ancienne servante : Jamet, ayant charge des affaires de Larthuy pour Marianne Polet, « ci-devant à son service ${ }^{60}$ ».

Quand on connaît leurs lieux de résidence, ces personnes habitent, pour l'essentiel, à Lyon (30; 65,2\%). Mais 16 (34,7\%) viennent de Savoie, du Bugey, du Dauphiné, du Roannais, du Beaujolais (2 cas) ou surtout de la proche région lyonnaise (10 cas) ${ }^{61}$. Dans l'ensemble, ils sont, le plus souvent, artisans ou commerçants (33 cas). Seul Blaise Tricaud se dit écuyer ${ }^{62}$. Les 7 autres sont laboureurs ou vignerons ${ }^{63}$. Au cours du siècle s'opère une nette fermeture : de moins en moins de ruraux ( 4 en 1600, 3 en 1650, aucun en 1700) placent leurs enfants à Lyon ( 9 en $1600 ; 5$ en $1650 ; 2$ en 1700). Ce qui explique que les conditions sociales sont de moins en moins variées : en 1700, 3 maîtres ouvriers en soie mettent leurs fils chez des homologues ${ }^{64}$, alors qu'en 1600 et 1650, l'arrivée en ville entraînait le changement d'activité et de condition.

Le nombre de métiers a d'ailleurs tendance à diminuer: en 1600, on place les 18 apprentis dans 11 métiers différents ; en 1650, les 11 jeunes dans 9 métiers; en 1700, les 19 apprentis dans 9 métiers ( 9 d'entre eux apprenant la profession de maître ouvrier en draps de soie et 2 celle de sellier). On discerne alors le passage de l'artisanat à la mono-industrialisation de la ville. Seule l'Aumône générale fait encore apprendre 18 professions différentes à ses 30 adoptifs.

La durée de l'apprentissage est loin d'être toujours conforme à celle qui est fixée dans les règlements : sur les 63 contrats sur lesquels elle figure, 22 sont moins longues - ainsi Georges Perrot et Benoît Beaujolais, marchands teinturiers de soie, qui prennent Jean Guittera pour trois ans quand il en faudrait quatre ${ }^{65}-; 7$ contrats le font durer plus que nécessaire, comme le maître futainier Noël Miot, qui se charge de Claude Fuerat pour quatre ans au lieu de trois ${ }^{66} ; 34$ (54\%) respectent les temps prévus, à l'instar du maître passementier Denis Filachat (quatre ans ${ }^{67}$ ). Une évolution nette se dessine au cours du temps : en 1700, $75 \%$ des durées sont conformes à la réglementation. La plus mauvaise contractante est l'Aumône générale au milieu du $\mathrm{XVII}^{\mathrm{e}}$ siècle $(33,3 \%$ de durées non conformes). Sur les 54 actes qui mentionnent le prix de la mise en apprentissage, $15(27,7 \%)$, à l'instar de Rambert Daffaud ${ }^{68}$, versent moins de 30 livres ; 32 (59,2\%), dont Andrée 
Coulhoud $^{69}$, de 31 à 150 livres ; 7 (12,9\%) plus de 150 livres. S'y ajoutent généralement des étrennes $\left(5\right.$ écus $\left.^{70}\right)$ ou des épingles ( 2 écus ${ }^{71}$ ) pour les femmes des maîtres. Ces sommes sont versées en plusieurs fois : Bernard Chirat paie 2 écus 12 sols à Noël, 2 écus 12 sols en mars et 2 écus 12 sols le Noël suivant ${ }^{72}$. On peut aussi payer en nature: Antoine Durand donne deux pièces de vin clairet de 4 asnées chacune à Antoine Polet, et Antoinette Cotele 50 livres et un baril de vin clairet de trois ans et demi ${ }^{73}$.

Les différences de prix s'expliquent difficilement. L'apprentissage d'un même métier requiert des sommes différentes : en 1600, un cordonnier demande 24 écus quand un autre en réclame $16^{74}$; en 1650, il est payé 48,12 ou 75 livres $^{75}$; en 1700, l'apprentissage d'un maître ouvrier en soie varie de 14 à 250 livres $^{76}$. Le lien n'est pas clair non plus avec le nombre d'années d'apprentissage: au début du XvII siècle, les trois ans d'apprentissage sont rémunérés 100 livres chez un libraire, 300 livres chez un procureur, 42 livres chez un serrurier ${ }^{77}$. Il faut donc conclure à une hiérarchie des métiers - l'Aumône générale verse 120, 140 et 150 livres pour l'apprentissage de maître chirurgien $^{78}$ quand elle paie 18 livres pour un maître tondeur de draps ${ }^{79}$ - et à l'excellence de certains maîtres par rapport à d'autres.

On notera cependant une nette évolution au fil des années: en 1600, aucune rémunération n'est supérieure à 150 livres, quand une l'est en 1650 et trois en 1700 . L'institution de l'Aumône générale est beaucoup plus généreuse que les particuliers : 10 contrats sur 14 prévoient une somme de 31 à 150 livres et 2 de 151 à 300 livres. Le maitre sellier Claude Richard reçoit 200 livres pour la formation d'Antoine Dumas, quand son homologue Benoît Garet en perçoit 60 et $100^{80}$.

30 À ce prix, destiné au paiement de la pension de l'apprenti et à la rémunération du maître pour le temps qu'il lui consacre, s'ajoutent, dans 68 contrats, d'autres frais que doivent prendre en charge les familles ou l'Aumône générale. 32 d'entre eux (47\%) doivent "entretenir, habiller, chausser ${ }^{81}$ " l'apprenti. Les recteurs précisent parfois leur nombre : « 3 habits neufs en plus de ce qu'il a »; « un habit d'hiver, un habit d'été et 3 chemises $^{82}$ ».

31 Le blanchissage est toujours évoqué : il est fait soit par la famille - la mère de Guillaume Chirat le «tiendra blanc de lessive ${ }^{83}$ »-, soit par le maître - Claude Carles «sera reblanchi par son maitre quand il fera la lessive ${ }^{84} » .6$ contrats sont beaucoup plus évasifs, la famille se contentant «d'entretenir l'apprenti en habits et autres choses nécessaires ${ }^{85} »$.

Dans 13 contrats, les familles doivent aussi se porter caution de l'apprenti, à l'instar de Françoise Cachard ${ }^{86}$. Jean Antoine, seul, doit de plus envisager de payer des dommages et intérêts " advenant qu'il lui fasse chose sinistre et digne de représentation ${ }^{87}$ ». Dans 16 contrats enfin, la famille s'engage à représenter l'apprenti et « à le faire réintégrer le service $^{88}$ " s'il s'absente de l'atelier. D'autres dispositions sont plus ponctuelles : Pierre Palleux et Andrée Couchard enverront « un maître chez les patrons pour apprendre à lire et à écrire à leurs fils ${ }^{89}$ "; Jean Montagnon " fournira un petit lit sur des tréteaux, garni d'une paillasse, d'un matelas, d'un traversin de plumes, de linceuls et de couverture $^{90} »$. Il semblerait que les préoccupations évoluent au cours du siècle: la fourniture des vêtements et l'entretien des apprentis n'apparaissent plus en 1700, date à laquelle la seule condition mentionnée est la réintégration, signe peut-être que les jeunes gens sont plus réticents vis-à-vis des maîtres. On pourrait penser à une évolution entre 1600 et 1700 , mais il peut ne s'agir que de formules propres à chaque notaire. 

siècle. Pour les apprentis, «servir, procurer profit, obéir, sans s'absenter ${ }^{91}$ ». Quelques variantes interviennent dans les termes du contrat : après "profit ", on ajoute " sans dommage, lui rendre compte de ce qu'il maniera pour lui ${ }^{92}$ "; après " obéir ", « en tout ce qui lui est commandé d'honnête et licite ${ }^{93}$ "; après "dommage ", " et autrement faire comme un vrai et loyal serviteur envers son maître sans lui forfaire aucunement ${ }^{94}$ ».

Les devoirs des maitres sont : « enseigner sans cacher ni celer, administrer son boire, manger et coucher ${ }^{95}$ ». Certains ajoutent « et autres aliments requis et nécessaires pour sa nourriture $\mathrm{e}^{96}$ \%. D'autres mentionnent la lumière ${ }^{97}$; concernant leur art, certains précisent ce qu'ils leur apprendront : «montrer à coudre, blanchir et couper le linge ${ }^{98}$ ». Deux contrats de l'Aumône générale insistent sur l'éducation morale : «l'enseigner en bonne vie et mœurs, crainte de Dieu, en bonne mère de famille ${ }^{99}$ "; « l'enseigner en bonnes mœurs et conversation en bon père de famille ${ }^{100}$ ». Ces constatations rejoignent, en gros, celles de Rafik Toumi portant sur 600 contrats $^{101}$.

Suivant la réglementation, les contrats semblent tout prévoir ; mais tout ne se passe pas toujours comme envisagé.

\section{Les ratés de l'apprentissage}

Dans l'ensemble, les relations entre les apprentis et les maîtres se passent bien. En témoignent les éloges des patrons à la fin de l'apprentissage. Si la plupart se contentent d'une formule brève - «Barthélemy Rey, maître emballeur, est satisfait de son apprenti Michel Volin ${ }^{102}$ »-, d'autres ajoutent une phrase relative à l'avenir de l'apprenti : « Jean Saint-Genis a fini son apprentissage; il l'a fidèlement servi et il consent qu'il aille travailler où bon lui semblera ${ }^{103} \%$. Ce brevet est le gage d'une embauche rapide: Isabeau Jubin, qui «a bien et fidèlement servi pendant quatre ans ${ }^{104}$ " Claudine Maupetit, épouse de François Roulliat, maître ouvrier en soie, s'engage immédiatement auprès de Charles Monnet et de sa femme.

Attestent également des bonnes relations entre apprentis et maîtres certaines attitudes décrites dans les plaintes déposées à la sénéchaussée, montrant que l'apprenti, sans se détacher de sa famille naturelle - comme dans le cas de Pierre Joannard, qui rend visite à son père, vigneron à Saint-Cyr-au-Mont-d'Or ${ }^{105}$ - fait désormais partie de celle du maître : Jean Franchelin dîne avec Alphonse Durantet, maître ouvrier en draps de soie, sa femme et leur servante ${ }^{106}$; Benoît Potin prend le frais devant la porte du domicile de son patron ${ }^{107}$.

38 S'il survient un incident, ils s'épaulent l'un l'autre : le perruquier Lequin entre dans la boutique du marchand Lempereur en son absence et agresse l'apprenti de ce dernier, qui le retrouve en pleurs à son retour. Le marchand se rend immédiatement chez le perruquier et lui envoie son compte ${ }^{108}$. Le jour de Pentecôte, Jacques Contant et sa femme entendent «que leur apprenti avait été frappé. Ils sont descendus pour obliger [l'agresseur] de venir à leur domicile ${ }^{109}$.» L'apprenti se range du côté des patrons: Benoîte Sapet va chez Claude Grebon pour avoir paiement de 44 livres que ce dernier doit à son mari : «Grebon et son apprenti ont fermé la porte sur elle et lui ont porté des coups de pieds et de poings en diverses parties de son corps ${ }^{110}$. " Catherine, veuve Jofferay, son fils et son apprenti ont injurié et prononcé des chansons insolentes à 
Étiennette Legat, épouse Bebin, et à sa fille. Les victimes «dirent que ce n'était pas honnête de faire dire à son fils et apprenti de telles chansons "; Catherine Jofferay « demande alors à son apprenti de jeter un seau d'eau sur elles et ils continuent de les injurier ${ }^{111} »$.

Pourtant, les relations ne sont pas toujours excellentes dans les ateliers. Les difficultés sont réglées à l'amiable ou doivent être portées en justice. Apprentis et maîtres peuvent se désister devant notaire, sans que la raison en soit donnée ou à cause d'une faute de l'apprenti - absence en particulier ${ }^{112}$. Dans d'autres cas, des apprentis sont transférés à un autre maître: «Benoît Bernard, maître ouvrier en draps de soie, remet Jean Lapiernaute, son apprenti, à Simon Coste, maître dudit art, pour le temps restant à faire de son apprentissage ${ }^{113}$.» Ces changements apparaissent souvent en fin d'apprentissage : Antoine Barillot, maitre ouvrier en drap de soie, est «satisfait du service et fidélité que Jean-François Rey lui a rendu depuis le 5 octobre 1696 pour parachever le temps de l'apprentissage commencé avec Jean Quidran le 7 juin $1695^{114}$ ». Ces événements peuvent être pluriels dans la vie d'un apprenti : le 21 juillet 1667, Nicolas Bourdet, maître ouvrier en drap de soie, remet Guillaume Girardon à Étienne Jourdan pour continuer son apprentissage, commencé le 15 janvier 1665 avec François Vidaud, qui l'avait lui-même remis à Nicolas Bourdet ${ }^{115}$. Les raisons des transferts, prévus dans les règlements à condition d'être validés par les maîtres gardes du métier ils le sont dans 3 cas $^{116}$ sur les 16 relevés - sont généralement inconnues, sauf une fois : Claudine Foucard, épouse de Nicolas de Lacour, maître passementier, confie Florie Jonas à Pierre Métaré « pour n'avoir de quoi l'employer ${ }^{117}$ ». Mais il n'est pas interdit de penser que les apprentis ont exaspéré les premiers maîtres.

Six types de conflits sont susceptibles d'être introduits en justice, à l'instar de ceux qui interviennent dans les relations de travail ${ }^{118}$. Il peut s'agir de difficultés entre apprenti et compagnon - comme pour le procès qui oppose, pour une raison inconnue, Jean Vanel et Pierre Charmezal, apprenti et compagnon chandeliers chez Pipon ${ }^{119}$ - ou de problèmes entre apprenti et ancien maître, comme pour le procès qui confronte le satinaire Jean Recaut à Marin Stango, chez qui il a fait son apprentissage ${ }^{120}$. Dans 10 cas, cependant, il s'agit de problèmes entre apprenti et maître. Dans 4 cas, l'apprenti, représenté généralement par un de ses parents, se plaint de mauvais traitements. Par exemple, Claude Sellimard est entré en apprentissage chez Claude Gret, maître ouvrier en soie, le 23 mars 1654. Il y est resté jusqu'au 26 avril 1656, jour où :

« [Gret] sans sujet quelconque l'ayant battu et excédé à coups de poings, de pieds et de nerfs de bœuf avec effusion de sang, [...] jurant et blasphémant le saint nom de Dieu et proclamant que tant que le fils Sellimard demeurerait à son service, il le maltraiterait ${ }^{121} »$.

41 Pierre Barset, apprenti ouvrier en soie chez Antoine Milleret, revient d'un pèlerinage à Valfleury où, la pluie l'ayant surpris, il est resté deux jours :

«Ayant quitté son justaucorps pour se mettre au travail, Milleret s'approcha un bâton à la main [et] prit plaisir à compter les cinquante coups qu'il lui donna. Il a mis le bâton en plusieurs morceaux. Il est demeuré comme mort sur place. Il l'a déjà battu deux fois avec la même cruauté ${ }^{122}$. "

Cette violence est assez semblable à celle que pratiqueront plus tard deux patronnes lyonnaises ${ }^{123}$. Dans d'autres cas, ce sont les injures qui pleuvent: Pierre-Noël Mory, apprenti de Pierre Fillon, maître juré tireur d'or, est abordé par le frère de son patron :

«Te voilà, bougre de fripon, de coquin, voleur, tu as dérobé les retailles de mon frère que tu as revendues à un orfèvre, injures atroces à l'honneur du plaignant ${ }^{124}$. » 


\section{la veuve Rivière :}

«[Elle] a conçu contre lui une telle haine et animosité sans aucun sujet qu'elle l'injurie et maltraite journellement et le fait injurier et maltraiter par ses parents. Hier vers $4 / 5$ heures du soir, il est monté au grenier étendre des peaux. La veuve l'a suivi, l'a pris par les cheveux et lui a donné des soufflets. Il est descendu dans la tannerie où il espérait trouver du secours. Mais le compagnon qui s'y trouvait lui a donné deux coups de barre de fer et l'a poussé. Blessé à la tête, il s'est relevé et s'est enfui. L'ouvrier l'a suivi en le menaçant : "Il faut que je t'assomme"125. »

De leur côté, les apprentis ne sont pas sans défauts. Certains fuguent : Pierre, l'apprenti de Louis Tillier, " est sorti de chez lui en emportant toutes les hardes qu'il lui avait

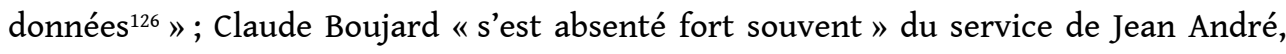
maître ouvrier en drap de soie ${ }^{127}$. D'autres se rebellent contre leur patron, l'insultant et exerçant des violences, comme Joseph Janin, apprenti de Pierre Gotail : «Ne pouvant souffrir les remontrances de son maître, il l'insulte et le menace tous les jours »; le $1^{\text {er }}$ juillet, il est venu avec deux complices pour maltraiter Pierre Gotail. « Il a saisi une des chevilles de son métier, lui en a donné plusieurs coups et a excédé sa femme à coups de pieds et de poings ${ }^{128}$.» Pierre Deville, apprenti de Jacques Mathelon, a été traité de fainéant par son patron, qui lui a demandé de travailler :

« [L'apprenti] s'est emporté contre lui en jurant et blasphémant le nom de Dieu, s'est rué sur lui en lui portant plusieurs coups en plusieurs endroits de son corps et notamment un coup de pied au genou, lui ayant arraché les cheveux et déchiré sa cravate. Puis il a pris un grand couteau, dont il l'a voulu frapper lui ayant porté un coup sur la main ${ }^{129}$.»

Jean Duperey, apprenti de Julien Perrin, abuse de sa confiance : il loue un cheval soidisant au nom de son maître, qui affirme qu'il n'a rien demandé et que Jean Duperey n'est plus à son service depuis deux ans ${ }^{130}$. Non content de fuguer, Claude Jumel a une conduite en tout répréhensible :

«Entre autres, sur la fin du mois de novembre dernier, il fut vu par beaucoup de personnes dans sa boutique tellement pris de vin qu'il n'y eut pas moyen de le faire bouger de la place où il était. Et d'ailleurs il s'est rendu si désobéissant qu'au lieu de porter les souliers dans les maisons qu'il lui indiquait, il sortait, allait se promener où bon lui semblait. »

Outre ce « mauvais naturel », « il a gâté beaucoup de besogne ${ }^{131}$ ».

\footnotetext{
Bien réglé sur le papier, l'apprentissage n'est donc pas forcément bien pratiqué à Lyon au XVII siècle.
} 


\section{BIBLIOGRAPHIE}

BAYARD Françoise, « Les conflits du travail portés en justice : Lyon, XVII ${ }^{\mathrm{e}}-\mathrm{XVIII}{ }^{\mathrm{e}}$ siècles ", dans Hamon Maurice (dir.), Le travail avant la révolution industrielle, actes du $127^{\mathrm{e}}$ Congrès national des sociétés historiques et scientifiques (Nancy, 2002), Paris, Éditions du CTHS, 2006, p. 71-81.

BAYARD Françoise, « Anne Meunier et Catherine Maria : deux mauvaises patronnes en 1751 », dans Terrier Didier et al. (dir.), Tisser l'histoire : l'industrie et ses patrons (XVI ${ }^{e}-\mathrm{XX}^{e}$ siècle), mélanges offerts à Serge Chassagne, Valenciennes, Presses universitaires de Valenciennes, 2009, p. 157-167.

TOUMI Rafik, « L'apprentissage à Lyon au XVII esiècle », mémoire de DEA d'histoire, Lyon, université Lumière - Lyon II, 2003.

\section{NOTES}

1. Les règlements se trouvent aux archives municipales de Lyon dans les séries $\mathrm{HH}$ et $1 \mathrm{C}$ et, dans une moindre mesure dans la série BP des archives départementales et métropolitaines du Rhône, où se trouvent aussi les contrats et les documents judiciaires, dans les séries 3E et BP. Dans les notes qui suivent, la localisation des fonds n'a pas été répétée.

2. HH 17, 8 mars 1669.

3. HH 167, 26 février 1682 (passementiers).

4. HH 35, 21 août 1698 (charpentiers).

5. HH 185 (tailleurs d'habits).

6. HH 183, 12 août 1599 (fabricants de canetilles) ; HH 112, 27 avril 1686 (orfèvres); HH 78, février 1671(cordonniers).

7. 1C 304107, 1660 (apothicaires) ; HH 31, 1685 (chapeliers) ; HH 77, 1683 (corroyeurs); HH 19, 30 mars 1700 (bouchers); HH 17, 24 décembre 1674 (benniers) ; HH 92, [s. d.] (guimpiers); HH 189, 29 novembre 1676 (tapissiers).

8. $\mathrm{HH} 77,1639$.

9. HH 98, 3 octobre, 4 octobre 1675.

10. HH 172, 22 juin 1671.

11. HH 181, 22 juin 1662 (selliers).

12. HH 91, 22 juin 1662, 3 mars 1672.

13. HH 181, 22 juin 1662.

14. HH 175, 2 septembre 1688.

15. HH 81, 6 juillet 1679.

16. HH 181, 1686.

17. HH 92, 9 avril 1699.

18. 1C 704 733, 23 mars 1673.

19. HH 27, 20 novembre 1631.

20. HH 174, 4 septembre 1681. 
21. HH 77, 1639 (cordiers) ; BP 3608, 4 août 1691 (fondeurs).

22. HH 88, 1670.

23. HH 88, 15 décembre 1676.

24. L'Aumône générale est une institution de charité adoptant les orphelins, les élevant et leur trouvant un métier.

25. 1C 304 339, 6 juin 1619 (libraires) ; 1C 305 146, 1637 ; HH 167, 26 février 1682 ; [s. d.] (passementiers).

26. 1C 304 161, 2 juin 1668 (balanciers).

27. HH 128, 2 juillet 1687 (ouvriers en soie) ; HH 191, 8 avril 1686 (teinturiers) ; HH 189, 1698 (tapissiers) ; HH 201, 16 novembre 1683 (tondeurs de drap) ; BP 3615, avril 1696 (imprimeurs).

28. HH 89, 15 décembre 1676 (futainiers) ; HH 31, 6 mai 1670 (chapeliers).

29. HH 87, 1673 (fourbisseurs) ; HH 174, 1681 (peintres et sculpteurs).

30. HH 98, 4 octobre 1675 ; 9 décembre 1681.

31. 1C $304265,1588$.

32. BP 3608, 18 janvier 1659 (boutonniers) ; HH 86, 1668 (fondeurs) ; HH 179, 20 juin 1668 (plieurs de soie).

33. 1C 304329, 1660.

34. HH 191, 8 avril 1686.

35. HH 202, 5 mars 1675.

36. HH 84, octobre 1619.

37. 1C 304 156, 23 octobre 1699.

38. HH 29, 1693.

39. 1C $702490,1629$.

40. HH 87, 23 juillet 1681.

41. 1C 304 339, 6 juin 1619.

42. 1C 305 146, 1637.

43. HH 92, s. d.

44. HH 28, 1675.

45. HH 181, 26 juin 1681

46. HH 36, 13 novembre 1670.

47. 1C 304 166, avril 1669.

48. HH 181, 25 juin 1681 ; HH 92, 21 juin 1668.

49. HH 109, 5 août 1678 (menuisiers) ; HH 208, 27 août 1693 (vitriers) ; HH 188, 1698 (tanneurs).

50. 1C 702490, 18 mars 1634.

51. HH 81, 6 juillet 1679 ; HH 87, 26 septembre 1698.

52. 1C 305 146, 1637.

53. HH 84, septembre 1600 .

54. BP 3615, 1661.

55. HH 172, 22 juin 1671. 
56. 3E 3793, 2 mars et 12 décembre 1700.

57. 3E 6245, 3 juin 1650.

58. 3E 3793, 25 juin 1700.

59. Ibid., $1^{\mathrm{er}}$ décembre 1700 .

60. 3E 3472, 24 décembre 1600.

61. 3E 6245, 21 février 1650 (Savoie) ; 3E 3472, 26 février 1600 (Bugey), 22 avril 1600 (Roannais), 3 juin 1600 (Beaujolais).

62. 3E 3472,14 juillet 1600.

63. 3E 6245, 12 mars 1650 (laboureurs), 24 août 1650 (vignerons).

64. 3E 3793, 17 mars 1700.

65. 3E 3472, 22 avril 1600.

66. 3E 6245, 21 février 1650.

67. 3E 3793, 2 mars 1700.

68. 3E 6245, 24 mai 1650.

69. 3E 3793, 7 juin 1700.

70. 3E 3472, 19 avril 1600.

71. Ibid., 3 juin 1600.

72. Ibid., 17 septembre 1600.

73. $3 \mathrm{E} 3793,5$ août, $1^{\mathrm{er}}$ septembre 1700.

74. 3E 3472, 16 février, novembre 1600.

75. 3E 6245, 17 mars, 24 mai, 3 juin 1650.

76. 3E 3799, 17 octobre, 12 août 1700.

77. 3E 4846, fol. 255, 18 novembre 1636 (libraire) ; 3E 4847, fol. 518, 18 novembre 1647 (procureur) ; 3E 4848, fol. 284, 19 mars 1654 (serrurier).

78. $3 \mathrm{E} 4846$, fol. 420,12 juillet 1639 ; 3E 4847, fol. 288 et fol. $392 \mathrm{v}^{\circ}, 31$ août et 26 octobre 1646 ; 3E 4846, fol. 346, 7 mai 1638.

79. 3E 4847, fol. 288, 31 août 1645.

80. 3E 4848, fol. 576, 3 septembre 1656 ; 3E $3793,1^{\text {er }}$ et 15 décembre 1700.

81. 3E 3472, 23 décembre 1600.

82. 3E 4846, fol. 148, 30 novembre 1634 ; 3E 4848, fol. 123, 3 mars 1652.

83. $3^{\mathrm{E}} 3472,7$ septembre 1600 .

84. 3E 3472, 17 septembre 1600 ; 3E 4847, fol. 292, 31 août 1645.

85. 3E 6245, 23 mai 1650.

86. $3 \mathrm{E} 3472,1^{\mathrm{er}}$ août 1600 .

87. Ibid., 4 septembre 1600.

88. 3E 3793, 17 mars 1700.

89. Ibid., 11 mai, 7 juin 1700.

90. Ibid., 25 novembre 1700.

91. 3E 3472, 19 janvier 1600.

92. 3E 6245, 3 juin 1650. 
93. 3E 3793, 17 février 1700.

94. 3E 4847, fol. 288, 31 août 1645.

95. 3E 3472, 19 avril 1600.

96. Ibid., 22 avril 1600.

97. 3E 3793, 2 mars 1700.

98. Ibid., 8 juin 1700 .

99. 3E 4849, fol. 143, 4 mai 1662.

100. 3E 4849, fol. 143, 4 mai 1662 ; 3E 4851, fol. 49, 23 janvier 1674 .

101. R. Toumi, «L'apprentissage à Lyon au XVII ${ }^{\mathrm{e}}$ siècle ».

102. 3E 3793, 10 septembre 1700.

103. 3E 4848, fol. $352 \mathrm{v}^{\mathrm{o}}, 9$ novembre 1654.

104. 3E 4849, fol. $656 \mathrm{v}^{\mathrm{o}}, 5$ octobre 1667.

105. BP 2902, 13 juin 1685.

106. BP 2904, 13 septembre 1685.

107. BP 2895, 12 juin 1684.

108. BP 2869, 7 août 1680.

109. BP 2918, 21 mai 1687.

110. BP 2868, 28 juillet 1680.

111. BP 2919, 13 juillet 1687.

112. 3E 4849, fol. 656, 20 septembre 1667 ; 3E 3793, 15 août 1700 ; 3E 4851, 22 avril 1674.

113. 3E 4849, fol. 194, 3 janvier 1663.

114. 3E 3793, 30 juin 1700 .

115. 3E 4849, fol. 639, 21 juillet 1667.

116. 3E 4848, fol. 771, 13 juillet 1658 ; 3E 4849, fol. 163 et 639, juillet 1662 .

117. 3E 4848, fol. 771, 13 juillet 1658.

118. F. Bayard, « Les conflits du travail portés en justice : Lyon, XVII ${ }^{\mathrm{e}}-\mathrm{XVIII}{ }^{\mathrm{e}}$ siècles ».

119. BP 2902, 18 juin 1685.

120. BP 2910, 14 juin 1686.

121. BP 2842, 26 avril 1656.

122. BP 2934, 6 juin 1689.

123. F. Bayard, «Anne Meunier et Catherine Maria: deux mauvaises patronnes en $1751 »$.

124. BP 2873, 3 mai 1681.

125. BP 2918, 3 mai 1687.

126. BP 2926, 31 juillet 1688.

127. BP 2873, 12 mai 1681.

128. BP 2919, 4 juillet 1687.

129. BP 2894, 8 mai 1694.

130. BP 2856, 12 mai 1673.

131. BP 4508, 17 décembre 1661. 


\section{RÉSUMÉS}

À Lyon au XVII ${ }^{\mathrm{e}}$ siècle, l'apprentissage des 68 métiers est régi par les règlements déposés à la municipalité et vérifiés par la sénéchaussée, rassemblés aux archives municipales de Lyon (séries HH et $1 \mathrm{C}$ ). Les 82 contrats d'apprentissage étudiés, signés devant notaire, précisent les personnes qui engagent les apprentis, leur origine géographique, le maître et le métier choisis, le prix de l'apprentissage, les obligations respectives des maîtres et des familles pour leur entretien (série 3E des archives départementales et métropolitaines du Rhône). De nombreuses difficultés d'application sont réglées à l'amiable ou portées en justice, attestant que maîtres et apprentis ne remplissent pas toujours leurs devoirs (série BP des archives départementales et métropolitaines du Rhône).

\section{AUTEUR}

\section{FRANÇOISE BAYARD}

Professeur honoraire d'histoire moderne à l'université Lumière - Lyon II 


\title{
La transmission de savoir-faire dans la grande entreprise : étude d'une relation éducative expert-novice
}

\author{
Jean-Louis Boutte
}

1 Les sciences de l'éducation étudient les situations et les dispositifs dans lesquels un individu ou un groupe apprend, que ce soit de manière formelle, au sein d'institutions, ou de manière informelle. Elles développent des champs théoriques comme la didactique, la pédagogie, l'apprentissage, l'évaluation et la formation. Pour ce faire, les approches sont multiréférencées, recourant à diverses disciplines, comme la philosophie, l'épistémologie, la psychologie, la sociologie, l'ethnologie et l'ergologie (Ardoino 1978 et 1990). Les approches historiques sont aussi éclairantes. Si les parcours scolaires occupent une large part des travaux, la formation professionnelle continue est aussi investiguée. Le lien formation initiale-formation professionnelle-travail, que certains nommeraient la professionnalisation, est un champ important de recherche en sciences de l'éducation.

2 La présente étude a été menée dans le monde de la grande entreprise entre 2000 et 2005 (Boutte 2007), et son intérêt est, nous semble-t-il, toujours vif dans le contexte d'aujourd'hui. Si son objet, la transmission de savoir-faire, est une pratique coutumière et traditionnelle dans le monde artisanal (Chevallier 1991), elle ne l'est plus dans la grande entreprise, si ce n'est de manière tacite. Or les éléments contextuels mettent en évidence la nécessité de réhabiliter cette pratique oubliée.

3 La grande entreprise contemporaine, encore marquée par les principes du taylorisme, vit au rythme des changements économiques, sociaux, technologiques et de leur accélération. Dès la fin des Trente Glorieuses, de profondes mutations ont transformé l'industrie française. La crise économique de 1992 a amplifié ces transformations et les a étendues aux autres secteurs, au tertiaire notamment. Ainsi, les années 1990 ont été marquées par de grands bouleversements : restructurations, offres publiques d'achat (OPA) plus ou moins hostiles, avec leurs cortèges de plans sociaux. Des cohortes de salariés atteints par la limite d'âge ont quitté leurs emplois prématurément. Les « plans 
amiante » sont venus accélérer ces départs massifs. Parallèlement, les recrutements se sont réduits et le taux de chômage n'a cessé d'augmenter.

Depuis 2006, avec l'intégration de nouvelles technologies, les entreprises vivent une nouvelle mutation démographique : l'accélération des départs à la retraite de la génération baby boom et l'arrivée massive de la génération $Y$, puis de la génération $Z$ (Barabel et al. 2012). La génération intermédiaire, dite $X$, qui aurait dû entrer sur le marché de l'emploi dans les années 1990, est sous-représentée. Les pyramides des âges se modifient, faisant cohabiter deux, voire trois générations, dont les aspirations et les représentations diffèrent largement. Les nouvelles générations ont intégré la précarité comme composante du rapport au travail, la nécessaire stratégie d'adaptation aux changements et la posture d'acteur réseau (Livian 2007), facilitée par l'usage familier des nouvelles technologies (Serres 2012). Les recrutements massifs de certains profils ont pour conséquence une pénurie déjà sensible dans certaines filières.

Pour l'entreprise, de nouveaux enjeux apparaissent: elle doit attirer et fidéliser ces nouveaux talents, optimiser leur professionnalisation, faciliter la cohabitation et la collaboration des générations. Parmi les dispositifs mis en œuvre, les contrats en alternance sont utilisés comme dispositifs de recrutement. La Direction de l'animation de la recherche, des études et des statistiques (DARES) a montré l'augmentation significative sur ces quinze dernières années des contrats d'apprentissage. Les rapports Masingue (2009) et Proglio (2009) encouragent le développement de ces contrats en alternance et la professionnalisation des tuteurs ou maitres d'apprentissage (Kunegel 2011). La réforme en cours de la formation professionnelle continue et de l'apprentissage confirme cette nécessité. Tout au long de ces années, les départs massifs et les différents mouvements de personnel (préretraites, mutations, licenciements, recrutements...) ont généré des problèmes parfois graves, mettant en évidence de manière très concrète des pertes de savoir-faire, jusqu'à nécessiter le rappel de retraités ou préretraités. Certaines entreprises ont dû alors questionner leur gestion prévisionnelle des emplois et des compétences (GPEC), leurs dispositifs de professionnalisation, la place accordée à l'expérience et aux savoirs tacites, et les moyens de les capitaliser.

Dans ce contexte, nous nous sommes intéressés particulièrement aux situations mettant en scène un "professionnel expérimenté » et un "successeur » en transmission de savoir-faire (Boutte 2007). Cette situation est à rapprocher non seulement de la formation en alternance et du tutorat évoqués plus haut, mais aussi du compagnonnage (Guédez 1994), voie traditionnelle de professionnalisation prônée par les compagnons du devoir. Dans les deux cas, il est question d'apprendre le métier et d'apprendre par le métier (Pastré 2004). Ces dispositifs articulent théorie et pratique, dans un aller-retour entre centre de formation et entreprise, et des transferts d'apprentissage. Mais au-delà, ils permettent l'acquisition des diverses dimensions culturelle, identitaire, initiatique et symbolique - transmises dans la relation tuteurtutoré, compagnon-apprenti ou, dans notre cas, professionnel expérimenté-successeur.

\section{La relation de transmission}

7 En première approche, la transmission peut être pensée sous l'angle de la relation éducative étudiée particulièrement par Postic (1988), Labelle (1996) et Lerbet-Séréni (1994). La relation éducative ne peut pas se résumer à un échange de messages et de 
feed-back entre un émetteur et un récepteur, à la manière d'un schéma simpliste de la communication. Elle ne peut pas non plus se réduire à une transmission d'un savoir stricto sensu. Les auteurs que nous venons de citer nous invitent à considérer cette relation éducative comme une rencontre complexe, une relation traversée de multiples processus que les apports de la psychologie cognitive, de la psychologie clinique et de la psychologie sociale peuvent rendre intelligibles.

Suivant Lerbet-Séréni (1994), nous abordons la relation éducative professionnel expérimenté-successeur sous l'angle systémique. Les interactions entre les processeurs d'une part et le système et son environnement d'autre part sont suffisamment denses et riches pour que Le Moigne (1990) considère ce système ouvert sur son environnement, complexe et non linéaire, comme doté d'une dynamique auto-écoorganisationnelle et de propriétés émergentes, évoluant par paliers de complexité croissante. Ce système combine, tresse, articule interactions de processus internes et interactions avec son environnement. L'entreprise, les autres, la hiérarchie, les règles et normes... apparaissent comme un "tiers exclu» (Lerbet-Séréni 1994), principe organisateur du système relationnel que nous étudions.

9 La relation tissée, tressée avec des processus, est révélatrice de cette dynamique et des processus à l'œuvre. L'auteur considère trois modalités relationnelles significatives de l'évolution de cette dynamique, repérables dans les échanges par des marqueurs linguistiques :

- eros: la relation est dite fusion / dépendance $(1+1=1)$; on parle au «nous », ou au «on » (avec le risque de la méprise du « on » impersonnel);

- philia : la relation est dite séparation / autonomie $(1+1=2)$; on parle au « je » et au « tu »;

- agape: la relation est autopoiétique, duale $(1+1=3)$ et paradoxale; elle intègre les deux précédentes; on parle au « je » et « tu » et « nous ».

10 La relation duale, troisième modalité relationnelle, fait émerger un troisième terme que l'auteur nomme «tiers inclus », co-construction, coréférence, monde commun propre au système et aux processeurs qui le composent.

11 Ces modalités relationnelles sont à rapprocher de la description que propose Steiner (2003) à partir d'une description détaillée des relations maître-disciple dans des champs très variés (philosophie, esthétique, religion). L'auteur montre que ces relations connaissent de longues périodes fusionnelles, qu'il qualifie d'homoérotisme, et se terminent par une séparation brutale, où il est question de répudiation, voire de trahison. Chez les compagnons du devoir (Guédez 1994), la dimension maître-disciple est aussi présente, traversée de savoirs formels et informels, de processus d'apprentissage, de dimensions culturelles, identitaires, initiatiques et symboliques. Postic (1988) étudie la relation éducative sous plusieurs angles disciplinaires et, recourant à la psychanalyse, évoque les transferts et contre-transferts qui accompagnent les processus d'apprentissage au sein de ce système relationnel. Ces approches sont aussi développées chez Hatchuel (2007).

12 Après avoir tenté de rendre intelligible la relation de transmission de savoir-faire, nous abordons chacun des protagonistes au regard du savoir-faire, de l'apprentissage et des motivations pour l'un à transmettre, pour l'autre à apprendre. Nous avons nommé le premier "professionnel expérimenté». Ces deux termes, volontairement joints, renvoient d'une part à une compétence référencée, évaluée et reconnue, telle qu'elle est comprise en entreprise, et d'autre part à une expérience donnant lieu à des apprentissages informels (Kolb 1984), des savoirs tacites peu, voire pas identifiés ni 
reconnus. En ce sens, nous considérons ce professionnel comme un expert au sens de Dreyfus (1992). Dans cette approche, l'expert se caractérise par une grande expérience intégrée, incarnée, qui lui donne une grande connaissance du champ d'exercice et lui permet une grande efficacité, la capacité de discriminer l'information pertinente, une prise de décision plus rapide basée sur un raisonnement par abduction, et un réseau relationnel important, qu'il sait mobiliser dans des collaborations tacites. Toutefois, il n'est plus en mesure de faire état de ses connaissances, de formuler ce qu'il sait. Vermerch (1996), reprenant ces caractéristiques, propose une technique d'explicitation par laquelle celui qui mène l'entretien facilite la formalisation et la mise au jour de ces savoirs tacites. Cette explicitation et cette mise à distance entraînent aussi chez l'expert une réappropriation, un réapprentissage de ce qu'il sait déjà.

13 Nous abordons enfin la motivation de l'expert à transmettre. Nuttin (1985) propose un modèle fonctionnaliste du processus motivationnel, articulant des motifs extrinsèques et intrinsèques en fonction d'un but. Dans ces motifs extrinsèques, nous incluons le tiers exclu (Lerbet-Séréni 1994), principe organisateur du système relationnel, mais aussi le mécanisme du don et du contre-don décrit par Mauss (1999). Le professionnel expérimenté serait donc engagé à transmettre ce qui fait son expertise d'une part pour répondre à une demande de sa hiérarchie et d'autre part pour s'acquitter d'une dette contractée envers ceux qui l'ont précédé et formé. Les motifs extrinsèques agissent sur les motifs intrinsèques, plus intimes et plus forts, de l'ordre du besoin, du désir, de l'envie. La psychologie clinique propose le concept de filiation (Legendre 1996), un désir de se projeter, de s'éterniser au travers de celui qui deviendra alors le fils symbolique. Enfin, dans cette approche, le sens de son engagement se reconstruit au cours de la transmission (Bourgeois 2000), les motifs intrinsèques se manifestent progressivement au fil de la transmission.

Le successeur, quant à lui, recruté en externe ou muté en interne, est désigné par l'entreprise pour s'approprier tout ou partie du savoir-faire $\mathrm{du}$ professionnel expérimenté. Au regard du modèle de l'expert et du novice de Dreyfus (1992), le successeur peut être considéré à toutes les étapes comme suivant sa compétence et son expérience déjà acquises. Dans la relation que nous étudions, il est en situation d'apprentissage, abordée sous l'angle socioconstructiviste, courant initié par les travaux de Vygotski (1985), Wallon (1970), Bruner (1998) et Bandura (1980). Ce courant, prolongeant les travaux de Bandura et ceux de Winnykamen (1990), considère l'apprentissage comme un processus de construction intrapsychique de connaissance, qui s'opère dans la relation à l'autre (aux autres) dans le jeu des interactions par imitation modélisation interactive. Le successeur apprend dans la relation au professionnel expérimenté, non pas par le mimétisme mais en construisant un modèle interne à partir du modèle réel, avec lequel il peut être en désaccord.

Dans cette relation se manifestent ainsi des conflits sociocognitifs (Doise et Mugny 1997), des moments de désaccord, d'argumentation et de contre-argumentation, dont le dépassement marque l'apprentissage. L'augmentation des conflits sociocognitifs peut marquer l'évolution de la relation, de fortement dissymétrique à faiblement dissymétrique, voire à symétrique (Winnykamen 1990), révélatrice par cela de la construction de compétence du successeur.

Nous abordons les motifs à apprendre dont Carré (2001) fait état à partir du modèle de Nuttin (1985). On retrouve ainsi l'influence du tiers exclu, de la hiérarchie, des pairs (motifs extrinsèques), et de la motivation à la compétence et à l'attachement (motifs 
intrinsèques). Ces motifs à apprendre intrinsèques s'enracinent dans le désir de savoir ; ceci nous conduit à une approche psychanalytique du rapport au savoir et à l'autre. Il n'y a de désir de savoir que du désir de l'autre, figurant le père symbolique qui permet l'accès au savoir. Comme précédemment pour le professionnel expérimenté, ces motifs intrinsèques se manifestent au fil de la transmission.

La relation professionnel expérimenté-successeur, que nous étudions comme un système complexe, articule interactions et processus d'explicitation, de réapprentissage pour l'un et d'apprentissage pour l'autre, manifestations de motifs extrinsèques et intrinsèques pour les deux, de conflits sociocognitifs, dans une dynamique auto-éco-organisationnelle. L'entreprise en tant que tiers exclu agit comme un principe organisateur du système; elle agit aussi sur la motivation des processeurs (motif extrinsèque). La relation évoluant, elle peut faire apparaître des modalités eros, philia et agape. Les conflits sociocognitifs marquent l'évolution de la relation et l'apprentissage du successeur. L'évolution de la relation vers la modalité agape, paradoxale, peut faire apparaître un troisième terme, le tiers inclus, coréférence du système.

Nous pouvons ainsi formuler notre hypothèse : la relation de transmission de savoirfaire, telle que nous l'étudions, est réciproque au sens de Labelle (1996). Dans la dynamique du système, la relation évolue vers plus de réciprocité dans les échanges ; chacun des protagonistes apprend; les motifs intrinsèques symboliques de père et de fils s'affirment chez l'un et l'autre.

\section{Méthode}

Pour soumettre à l'épreuve du terrain notre hypothèse, nous observons dix situations de transmission de savoir-faire : dix dyades professionnel expérimenté-successeur, au sein de quatre entreprises industrielles du sud de la France. Chacune d'elles initie la transmission et choisit les protagonistes. Nous posons le volontariat comme principe et garantissons l'anonymat des acteurs, informés préalablement de l'objectif de la recherche et de la méthode.

Pour rendre compte de l'évolution de la relation de chaque dyade, nous filmons dix séquences réparties tout au long de la transmission. Chaque séquence est filmée pendant une heure; nous conservons pour l'analyse les trente dernières minutes. Cette précaution permet d'éliminer de l'analyse la période pendant laquelle les protagonistes, se sentant observés par la caméra, peuvent avoir un comportement peu naturel. Altet (1994) définit des épisodes inducteurs, médiateurs et adaptateurs, repérables par des marqueurs linguistiques de début et de fin, marquant la réciprocité croissante des échanges.

21 Pour chaque séquence analysée, nous comptons le nombre de chaque type d'épisodes et leur durée cumulée, et nous évaluons les conflits sociocognitifs révélateurs de l'évolution de la relation, de fortement dissymétriques à faiblement dissymétriques, voire symétriques (Winnykamen 1990), et de facto des processus d'apprentissage.

Pour mettre en évidence les apprentissages chez les protagonistes de chaque dyade, nous menons avec chacun un entretien au début, à la fin de la transmission, puis six mois après que la transmission est terminée. Une analyse catégorielle quantitative (Bardin 2005) permet de comparer les poids respectifs de chaque catégorie. L'évolution 
entre le début et la fin de la transmission marque l'évolution des représentations de soi, de l'autre, de la relation, du tiers exclu et des sous-catégories afférentes. Les entretiens menés six mois après la transmission, analysés avec la même grille, montrent l'évolution des représentations, et notamment la présence et la rémanence du tiers inclus, émergence d'une relation duale et paradoxale (Lerbet Séréni 1994). Enfin, la manifestation des motifs intrinsèques, notamment filiaux, nécessite une analyse qualitative des entretiens, une interprétation des verbatims recueillis dans chaque entretien.

\section{Résultats}

À partir du dispositif méthodologique présenté plus haut, les résultats relatifs à l'évolution des relations et des représentations de part et d'autre sont ainsi recueillis pour chaque dyade. Nous rendons compte ci-dessous des tendances repérables, obtenues par la moyenne des occurrences sur chaque variable.

Le premier graphique montre l'évolution moyenne des types d'épisodes inducteurs, médiateurs et adaptateurs dénombrés par séquence, ainsi que les conflits sociocognitifs (fig. 1).

Fig. 1. - Analyse de la relation expert-novice par séquence (séquences S1 à S10) : moyennes d'occurrences des épisodes inducteurs, médiateurs et adaptateurs et des conflits sociocognitifs.

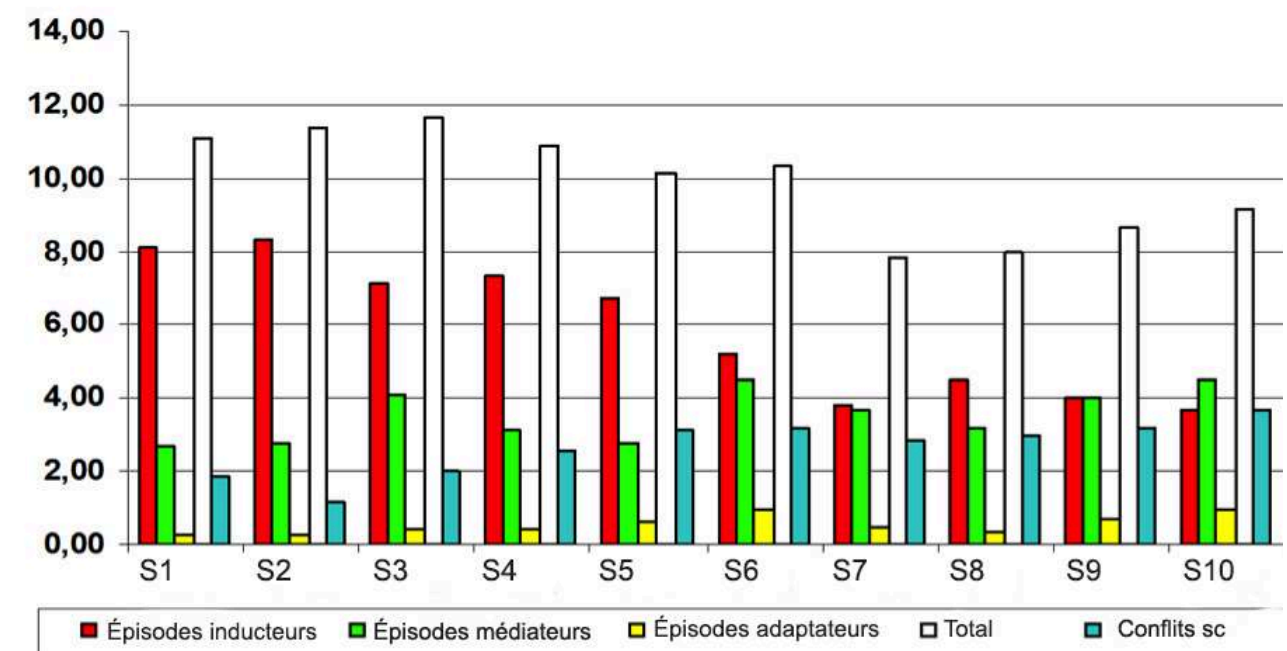

(c) Jean-Louis Boutte.

Le second graphique vient compléter et confirmer la tendance d'évolution de la relation à partir du temps cumulé moyen pour chaque type d'épisode et pour chaque séquence (fig. 2). 
Fig. 2. - Analyse de la relation expert-novice par séquence (séquences S1 à S10) : épisodes inducteurs, médiateurs et adaptateurs en temps cumulé moyen.

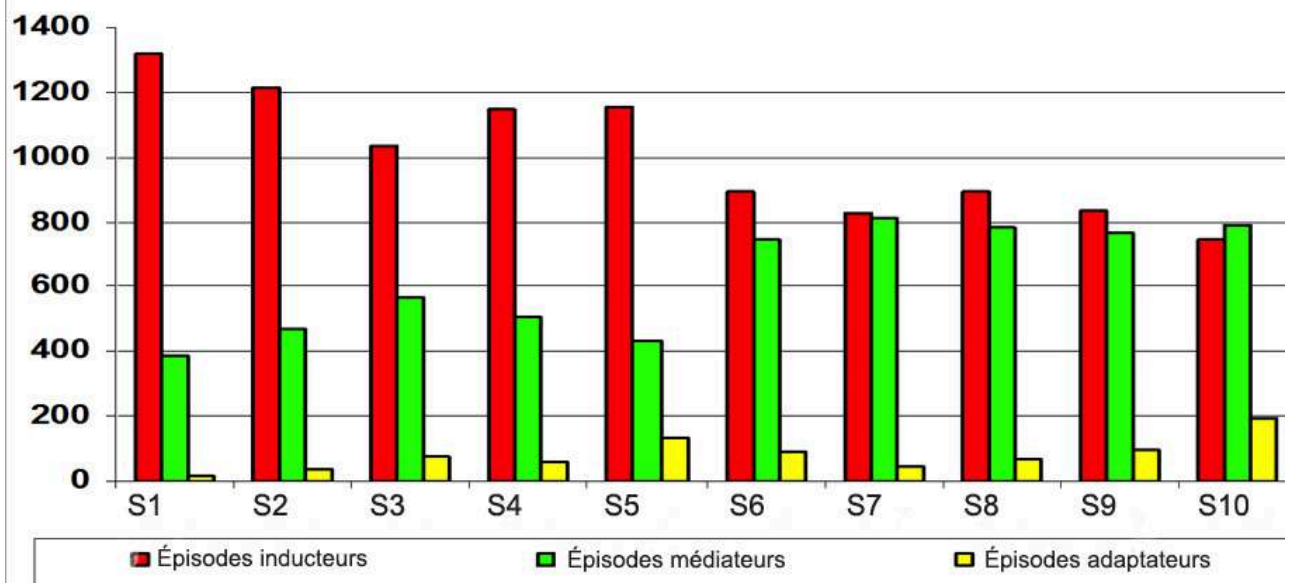

(c) Jean-Louis Boutte.

Ces deux graphiques tendent à montrer une évolution non linéaire. La relation montre deux périodes distinctes: la première se caractérise par une prédominance des épisodes inducteurs et par peu, voire pas de conflit sociocognitif. La seconde fait apparaître des épisodes inducteurs et médiateurs qui s'équilibrent et des conflits sociocognitifs plus fréquents.

Les résultats moyens de l'analyse quantitative des entretiens est représentée sur la figure 3 ci-dessous. Le premier graphique (3A) montre l'évolution des représentations des experts, le second (3B) l'évolution des représentations des successeurs aux trois temps : début, fin et six mois après.

Fig. 3. - Analyse des trois entretiens E1, E2, E3 en pourcentages moyens d'occurrences des représentations de soi, de l'autre, du tiers exclu et de la relation.
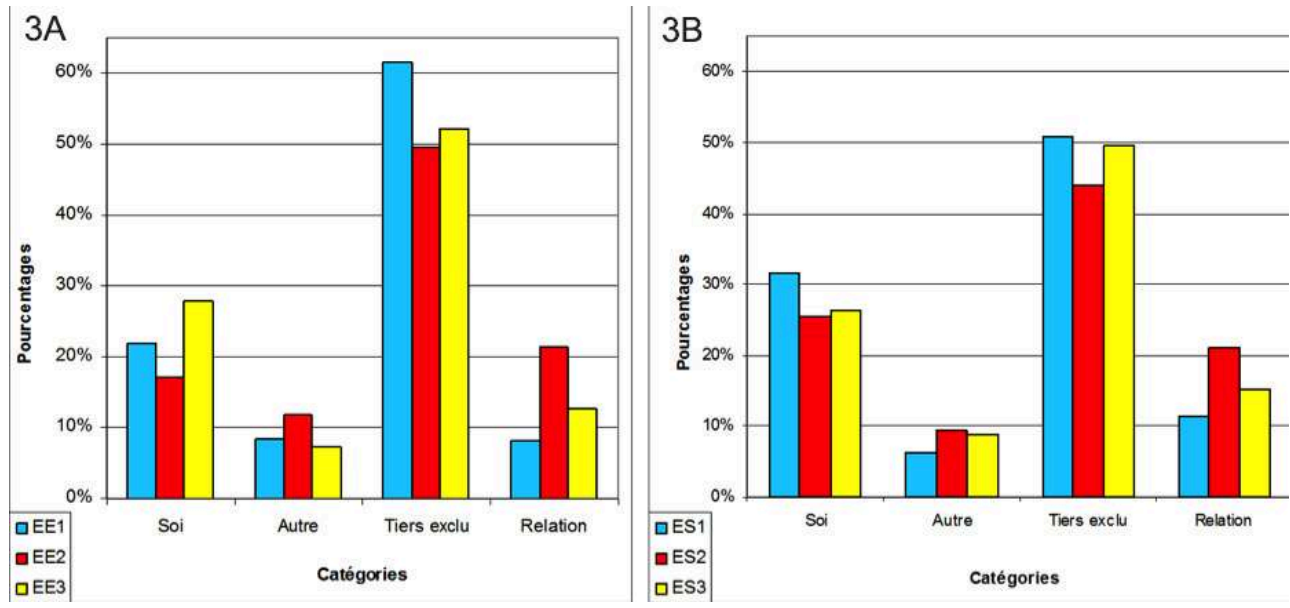

3A : évolution des représentations des experts (entretiens EE1, EE2, EE3) ; 3B : évolution des représentations des successeurs (entretiens ES1, ES2, ES3).

(c) Jean-Louis Boutte.

Ces tableaux montrent des mouvements, des répartitions sur les quatre catégories qui évoluent dans le même sens du côté des experts et des successeurs. Les entretiens 
montrent en fin de transmission une décentration : chacun parle moins de soi et plus de l'autre. Pour tous, la relation gagne en importance aux dépens du tiers exclu. Nous notons aussi qu'après la fin de la transmission, chacun se recentre sur soi, le tiers exclu reprend de son importance, la relation ne revient pas tout à fait à son niveau initial.

L'analyse des sous-catégories met en évidence le fait que la relation est bien passée, pour l'un et l'autre, d'une modalité eros à une modalité philia. En revanche, la modalité agape n'apparaît pas autant que les précédentes. Le tiers inclus montre une certaine évolution entre le premier et le deuxième entretien ; il demeure à un niveau élevé après la fin de la transmission. Autrement dit, il s'est construit pour l'un et l'autre un monde commun, une coréférence qui perdure au-delà de la séparation physique de la transmission.

\section{Analyse}

Le système que nous étudions n'évolue pas linéairement. L'analyse de cette relation montre une évolution par paliers de complexité croissante. En ce sens, l'approche systémique prônée par Le Moigne (1990) s'avère pertinente. Les deux périodes identifiées plus haut sont interprétables avec les outils fournis par Altet (1994).

Dans un premier temps, les épisodes inducteurs prégnants montrent que le successeur est passif, il subit le flot d'informations transmis par le professionnel expérimenté. La relation est dite "complémentaire rigide", et l'apprentissage "par réceptionconsommation ».

Dans la deuxième période, les épisodes médiateurs sont plus présents et s'équilibrent avec les épisodes inducteurs. Le successeur est actif, présent, interactif, et la relation s'équilibre. Les conflits sociocognitifs sont plus nombreux. Le professionnel expérimenté est questionné, contredit, amené à expliciter son savoir-faire. La relation devient plus symétrique, complémentaire, souple, et l'apprentissage devient «par production » (Altet 1994). C'est donc dans la deuxième période que la transmission de savoir-faire est efficace et produit des apprentissages. Il a donc fallu que le successeur apprenne suffisamment pour être en mesure de questionner, de contredire l'expert, pour que s'opère chez ce dernier l'explicitation de ses savoirs incorporés, incarnés (Vermerch 1996). On comprend ici l'importance du facteur temps, repérable dans les pratiques traditionnelles de transmission de savoir-faire.

L'analyse des représentations de chaque acteur montre que le successeur a appris, bien au-delà d'une simple pratique ou d'un geste professionnel, tout ce qui n'est pas écrit. Les expressions recueillies montrent que le professionnel expérimenté réapprend ce qu'il savait déjà, et apprend aussi quelque chose de nouveau au contact du successeur. Par exemple, et souvent de manière quasi caricaturale, l'utilisation de l'informatique est présentée comme objet de transmission réciproque. Le professionnel expérimenté apprend enfin du rapport à l'autre et à son apprentissage.

L'analyse des entretiens met aussi en évidence l'évolution des motivations respectives de l'un et de l'autre à s'engager dans ce dispositif (Carré 2001). Chacun des deux acteurs reconstruit le sens de son engagement dans ce dispositif - pour le successeur à se former, pour l'expert à transmettre - et s'en attribue la raison (Bourgeois 2000). Les motivations intrinsèques, filiales, s'expriment en fin de transmission. L'analyse et l'interprétation des verbatims font apparaître pour chacun des références au don et 
contre-don, au deuil, aux figures symboliques père et fils, particulièrement présentes en fin de transmission. Enfin, pour chacun d'entre eux, la relation se construit et évolue de la modalité fusionnelle (eros) à la modalité séparation (philia), de la dépendance à l'autonomisation (Lerbet-Séréni 1994).

Nous notons que la séparation initiée par l'entreprise ne ressemble pas à la « répudiation » et la «trahison », que Steiner (2003) repère dans les relations maîtresdisciples qu'il étudie. Sans doute faut-il voir là aussi le facteur temps : les relations que Steiner évoque s'inscrivent dans une durée beaucoup plus longue que celles que nous observons. Enfin, cette séparation génère la construction d'un monde commun, d'une coréférence, d'un tiers inclus (Lerbet-Séréreni 1994) qui perdure au-delà de la fin de la transmission. Ce qui s'est construit pendant la transmission entre les deux protagonistes demeure chez l'un et l'autre bien après que la transmission est terminée, et cela leur appartient en propre.

Compte tenu de ces résultats, notre hypothèse semble vérifiée: la relation de transmission de savoir-faire telle que nous l'étudions s'avère réciproque. Elle provoque des apprentissages chez l'un et l'autre des acteurs, elle favorise la manifestation de motifs intrinsèques et notamment des figures symboliques de père et de fils.

\section{Discussion}

Au-delà des résultats obtenus et commentés plus haut, nous souhaitons revenir sur le contexte initialement présenté et mettre en perspective les résultats de cette recherche.

$\mathrm{Au}$ premier abord, la transmission de savoir-faire fait référence à une tradition compagnonnique encore présente chez les hommes de métier, les hommes de l'art, les artisans. Mais ce dispositif est largement oublié dans les pratiques modernes des gestionnaires de ressources humaines au sein des grandes entreprises. L'approche dominante de la compétence, individualiste et normative, a privilégié une gestion analytique, un référencement des savoirs théoriques et procéduraux.

La complexification de la société, l'accélération des changements et la problématique générationnelle sont l'occasion de redécouvrir les vertus de cette transmission sous plusieurs formes possibles : interindividuelle, telle que nous l'avons étudiée, et dont le tutorat peut se rapprocher, mais aussi collective. Les nouvelles exigences imposent un changement de paradigme. Les nouvelles organisations, matricielles et en réseau, reposent sur une conception biologique, complexe. S'il est toujours question de compétence, cette dernière doit être pensée individuelle et collective, complexe, évolutive, émergente, faite de multiples ingrédients dont certains échappent à l'inventaire, à l'analyse, au référencement.

40 Les profondes mutations imposent désormais des organisations plus flexibles, plus réactives et apprenantes pour s'adapter aux turbulences de leur environnement (Mallet 1996 et 2007, Fillol 2009, Boutte 2008). Elles doivent tirer profit de leurs expériences, capitaliser les savoirs théoriques ou procéduraux référencés, mais aussi des savoirs expérientiels ou tacites. Elles doivent aussi faire fructifier les gisements de connaissances non reconnues, souvent ignorées, présentes en son sein. La plus-value désormais n'est plus dans la conformité à un référentiel, elle réside dans la capacité à mobiliser, développer et partager les connaissances, sources de performance, 
connaissances individuelles et collectives, formalisées, explicites mais aussi tacites. Il s'agit de considérer l'apprentissage organisationnel par une multiplicité de dispositifs participant à la dynamique proposée par Nonaka et Takeuchi (1995) et regroupés sous le terme knowledge management (Moingeon et Ramanantsoa 2000).

41 Les compétences requises s'enrichissent, de nouvelles exigences se font jour : outre les savoirs, savoir-faire et savoir-être jusque-là référencés, le professionnel doit désormais faire preuve de réflexivité (Schön 1994, Perrenoud 2001), de capacités cognitives et relationnelles, d'intelligence de situation (Zarifian 2004), de participation à l'émergence d'une compétence collective, voire d'une intelligence collective (Mallet 2007, Wittorski 2007).

D'autres ingrédients encore pourraient être évoqués, particulièrement l'expérience, comme source de savoirs tacites à expliciter et transmettre (Schwartz 1997). La professionnalisation est ainsi interrogée tant sur le plan épistémologique que sur les objectifs et les méthodes. La formation par alternance, la formation ouverte à distance (FOAD), la simulation, les serious games ${ }^{1}$, les analyses de pratiques, la modularisation et l'individualisation de la formation, les communautés de pratiques (Wenger 2005) viennent enrichir les voies de professionnalisation (Wittorski 2007).

Quelle place peut occuper la transmission de savoir-faire dans une telle dynamique? Nos observations montrent qu'il est pertinent d'envisager la présence de savoirs tacites, de savoirs d'expérience, même s'ils ne sont pas identifiés, formalisés. Dans ce dispositif, non seulement le successeur destinataire de la transmission apprend, construit ses compétences, s'inscrit dans le réseau de l'expert et ses collaborations tacites, mais l'expert lui-même réapprend ce qu'il savait déjà, réinterroge ses acquis, apprend au contact du successeur, acquiert de nouvelles compétences relationnelles, voire pédagogiques. La transmission de savoir-faire favorise donc la réflexivité, l'échange, le partage de connaissances. Enfin, l'un et l'autre apprennent à se connaître, se reconnaître mutuellement (Ricœur 1990).

Pour l'entreprise, le dispositif est donc profitable à trois niveaux: la professionnalisation du successeur, la professionnalisation de l'expert, le lien social entre les deux. Ce dernier point est à considérer plus particulièrement dans la problématique démographique, intergénérationnelle détaillée plus haut. En généralisant ce dispositif, l'entreprise peut faciliter la cohabitation, la collaboration des générations baby boom, $\mathrm{Y}$ et $\mathrm{Z}$. Ainsi, la transmission de savoir-faire permet de répondre aux enjeux exposés plus haut de l'apprentissage organisationnel et de cohabitation, de collaboration intergénérationnelle. Cette transmission s'inscrit donc pleinement parmi les voies de professionnalisation et favorise aussi la construction identitaire.

En ce sens et paradoxalement, un dispositif traditionnel, inscrit dans une longue histoire, celle des compagnons du devoir (Guédez 1994) est aussi l'occasion d'initier une dynamique de réflexion sur l'action et de partage de connaissances, un lien social réactivé, une culture de l'apprentissage individuel, collectif et organisationnel que prônent désormais les nouvelles conceptions de l'organisation. Mais pour cela, l'entreprise doit elle aussi apprendre, changer ses propres conceptions et changer de paradigme. 


\section{BIBLIOGRAPHIE}

ALTET M., 1994, La formation professionnelle des enseignants : analyse des pratiques et situations pédagogiques, Paris, Presses universitaires de France.

ARDOINO J., 1978, Propos actuels sur la formation, Paris, Gauthier-Villars (Hommes et organisations).

ARDOINO J., 1990, « Les postures (ou impostures) respectives du chercheur, de l'expert et du consultant ", dans Ardoino J. et Berger G. (dir.), Les nouvelles formes de la recherche scientifique en éducation au regard d'une Europe en devenir, colloque international francophone de l'AIPELF / AFIRSE, Matrice, p. 15-21.

BANDURA A., 1980, L'apprentissage social, Bruxelles, Mardaga.

BARABEL M., MEIER O., PERRET A., 2012, Travailler avec les nouvelles générations Y et Z, Levallois-Perret, Studyrama.

BARDIN L., 2005, L'analyse de contenu, Paris, Presses universitaires de France.

BOURGEOIS E., 2000, « Le sens de l'engagement en formation », dans Barbier J.-M. et Galatanu O.

(dir.), Signification, sens, formation, Paris, Presses universitaires de France, p. 87-106.

BOUTTE J.-L., 2007, Transmission de savoir-faire, réciprocité de la relation éducative expert-novice, Paris, L'Harmattan.

BOUTTE J.-L., 2008, « De Taylor au KM, quelle(s) approche(s) de la compétence ? » Questions vives, vol. 10, p. 11-23.

BRUNER J., 1998, Savoir faire, savoir dire, Paris, Presses universitaires de France (Psychologie d'aujourd'hui).

CARRÉ P., 2001, De la motivation à la formation, Paris, L'Harmattan (Savoir et formation).

CHEVALLIER D. (dir.), 1991, Savoir-faire et pouvoir transmettre, Paris, Maison des sciences de l'homme (Ethnologie de la France, cahier 6).

DOISE W. et MUGNY G., 1997, Psychologie sociale et développement cognitif, Paris, Armand Colin.

DREYFUS H. L., 1992, « La portée philosophique du connexionnisme » dans Andler D. (dir.), Introduction aux sciences cognitives, Paris, Gallimard, p. 352-373.

FILLOL C., 2009, L'entreprise apprenante : le knowledge management en question? Études de cas chez EDF, Paris, L'Harmattan.

GUEDEZ A., 1994, Compagnonnage et apprentissage, Paris, Presses universitaires de France (Sociologie d'aujourd'hui).

HATCHUEL F., 2007, Savoir, apprendre, transmettre, une approche psychanalytique du rapport au savoir, Paris, La Découverte.

KOLB D., 1984, Experiential learning, Englewood Cliffs, Prentice Hall.

KUNEGEL P., 2011, Les maîtres d'apprentissage : analyse des pratiques tutorales en situation de travail, Paris, L'Harmattan (Action et savoir).

LABELLE J.-M., 1996, La réciprocité éducative, Paris, Presses universitaires de France (Pédagogie d'aujourd'hui). 
LE MOIGNE J.-L., 1990, La modélisation des systèmes complexes, Paris, Dunod.

LEGENDRE P., 1996, Filiation : fondement généalogique de la psychanalyse, leçon IV, suite 2, Paris, Fayard.

LERBET-SÉRÉNI F., 1994, La relation duale, complexité, autonomie et développement, Paris, L'Harmattan (Alternances et développements).

LIVIAN Y.-F., 2007, « Sociologie de l'acteur réseau et pratiques de gestion : une tentative d'analyse au sujet de la gestion des compétences », Journée ANT du 14 juin 2007, Université Paris IX - ParisDauphine, https://halshs.archives-ouvertes.fr/halshs-01276284.

MALLET J., 1996, L'organisation apprenante, Aix-en-Provence, Université de Provence.

MALLET J., 2007, « Intelligence collective, équipe apprenante et TICE : les problèmes culturels sousjacents », dans Actes du colloque TICE Med, Marseille, mai 2007.

MASINGUE B., 2009, « Seniors tuteurs : comment faire mieux? ", rapport au secrétaire d'État chargé de l'emploi, Paris, La Documentation française.

MAUSS M., 1999, Sociologie et anthropologie, Paris, Presses universitaires de France (Quadrige).

MOINGEON B. et RAMANANTSOA B., 2000, « Apprentissage organisationnel : éléments pour une discussion », dans Argyris C., Savoir pour agir : surmonter les obstacles à l'apprentissage organisationnel, Paris, Dunod, p. 295-315.

NONAKA I. et TAKEUCHI H., 1995, The knowledge-creating company: how Japanese companies create the dynamics of innovation, New York, Oxford University Press.

NUTTIN J., 1985, Théorie de la motivation humaine, Paris, Presses universitaires de France.

PASTRÉ P., 2004, Les compétences professionnelles et leur développement, Paris, Presses universitaires de France.

PERRENOUD P., 2001, Développer la pratique réflexive dans le métier d'enseignant, Paris, ESF.

POSTIC M., 1988, La relation éducative, Paris, Presses universitaires de France.

PROGLIO H., 2009, « Promouvoir et développer l'alternance : voie d'excellence pour la professionnalisation », rapport au Président de la République française, mission Alternance, Paris, La Documentation française.

RICOEUR P., 1990, Soi-même comme un autre, Paris, Le Seuil.

SCHÖN D., 1994, Le praticien réflexif : à la recherche du savoir caché dans l'agir professionnel, Montréal, Éditions logiques.

SCHWARTZ Y., 1997, « Les ingrédients de la compétence : un exercice nécessaire pour une question insoluble ", Éducation permanente, $\mathrm{n}^{\circ} 133$, vol. 199, nº 4, p. 9-34.

SERRES M., 2012, Petite Poucette, Paris, Le Pommier.

STEINER G., 2003, Maîtres et disciples, Paris, Gallimard.

VERMERCH P., 1996, L'entretien d'explicitation, Paris, ESF (Pédagogies).

VYGOTSKI L. S., 1985, Pensée et langage, Paris, Messidor.

WALLON H., 1970, De l'acte à la pensée, Paris, Flammarion (Nouvelle Bibliothèque scientifique).

WENGER E., 2005, La théorie des communautés de pratique : apprentissage, sens et identité, Québec, Presses de l'université Laval. 
WINNYKAMEN F., 1990, Apprendre en imitant ? Paris, Presses universitaires de France (Psychologie d'aujourd'hui).

WITTORSKI R., 2007, Professionnalisation et développement professionnel, Paris, L'Harmattan.

ZARIFIAN P., 2004, Le modèle de la compétence, Rueil-Malmaison, Liaisons.

\section{NOTES}

1. Serious games: "jeux sérieux ", dispositifs de formation à partir de jeux scénarisés reproduisant des situations réelles référencées.

\section{RÉSUMÉS}

Alors que la transmission de savoir-faire est plutôt associée au métier, au compagnonnage et à l'artisanat, la grande entreprise a adopté les notions de professionnel, de compétence et de professionnalisation, marquant la volonté de rationaliser la gestion des ressources humaines. Les plans sociaux puis les départs massifs en retraite des baby boomers et l'arrivée des générations $Y$ et $\mathrm{Z}$ ont généré des pertes de savoir-faire, dues au déni des savoirs expérientiels, tacites, et de leur nécessaire transmission. Dans ce contexte, nous analysons l'évolution de la relation de transmission de savoir-faire entre un professionnel expérimenté et son successeur, des processus d'apprentissage et d'explicitation ainsi que des motivations des protagonistes dans trois grandes entreprises industrielles. La réciprocité invite à penser cette voie de professionnalisation particulièrement efficiente dans une perspective d'entreprise apprenante.

\section{AUTEUR}

\section{JEAN-LOUIS BOUTTE}

Maître de conférences en sciences de l'éducation à Aix-Marseille Université, EA 4671 ADEF, BAP

Psychologie et sciences de l'éducation 


\title{
La transmission du savoir au sein de deux coopératives au Gabon
}

\author{
Nina-Marinette Makouatsa Boupo
}

1 La transmission des institutions et valeurs d'une génération à une autre est la condition de leur survie dans le temps, et donc de leur continuité. Celle-ci n'étant pas immuable, elle s'assure dans et par le changement qui oppose les nouvelles générations aux anciennes : les coopératives ne sont pas épargnées. La réflexion sur la transmission du savoir au sein des coopératives au Gabon part du fait que j'ai été confrontée, sur le terrain, à des propos sur la nécessité d'acquérir le savoir, sur la perte des savoirs liés aux métiers agricoles et artisanaux et sur l'incapacité de transmettre certains savoirs. Par ailleurs, les recherches sur les coopératives, leur histoire et leur fonctionnement, n'abordent que partiellement cette problématique. Or la transmission est au cœur des préoccupations de leurs acteurs, surtout sous la forme d'une crise de la transmission du savoir. Les études existantes insistent sur le fait que la culture et la tradition se transmettent par l'imitation, l'apprentissage et l'éducation ${ }^{1}$ et, phénomène nouveau, par le biais d'Internet et de son influence dans la sphère socioculturelle. Cet article ambitionne d'enrichir la réflexion menée à ce jour sur la transmission du savoir.

2 J'avais déjà travaillé sur la dynamique de coopération dans le secteur de l'économie sociale et solidaire au Gabon lors de mes recherches doctorales. J'ai décidé de m'intéresser à la transmission du savoir en adoptant deux approches complémentaires: l'une dynamique, où les sociétés connaissent une contradiction entre tradition et modernité, et l'autre interactionniste, où les rapports entre individus et leurs groupes sont privilégiés. Cela nécessite que l'on considère simultanément les processus d'apprentissage des coopérateurs et les processus de transmission organisés par leur environnement social, culturel et économique.

3 L'étude a été limitée à la province de l'Estuaire, dans les villes de Ntoum pour la Coopérative des exploitants agricoles de Ntoum (COOPEAN, quartier Cimenterie) et de Libreville pour la Coopérative des produits artisanaux de Mbigou (COOPAM, quartier Alibandeng), avec pour objectif une approche anthropologique des réalités socioculturelles des acteurs de ces coopératives. Celles-ci exercent respectivement dans le maraîchage et la sculpture de la pierre et sont composées de 20 membres pour la 
première, dont 17 hommes et 3 femmes, et 19 membres pour la seconde, tous des hommes. Ma méthodologie fut la recherche et l'analyse documentaire, les entretiens individuels et collectifs dit focus groups, et l'observation participante en m'immergeant autant que possible dans ces coopératives. Cela m'a conduite à l'analyse de contenu suivant deux thèmes : les acteurs de la transmission culturelle de la coopération et la transmission de la culture coopérative.

4 «Les organisations coopératives vivent comme des enfants qu'on a eu à faire et qu'on a laissés dans la rue ${ }^{2}$.» Selon cet informateur, les coopératives ont été créées puis délaissées et leurs membres ont des difficultés à se prendre en charge et se maintenir. Ce travail a pour origine l'interrogation suivante: comment la transmission de la culture coopérative est-elle vécue au sein des coopératives gabonaises, sachant que celles-ci se sont développées sous l'impulsion de l'État? Autrement dit, comment se transmettent les savoirs dans les coopératives gabonaises, sachant que les coopérateurs ont été formés par des agents étatiques et qu'ils sont dans une logique intergénérationnelle où se confrontent des valeurs?

5 Mon hypothèse est que les défaillances culturelles des coopératives ont plusieurs causes: la persistance de coutumes locales en leur sein, les mauvaises politiques étatiques associées à l'éducation coopérative et les représentations sociales des adhérents qui ne favorisent pas la transmission et la valorisation des savoirs. Mon travail est organisé en trois parties: la définition des concepts, les acteurs de la transmission des savoirs et la culture coopérative face à l'influence des savoirs exogènes.

\section{Définition des concepts}

\section{La transmission}

Dans la littérature scientifique, la transmission renvoie à la passation de quelque chose et à la perpétuation du culturel en ce qu'elle contribue, de manière transformée, à la persistance des représentations, pratiques, émotions et institutions. Les définitions émiques insistent sur le transfert, la diffusion, la circulation des connaissances, la communication, la relève, la succession, la diffusion de nouveaux savoirs et nouvelles pratiques, leur circulation entre individus et leur perpétuation. Dans le cas des coopératives, ces définitions envisagent la transmission dans sa dimension formelle et standardisée, qui tient aux lieux destinés à la transmission, et dans sa dimension informelle où les pratiques, savoirs ou connaissances liés à la gestion et aux techniques des métiers, circulent ou se transmettent relativement à ce qui est codifié et ce qui ne l'est pas ; et ce, par rapport à la tradition, aux enjeux de la coopération et des différents métiers.

7 Aussi, l'homme n'est rien s'il est seul. La transmission du savoir lui est utile pour améliorer sa condition et faire face à son milieu. C'est la raison pour laquelle les coopérateurs la conçoivent comme une affirmation de soi, un enjeu pour la gestion des coopératives, un processus de passation du métier aux descendants, et un instrument à la fois de valorisation et de dévalorisation lié à la promotion ou non de leurs structures, activités, membres, produits et territoires. Ce savoir tient aux savoir-faire, savoir-être et savoir-vivre liés à la coopération. 


\section{La coopérative}

8 Dans l'absolu, la coopérative, avec ses principes et valeurs, est reconnue par les institutions internationales comme un projet humaniste. C'est «une association autonome de personnes volontairement réunies pour satisfaire leurs aspirations et besoins économiques, sociaux et culturels communs au moyen d'une entreprise dont la propriété est collective et où le pouvoir est exercé démocratiquement ${ }^{3}$ ». Cependant, sur le terrain, elle est perçue comme un projet étatique, favorisé à l'origine par l'intrusion coloniale française qui a permis l'implantation de systèmes coopératifs au service de l'administration coloniale. Après l'indépendance du pays en 1960, l'État les a récupérées pour les instrumentaliser dans sa politique de développement rural. Cela a permis de regrouper les paysans dans ces entreprises.

9 Les coopératives sont des entreprises communautaires. Elles constituent un espace social et un lieu symbolique où s'opère la transmission du savoir et par là, des savoirs pratiques ayant des effets sur les comportements coopératifs. La transmission culturelle y est perçue, selon Luigi Cavalli-Sforza ${ }^{4}$, comme un processus par lequel des comportements, attitudes ou techniques sont acquis selon la voie de l'empreinte passive, du conditionnement, de l'imitation, de l'enseignement et apprentissage actif ou d'une combinaison de ces méthodes.

\section{La culture coopérative moderne}

10 Les systèmes coopératifs sont un héritage colonial, qui a induit une culture coopérative perçue sous l'angle de la modernité, constituée de valeurs et principes. Elle consiste, d'après Ward Goodenough ${ }^{5}$, en tout ce qu'il faut savoir ou croire pour se conduire d'une manière acceptable pour les membres, et ce dans tout rôle qu'ils accepteraient pour chacun des leurs. Sur le terrain, elle est définie par les expressions comme «la coopérative », "le coopérateur», "les statuts et règlements intérieurs», "le comportement à avoir ", "l'exemple à donner ", "les connaissances à avoir », qui renvoient à l'institution, aux acteurs et éléments utiles à leurs interactions et transmission. L'appartenance et l'acceptation d'un individu à la coopérative passent en effet par l'appropriation d'un savoir-faire et d'un savoir-être définis culturellement. Celle-ci est rendue possible grâce aux processus d'enculturation et de socialisation. Les règles de coopération moderne portent une structure comportementale caractéristique de cette culture qui exprime l'apprentissage et la transmission d'un héritage social.

\section{L'éducation coopérative}

11 La culture coopérative se transmet par le biais de l'éducation coopérative, qui est un ensemble d'idées et de pratiques ayant pour finalité la transformation individuelle et sociale. Cette éducation est un processus d'apprentissage allant de l'information à la formation, afin d'aboutir à l'éducation. Selon Olivier Reboul, «Apprendre, c'est se délivrer d'une ignorance, d'une incertitude, d'une maladresse, d'une incompétence, d'un aveuglement : c'est parvenir à mieux faire, à mieux comprendre, à mieux être. Or, qui dit mieux dit valeur ${ }^{6}$. " Le rôle de l'éducation coopérative est donc de permettre, par la pédagogie et la formation, des apprentissages cohérents, progressifs et exhaustifs. Elle impose que les savoirs, connaissances et objets culturels transmis soient 
intégrés par les individus afin qu'ils les réutilisent dans leur communauté. Elle intègre la question du "sens " de la coopération et vise l'émergence d'individus autonomes capables de s'autogérer et de s'adapter aux changements. Elle renvoie sur le terrain aux formations, stages, séminaires, apprentissages, périodes d'essai, et à l'instruction. Ces éléments permettent d'acquérir des savoirs formels et/ou informels inséparables des processus historiques et des rapports sociaux qui déterminent la transmission des savoirs.

\section{Les principaux acteurs de la transmission de la culture coopérative moderne}

\section{L'administration coloniale}

$\mathrm{Au}$ début $\mathrm{du} \mathrm{xx}^{\mathrm{e}}$ siècle, l'administration coloniale, avec l'aide des missionnaires, introduisit de nouveaux modèles coopératifs dans les villages, selon la législation française ${ }^{7}$. Unifonctionnels et centralisés, ces modèles se déployaient sous diverses formes et servaient les intérêts de l'administration. Ils avaient peu ou pas de lien avec les institutions et pratiques transmises par la tradition, selon laquelle les chefs et les anciens encadraient et éduquaient les jeunes afin de leur faire assimiler les valeurs et principes de la communauté. Et ils redéfinissaient la rationalité capitaliste, la division du travail et des mutations des formes de solidarité, les savoirs et savoir-faire locaux et leur transmission.

Un ensemble de procédés destiné à leur implantation s'est répandu dans le monde rural pour moderniser les cultures et développer les produits destinés au commerce et à l'exportation. Les agences d'assistance facilitaient l'implantation avec l'autorité des chefs. Les structures d'enseignement formaient des élites pour les besoins de l'administration qui gérait les systèmes coopératifs. Ceux-ci obéissaient, pour certains, à une dynamique qui intégrait un dispositif de développement spécifiant les structures concrètes et organisées de conception et d'administration des interventions et l'ensemble des représentations et normes acquises qui structurent les façons de percevoir, de penser et d'agir des agents de développement.

14 L'ancrage culturel de ces modèles s'est fait dans un contexte d'adaptation et de rejet. Selon Bronislaw Malinowski :

«[Les colonisateurs] ne réussiraient pas à imposer des institutions nouvelles tant que ces institutions nouvelles ne seraient pas aptes, en plus de leurs avantages formels, à remplir les mêmes fonctions que les institutions anciennes qu'elles étaient chargées de remplacer"."

La culture coopérative transmise aux paysans se détachait donc de celle transmise par la tradition en matière d'apprentissage et de comportements attendus. Les paysans qui s'adaptaient s'éloignaient de leurs familles pour adhérer aux structures destinées à la production agricole et d'objets culturels. Ceux qui les rejetaient étaient contraints par le travail forcé d'y adhérer. Les paysans étaient de plus exploités par les notables qui contrôlaient, pour les besoins de l'administration, la production des biens marchands. Ces systèmes impopulaires, ne profitant pas aux adhérents, furent un échec. Malgré cela, après la colonisation, ils seront repris par l'État postcolonial. 


\section{L'administration postcoloniale}

16 Après l'indépendance du Gabon le 17 août 1960, l'État est confronté à l'exode rural, à l'absence d'infrastructures et de moyens financiers dans les zones rurales, au sousemploi et au chômage dans les villes. Il élabore alors une politique de développement où les systèmes coopératifs hérités suscitèrent un regain d'intérêt. Cette politique s'inscrivait dans une vision globale des transformations sociales. Elle voulait amener les paysans à prendre connaissance de leur place dans le contexte socio-économique du pays et à les convaincre de la nécessité de s'organiser pour tirer profit de leurs efforts productifs. Il s'agissait de les aider à jouer pleinement leur rôle dans une société qui amorçait sa mutation, cela tout en faisant des coopératives de véritables entreprises de développement au service du monde rural.

17 Toutefois, les élites ont réinterprété les coopératives selon les valeurs communautaires, en réconciliant les solidarités traditionnelles et la modernisation technique. Ces élites véhiculaient l'idéologie et la culture coopératives via des agences assurant une sensibilisation et un accompagnement incitatif, technocratique et non directif. Cette transmission s'est réalisée selon deux tendances: la première, former les paysans sélectionnés via des concours aux techniques du métier, puis les installer en coopérative ; la seconde, poser les bases d'un système communautaire et lignager, où les coopératives seraient une ressource importante du dispositif nationaliste. C'est ainsi qu'au début des années 1980, la coopérative des exploitants agricoles de Ntoum et la coopérative des produits artisanaux de Mbigou furent créées, avec des structurations différentes selon leurs secteurs d'activité et une culture coopérative différente.

Les paysans adhéraient à ces structures pour accéder à des services ou aides étatiques, sans véritablement assimiler les rudiments de la culture du développement et de la culture coopérative. À ce sujet, un interlocuteur déclare :

«Chez nous, au Gabon, nos populations n'ont pas encore la culture de se mettre ensemble. C'est pour cela que l'État, à travers certaines administrations, met des fonds à disposition pour encourager les gens à se prendre en charge. Mais pour que ces personnes puissent bénéficier de ces fonds, l'administration est obligée de leur demander de se regrouper en coopérative ou association. Vous voyez que l'idée de se regrouper ne vient pas des populations. C'est l'administration qui leur demande ça ${ }^{9}$.

19 L'éducation coopérative utile au développement des paysans et à leur épanouissement avait été reléguée au second plan, au profit de l'apprentissage technique. Certains assimilaient des connaissances techniques liées au métier sous l'autorité des tuteurs, tandis que d'autres n'ont pas bénéficié d'un apprentissage professionnel. Si l'apprentissage et la formation professionnelle sont des formes d'éducation, selon l'article 11 du Code du travail de 1978, il ressort que les savoirs techniques n'ont pas été transmis de manière efficace et effective pour tous les adhérents. Pourtant, c'est par la formation professionnelle que l'on découvre les rudiments du métier et ceux des coopératives.

20 Transmettre un « patrimoine coopératif », ce n'est pas juste transmettre les techniques du métier qui lui est associé. Au-delà des apprentissages techniques, la transmission de la culture coopérative consiste, aussi et surtout, à transmettre des valeurs et principes qui n'existent que lorsqu'ils sont matérialisés par des actes. Mais les agents étatiques, faute de compétences et de formations adaptées, n'ont pas développé auprès des adhérents une approche de participation. L'État gabonais n'avait pas assez de personnel 
qualifié pour instruire ses formateurs sur l'éducation coopérative et contrôler les coopératives. Les cours dispensés étaient des cours enseignés dans les pays industrialisés, mal adaptés par des formateurs qui ne se souciaient pas assez des liens entre réalités locales, matières enseignées, contraintes et revendications de chaque secteur d'activité, de chaque communauté. Il y eut des écarts et contradictions entre les structures de formation et les discours politiques. Ainsi, dans le cas de la COOPAM, aucune formation sur la gestion et l'éducation coopérative n'a été donnée aux sculpteurs. À la COOPEAN, en revanche, les défections dues à la pénibilité du travail et à l'incompréhension du système coopératif ne facilitaient pas ces formations, qui furent abandonnées par les formateurs.

21 L'État imposait des statuts et règlements intérieurs en confinant les paysans dans une vision utilitariste, régie par une dynamique socio-économique où la culture coopérative était faible. Il reniait l'autogestion et la participation. Cela conduisit les adhérents à un formalisme et à des fonctions sans contenu. Comment fut alors vécue la transmission entre membres et entre anciens et nouveaux dans les coopératives?

\section{Les coopérateurs}

Les coopérateurs ayant peu assimilé la culture coopérative moderne évoluent dans des milieux où sa transmission est faible, et où celle des savoirs se fait de manière traditionnelle, de génération en génération. Les membres de la COOPEAN et de la COOPAM exercent, en effet, dans des environnements où coexistent trois générations. Ils ont des connaissances acquises pour les uns lors des séminaires ou stages organisés par des agences d'encadrement, pour les autres sur le tas, ou par un apprentissage personnel via les nouvelles technologies de l'information et de la communication (NTIC). Ce sont des personnes économiquement faibles et faiblement instruites, incapables d'assurer par elles-mêmes, avec les fonds de leur coopérative, leur formation professionnelle. Elles se différencient par leur âge, leur instruction, leur ancienneté et leur expérience.

La transmission des savoirs se fait dans et par les rapports entretenus dans chaque communauté. Elle repose sur trois processus ${ }^{10}$ tributaires de la confiance que les uns accordent aux autres, confiance née du déploiement d'une histoire en commun.

Le premier processus est lié à la sensibilisation et l'information. Ceux qui «savent » ou sont expérimentés diffusent, par souci d'exemplarité, de ralliement et/ou de mieux faire, tout type de connaissance par des paroles ou conseils. Cela leur permet de valoriser l'expérience et le savoir acquis et de transmettre un message, comme le laisse entendre cet interlocuteur :

«Plus on pose des actions qui sont porteuses, plus ils comprennent que ça ne sert à rien d'être isolé. La sensibilisation va dans ce sens. On leur dit: "Améliorons notre façon de faire. Si on n'a pas bénéficié d'un certain nombre de choses, c'est parce qu'on n'a pas été organisé. Mais si nous sommes organisés, on va avoir beaucoup plus que ce que nous avons quand chacun est individuel." On leur tend ce message et beaucoup sont en train de comprendre qu'il y a nécessité de travailler ensemble ${ }^{11}$.»

Les coopérateurs vivent aussi, selon les cas et les situations, surtout à la COOPEAN, des échanges qui stimulent l'enrichissement réciproque sur des points précis. Mais cela reste entravé par les stratégies et logiques tribales et les conflits de mémoire, c'est-àdire les conflits passés qui influent sur leur situation actuelle d'affrontement. Certains 
usent, de manière volontaire ou non, de stratégies de rétention des savoirs. Selon Claude Meillassoux, l'acquisition des connaissances donne à celui qui les possède une autorité réelle sur le profane, puisque c'est de ces connaissances que dépend la perpétuation du groupe. Des leaderships plus ou moins durables s'établissent au profit de celui qui manifeste sa supériorité dans telle ou telle technique ${ }^{12}$.

Le second processus est l'imitation. Les coopérateurs par l'observation, l'écoute et l'apprentissage des pratiques organisent eux-mêmes leurs initiations. Ils essaient d'assurer une transmission des savoirs et savoir-faire liés au métier pour garantir leurs activités économiques dans leur communauté et maintenir les coopératives dans le temps. Les moments de travail passés ensemble dans les espaces communs sont pour eux des occasions de se transmettre ou de transmettre des savoirs sur les espèces, la nature des matières, l'usage des outils et les techniques de production. Ces savoirs sont assimilés au gré des apprentissages et expériences, et ce par un investissement qui associe l'œil, la tête et les mains. Ainsi, les coopérateurs expérimentés maîtrisent un savoir-faire résultant de leur apprentissage personnel, de leur expérience et de leur habileté. Il n'est transmissible, pour eux, que par la reproduction plus ou moins à l'identique d'individus au cours du travail lui-même. L'apprentissage informel débute donc au sein des communautés dès l'enfance et fait l'objet d'un encadrement des aînés.

Le troisième processus est l'intégration à la communauté des membres. Selon le scénario culturel ou organisationnel, les anciens transmettent aux nouveaux différents savoirs pour les aider à se repérer dans la coopérative et à réaliser leur travail. Ces savoirs ont trait à l'exercice du métier, à l'histoire de la coopérative et à son fonctionnement. Le processus de transmission est favorisé, en plus de la confiance, par les affinités, la curiosité et la patience. À la COOPEAN, celui qui demande à intégrer la coopérative subit une période d'essai de six mois pour jauger ses capacités de travail et d'intégration des normes. Il est ensuite gardé ou refoulé, selon son comportement et ses capacités de travail. Aussi, l'unité de production étant de type familial, le chef de famille sociétaire peut, en cas d'incapacité, désigner parmi les membres de sa famille un représentant initié au métier qui sera membre de la coopérative à sa place. À la COOPAM, où le système lignager est intégré au système coopératif, la période d'essai n'est pas une contrainte pour les nouveaux, déjà connus. Le travail se transmet de père en fils dès l'enfance. L'adhésion est directe par la filiation, ou indirecte via les mariages contractés par les membres. On constate dans les deux coopératives des transferts de statuts, des rôles et représentations et une succession dans les activités, qui assurent leur gestion et leur maintien.

Toutefois, il ne peut y avoir de transmission des savoirs entre coopérateurs ou entre ces derniers et les nouveaux adhérents, s'il n'y a pas un climat propice à la transmission ou l'acquisition des savoirs. Selon Catherine Choron-Baix, la transmission agit comme " une dynamique subtile, traversée de contradictions, entravée par les obstacles, les interférences, les brouillages et autres ratages, mais capable aussi d'engendrer de la création ou de la recréation ${ }^{13}$ ». 


\section{La transmission de la culture coopérative et l'influence des savoirs exogènes}

\section{Les coopérateurs face à leur environnement organisationnel}

(a)

consistent à bloquer et paralyser spirituellement et/ou physiquement les individus ou leurs projets ; d'autre part, à l'égoïsme des aînés ou dirigeants cherchant à conserver leur pouvoir et leur savoir au détriment de leur communauté. Elle crée une frontière entre ceux qui peuvent savoir et donc à qui l'on peut transmettre des savoirs et des compétences, et ceux qui n'ont pas le droit de savoir et qui, de fait, sont victimes de rétention. Aussi la tendance de ces gens de pouvoir à converser en langue maternelle dans les espaces communs, parfois pour entretenir le secret, viole-t-elle le langage commun. La conversation est, souligne Candau, « un comportement coopératif entre un locuteur et un auditeur, dont une des finalités est de diffuser de l'information ${ }^{17}$ ». Par ailleurs, cet auteur note que la «transmission est aussi production de la part de celui qui la reçoit car [...] les informations acquises sont remaniées par le groupe ou le sujet ${ }^{18}$ ». Par rapport à cela, l'acquisition grâce à l'école de certains modes de raisonnement, 
certaines techniques ou habitudes langagières, révèle une remise en cause constante des savoirs et pratiques des uns et des autres, favorisant des inégalités et tensions parmi les membres. Cela aboutit à une marginalisation où l'ignorance des uns et la faible expérience des autres les mettent en marge des activités et du processus de décision. Cette marginalisation enfreint toute égalité et participation et freine la transmission des valeurs et principes coopératifs. Les inégalités en matière d'instruction et d'expérience créent des incompréhensions et influent, tout en suscitant des incivilités, sur l'exemplarité à donner quant aux comportements honnêtes, responsables et solidaires attendus.

\section{Un passage de relais incertain}

Les communautés encadrent leurs membres pour animer et maintenir les activités coopératives. Cependant, cet encadrement ne s'adapte que difficilement à l'évolution de la société. La COOPEAN et la COOPAM montrent en effet une faible dynamique de transmission des connaissances du métier et de coopération entre les générations. Cela est dû au manque de motivation et d'incitation des anciens, et au désintéressement et à l'absence des jeunes.

«On ne transmet que ce qu'on a ou qu'on a reçu. Si tu as été mal éduqué, tu vas donner quel exemple aux autres? Quand on dit aux enfants que "le travail là ce n'est pas bien pour vous", quelle relève on assure là ${ }^{19}$ ?»

Certains anciens, du fait du manque de transparence, de solidarité et d'inclusion dans leurs comportements coopératifs, reconnaissent ne pas être des exemples à suivre; d'autres n'accordent que peu d'intérêt ou d'estime à leur métier. Il y a ceux qui se sousestiment et pensent ne pas être en possession des savoirs pertinents à transmettre, et ceux qui sont partagés entre l'envie de transmettre, le découragement face à l'inattention, l'arrogance et l'impatience des jeunes et la peur d'être remplacés par ces derniers.

En outre, la société du travail étant en pleine mutation, les métiers agricoles et artisanaux souffrent d'une image péjorative liée au monde rural. Pour certains anciens, ces métiers mènent à une vie ratée et pour certains jeunes, le métier exercé n'est qu'une activité de passage, en attendant de trouver mieux; ce qui entraîne un refus, conscient ou non, d'encourager les jeunes à exercer le métier et l'absence d'un réel engagement dans les coopératives. La majorité des coopérateurs perçoivent d'ailleurs leur métier comme rabaissant, dégradant, parfois peu rentable, et leurs coopératives comme n'existant pas. Sans compter que les jeunes s'intéressent peu aux activités coopératives. Certains travaillent ailleurs. Les difficultés des coopératives et la précarité des anciens freinent la transmission de ces institutions aux jeunes générations. Certains ne sont pas disposés ni destinés à prendre la relève de leurs pères. Cette vision est encouragée par certains anciens préférant les voir acquérir d'autres savoirs qui les distingueront dans la société.

Les dynamiques familiales et les modèles éducatifs des coopérateurs véhiculent de plus en plus l'idée que la réalisation de soi et la réussite sociale passent par la carrière professionnelle. La majorité d'entre eux s'accorde même sur le fait qu'il n'y aura jamais de relève dans leurs coopératives, et estime être la dernière génération qui y travaille. Les anciens vieillissent et les jeunes ont peu de rapports avec eux, du fait d'un autre emploi ou de l'école, des NTIC, médias ou jeux vidéo. Ces jeunes ouverts à d'autres 
savoirs passent moins de temps auprès des anciens pour observer et apprendre un métier et les pratiques coopératives.

Les valeurs du travail et sa symbolique disparaissent donc peu à peu. Certains anciens assistent, impuissants et révoltés, à la perte de leurs valeurs et savoir-faire, dans la génération de leurs enfants qui développent d'autres techniques face à la concurrence sur le marché, et plus encore dans celle de leurs petits-enfants, exposés à d'autres savoirs. Cette dernière génération est destinée à un cursus scolaire, pour atteindre un meilleur rang social que la première et deuxième génération. Faire des études permet certes d'avoir un diplôme, d'ouvrir les portes, d'avoir une ascension sociale, mais la question de la pérennité des coopératives reste posée dans les communautés.

\section{Une révolution dans les pratiques et rapports coopératifs?}

La COOPEAN et la COOPAM ont un rôle à jouer dans la satisfaction et le bien-être collectifs. Quelques coopérateurs l'ont compris. Ils estiment que la transmission de nouveaux savoirs leur permettrait de s'affranchir des vieilles habitudes et comportements acquis, résultats d'influences d'idéologies diverses. Cela pourrait les aider à donner une nouvelle dynamique à leur coopération, à être mieux armés pour répondre à leurs problèmes et à transmettre aux générations futures un héritage en adéquation avec l'environnement. Ils reconnaissent toutefois que l'application des valeurs et principes coopératifs et leur transmission aux nouvelles générations sont un défi. Les comportements hybrides et non stabilisés observés contribuent en fait au maintien d'aînés gérants et au transfert des relations privilégiées et logiques tribales, des inégalités de pouvoir, du rejet et des résistances. Ils font donc circuler des représentations relatives à ce qui doit être transmis, comment cela doit l'être et avec quelle finalité.

Cette compréhension du rôle et des enjeux de la coopération vient cependant de l'usage d'Internet et des médias, qui transforment la sphère socioculturelle des coopérateurs. Ces outils bouleversent chez certains les références, valeurs et codages anciens assurant une relative stabilité des coopératives. Ils leur donnent accès à d'autres systèmes de pensée, d'autres façons de s'exprimer, d'autres savoirs, qui parfois entrent en contradiction avec les savoirs acquis et remettent en cause les sources traditionnelles d'autorité et les processus de transmission des savoirs. Vincent de Gaulejac et Fabienne Hanique, dans Le capitalisme paradoxant, un système qui rend fou, publié en 2015, montrent que les dominations culturelles, sociales, familiales, religieuses et politiques sont débordées par ces outils puisqu'elles n'imposent plus aux individus leur langage, leur enseignement, leurs dogmes et systèmes de valeurs. Par leur potentiel révolutionnaire ${ }^{20}$, les NTIC renouvellent chez ces coopérateurs certaines valeurs et affectent ainsi leurs représentations et comportements en créant parfois le désordre, la résistance et le manque de respect mutuel.

«Il y a un réveil chez beaucoup, on n'est plus comme avant, où certains acceptaient tout. On s'informe. Les gens pensent qu'on parle pour parler. Le monde est en train de s'occidentaliser. Il se transforme en un petit village où on sait quand même comment ça se passe chez les autres ${ }^{21}$. »

Le cyberespace permet en outre de relier les habitants de la planète et de faire converger les actions humaines. De la sorte, la transmission des savoirs apparait comme un processus dynamique qui entraîne à la fois la recréation du processus technique et celle du groupe social des coopérateurs. Certains perçoivent les codes, 
pratiques et valeurs de leurs coopératives comme caducs, en inadéquation avec les coopératives prônées en Europe. Par des résistances, ils se désolidarisent et boycottent les pratiques qui les gardent dans le schéma traditionnel. Les savoirs acquis par ces outils et l'école leur permettent donc, bien que faiblement, de s'y opposer.

La prise de conscience et la révolte de certains traduisent une volonté de changer les choses. Plus leur conscience est éveillée, plus elle s'affranchit des manières anciennes de penser et plus elle discerne les injustices et anomalies liées à la coopération. On a alors un double langage entre "conservateurs » et "réformistes " par rapport à la gestion coopérative. Les premiers refusent d'actualiser leurs savoirs, de s'ouvrir à une génération ouverte au monde. Ils affichent un conservatisme qui n'a plus lieu d'être du fait des évolutions récentes rendant obsolètes leurs pratiques et l'expérience des membres âgés. Les réformistes cherchent à rehausser les valeurs et principes coopératifs en rejetant les anciennes politiques et pratiques pour favoriser la transparence, la démocratie, l'égalité et l'équité. Pour eux, la consolidation de la coopération passe par une formation et une éducation bien pensées par rapport à l'évolution de la société.

Pour conclure, l'administration coloniale, l'État postcolonial et les coopérateurs ont joué, chacun à leur niveau, un rôle qui a peu favorisé la transmission de la culture coopérative moderne, d'où les défaillances culturelles des coopératives. On a, en leur sein, une hybridation des pratiques coopératives et une persistance des habitudes traditionnelles, qui influent sur les représentations et comportements des adhérents et apparaissent comme des obstacles à la transmission des savoirs et à la promotion de la culture coopérative moderne revendiquée par une génération exposée à des savoirs qui transforment leur mémoire, leur perception et leur raisonnement. L'enjeu dans la transmission de cette culture est, en fait, de former l'individu lui-même, passionné par le métier, afin qu'il intègre pleinement le statut de coopérateur.

Cette étude de la transmission des savoirs étant réduite à deux coopératives créées dans les années 1980, de nouvelles recherches sont en cours pour étayer mes arguments et éclaircir certaines zones d'ombre. Elles portent sur les stratégies de socialisation et d'apprentissage et visent les coopératives liées au nouveau dispositif de l'Organisation pour l'harmonisation en Afrique du droit des affaires (OHADA) relatif au droit des sociétés coopératives. L'objectif est de saisir les pratiques culturelles transmises par ce dispositif et leur impact sur les idéologies, comportements et pratiques des acteurs.

\section{BIBLIOGRAPHIE}

BASTIDE Roger, Le prochain et le lointain, Paris, Éditions Cujas, 1970. 
BERLINER David, « Anthropologie et transmission », Terrain, 2010, vol. 55, p. 4-19.

BRIL Blandine, «Apprentissage et culture », dans Chevallier Denis (dir.), Savoir-faire et pouvoir transmettre, Paris, Éditions de la Maison des sciences de l'homme, 1991, p. 15-21.

BUREAU INTERNATIONAL DU TRAVAIL, « Recommandation nº 193 sur la promotion des coopératives », $90^{\mathrm{e}}$ session CIT, Genève, 2002.

CANDAU Joël, « Pourquoi coopérer », Terrain, 2012, vol. 58, p. 4-25.

CANDAU Joël, Anthropologie de la mémoire, Paris, Armand Colin, 2005.

CHORON-BAIX Catherine, « Transmettre et perpétuer aujourd'hui », Ethnologie française, 30 (3), 2000, p. 357-360.

GAULEJAC Vincent de et HANIQUE Fabienne, Le capitalisme paradoxant, un système qui rend fou, Paris, Le Seuil, 2015.

LÉVY Joseph et LASSERRE Evelyne, «Internet, savoirs et savoir-faire : de quelques perspectives anthropologiques ", Anthropologie et sociétés, 2011, vol. 35, n 1-2, p. 17-34.

MAKOUATSA BOUPO Nina-Marinette, «La dynamique de coopération dans le secteur de l'économie sociale et solidaire au Gabon. Cas de la COOPEAN et de la COOPAM : état des lieux et perspectives ", thèse de doctorat en anthropologie, Nice, université Nice - Sophia-Antipolis, 2017. MAQUET Jean et QUAZZA Jean-Pierre, « Transmission... », Actualités en analyse transactionnelle, 2009, vol. $129, \mathrm{n}^{\circ} 1$, p. $71-73$.

MEILLASsoux Claude, Terrain et théorie, Paris, Anthropos, 1977.

REBOUL Olivier, Les valeurs de l'éducation, Paris, Presses universitaires de France, 1992.

WINKIN Yves, Anthropologie de la communication : de la théorie au terrain, $2^{\mathrm{e}}$ éd., Paris, Le Seuil (Points), 2001.

\section{NOTES}

1. D. Berliner, « Anthropologie et transmission », p. 6.

2. Dieudonné, 48 ans, expert en agrodéveloppement, 2012, Libreville.

3. Bureau international du travail, «Recommandation $n^{\circ} 193$ sur la promotion des coopératives ", $90^{\mathrm{e}}$ session CIT.

4. L. Cavalli-Sforza, cité dans B. Bril, « Apprentissage et culture », p. 16.

5. W. H. Goodenough, cité dans Y. Winkin, Anthropologie de la communication: de la théorie au terrain, p. 127.

6. O. Reboul, Les valeurs de l'éducation, p. 1.

7. Loi $n^{\circ} 47-1775$ de l'AEF, de l'arrêté $n^{\circ} 2097$ du 25 octobre 1947 et décret-loi du 2 février 1955 portant statut de la coopération dans les territoires relevant du ministre de la France d'outre-mer.

8. B. K. Malinowski, cité dans R. Bastide, Le prochain et le lointain, p. 45.

9. Jean-Louis, 56 ans, agent de la Direction générale des coopératives, 2014, Libreville.

10. J. Maquet et J.-P. Quazza, « Transmission... », p. 71-73.

11. Richard, 44 ans, président de la COOPAM, 2012, Libreville. 
12. C. Meillassoux, Terrain et théorie, p. 33-34.

13. C. Choron-Baix, «Transmettre et perpétuer aujourd'hui », p. 359.

14. N.-M. Makouatsa Boupo, «La dynamique de coopération dans le secteur de l'économie sociale et solidaire au Gabon : cas de la COOPEAN et de la COOPAM, état des lieux et perspectives ", p. 280.

15. Mboumba, 73 ans, membre de la COOPAM, 2012, Libreville.

16. Jacques, 64 ans, membre de la COOPEAN, 2012, Ntoum.

17. J. Candau, « Pourquoi coopérer », p. 12.

18. J. Candau, Anthropologie de la mémoire, p. 152.

19. David, 56 ans, membre de la COOPAM, 2012, Libreville.

20. J.-J. Lévy et E. Lasserre, «Internet, savoirs et savoir-faire : de quelques perspectives anthropologiques », p. 19.

21. Gatien, 38 ans, membre de la COOPAM, 2012, Libreville.

\section{RÉSUMÉS}

Au Gabon, l'intérêt pour les paysans d'adhérer aux coopératives étatiques, au-delà d'un appui financier, est de bénéficier des savoirs aussi bien techniques qu'organisationnels essentiels à la réussite de leurs activités. Ce travail de recherche identifie les acteurs intervenant dans la transmission des savoirs endogènes et exogènes au sein de ces organisations. Ces dernières étant inscrites dans une perspective lignagère et intergénérationnelle, nous montrons comment les savoirs exogènes véhiculés par les familles, les écoles, les nouvelles technologies de l'information et de la communication modifient les comportements coopératifs tout en affectant le développement des coopératives.

\section{AUTEUR}

\section{NINA-MARINETTE MAKOUATSA BOUPO}

Docteur en anthropologie, Laboratoire d'anthropologie et de psychologie cognitives et sociales (LAPCOS), université Nice - Sophia-Antipolis 
Rôle historique des sociétés savantes et des savants de terrain 


\title{
L'érudition normande dans la France du xix siècle : le rôle d'Arcisse de Caumont
}

\author{
François Guillet
}

1 Dans l'avertissement qui précède son Cours d'antiquités monumentales, publié en 1830, Arcisse de Caumont écrit :

«Il faut l'avouer, la science des antiquités n'est encore le partage que d'un petit nombre de personnes privilégiées; elle n'est point assez répandue [...]. J'ai pensé que je me rendrais utile à mon pays en créant ici un enseignement qui n'existe pas encore ${ }^{1}$."

La Normandie est le berceau de l'archéologie médiévale pendant le XIX ${ }^{\mathrm{e}}$ siècle. Arcisse de Caumont, archéologue et érudit, en est la figure de proue. Le remarquable réseau de sociétés savantes qui irrigue la région durant cette époque permet le lancement d'une vaste entreprise d'inventaire et d'étude des constituants naturels et humains de la région; il permet surtout d'en révéler le passé, en procédant à un recensement et à une analyse minutieux des monuments anciens, dont les vestiges et les édifices médiévaux sont les plus emblématiques. Cette entreprise aboutit à un cadre général de classement des monuments médiévaux qui servira de base à tous les travaux ultérieurs et aura une influence profonde sur les modes de perception de la province. La volonté de diffusion et de vulgarisation des connaissances accumulées est constitutive de ce projet, puisqu'il s'agit pour Caumont de fonder ou de refonder une identité provinciale face au centralisme parisien, en favorisant la renaissance et l'épanouissement d'une vie culturelle et même de formes d'administration autonomes. Porte-parole des notabilités provinciales, politiquement conservateur, Caumont entend faire partager sa passion érudite par un public qu'il souhaite le plus large possible et qui ne s'arrête pas d'ailleurs aux limites de la province. Nous nous efforcerons ici de montrer l'originalité de ce projet en explorant les chemins empruntés par les érudits normands pour diffuser et transmettre les connaissances qu'ils ont patiemment réunies ${ }^{2}$, et évaluer l'influence de cette école dans la France du XIX ${ }^{\mathrm{e}}$ siècle. 


\section{Le rassemblement de la France provinciale savante}

3 Principal chantre du milieu érudit normand, Arcisse de Caumont est à l'origine de la fondation de nombreuses sociétés savantes, qui sont l'expression d'une sociabilité érudite dont l'essor a commencé dès le XvII ${ }^{\mathrm{e}}$ siècle. Ce mouvement, dont Jean-Pierre Chaline a retracé la genèse ${ }^{3}$, touche l'ensemble de la France, mais il prend en Normandie une ampleur particulière. Au réseau ancien, constitué des académies provinciales d'Ancien Régime et des sociétés d'émulation des premières années de la Révolution, s'ajoutent des sociétés nouvelles qui s'éloignent du modèle académique par leur absence de spécialisation et le nombre illimité de leurs membres. Abandonnant l'esprit polymathique des Lumières, ces sociétés nouvelles se spécialisent dans deux domaines principaux, qui correspondent à la formation de Caumont comme à celle de nombreux antiquaires, et qui sont étroitement associés: les sciences naturelles et l'archéologie. Il faut y ajouter l'agronomie, qui constitue un centre d'intérêt de premier ordre pour des érudits souvent propriétaires terriens.

De la première catégorie relève la Société linéenne du Calvados, fondée en 1823 par Henri de Magneville, président de l'Académie de Caen et créateur du musée d'histoire naturelle de la ville, dont Caumont est nommé secrétaire; elle étend en 1826 ses activités à l'ensemble de la Normandie. De la seconde relèvent plusieurs sociétés parmi les plus importantes de Normandie, qui s'inscrivent dans un mouvement déjà ancien, marqué sous la Révolution par la création d'institutions destinées à classer et à sauvegarder des monuments. C'est en s'inspirant de la Commission des antiquités de la Seine-Inférieure, fondée en 1818 sous l'impulsion du comte de Kergariou, préfet du département, que Caumont met sur pied en 1824 la Société des antiquaires de Normandie, véritable modèle des sociétés savantes provinciales du $\mathrm{XIX}^{\mathrm{e}}$ siècle. De l'intérêt pour l'agronomie relève, en 1832, l'Association normande, dont le nom complet est Association normande et anticentrale pour l'encouragement des études et de l'industrie provinciale.

5 L'activité de Caumont ne se limite pas à la Normandie. Après les cinq départements normands, ce sont les régions de l'Ouest qu'il cherche à rassembler. Le voyage qu'il accomplit dans cette portion de la France en 1830 le pousse à créer, en 1834, la Société française pour la conservation et la description des monuments historiques, qui prendra le nom de Société française d'archéologie et qui élargit ses activités à la France tout entière, en commençant par la France de l'Ouest. Après un premier congrès à Douai, la société française d'archéologie tient ses congrès suivants à Vire, Caen, Alençon, au Mans et à Tours. L'organisation par Alexandre de Humboldt de congrès scientifiques, parmi lesquels celui de Berlin en 1828 et surtout de Vienne en 1832, réunissant près de 1100 délégués, inspire à Caumont l'idée de créer des «assises ou congrès scientifiques", dont la première cession se tient à Caen en 1833, et qui rassemblent des délégués des sociétés savantes des provinces, afin de leur permettre d'échanger leurs idées et de faire connaître leurs travaux. La Société des antiquaires de Normandie entretient par ailleurs des liens privilégiés avec les sociétés sœurs et les érudits de l'Ouest, en particulier de la Sarthe, liens renforcés à l'occasion de l'affaire du baptistère de Saint-Jean de Poitiers, sauvé de la destruction en 1832 par une ligue de circonstance entre sociétés savantes de l'Ouest. Sur le modèle de la Société des antiquaires de Normandie naissent la société des antiquaires de la Morinie à Saint- 
Omer en 1831, la Société des antiquaires de l'Ouest à Poitiers en 1834, la Société des antiquaires de Picardie à Amiens en 1836.

De l'Ouest, Caumont passe à la province tout entière lorsqu'il crée en 1839 l'Institut des provinces, terme réservé en principe à l'Institut de France. Conçu comme une sorte d'académie centrale chargée de soutenir les associations et de coordonner leurs travaux, son siège est d'abord fixé au Mans, puis migre bientôt à Caen, où la direction est assurée par un directeur et un secrétaire général. Les réunions ont lieu à l'occasion des congrès scientifiques, mais la dispersion des membres de l'institution et l'autoritarisme de Caumont, sans compter les réticences du pouvoir, freinent l'essor de l'institution. À partir de 1850, Caumont met sur pied le Congrès des sociétés savantes des départements, sous la direction de l'Institut des provinces, dont la première réunion a lieu en 1850 à Paris, au palais du Luxembourg, dans l'ancienne chambre des pairs. Les réunions se maintiendront jusqu'en 1869, donnant lieu à la publication jusqu'en 1870 de trois volumes de mémoires et d'un annuaire.

7 La démarche de Caumont et des antiquaires normands vise à mettre au jour tous les éléments qui fondent l'identité provinciale et à diffuser les savoirs ainsi constitués. Dans la circulaire qui paraît en 1825 dans le tome II des Mémoires de la Société des antiquaires de la Normandie, le Rouennais Auguste Le Prévost écrit :

«Il ne s'agit plus ici de conserver sur quelques points et pour un petit nombre d'adeptes un dépôt de connaissances acquises, mais d'arracher au néant et à l'oubli, par des efforts prompts et unanimes, tout ce qui n'a pas encore péri des monuments et des souvenirs attachés à notre sol. Il faut que tous les amis du nom normand se lèvent comme un seul homme pour accomplir cette sainte entreprise; les divisions arbitraires du territoire, les anciennes formes académiques, ne sauraient être prises en considération. Quiconque habite la Normandie et s'intéresse à sa gloire doit venir avec nous prendre part aux travaux, comme il sera admis à profiter de ses résultats ${ }^{4}$.»

8 Au-delà de la Normandie, c'est la France provinciale qu'il s'agit d'éveiller, comme l'écrit Caumont dans le deuxième volume de la Revue normande:

« [Je veux] ranimer en province l'activité intellectuelle, éveiller l'émulation entre les corps savants qui allaient se multipliant sur tous les points du royaume, produire au grand jour les talents personnels qui trop souvent restent inconnus, et s'ignorent eux-mêmes. [...] Il faut qu'on puisse être écrivain, homme politique, savant, artiste, ailleurs que dans la capitale ${ }^{5}$.»

9 La province, aux yeux de l'antiquaire, c'est pour une large part les provinces, au sens où l'Ancien Régime l'entendait. Le projet de Caumont pour l'Institut des provinces prévoit une division du pays en douze ou quinze circonscriptions, dont les limites seraient celles des provinces de l'ancienne France et qui seraient chacune dotées d'une académie située au chef-lieu et exerçant son autorité sur toutes les autres sociétés de sa circonscription.

Ce projet n'est ainsi pas sans rapport avec le projet politique de la monarchie censitaire. Le provincialisme de Caumont semble s'inscrire dans l'ultracisme de la Restauration, mais s'y ajoute une dimension capacitaire qui le rapproche du dessein de Guizot sous la monarchie de Juillet. Le milieu érudit normand en témoigne. Outre des personnalités très actives, comme Caumont et le Rouennais Auguste Le Prévost, ancien sous-préfet durant les Cent-Jours, puis député à partir de 1834, après avoir conquis le siège laissé vacant par la mort de Dupont de L'Eure, ce milieu rassemble de grands notables et des personnalités politiques de premier plan, comme Guizot, député de 
Lisieux, ou des préfets, tel Antoine Passy, préfet de l'Eure, ainsi que des membres de grandes familles nobles comme le comte de Beaurepaire, dans le Calvados. Mais à ces grands notables s'ajoute un réseau de personnalités implantées localement, dont l'origine est plus modeste et qui exercent souvent des professions intellectuelles ou libérales : enseignants, ingénieurs, fonctionnaires locaux, conservateurs, magistrats, avocats. Parmi les correspondants de Caumont figurent Julien Travers, successivement professeur au collège de Saint-Lô, principal du collège de Falaise, puis professeur à la faculté des lettres de Caen; Dubourg d'Isigny, président du tribunal de Vire ; Frédéric Galeron, procureur du roi et bibliothécaire de la ville d'Alençon; Pierre-Amable Floquet, ancien élève de l'École des chartes, avocat, greffier en chef de la cour de Rouen; Frédéric Pluquet, libraire à Paris, puis pharmacien à Bayeux : une bourgeoisie capacitaire que le régime de Juillet entend favoriser. Parmi les quatre-vingt-cinq membres titulaires et les vingt-cinq membres correspondants de la Société des antiquaires de Normandie figurent des personnalités prestigieuses, dont l'adhésion est honorifique. C'est le cas des cinq préfets normands, membres de droit, de deux souspréfets et des cinq maires, dont celui de Rouen, le marquis de Martainville et celui de Caen, le comte d'Osseville. La société réunit parmi ses membres titulaires une majorité de propriétaires, mais aussi onze membres de la magistrature, quatre médecins, deux inspecteurs de l'université. Vingt-six sont explicitement nobles et soixante appartiennent à d'autres sociétés savantes ${ }^{6}$. On retrouve la même sociologie dans les autres provinces ou dans d'autres sociétés fondées en Normandie, comme la Société archéologique d'Avranches, fondée par Édouard Le Héricher, professeur au lycée de la ville ${ }^{7}$.

11 L'objectif est d'élargir sans cesse le nombre d'adhérents. Les congrès et les assises qui se tiennent régulièrement, comme les congrès annuels organisés par la Société des antiquaires de France, permettent de susciter de nouvelles adhésions, pour une part temporaires, dans la région choisie. Le monde économique est cependant largement absent, les industriels rouennais ne se retrouvant que dans la Société d'émulation de la Seine-Inférieure ${ }^{8}$.

12 La participation aux travaux des sociétés savantes répond à un désir des classes moyennes et supérieures provinciales et s'inscrit dans une démarche d'émulation. Le principal ouvrage de Caumont, le Cours d'antiquités monumentales, a d'abord été conçu sous la forme de leçons orales. Le journal Le Temps en fait un compte rendu en décembre 1829:

«Avant de publier sa méthode analytique d'archéologie, M. de Caumont a été sollicité par tous les habitants instruits de faire un cours d'antiquités monumentales. Ce cours, qui sera gratuit, manque à nos grandes villes, même à Paris. Nos salons, s'ils ne sont pas gothiques, se décorent d'objets qui revêtent des formes antiques; et pourtant, très peu de personnes sont capables d'analyser la construction de nos édifices du Moyen Âge et des époques de transition ${ }^{9}$. »

L'orientation historisante du mouvement relève certes d'une culture nobiliaire qui doit se réinventer. Mais le mouvement érudit normand et provincial n'est pas seulement tourné vers le passé. Il porte une volonté de progrès, qui s'exprime notamment au sein de l'Association normande. L'Association normande, dit son programme, a pour but "d'encourager les progrès de la morale publique, de l'enseignement élémentaire, de l'industrie agricole, manufacturière et commerciale dans les départements de l'ancienne Normandie », en contribuant à "l'amélioration morale, intellectuelle et 
matérielle de l'homme» afin d'amener en Normandie "un état de choses aussi satisfaisant qu'en Flandres ou en Alsace ${ }^{10} »$.

\section{Les activités savantes}

14 Rassembler les savants des provinces, c'est partager et transmettre les savoirs afin de permettre cette élévation morale, intellectuelle et matérielle que Caumont souhaite promouvoir. L'activité scientifique de ces sociétés s'inscrit nettement dans un provincialisme revendiqué. L'œuvre scientifique du mouvement est considérable : un immense travail de recensement s'organise et touche tous les domaines. Le tome I de l' Annuaire de l'Association normande comporte des notes sur l'histoire de la Normandie, une étude géographique de la région, un article sur le mouvement de la population, d'autres sur l'hydrographie, l'administration de la province, l'instruction publique, l'agriculture ${ }^{11}$. Caumont lui-même s'intéresse aussi bien à la géologie, aux sciences naturelles qu'à l'archéologie ${ }^{12}$.

15 L'apport le plus important de ce mouvement touche à l'archéologie médiévale, dont Caumont définit le classement chronologique et fixe les caractères, en consacrant notamment à la différenciation entre art roman et art gothique plusieurs ouvrages, parmi lesquels le Cours d'antiquités monumentales professé à Caen, dont la publication s'échelonne sur onze années, de 1830 à 1841 , et qui résulte d'un travail minutieux d'observations faites sur le terrain, même si Caumont conduit rarement lui-même les fouilles. Consacré aux monuments nationaux de l'ouest de la France, de la période gauloise à la fin du Moyen Âge, l'ouvrage participe de la recherche d'une généalogie du territoire où le monument prend place dans une chaîne temporelle qui débute avec le sous-sol, longuement étudié par Caumont, et dans laquelle s'inscrit l'antiquaire.

Pour Auguste Le Prévost, en scrutant les monuments, l'observateur célèbre une union imaginaire avec les générations passées et contemple une part de lui-même :

«Chaque jour révèle en nous quelque nouvel attrait, quelque nouveau motif de prédilection dans ces édifices élevés pour nous par la main de nos pères, en rapport avec nos paysages autant qu'avec nos croyances, nos habitudes et les dispositions les plus intimes de nos âmes ${ }^{13}$. »

Recherche savante, patriotisme provincial mais aussi philanthropie se conjuguent dans la volonté de diffuser les travaux des sociétés savantes et les idées de leurs principaux représentants. Toutes les sociétés fondées par Caumont fonctionnent peu ou prou selon les mêmes modalités. Les objectifs officiels de la Société des antiquaires de Normandie sont le recensement, la sauvegarde et surtout l'étude de l'architecture, particulièrement de l'architecture médiévale, ainsi que la mise à la disposition du public des connaissances ainsi acquises. Chaque membre est invité à rechercher à proximité de sa résidence les monuments et décorations architectoniques qui existent encore ou ceux que des fouilles auraient mis au jour, d'en faire l'historique, d'en constater l'âge ou l'état de dégradation, de les dessiner s'il le peut et de faire parvenir à la société des observations sur les moyens de les conserver. Les résultats des recherches menées par les membres de la société sont ensuite publiés dans les Mémoires ${ }^{14}$. La création d'un musée est projetée.

Les autres sociétés fonctionnent de la même manière. Les statuts de l'association normande prévoient une assemblée générale annuelle dans une ville de Normandie, la publication d'un annuaire et l'esquisse d'un projet de statistique générale de la 
province. La Société des antiquaires de France organise, on l'a dit, des congrès annuels dans une ville nouvelle et une nouvelle revue, le Bulletin monumental, est créée à partir de 1835 afin d'assurer la liaison entre les antiquaires provinciaux et de rendre compte des congrès, avant que ceux-ci fassent l'objet d'une publication séparée.

Outre des réunions régulières, la principale activité des sociétés est la publication de leurs travaux. Le nombre de publications est, dans tous les domaines, absolument considérable: outre les Mémoires des diverses sociétés, beaucoup de membres des sociétés font paraître plusieurs ouvrages sur les sujets les plus divers, qui sont presque toujours publiés à compte d'auteur. Les assemblées, congrès et assises scientifiques donnent lieu également à des publications.

Celles-ci sont assurées à Caen par l'imprimeur-éditeur Chalopin, spécialisé dans la littérature de colportage et les livres pieux. La maison est dirigée par Antoine Chalopin, ancien camarade de collège de Caumont, puis par Hardel après la mort de Chalopin en 1832, puis enfin par Le Blanc, gendre du précédent, à partir de 1864. Chalopin installe en 1830 la première presse lithographique de Normandie, ce qui permet à Caumont de faire imprimer sur place les dessins et les cartes géologiques qu'il devait jusque-là faire imprimer à Paris. À partir de 1840, Caumont a recours à la gravure sur bois, plus économique, car elle permet de conserver les matrices et de les réutiliser.

21 La diffusion des publications s'effectue en partie en circuit fermé, puisque les membres contractent en adhérant l'obligation d'acheter les volumes publiés. Ils contribuent aussi à une diffusion locale en recevant cinq ou six exemplaires et en les vendant de la main à la main, ce qui permet d'économiser les frais d'envoi. Les libraires participent également au travail de diffusion. Outre Hardel à Caen, la maison Frère met en vente les mémoires en payant à la société six exemplaires sur treize, les sept autres, valant six, étant réglés après leur vente moyennant une commission prélevée par le libraire. À Paris, Caumont, comme d'autres membres de sociétés savantes provinciales, laisse en dépôt ses ouvrages et recueils à la librairie Lance, située à côté de la Bibliothèque royale, rue des Petits-Champs, reprise par Derache en 1835. La librairie assure la liaison entre les sociétés et leurs membres résidant à Paris ou dans les régions éloignées. On peut y procéder à des échanges entre publications provinciales ${ }^{15}$. Caumont n'hésite pas, en outre, à procéder à des distributions gratuites d'ouvrages illustrés d'archéologie ${ }^{16}$. Aux ouvrages d'érudition s'ajoutent les nombreuses revues éditées par les sociétés : Caumont participe ainsi à la fondation du Journal de Caen, du Journal de Falaise, de la Revue normande enfin, qui a pour ambition d'offrir tous les quatre mois une somme à caractère encyclopédique sur la Normandie, mais qui n'a qu'une brève existence.

\section{La diffusion des connaissances : une ambition pédagogique}

La diffusion des publications savantes est certes limitée, et plus encore celle des ouvrages publiés par beaucoup d'antiquaires locaux. Mais la démarche des antiquaires est bien de toucher un public aussi large que possible. L'œuvre de Caumont comporte d'emblée une dimension pédagogique dont porte la trace le titre de son principal ouvrage, le Cours d'antiquités monumentales, qui a d'abord été conçu sous la forme de leçons orales. Le libraire Derache prépare le lancement de l'ouvrage en envoyant systématiquement des prospectus annonçant la parution des divers volumes du Cours aux auteurs de publications archéologiques qu'il relève dans le Journal de la librairie. Le 
nombre d'exemplaires vendus est certes modeste, mais le quatrième tome, consacré au Moyen Âge, est réédité avec le cinquième volume en 1836, 1837, 1838 et 1841 sous le titre Histoire sommaire de l'architecture religieuse, civile et militaire du Moyen Âge. Surtout, l'ensemble du Cours reparait avec quelques modifications entre 1851 et 1862 sous le titre de Abécédaire ou rudiment d'archéologie, dont le premier volume est consacré à l'architecture religieuse du Moyen Âge, le second à l'architecture civile et militaire et le troisième à la période gallo-romaine ${ }^{17}$. L'ambition vulgarisatrice de l'ouvrage est soulignée par Caumont en introduction : "Je travaille ici pour ceux qui ne savent rien, pour ceux qui n'ont pas encore épelé dans les grands livres ${ }^{18}$. » La série est rééditée en 1869-1870. Illustrés de gravures sur bois, ces livres contribuent plus que tout autre publication à la diffusion des idées de Caumont.

Caumont s'efforce d'élargir également le public concerné par ses publications en s'efforçant de toucher un public particulier, le public ecclésiastique. Les édifices cultuels étant placés sous la tutelle artistique et financière du ministère des cultes, les services diocésains d'architecture ont dans leurs attributions les travaux exécutés dans les églises paroissiales. Caumont envoie personnellement à tous les séminaires de Normandie et des régions voisines des exemplaires de son Cours, en espérant que son enseignement y serait diffusé. Il rencontre un succès relatif. L'évêque de Bayeux, Dancel $\mathrm{Du}$ Tot, incite dans ses mandements les séminaires de son diocèse à donner un supplément de formation dans ce domaine; en 1836, selon Caumont, quatre abbés professent ses théories en Normandie et dans la Sarthe ${ }^{19}$. En 1837, l'abbé Chevreau, enseignant au grand séminaire du Mans, explique dans un rapport que le prêtre, gardien de l'église, doit savoir la décrire et en apprécier la valeur artistique et historique $^{20}$. Caumont fait réimprimer spécialement à l'intention des séminaires le quatrième volume de son cours en $1841^{21}$, tandis que de nombreux manuels et compilations de ses écrits sont publiés à Paris ou dans les provinces en aggravant, selon les spécialistes, les erreurs de l'auteur. En Bretagne, le chanoine Brune publie un manuel d'archéologie religieuse, qu'il professe au séminaire de Rennes pendant neuf $a^{22}{ }^{22}$. À Tours, l'abbé Bourassé, membre de la société française d'archéologie, de la société archéologique de Touraine et professeur d'archéologie au petit séminaire de Tours, publie en 1841 une Archéologie chrétienne ${ }^{23}$. Caumont se soucie enfin de faire connaître ses idées auprès des élèves adultes de l'école élémentaire en publiant en 1868 dans un format in-dix-huit une Archéologie des écoles primaires ${ }^{24}$.

Les activités des sociétés savantes ne se limitent pas au travail de publication des travaux entrepris par leurs membres. Caumont développe un enseignement oral sous forme de conférences, de leçons, de visites sur le terrain. Dès l'époque de sa jeunesse, en 1820-1821, il forme une sorte de cercle d'enseignement mutuel qui réunit ses compagnons d'étude, la Société d'émulation des sciences et des belles-lettres.

En 1829, il met sur pied des conférences littéraires et scientifiques, qu'il aurait voulues, à l'instar de celles organisées par la société d'émulation de Rouen, ouvertes à tous, se chargeant lui-même des leçons d'archéologie. Il veut, explique-t-il, attirer les jeunes gens, leur donner les éléments qui leur manquent, faire de ces réunions une école préparatoire où l'on fait ses preuves avant d'être admis dans l'une des sociétés littéraires ${ }^{25}$. Mais il est décidé par les instances dirigeantes que seuls les membres titulaires pourraient s'abonner au cercle. Caumont parvient tout de même à attirer une soixantaine d'auditeurs au cours d'antiquités qu'il professe à Caen selon des méthodes 
bien spécifiques. Les leçons orales s'appuient sur des dessins, comme il l'écrit à son ami Frédéric Galeron :

«Je chercherai toujours à parler aux yeux en même temps qu'à l'esprit, et je fais une suite de dessins forts grands, où les formes caractéristiques de chaque groupe seront exprimées ${ }^{26}$."

Ces leçons sont en outre complétées par des visites faites aux églises et aux monuments de la région. Le cours prend fin en décembre 1830, après une dernière séance consacrée à la visite de Saint-Pierre de Caen.

Caumont instaure ainsi la tradition des visites sur le terrain, qui sera poursuivie par luimême et par ses successeurs. En 1857, il organise une excursion dans l'Orléanais, où il visite en compagnie de ses confrères les cryptes de Saint-Avit et de Saint-Aignan et s'efforce d'en préciser la datation en s'appuyant sur la forme des chapiteaux, qu'il fait dessiner, et sur les légendes locales. L'excursion s'achève sur la visite du musée d'Orléans ${ }^{27}$. Les méthodes de Caumont, fondées sur la visite in situ et le dessin, sont du reste reprises par les religieux professant dans les séminaires.

Ces activités sont naturellement prolongées par la naissance du musée de la société des antiquaires de Normandie, créé lorsque les objets accumulés dans le pavillon où avaient lieu les séances, rue Daniel Huet à Caen, sont transposés dans l'ancien collège du Mont et montrés au public en 1860. C'est à cette occasion qu'est réalisé le seul catalogue imprimé du musée, comprenant 762 numéros classés par grandes périodes chronologiques : colonnes, sarcophages, moulages de sculptures, collections lapidaires, objets divers, et même la façade d'une maison du $\mathrm{xvI}^{\mathrm{e}}$ siècle, remontée dans la cour. Une bibliothèque y est associée ${ }^{28}$.

En outre, Caumont conçoit dès 1824 un plan prévoyant la création de quatre-vingt-cinq bibliothèques rurales dans le seul département du Calvados, chaque bibliothèque étant installée au chef-lieu de canton et disposant d'un choix de vingt-cinq ouvrages portant sur l'agriculture, la morale, mais aussi l'histoire, mis gratuitement à la disposition des lecteurs ${ }^{29}$. Le projet n'aboutira pas, mais l'Association normande soutiendra la création de bibliothèques rurales.

Si le nombre de membres réellement actifs des sociétés que Caumont a fondées est limité, les divers congrès qu'il organise rencontrent un succès populaire incontestable, même si les adhésions qu'ils suscitent sont pour une part temporaires. À Strasbourg, en 1842, 1008 membres sont présents au congrès scientifique, qui s'étend sur dix jours ; quatre-vingt-neuf séances de sections et vingt-deux séances générales ont lieu, tandis que cent dix-sept mémoires sont présentés. Le congrès de Reims, en 1845, réunit quant à lui 1078 membres. Ces réunions sont aussi de véritables fêtes populaires. Tous les témoins ont souligné leur succès et l'étonnant déploiement de fastes qui les accompagnent: entrées triomphales dans les villes, rosettes multicolores, drapeaux, fanfares, lanternes vénitiennes, décharges d'artillerie, promenades aux flambeaux, banquets et toasts, qui déconcertent parfois certains participants. À Lyon, en 1841, raconte Caumont, le congrès descend le Rhône jusqu'à Vienne sur deux bateaux à vapeur, richement pavoisés d'écussons et de pavillons aux armes de toutes les nations européennes :

« Ils avaient à peine levé l'ancre, au bruit du canon, qu'une musique militaire et des chœurs, qui devaient chanter toute la traversée des hymnes composés pour la fête, faisait retentir les coteaux voisins ${ }^{30}$." 
31 Sur les rives du fleuve, les congressistes sont salués à maintes reprises par les décharges de mousqueterie de la Garde nationale et acclamés par les populations, en la présence desquelles Caumont voit «la preuve de la sympathie qui anime la province pour ceux qui, comme les membres du Congrès scientifique, travaillent à élargir le cercle étroit de la centralisation scientifique et littéraire ${ }^{31} »$. Au-delà des formes de sociabilité propres à ce type de manifestations, ces fastes révèlent une part de la France provinciale fière de participer ainsi aux progrès du genre humain.

Caumont et les antiquaires normands s'emparent enfin d'un moyen particulier de diffusion de leurs idées, les guides et descriptions touristiques. Avant que soient éditées, au milieu du siècle, des séries comme le guide Joanne, les éditeurs-libraires situés dans les villes provinciales ou à Paris font paraître, avant même l'apparition du chemin de fer, de nombreux guides destinés aux voyageurs. Ces guides comportent des indications pratiques, mais aussi indiquent les curiosités locales, les points de vue, les promenades qu'on peut y faire. La Normandie se distingue, dans cette perspective, par la précocité des pratiques touristiques qu'on y accomplit, en particulier les bains de mer, et des publications qui les accompagnent. Certains de ces guides sont consacrés, suivant une tradition ancienne, à la description d'un itinéraire, d'autres à la description des villes et des localités, d'autres, avec plus d'ampleur, se consacrent à la région tout entière. Pour les rédiger, les éditeurs font naturellement appel aux membres des sociétés savantes locales, comme du reste l'avaient fait les préfets pour réaliser pendant la période napoléonienne la Statistique de la France. Arcisse de Caumont est prompt à s'emparer de ce mode de diffusion. Dans l'introduction de sa Statistique routière de Normandie, publiée en 1842 , il écrit :

«J'avais, il y a quinze ans, réuni mes notes de façon à former un corps d'ouvrage que j'intitulais "Guide du voyageur en Normandie". J'annonçai en 1827 la publication prochaine de cet opuscule, et l'empressement que l'on mit à accueillir mon projet me confirma dans la persuasion où j'étais qu'un guide du voyageur, tel que je l'avais conçu, serait une chose utile ${ }^{32}$."

Outre cet ouvrage, Caumont rédige une Statistique routière de Caen à Rouen, ainsi que deux guides destinés aux baigneurs de la côte du Calvados, dont un Guide du baigneur aux environs de Trouville en 1850 et de nombreuses descriptions de promenades ou excursions. À côté de remarques qui relèvent d'une curiosité encyclopédique et qui amènent les auteurs à exposer les méthodes agricoles utilisées ou à faire une visite de la prison locale, ces ouvrages se penchent longuement sur les vestiges et les paysages, qui sont d'ailleurs étroitement associés. Caumont ne manque pas dans ces publications d'expliquer au voyageur les caractéristiques des édifices rencontrés et ses théories sur le passage du roman au gothique. À ces guides, souvent ornés d'illustrations, s'ajoutent de grands ouvrages illustrés de gravures ou de lithographies publiés à Paris, comme les Monuments les plus remarquables de la ville de Rouen de Théodore de Jolimont en $1822^{33}$.

Peut-on ainsi mesurer l'influence de l'érudition normande dans et hors de la province ? L'école normande est une source de connaissance et d'inspiration pour toute la génération romantique, nombreuse à faire le voyage de Normandie et à en tirer les fruits dans leurs propres publications. Nodier est le premier, en consacrant à la Normandie le premier tome de ses Voyages pittoresques et romantiques dans l'ancienne France en $1820^{34}$, suivi par beaucoup d'autres : Hugo, avec Notre-Dame de Paris, Sainte- 
Beuve, Michelet, Viollet-Le-Duc. Caumont parvient à sensibiliser les élites à la sauvegarde des monuments, comme en témoigne le célèbre article de Hugo publié en 1832 par la Revue des deux mondes, « Guerre aux démolisseurs ${ }^{35}$ ».

Les théories de l'école normande concernant l'architecture religieuse médiévale demeurent la base des classements entrepris ultérieurement par les spécialistes. Les recherches de Caumont inspirent le travail de Jules Quicherat, le fondateur de l'archéologie critique, chargé en 1847 par le ministre Salvandy d'enseigner l'archéologie à l'École des chartes et qui reprend, outre la classification qui distingue le style roman du style gothique, la méthode d'observation sur le terrain ${ }^{36}$. Le Cours d'antiquités monumentales et les Abécédaires seront les seuls guides des archéologues français jusqu'à la parution du Manuel d'archéologie française de Camille Enlart en 1902. Si le Cours connaît des ventes modestes, les Abécédaires ont un succès certain : en 1870, 15000 exemplaires auront été vendus ${ }^{37}$.

Au-delà de ces cercles, Caumont est-il parvenu à insuffler le goût de l'histoire, le respect des monuments et du patrimoine, l'amour des paysages locaux à ses compatriotes provinciaux ? Le succès du mouvement érudit normand se mesure à sa pérennité : les effectifs cumulés des sociétés savantes provinciales et parisiennes, mesurés par Jean-Pierre Chaline, ne cessent d'augmenter au long du xIX $x^{e}$ siècle, pour connaître un apogée au début du xx $x^{e}$ siècle avec près de 200000 membres, dont plus de 8000 pour la seule Seine-Inférieure. Cette montée en puissance s'accompagne d'une lente démocratisation de leur recrutement, où figurent désormais des salariés de la fonction publique ou parfois même du commerce ${ }^{38}$. Le succès des Assises scientifiques témoigne du goût d'un public qui relève sans doute des classes moyennes, au sens large, pour ce type de manifestation, ce dont Flaubert ne manque pas d'ailleurs de se moquer dans Bouvard et Pécuchet ${ }^{39}$. L'influence de l'érudition normande auprès de la population provinciale peut aussi se mesurer à l'hommage rendu par la ville de Falaise à Guillaume le Conquérant, qui y naquit. Une statue conçue par le sculpteur Louis Rochet et financée grâce à une souscription à laquelle participent beaucoup de Falaisiens, mais aussi le comte de Chambord et le prince Louis-Napoléon Bonaparte, est inaugurée le 26 octobre 1851 par Guizot, qui prononce son discours devant une foule réunissant près de 30000 personnes $^{40}$. Ce succès semble préfigurer celui des fêtes du millénaire normand, organisées à Rouen en 1911, marquées par un grand cortège historique où mille personnes costumées et quinze chars allégoriques défilent le 11 juin devant une foule comptant plusieurs centaines de milliers de personnes ${ }^{41}$.

La Normandie offre ainsi l'exemple d'un foyer érudit provincial dont l'influence fut grande sur la capitale. La Normandie apparaît ainsi, dans une certaine mesure, comme l'exemple d'un renversement du rapport habituel entre Paris et la province : c'est ici la province qui entend nourrir Paris, grâce au dynamisme du mouvement érudit, mais aussi à la richesse exceptionnelle du patrimoine provincial. Caumont est représentatif d'une période, la première moitié du XIX ${ }^{e}$ siècle, et d'un milieu, les notables érudits provinciaux, qui demeurent des amateurs éclairés. La volonté de toucher le grand public n'est pas une spécificité dans la France provinciale, où des réseaux érudits semblables se développent, que ce soit dans le Nord ou en Lorraine, mais le Normand se distingue par son activisme vulgarisateur. Il révèle ainsi la place éminente de ces réseaux provinciaux dans la sensibilisation et l'éducation d'une fraction de la population dont l'importance ne peut être négligée. 


\section{BIBLIOGRAPHIE}

BERCÉ Françoise, « Arcisse de Caumont et les sociétés savantes », dans Nora Pierre (dir.), Les lieux de mémoire, vol. 1, Paris, Gallimard (Quarto), 1997, p. 1552-1553.

BOURASSÉ Jean-Jacques (abbé), Archéologie chrétienne, ou précis de l'histoire des monuments religieux du Moyen Âge, Tours, Mame, 1867.

BRUNE Joseph (chanoine), Résumé du cours d'archéologie professé au séminaire de Rennes, suivi de notices historiques et descriptives sur les principaux monuments religieux du diocèse, Rennes, Vatar et Jausions, 1846.

CAUMONT Arcisse de, Cours d'antiquités monumentales : histoire de l'art dans l'ouest de la France depuis les temps les plus reculés jusqu'au XVI ${ }^{e}$ siècle, Caen, Chalopin, 1830-1841, 10 vol.

CAUMONT Arcisse de, Histoire religieuse de l'architecture au Moyen Âge : ouvrage destiné à l'enseignement de l'archéologie dans les séminaires et les écoles ecclésiastiques, Caen, Hardel, 1841.

CAUMONT Arcisse de, Statistique routière de Normandie : routes de Caen à Cherbourg et de Caen à Rouen, Paris, impr. Le Roy, 1842, 59 p.

CAUMONT Arcisse de, Abécédaire ou rudiments d'archéologie, Caen, Hardel, 1850-1862, 3 vol.

CAUMONT Arcisse de, Archéologie des écoles primaires, Caen, Le Blanc-Hardel, 1853.

CHALINE Jean-Pierre, Sociabilité et érudition : les sociétés savantes en France, Paris, Éditions du CTHS, 1995.

GERVAIS Charles, Musée de la Société des antiquaires de Normandie : catalogue et description des objets d'art de l'Antiquité, du Moyen Âge, de la Renaissance et des Temps modernes exposés au musée, Caen, Le Blanc-Hardel, 1864.

GUILLET François, Naissance de la Normandie : genèse et épanouissement d'une image régionale en France, 1750-1850, Caen, Études normandes, 2000.

HUBERT Jean, « Leçon d'ouverture du cours d'archéologie du Moyen Âge à l'École des chartes », Bibliothèque de l'École des chartes, 1955, nº 113, p. 171-184.

HUCHET Bernard, « Arcisse de Caumont », thèse, Paris, École nationale des chartes, 1984.

HUMBAIRE Bernard, « Une académie savante au XIX siècle : la Société d'archéologie d'Avranches (1835-1891) », thèse, Paris, université Paris VI, 1986.

HUGO Victor, « Guerre aux démolisseurs », Revue des deux mondes, t. V, 1832.

JoLIMONT Théodore Basset de, Monuments les plus remarquables de la ville de Rouen, Paris, Leblanc, 1822.

JUHEL Vincent (dir.), Arcisse de Caumont (1801-1873), érudit normand et fondateur de l'archéologie française, actes du colloque international organisé à Caen du 14 au 16 juin 2001, Caen, Société des antiquaires de Normandie, 2004.

JUHEL Vincent, « Arcisse de Caumont, un communicateur-né ? », dans Juhel V. (dir.), Arcisse de Caumont (1801-1873), érudit normand et fondateur de l'archéologie française, actes du colloque international organisé à Caen du 14 au 16 juin 2001, Caen, Société des antiquaires de Normandie, 2004, p. 219-251. 
LEVESQUE Jean-Marie, « Le mythe normand », dans D'Onofrio Mario, Les Normands, peuple d'Europe, 1030-1200, recueil d'études et catalogue de l'exposition tenue à Rome et Venise en 1994, Paris, Flammarion, 1994, p. 75-81.

NODIER Charles, TAYLOR Isidore, CAILLEUX Alphonse de, Voyages pittoresques et romantiques dans l'ancienne France : ancienne Normandie, Paris, Gide fils, 1820.

PARSIS Odile, La province antiquaire : l'invention de l'histoire locale en France (1800-1870), Paris, Éditions du CTHS, 2011.

TUDESQ André-Jean, Les grands notables en France (1840-1849), Presses universitaires de France, 1964.

\section{NOTES}

1. A. de Caumont, Cours d'antiquités monumentales, p. 4.

2. F. Guillet, Naissance de la Normandie: genèse et épanouissement d'une image régionale en France, 1750-1850 ; O. Parsis, La province antiquaire: l'invention de l'histoire locale en France, 1800-1870.

3. J.-P. Chaline, Sociabilité et érudition : les sociétés savantes en France.

4. A. Le Prévost, "Circulaire de M. le directeur de la Société des antiquaires de la Normandie à MM. les membres titulaires de cette société », p. 1.

5. A. de Caumont, « Prospectus ».

6. Mémoires de la Société des antiquaires de Normandie, t. I, 1824.

7. B. Humbaire, «Une académie savante au $\mathrm{XIX}^{\mathrm{e}}$ siècle: la Société d'archéologie d'Avranches (1835-1891)».

8. Selon A. J. Tudesq, Les grands notables en France (1840-1849).

9. Le Temps, décembre 1829, cité par B. Huchet, " Arcisse de Caumont », p. 94.

10. Annuaire normand, 1835, p. 1.

11. «Lettre du secrétaire général de l'Association, M. Daniel », Annuaire normand, 1835, p. IV.

12. Ce dont témoigne, par exemple, son Essai sur la topographie géognosique du Calvados.

13. A. Le Prévost, prospectus du Cours d'antiquités monumentales d'Arcisse de Caumont, p. 3.

14. Statuts de la Société des antiquaires de Normandie, art. II, Mémoires de la Société des antiquaires de Normandie, t. I, 1824.

15. B. Huchet, « Arcisse de Caumont », p. 105.

16. C'est le cas en 1862, où la Société française d'archéologie distribue 1500 ouvrages : Arch. nat., F17 17181.

17. A. de Caumont, Abécédaire ou rudiments d'archéologie.

18. Ibid., t. I, Introduction, p. IV.

19. Selon une lettre de Caumont à Moreau, directeur de La Quotidienne, 15 janvier 1836, Bib. mun. Rouen.

20. Bulletin monumental, t. III, p. 343-368. 
21. A. de Caumont, Histoire de l'architecture religieuse au Moyen Âge: ouvrage destiné à l'enseignement de l'archéologie dans les séminaires et les écoles ecclésiastiques.

22. J. Brune, Résumé du cours d'archéologie professé au séminaire de Rennes, suivi de notices historiques et descriptives sur les principaux monuments religieux du diocèse.

23. J. Bourassé, Archéologie chrétienne, p. 121-122.

24. A. de Caumont, Archéologie des écoles primaires.

25. Lettre à Frédéric Galeron, 17 mars 1829, Arch. dép. Calvados, F 6020.

26. Arch. dép. Calvados, F 6020, 15 octobre 1829.

27. A. de Caumont, «Rapport verbal d'une excursion faite dans l'Orléanais en 1857 », Mémoires de la Société des antiquaires de Normandie, cité par F. Bercé, "Arcisse de Caumont et les sociétés savantes ».

28. C. Gervais, Musée de la Société des antiquaires de Normandie: catalogue et description des objets d'art de l'Antiquité, du Moyen Âge, de la Renaissance et des Temps modernes exposés au musée.

29. A. de Caumont, "Création de bibliothèques dans les communes rurales", cité par V. Juhel, «Arcisse de Caumont, un communicateur-né ? », p. 243.

30. F. Bercé, « Arcisse de Caumont et les sociétés savantes », p. 1554-1555.

31. Ibid.

32. A. de Caumont, Statistique routière de Normandie, p. 3-4.

33. T. de Jolimont, Monuments les plus remarquables de la ville de Rouen.

34. C. Nodier et al., Voyages pittoresques et romantiques dans l'ancienne France: ancienne Normandie.

35. V. Hugo, «Guerre aux démolisseurs ».

36. J. Hubert, «Leçon d'ouverture du cours d'archéologie du Moyen Âge à l'École des chartes".

37. B. Huchet, « Arcisse de Caumont », p. 105.

38. J.-P. Chaline, Sociabilité et érudition : les sociétés savantes en France, p. 107-127.

39. G. Flaubert, Bouvard et Pécuchet, chap. IV, p. 125-165.

40. J.-M. Levesque, « Le mythe normand».

41. J.-P. Chaline, "Les fêtes du millénaire normand, Rouen 1911 »; R. Dalisson, «La fabrique culturelle d'une petite patrie sous la $\mathrm{III}^{\mathrm{e}}$ République: le cas du millénaire normand de $1911 »$.

\section{RÉSUMÉS}

La Normandie est marquée pendant la première moitié du XIX ${ }^{\mathrm{e}}$ siècle par l'essor d'une sociabilité érudite dont le rayonnement intellectuel est exceptionnel. Les antiquaires normands, sous l'égide d'Arcisse de Caumont, inventorient leur région et en étudient les composants naturels et historiques. Ils accomplissent surtout un travail considérable de recensement et de classement 
des monuments historiques normands, particulièrement des monuments religieux, qui servira longtemps de grille de lecture pour tous ceux qui se penchent sur l'architecture religieuse médiévale en France. Le mouvement qui porte les antiquaires normands vers l'étude de leur région est indissociable d'un mouvement plus large visant à inventorier le territoire national et à se l'approprier. Soucieux de diffuser leur savoir, de faire partager leur amour pour leur patrie régionale et de lutter aussi contre la prééminence parisienne, les antiquaires normands jouent pendant cette période un rôle d'intermédiaires culturels en utilisant des moyens variés: rédaction de guides touristiques, d'ouvrages de vulgarisation (les fameux Abécédaires d'Arcisse de Caumont), de manuels à destination des séminaires, organisation de congrès accompagnés de manifestations festives. Leur influence est considérable auprès de la bourgeoisie et des classes intellectuelles françaises.

\section{AUTEUR}

\section{FRANÇOIS GUILLET}

Professeur d'histoire en classes préparatoires aux grandes écoles au lycée Lakanal (Sceaux) 


\title{
Le rôle d'enseignant $\mathrm{du}$
} conservateur de musée de province membre de sociétés savantes sous la III République

\author{
Géraldine Masson
}

«Vous favoriseriez nos efforts qui tendent à rendre le musée d'Annecy aussi instructif que possible ; l'idée directrice de cet établissement étant de compléter par la présentation de documents soigneusement choisis les leçons des professeurs de tout ordre et d'enseigner au public le goût des belles choses ${ }^{1}$. »

1 Ces mots sont ceux du conservateur du musée d'Annecy, Marc Le Roux, qui sollicite la mise en dépôt de céramiques auprès de l'administration des Beaux-Arts. Ils illustrent parfaitement la mission pédagogique du musée de province sous la III ${ }^{\mathrm{e}}$ République ainsi que le rôle essentiel de ses conservateurs dans la transmission des savoirs et du patrimoine historique et culturel de la nation.

2 Ce sujet a été étudié dans le cadre d'une thèse intitulée Préserver et transmettre le patrimoine de la nation : les conservateurs de musées de province sous la III ${ }^{e}$ République ${ }^{2}$, sous la direction du professeur Dominique Poulot, dans laquelle il est démontré que c'est le fait de placer le musée en corollaire de l'école qui a amené les conservateurs des musées de province vers de nouvelles pratiques de l'exercice de leurs fonctions et qui les a engagés dans les premières étapes d'un processus de professionnalisation. Cette recherche se situe à la confluence de l'histoire de l'art, de l'histoire du goût, de l'histoire des collections et des institutions culturelles, à un moment important de l'histoire de l'enseignement et de la transmission des savoirs.

Pour restituer le rôle d'enseignant du conservateur de musée, dans lequel excellent particulièrement les conservateurs membres de sociétés savantes et du Comité des travaux historiques et scientifiques (CTHS), il est nécessaire, dans un premier temps, de resituer les musées au regard de la transmission des savoirs sous la $\mathrm{III}^{\mathrm{e}}$ République. Les missions d'enseignements qui incombent alors aux conservateurs de musées de 
province seront ensuite exposées pour enfin présenter plus précisément l'apport personnalisé des conservateurs savants.

\section{Les musées de la III République et la transmission des savoirs}

$4 \mathrm{Au}$ moment de la $\mathrm{III}^{\mathrm{e}}$ République, l'administration des Beaux-Arts dépend du ministère de l'Instruction publique; aucun ministère spécifiquement dédié n'administre les affaires culturelles et patrimoniales, tout au mieux un sous-secrétariat d'État aux Beaux-Arts, selon les périodes et les budgets accordés. Les musées de province affrontent alors de sérieuses difficultés de bonne conservation de leurs collections, notamment en termes d'inventaire et de conditions d'exposition des œuvres. Des difficultés financières et un statut juridique des collections mal défini en sont les causes. La nécessité d'une législation spécifique se fait nettement ressentir. Le soussecrétaire d'État aux Beaux-Arts Étienne Dujardin-Beaumetz crée ainsi en 1905 une commission extraparlementaire pour statuer et légiférer sur la question.

\section{Transmettre une mémoire collective, une histoire de la nation}

Ce moment correspond par ailleurs en France à celui d'une nouvelle écriture de l'histoire. Au xix siècle, une place primordiale est accordée à l'historien dans l'élaboration des fondements de l'identité nationale et de la mémoire collective, devenues nécessités politiques et culturelles. Les historiens de la III ${ }^{e}$ République, à la suite du ministre de Louis-Philippe, François Guizot, font du travail historique un acte politique et procèdent à une écriture nouvelle de l'histoire. Animés par la recherche des fondements de l'unité nationale, ils sont, tout comme le ministre de l'Intérieur, convaincus que l'histoire nationale peut y pourvoir tout en constituant un formidable moyen de légitimation historique du régime républicain. Dès lors, il ne s'agit plus de recenser l'histoire des monarques et de leurs règnes, mais plutôt de définir les origines et l'évolution de la nation advenue en 1789.

\section{Le musée corollaire de l'école}

6 L'histoire des musées français ne se réduit pas à celle d'une collection devenue publique. La nationalisation des chefs-d'œuvre de la nation s'est toujours accompagnée d'une réflexion qui veille à leur accès pour tous les citoyens, en accord avec les idéaux démocratiques de progrès social et d'éducation d'un État républicain. Le patrimoine, science de la mémoire collective à transmettre, se détermine selon un quadruple objectif que Dominique Poulot qualifie de « préoccupation d'efficacité [...], tout à la fois moyen de dissiper l'ignorance, de perfectionner les arts, de réveiller l'esprit public et d'entretenir l'amour de la patrie ${ }^{3} »$. Les fondements du musée républicain, organe de diffusion du patrimoine, reposent sur ce même objectif.

7 Le régime républicain instaure une culture républicaine de l'institution muséale, rendue d'utilité civique, qui dispense une éducation universelle. Le musée constitue, par ailleurs une pierre d'angle de l'édifice scolaire de la III ${ }^{e}$ République. La circulaire de 1881 l'institue en lieu d'enseignement, complément nécessaire de l'école, énonçant explicitement : 
« Si c'est à l'école que l'enfant et l'ouvrier reçoivent l'enseignement, c'est surtout au musée qu'ils trouvent l'exemple. La réorganisation du musée est donc le corollaire obligatoire de celle de l'école ${ }^{4}$."

8 Les républicains expriment ensuite, par la loi de 1882, le dessein d'une école d'éducation libérale qui diffuse un savoir émancipateur. Ferdinand Buisson, proche collaborateur de Jules Ferry, apporte une contribution décisive du point de vue des méthodes d'enseignement. Il est le maître d'œuvre d'une école dont le rôle éducateur excède les simples dimensions d'instruction et d'accès aux bases du «lire, écrire, compter » et initie une réflexion sur le degré de valeur éducative des enseignements, qui doit envisager des activités à portée ludique et épanouissante dites " enseignements accessoires ", auxquelles s'intègre parfaitement le musée.

Cet objectif philanthropique avoué ne constitue par ailleurs pas la seule motivation des hommes politiques de la III République. Au-delà de l'instruction publique, ils cherchent à instituer un système éducatif incluant le patriotisme pour nouvelle référence commune qui n'admette aucun dissident. La foi patriotique doit être suscitée par la sollicitation de «l'imagination des élèves charmée par des peintures et des récits [qui] rendra leur raison enfantine plus attentive et plus docile ${ }^{5} "$, selon les termes de Buisson. Les recours utilisés sont ceux d'une religion laïque de la patrie, dispensée par un catéchisme mettant en scène images et légendes de héros nationaux et patrimoniaux. Les musées, comme les manuels scolaires de l'universitaire Ernest Lavisse, loué par Ferdinand Buisson ${ }^{6}$, sont ainsi les outils de transmission privilégiés de cette religion civile, de ce patriotisme patrimonial.

\section{Le musée de province au sein de cet édifice}

10 Désignés sous les vocables de «musées de province » ou «musées des départements », ces établissements se répartissent en trois catégories d'un point de vue administratif : aux trois musées nationaux ${ }^{7}$ gérés et administrés par l'État, s'ajoutent les musées départementaux, propriétés des départements et des sociétés savantes, et enfin les musées municipaux, les plus nombreux. Avec le régime républicain, l'institution muséale s'amplifie et l'État dote d'un musée les petites et moyennes villes françaises, en procédant à l'envoi d'œuvres d'art en dépôt.

11 Le musée de province s'inclut, de plus, dans l'élaboration d'un discours qui recherche la cohésion nationale par le partage d'une connaissance commune de la nation dans son ensemble, jusque dans ses identités et entités les plus humbles. Pourvoyeuse d'une histoire locale, l'institution permet une meilleure connaissance des territoires et de leurs spécificités, dans l'esprit de l'ouvrage Le Tour de la France par deux enfants, publié en 1878 par Augustine Fouillée sous le pseudonyme de G. Bruno. Le musée exalte le sentiment national chez le jeune élève pour l'inciter à défendre son territoire familier8.

Si, selon la formule de Ferdinand Buisson, «l'amour de la petite patrie doit mener à la grande ${ }^{9}$ ", l'enseignant doit dispenser une culture générale garante d'ascension sociale comme d'une connaissance de son environnement, qui renforce le lien local et freine l'exode rural, grande inquiétude des pouvoirs publics. L'école doit prôner un humanisme ouvert et trouver un équilibre pour faire accéder les élèves aux valeurs universelles de démocratie et de progrès. Le musée de province doit enseigner l'histoire de l'art universelle et de ses grands chefs-d'œuvre à travers l'illustration par les gloires locales. 


\section{Les conservateurs des musées de province et la transmission des savoirs : une noble mission vers la voie de la professionnalisation}

13 La commission extraparlementaire des musées de province de 1905, réunie par Dujardin-Beaumetz, a fait l'objet d'un rapport publié qui s'accompagne d'un rapport d'inspection des conservateurs des établissements. Le rapport Lapauze ${ }^{10}$ permet d'aller à la rencontre de ceux qui ont en charge les collections de l'État ; ils ont été désignés en raison d'un solide parcours préalable. L'obligation, pour le maire, de soumettre une liste de candidats sérieux et aptes à la décision du préfet, a porté aux fonctions de conservateur des personnes bénéficiant de l'assurance d'acquis en termes de protection et de transmission du patrimoine.

\section{Des acteurs de la transmission des savoirs}

Qu'il soit patrimonial, artistique ou politique, leur engagement intellectuel les implique dans des problématiques d'édification du citoyen, de diffusion des connaissances de l'histoire et du patrimoine de la nation. Un tiers des conservateurs dont on a identifié l'origine professionnelle est fonctionnaire et occupe des métiers dont la problématique rejoint celle des musées de la III ${ }^{e}$ République : ils sont enseignants, bibliothécaires ou archivistes.

15 Les enseignants représentent les fonctionnaires les plus nombreux du corps des conservateurs de musées de province du rapport Lapauze. On dénombre 19 professeurs de dessin et 11 professeurs dans les collèges ou les lycées. Alcius Ledieu, conservateur des musées d'Abbeville, et Léon Coulon, du musée d'Elbeuf, sont instituteurs; Auguste Audollent, conservateur du musée de Clermont-Ferrand, est maître de conférences à l'université de la ville. Si la majorité d'entre eux enseignent des matières littéraires, Auguste Thiriet de Sedan et David Martin de Gap sont professeurs de sciences naturelles. Tous ont le même souci de la transmission des savoirs chère au musée républicain ; deux d'entre eux sont fondateurs de leur musée et promeuvent ainsi leur vision pédagogique de l'institution. En outre, Étienne Port a créé la bibliothèque puis le musée de Saint-Nazaire.

16 Les mêmes motivations pédagogiques sont, par ailleurs, présentes chez les 32 conservateurs bibliothécaires.

\section{Une conception didactique des missions de conservateur}

17 Proposer une visite instructive et pédagogique à l'élève, l'ouvrier et l'artiste constitue le leitmotiv des conservateurs des musées de province. Pour y parvenir, ils mobilisent leurs efforts à tous les niveaux de leurs prérogatives. Ainsi l'enrichissement des collections, bénéficiant de budgets restreints et crispant les volontés hégémoniques du pouvoir local comme national, offre-t-il l'occasion au conservateur des musées de province de mobiliser ses relations, entretenues dans les lieux de sociabilité et au sein des sociétés savantes, parmi les collectionneurs, les artistes et les députés, afin de 
développer l'ancrage local de collections tournées vers l'histoire et le patrimoine de la région.

De même, la présentation des œuvres et le discours d'accompagnement qu'elle suppose à destination d'un public toujours plus large décrit-elle les heureuses initiatives de conservateurs des musées de province palliant les mauvaises conditions de conservation en proposant un musée aussi didactique que possible. Le catalogue de musée devient ainsi le double emblème du métier de conservateur et de la vocation du musée lieu d'enseignement. Les conservateurs des musées de province, pénétrés de leur mission de pédagogue, excellent dans l'élaboration de tels ouvrages.

19 L'étude du métier de conservateur de musée de province à partir du rapport Lapauze présente ainsi l'implication et l'engagement d'un conservateur des musées de province républicain, qui s'adapte à une organisation nouvelle de son métier, accepte de nouvelles responsabilités et acquiert la reconnaissance de ses pairs.

\section{Les conservateurs de musées membres des sociétés savantes très impliqués dans la transmission des savoirs}

\section{Les musées des sociétés savantes sous la III République}

Les sociétés savantes gèrent les musées départementaux : soit qu'elles les aient fondés, soit qu'un de leurs membres soit désigné aux fonctions de conservateur, soit que les conseils municipaux des villes qui ont la charge de ces établissements les associent de droit à la gestion du musée. Ainsi, à Troyes, le nom du musée est « Musée municipal, départemental et académique fondé en 1831 ». De même, le titre du catalogue de 1909 précise : « musée de Troyes, fondé et dirigé par la Société académique de l'Aube ${ }^{11}$ ».

21 Les sociétés savantes entretiennent une vie artistique locale potentiellement très bénéfique au musée. Elles peuvent notamment apporter leur concours pour la réalisation de salons. Et par exemple, à Nantes, la Société des amis des arts est subventionnée par la ville : "Elle organise un dynamique salon annuel où le musée fait parfois des acquisitions ${ }^{12} »$.

22 Les dons et legs des membres des sociétés savantes, qui conditionnent parfois leur adhésion, comme à Abbeville, représentent un apport financier conséquent contribuant à un enrichissement diversifié des collections. Ainsi, à Brive, « la plupart des donations sont le fruit d'amitiés qu'entret[ient] Ernest Rupin avec des savants, artistes et riches érudits de la région ${ }^{13} »$.

23 Les musées dirigés par des conservateurs savants se situent dans la continuité des cabinets de curiosités des Lumières, aux collections encyclopédiques riches d'enseignement. Le rapport d'inspection de 1885 du musée des Beaux-Arts de Troyes mentionne ainsi :

«Le musée de Troyes est de premier ordre. Les deux salles de sculpture peuvent compter parmi les mieux aménagées, les mieux présentées et les plus riches du département. On y remarque les belles œuvres de Simart, Paul Dubois, Boucher. Les deux salles de peinture, quoique relativement moins riches, sont aussi bien aménagées et présentent un grand intérêt. Un classement méthodique est à désirer. La nouvelle salle des arts décoratifs, le musée archéologique, les collections des 
émaux peints, de sigillographie, de carrelages incrustés font de cet établissement

un musée de premier ordre ${ }^{14}$." œuvres proche de l'entassement et certains conservateurs se laissent submerger, notamment pour les sections qui ne relèvent pas de leur domaine de compétences. Pour ne citer qu'un exemple, Deschamps de Pas, du musée de Saint-Omer, est à l'origine de sa collection archéologique. Or l'inspection Lapauze en 1907 conclut que «si le musée lapidaire est très bien installé dans onze salles, [...] les collections artistiques sont négligées au-delà de toute idée ; les tableaux sont posés par terre, les uns contre les autres. Impossible de les accrocher faute de place ${ }^{15} »$.

\section{Représentativité dans le corpus} apprécie, outre les connaissances en art ou la pratique artistique, l'engagement dans la sauvegarde du patrimoine et donc, de fait, l'appartenance à une société savante. Des 233 conservateurs du rapport Lapauze identifiés, 160 adhèrent à au moins une société savante patrimoniale, historique ou scientifique.

Simples membres, membres fondateurs ou présidents, les conservateurs appartiennent dans leur grande majorité à des sociétés savantes à obédience scientifique, historique, de défense du patrimoine ou philomathique, c'est-à-dire pluridisciplinaire. Certains sont, parfois, membres de plusieurs sociétés représentant l'ensemble de ces domaines d'activité et cumulent ainsi jusqu'à une dizaine d'adhésions. Le record est détenu par le marquis Gérard de Fayolle, conservateur du musée de Périgueux, qui fait partie de seize sociétés savantes nationales ou du Périgord.

En outre, 27 conservateurs inspectés en 1905-1907 sont membres du CTHS en tant que « membre correspondant » ou « membre non résidant ». Le CTHS a été créé en 1834 par le ministre François Guizot, qui a la tutelle des sociétés savantes. Il a, dès son origine, publié les documents inédits de l'histoire de France. Il ne se charge toutefois pas uniquement de recevoir et d'éditer les travaux: il guide et regroupe également les recherches et organise à partir de 1861 le Congrès national des sociétés savantes. Il dispose d'un organe de diffusion pour ses membres, la Revue des sociétés savantes.

\section{Philanthropes, philologues, collectionneurs, polygraphes : des figures de la transmission des savoirs}

Pour légitimer et mener à bien leur combat, les conservateurs de musées de province rejoignent ou créent des sociétés savantes ou des associations de protection du patrimoine d'importance diverse, qui véhiculent le même discours que le musée, tant par la défense d'une histoire commune que par l'utilité de sa diffusion. Ainsi, Henri Rachou, du musée des Augustins de Toulouse, est membre de la Commission du vieux Carcassonne, puis à partir de 1901 de la Commission du vieux Toulouse, dont l'objectif est de «rechercher et faire connaître les œuvres du passé toulousain à caractère historique, artistique, archéologique dignes d'être conservées et de perpétuer les souvenirs de notre histoire locale ${ }^{16} »$.

Comme lui, le Dr Francillon, conservateur du musée de Chinon, est président de l'Association des amis du vieux Chinon; Jules Momméja, archéologue et critique d'art, 
conservateur du musée d'Agen, est membre du Comité des sites et monuments pittoresques auprès du Touring club de France. D'autres appartiennent au Comité des monuments historiques, tels le marquis Gérard de Fayolle, conservateur du musée de Périgueux, désigné pour le mobilier de la Dordogne, ou Adolphe Dufour, bibliothécaire, archiviste, historien et fondateur du musée de Corbeil et qui fait campagne dans le Petit Journal pour la conservation de la tour dite Louis le Gros, à Corbeil ${ }^{17}$.

Les conservateurs de musées de province membres du CTHS sont, en outre, des enseignants, distingués pour quatre d'entre eux par les palmes académiques et correspondants permanents du ministère de l'Instruction publique et des beaux-arts. Ils sont par ailleurs fondateurs de leur propre institution, qu'ils dotent de leur collection personnelle, comme Adolphe Dufour à Corbeil ou Joseph Déchelette à Roanne. David Martin a utilisé les collections de la Société d'études scientifiques et littéraire de Gap comme fonds du nouveau musée d'histoire naturelle et des beaux-arts en 1903. Géologue, archéologue et érudit, il a voulu doter la ville de Gap «d'un établissement d'une véritable utilité et qui rendrait de grands services soit à l'industrie locale soit à l'instruction publique ${ }^{18}{ }$. S'ils ne sont pas fondateurs, ils initient du moins des sections de collections qui présentent un intérêt didactique, notamment pour les collections d'art local en lien avec leurs travaux et leurs spécialités. Paul Dissard, à Lyon, est ainsi à l'origine d'une collection de médailles et de sceaux. Enfin, selon un article anonyme dans la revue de la société du Saintonge :

"[Charles Dangibaud,] conservateur du musée de peinture et de numismatique, [de Saintes] exerce ses fonctions gratis pour le simple bonheur de mettre de l'ordre dans les collections de la ville de Saintes, de les enrichir de quelques joyaux autant, du moins, que le modeste budget dont le musée dispose le lui permet ${ }^{19}$. »

Dans un rôle souvent précurseur, ces conservateurs ont pour métier de produire l'histoire. Archivistes et bibliothécaires, ils mettent à disposition les sources et documents nécessaires à son écriture. Leur méthode est novatrice en termes de sources et de thèmes de recherches. Les archivistes s'efforcent de présenter des documents jamais étudiés, qu'ils mettent à disposition. Ils sont ainsi instigateurs d'un renouveau de l'histoire locale, abordée à travers l'étude de groupes sociaux. On peut retenir, parmi de nombreux exemples, Camille de Saint-Marc, conservateur du musée de Niort, sur la noblesse poitevine, distingué pour ses écrits par de prestigieuses institutions en tant que lauréat des concours qu'elles organisent. De même le quatrième ouvrage d'Ernest Rupin sur Rocamadour lui permet-il de remporter, en 1904, la deuxième médaille du concours des Antiquités nationales de l'Académie des inscriptions et belles-lettres.

Par ailleurs, ce commentaire sur la bibliographie du conservateur du musée de Quimper, Henri Bourde de La Rogerie, pourrait s'appliquer à la plupart des conservateurs de musée auteurs et qualifie avec pertinence leurs publications :

«Ses nombreux travaux, presque tous sur l'histoire de la Bretagne, excellent par

l'étendue et la solidité de l'érudition ainsi que par l'originalité des vues ${ }^{20}$. »

Le CTHS relaye ces parutions en tant que productions historiques qui relèvent de l'histoire érudite et scientifique. En 1903, à l'instigation de Jean Jaurès, est créée une commission de publication des documents d'archives relatifs à la vie économique de la Révolution française. Les travaux de Charles Porée ${ }^{21}$, archiviste historien de l'Yonne et conservateur du musée d'Auch, de Mathieu-Henri Bardy ${ }^{22}$, historien des Vosges et conservateur du musée de Saint-Dié, ainsi que de Henri Bourde de La Rogerie ${ }^{23}$, archiviste, historien de la Bretagne, se sont orientés selon cet axe de recherche. 


\section{Une diffusion des savoirs spécifique aux conservateurs de musée savants}

34 Très concernés par leur mission d'enseignement et de transmission des savoirs, les conservateurs de musées de province membres des sociétés savantes le manifestent par un investissement renouvelé, échangeant des méthodes de travail, développant leur propres moyens de diffusion de l'actualité de leurs recherches, publiant des ouvrages de référence et participant à des expositions. Ils procèdent ainsi à un enrichissement des connaissances des collections muséales et à une transmission des savoirs de qualité.

L'entraide des conservateurs des musées de province dans l'exercice de leurs fonctions est motivée par une recherche d'efficacité. Ils entreprennent certaines activités de concert et coordonnent leurs efforts pour publier catalogues et historiques des collections ou pour organiser des expositions.

$\mathrm{Au}$ sein des conservateurs de musées se détache un petit groupe, celui des archéologues, qui développent leurs propres réseaux de confraternité. Ernest Rupin à Brive $^{24}$, Jacques Laurent à Châlons-sur-Marne, Léon-Honoré Labande à Avignon, Léon Le Clert à Troyes, Joseph Déchelette à Autun ${ }^{25}$ et Gérard de Fayolle à Périgueux organisent ainsi le Congrès archéologique de France dans leur ville.

Les bulletins des sociétés savantes, dans lesquels ils publient, bien que n'étant pas leur objectif premier, jouent le rôle de presse spécialisée sinon "professionnelle » et annoncent le Bulletin des musées de France, la revue de l'Association des conservateurs des collections publiques de France créée en 1923. La parution des articles donne l'occasion d'établir des relations, de se conseiller, de se congratuler. Frédéric Henriet et Henri Jadart ${ }^{26}$, des musées de Château-Thierry et de Reims, entretiennent ainsi une correspondance par articles interposés. Frédéric Henriet est membre de l'Académie de Reims et parfois chroniqueur de la vie culturelle de la ville dans les Annales de la société historique et archéologique de Château-Thierry. Il se fait l'écho de la grande exposition rétrospective de Reims en $1895^{27}$ et écrit un article sur le musée des Beaux-Arts en $1900^{28}$. Dans les deux cas, il ne tarit pas d'éloges sur son confrère Jadart. Or Jadart lit les Annales de la société historique et archéologique de Château-Thierry,et il adresse une lettre à Henriet pour lui présenter son travail sur une œuvre du musée de Reims figurant la famille Balhan, qui pourrait avoir des origines castelthéodoriciennes. Le conservateur en profite pour soumettre un article sur le sujet, publié dans le numéro suivant des Annales ${ }^{29}$.

Les conservateurs des musées de province savants s'ingénient, en outre, à produire des outils pédagogiques diversifiés pour accompagner la visite de leur musée et la rendre la plus instructive et pédagogique possible. À Brive, Rupin sollicite une nouvelle subvention de la mairie dans une lettre datée du 21 août. Il expose ses objectifs en justification de la somme: "J'ai l'intention de présenter chaque objet sur un support, avec étiquette explicative de façon à intéresser et à instruire les visiteurs ${ }^{30}$ ». Au musée de Saint-Dié : "Deux plaquettes de M.Bardy, donnent des renseignements sur la fondation du musée et ses collections ${ }^{31} »$. Enfin, les notices d'œuvres et les historiques des collections de Léon-Honoré Labande au musée Calvet d'Avignon rencontrent un certain succès d'édition, dont le conservateur a l'exclusivité. Il rédige des études et analyses d'œuvres emblématiques du musée Calvet, représentatives de l'histoire régionale, comme sa Description d'un pied de croix du XIVe siècle ayant appartenu à l'ancien 
monastère de Saint-Véran, près Avignon ou bien encore ses articles relatifs aux œuvres d'art conservées au musée Calvet à l'effigie du bienheureux Pierre de Luxembourg ${ }^{32}$.

Cependant, Labande excelle particulièrement dans la rédaction des catalogues généraux de musées ou des sections thématiques des collections, comme l'ensemble des conservateurs des musées de province savants, pour lesquels le catalogue de musée est une priorité. Au musée de Saintes, où exerce Charles Dangibaud, la publication a même précédé l'ouverture du musée, ainsi que le mentionne le rapport d'inspection ${ }^{33}$. Les ouvrages sont parfois publiés par les sociétés savantes pour faire face aux importantes dépenses que suppose la publication. Ce sont de beaux ouvrages pédagogiques illustrés, comme celui du musée départemental d'archéologie de Quimper ${ }^{34}$, dirigé par Henri Bourde de La Rogerie. Des ouvrages de référence et des catalogues spécialisés sont publiés au musée des Beaux-Arts d'Annecy par Marc Le Roux, associé pour l'occasion au spécialiste d'histoire gallo-romaine et agrégé de lettres classiques Charles Marteaux ${ }^{35}$. Le catalogue est parfois mis à disposition le temps de la visite, comme au musée d'Elbeuf, dirigé par l'instituteur Coulon. De nombreux exemplaires sont vendus annuellement : 50 au musée d'archéologie de Quimper ${ }^{36}$ ainsi qu'au musée des BeauxArts de la Rochelle ${ }^{37}$ ( 50 centimes) et au musée Calvet d'Avignon, où il coûte $2 \mathrm{~F}^{38}$. Au musée Fesch, à Ajaccio, le record est de 100 exemplaires vendus par an $^{39}$, preuve de la très forte fréquentation de ces musées riches d'enseignements, dirigés par des conservateurs de musées savants membres du CTHS.

La principale difficulté des musées de province de la III République est d'ordre financier. Les sociétés savantes apportent une précieuse contribution et un budget de fonctionnement appréciable aux musées qui relèvent de leur responsabilité. Ainsi exemptés de tout souci matériel, ces derniers peuvent se consacrer entièrement à la mise en œuvre de la politique du musée républicain, lieu d'enseignement, et figurent parmi les meilleurs établissements présentant d'excellentes conditions de conservation et de présentation des collections. Par ailleurs, les conservateurs de musées membres de sociétés savantes et du CTHS honorent la fonction par l'envergure de leurs travaux et la conviction de leur engagement dans la transmission des savoirs. Cette citation de Claude Roger-Marx, inspecteur général des musées de province, dans le rapport d'inspection de 1903, laisse penser que l'administration des Beaux-Arts a trouvé son meilleur élément en la personne de Jules Moméja, conservateur du musée des BeauxArts d'Agen :

«On souhaiterait, dans l'intérêt de nos musées départementaux, qu'ils fussent souvent administrés par des conservateurs tels que M. Momméja, à ce point compétents, actifs et pourvus d'une connaissance générale de l'histoire des arts. C'est un érudit chez qui l'amour de la science n'a nullement aboli le sentiment instinctif de l'art, la sûreté spontanée du goût. Il convenait de rendre tout d'abord hommage à de pareils mérites, si rares et si aptes à faciliter la tâche que vous m'aviez bien voulu confier ${ }^{40}$. » 


\section{BIBLIOGRAPHIE}

BABEAU Albert, Catalogue des sculptures du musée de Troyes fondé et dirigé par la Société académique de l'Aube, 5 éd., Troyes, édité au musée, 1905.

BARDY Mathieu-Henri, Les événements militaires dans le pays de Saint-Dié pendant la Révolution:

discours prononcé à la réunion générale de la Société philomatique vosgienne le 23 février 1896, Saint-Dié, impr. Humbert, 1896.

BARDY Mathieu-Henri, Les ateliers révolutionnaires de salpêtre et de charbon à Saint-Dié, Saint-Dié, impr. Cuny, 1900.

BOURDE DE LA ROGERIE Henri, La vie économique à Saint-Marc-Le-Blanc, Ille-et-Vilaine, pendant la Révolution : extraits des registres des délibérations municipales, Rennes, impr. Oberthur, 1913.

BRUNO G. [i. e. FOUILLÉE Augustine], Le tour de la France par deux enfants, devoir et patrie : livre de lecture courante avec 212 gravures instructives pour leçons de choses 19 cartes géographiques, Paris, Belin, 1877.

BUISSON Ferdinand (dir.), Dictionnaire de pédagogie et d'instruction primaire, Paris, Hachette, 1878-1887.

CREUZET Émile, « Dufour (Marc Adolphe) (1827-1914) », Bulletin de la Commission des antiquités et des arts du département de la Seine-et-Oise, 34, 1914, p. 63-67.

DIOCQUE Georges, Dictionnaire biographique des Hautes-Alpes, Gap, impr. Louis Jean, 1996.

HENRIET Frédéric, « Exposition rétrospective de Reims », Annales de la société historique et archéologique de Château-Thierry, 1895, p. 138-144.

HENRIET Frédéric, « Le musée de Reims », Annales de la société historique et archéologique de ChâteauThierry, 1900, p. 43-48.

JADART Henri, «La famille Balhan », Annales de la Société historique et artistique de Château-Thierry, 1900 , p. $40-42$.

LABANDE Léon-Honoré, « Notes sur deux médailles du bienheureux Pierre de Luxembourg et sur son portrait conservé au musée Calvet ", Mémoires de l'Académie de Vaucluse, 18, 1899, p. 409-413.

LABANDE Léon-Honoré, Description d'un pied de croix du XIVe siècle ayant appartenu à l'ancien monastère de Saint-Véran, près Avignon, Paris, Imprimerie nationale, 1901.

LAVISSE Ernest, « Histoire », dans Buisson Ferdinand (dir.), Dictionnaire de pédagogie et d'instruction primaire, Paris, Hachette, 1878, partie 1, t. I, p. 1264-1272.

LAPAUZE Henri, Les musées de province : rapport, enquête, législation. Rapport de la commission chargée d'étudier toutes les questions relatives à l'organisation des musées de province et à la conservation de leurs richesses artistiques, Paris, typographie Plon-Nourrit, 1908.

LE ROUX Marc, Catalogue sommaire du musée d'Annecy : collections artistiques, industrielles, archéologiques, numismatique, céramique, armures, collections régionales, histoire naturelle de la Savoie et de la chaîne du Mont-Blanc, Annecy, Abry, 1900.

MARTEAUX Charles et LE ROUX Marc, Musée de la ville d'Annecy : catalogue descriptif du musée galloromain, marques de fabrique, estampilles, poinçons, graffiti, etc., Annecy, Abry, 1895. 
MASSON Géraldine, «Préserver et transmettre le patrimoine de la nation : les conservateurs de musées de province sous la III ${ }^{\mathrm{e}}$ République », thèse en histoire de l'art, Paris, université Paris I Panthéon Sorbonne, 2016, 2 vol.

NORA Pierre, «L'Histoire de France de Lavisse. Pietas erga patriam », dans Nora Pierre (dir.), Les lieux de mémoire, t. II, La nation, Paris, Gallimard, vol. 2, p. 851-902.

PORÉE Charles, Documents sur la révolution française. Département de l'Yonne : procès-verbaux de l'administration départementale de 1790 à 1800, publiés sous les auspices du conseil général, Auxerre, Gallot, 1889-1903.

POULOT Dominique, Musée, nation, patrimoine, 1789-1815, Paris, Gallimard, 1997.

PREVOST Michel et ROMAN D’AMAT Jean-Charles (dir.), Dictionnaire de biographie française, t. VI, Paris, Letouzey et Ané, 1954.

RIENZI Émile Michelis di et FRANCE Anatole, Panthéon des lettres, des sciences et des arts, première série : Profils contemporains, Paris, Administration du panthéon des lettres, des sciences et des arts, 1893.

SERRET André, Catalogue du musée archéologique et du musée des anciens costumes bretons de la ville de Quimper, Quimper, impr. Cotonnec, 1901.

THOMAS Hélène, « Henri Rachou, 1855-1944, un Toulousain oublié », Archistra, numéro spécial

«Henri Rachou », 138, août 1995, p. 99-114.

\section{NOTES}

1. Arch. nat., Inspection des musées, $\mathrm{F}^{21} 4514 \mathrm{~B}, 11^{\mathrm{e}}$ série, 1901-1910, Abbeville-Bougie, dossier Annecy, pièce 1, « Lettre de Marc Le Roux au ministre de l'Instruction publique, 7 décembre $1910 »$.

2. G. Masson, «Préserver et transmettre le patrimoine de la nation : les conservateurs de musées de province sous la III ${ }^{\mathrm{e}}$ République ».

3. D. Poulot, Musée, nation, patrimoine, 1789-1815, p. 8.

4. Arch. nat., inspection des Musées, $4500 \mathrm{~A}$, dossier 1, Législation, organisation, liasse C, « Circulaire de $1881 »$.

5. F. Buisson, Dictionnaire de pédagogie et d'instruction primaire, p. 986.

6. Ernest Lavisse est l'un des auteurs du dictionnaire de pédagogie qu'a publié Buisson ;

E. Lavisse, « Histoire ».

7. Le musée de Versailles, le musée d'Archéologie national, à Saint-Germain-en-Laye et le musée de la Céramique de Sèvres, en vertu des décrets des 23 août et 9 septembre 1878.

8. P. Nora, «L'Histoire de France de Lavisse : Pietas erga patriam ».

9. F. Buisson, Dictionnaire de pédagogie et d'instruction primaire, p. 986.

10. H. Lapauze, Les musées de province : rapport, enquête, législation.

11. A. Babeau, Catalogue des sculptures du musée de Troyes fondé et dirigé par la Société académique de l'Aube.

12. Ibid., p. 127. 
13. F. Bourzat, «Ernest Rupin, érudit corrézien et conservateur du musée de Brive » (mémoire non publié), $\mathrm{Br} 4^{\circ} 8878$ et $\mathrm{Br} 4^{\circ}$ 8879.1997, 2 vol. p. 69.

14. Arch. nat., inspection des Musées, $\mathrm{F}^{21} 4514 \mathrm{~A}$, dossier Troyes, pièce 1.

15. H. Lapauze, Les musées de province : rapport, enquête, législation, p. 174.

16. «Registre de délibérations du comité de surveillance du musée des Augustins », cité dans H. Thomas, « Henri Rachou, 1855-1944 : un Toulousain oublié », p. 110.

17. É. Creuzet « Dufour (Marc Adolphe) (1827-1914)», p. 65.

18. G. Diocque, Dictionnaire biographique des Hautes-Alpes, p. 50.

19. É. M. di Rienzi, Panthéon des lettres, des sciences et des arts. Première série: profils contemporains.

20. M. Prevost et J.-C. Roman d'Amat (dir.), Dictionnaire de biographie française, t. VI, p. 1432.

21. C. Porée, Documents sur la révolution française. Département de l'Yonne. Procès-verbaux de l'administration départementale de 1790 à 1800 .

22. M.-H. Bardy, Les ateliers révolutionnaires de salpêtre et de charbon à Saint-Dié et : Les é vénements militaires dans le pays de Saint-Dié pendant la Révolution: discours prononcé à la réunion générale de la Société philomatique vosgienne le 23 février 1896.

23. H. Bourde de La Rogerie, La vie économique à Saint-Marc-Le-Blanc, Ille-et-Vilaine, pendant la Révolution : extraits des registres des délibérations municipales.

24. E. Rupin a beaucoup cuvré pour l'organisation d'une session du Congrès archéologique de France à Brive ; son ambition s'est réalisée en 1890.

25. En 1907, J. Déchelette organise le congrès d'archéologie préhistorique d'Autun, où il propose sa propre définition des oppida.

26. Voir notice de H. Jadart dans la base prosopographique du CTHS, «France savante $»$ : http://cths.fr/an/prosopo.php?id=105414\#

27. F. Henriet, « Exposition rétrospective de Reims ».

28. F. Henriet, « Le musée de Reims ».

29. H. Jadart, « La famille Balhan ».

30. F. Bourzat, «Ernest Rupin, érudit corrézien et conservateur du musée de Brive ", École du Louvre, $\mathrm{Br} 4^{\circ} 8878$ et $\mathrm{Br} 4^{\circ} 8879.1997$, p. 77.

31. H. Lapauze, Les musées de province : rapport, enquête, législation,p. 223.

32. L.-H. Labande « Notes sur deux médailles du bienheureux Pierre de Luxembourg et sur son portrait conservé au musée Calvet ».

33. Arch. nat., inspection des Musées, $\mathrm{F}^{21} 4910 \mathrm{~A}$, dossier l, pièce 28, «Rapport d'inspection"; en 1908, le rapport Lapauze mentionne "Catalogue : oui ( $\mathrm{I}^{\mathrm{er}}$ édition : 1864, date de fondation; dernière édition 1893)». H. Lapauze, Les musées de province: rapport, enquête, législation, p. 68.

34. A. Serret, Catalogue du musée archéologique et du musée des anciens costumes bretons de la ville de Quimper.

35. C. Marteaux et M. Le Roux, Musée de la ville d'Annecy. Catalogue descriptif du musée gallo-romain, marques de fabrique, estampilles, poinçons, graffiti, etc.; M. Le Roux, Catalogue sommaire du musée d'Annecy: collections artistiques, industrielles, archéologiques, 
numismatique, céramique, armures, collections régionales, histoire naturelle de la Savoie et de la chaîne du Mont-Blanc.

36. H. Lapauze, Les musées de province : rapport, enquête, législation, p. 93.

37. Ibid., p. 66.

38. Ibid.,p. 214.

39. Ibid., p. 71.

40. Arch. nat., inspection des Musées, $\mathrm{F}^{21} 4514 \mathrm{~B}$, dossier Agen, pièce 4.

\section{RÉSUMÉS}

La III ${ }^{\mathrm{e}}$ République offre au musée, corollaire de l'école, une vocation pédagogique d'édification du citoyen républicain. Le conservateur de musée devient ainsi un acteur de la transmission du patrimoine historique et culturel de la nation. Historiens, archéologues, scientifiques, érudits, les conservateurs des musées de province membres des sociétés savantes sont particulièrement investis dans l'application de cette mission didactique. À la tête de musées aux collections encyclopédiques, ils dispensent une leçon d'histoire de la nation qui bénéficie de leurs réseaux institutionnels riches d'échanges et de conseils entre savants en termes d'acquisitions, d'attribution d'œuvres, de découvertes et d'actualités de leurs travaux et d'expositions. Ils publient des ouvrages de référence et des catalogues de musées et rédigent des articles dans les bulletins des sociétés savantes, autant de sources permettant de mettre en évidence le rôle essentiel de ces acteurs de la transmission des savoirs.

\section{AUTEUR}

\section{GÉRALDINE MASSON}

Collaboratrice scientifique arts graphiques au musée d'Orsay 


\title{
L'excursion archéologique, outil de construction et vecteur de diffusion des savoirs antiquaires en France au $\mathrm{XIX}^{\mathrm{e}}$ siècle
}

\author{
Odile Parsis-Barubé
}

1 L'excursion archéologique constitue l'une des pratiques majeures des érudits réunis dans les sociétés d'antiquaires créées sous la monarchie de Juillet selon le vœu de Guizot, dans le but explicite de réaliser l'inventaire des ressources historiques et archéologiques de la France. Sur le plan concret, elle revêt un double aspect: expérience solitaire de l'antiquaire qui part explorer les vestiges archéologiques de son département afin de les répertorier et d'évaluer le coût de leur restauration, l'excursion archéologique devient aussi très vite une pratique de sociabilité qui, une fois l'an, réunit l'ensemble des membres d'une société pour une séance foraine conçue autour d'un itinéraire qui permet de prendre la mesure visuelle du travail de découverte et d'étude réalisé au cours de l'année académique.

Intrinsèquement liée à l'inventaire monumental, dont la méthodologie se précise et se diffuse au sein du monde des antiquaires provinciaux à partir de la fin de l'année 1835 sous la forme d'instructions visant à en unifier les pratiques, l'excursion archéologique se dote peu à peu d'une méthodologie qui l'inscrit dans l'éventail des savoirs sur le territoire, dont se nourrit alors une science statisticienne encore très marquée au coin de la description littéraire. Pour autant, dans la forme que lui donnent les antiquaires du milieu du XIX ${ }^{e}$ siècle, elle n'en demeure pas moins une expérience sensible où, dans l'émotion de la rencontre avec le vestige, l'érudit s'abandonne volontiers à une méditation solitaire sur la fuite du temps. Dans les publications périodiques des sociétés d'antiquaires, le compte rendu d'excursion s'érige en genre scripturaire où se fixe la rhétorique de l'archéologie descriptive et s'exprime, dans une poétique qui n'est parfois pas sans rappeler celle des voyages pittoresques et romantiques, toute la gamme des émotions liées à la découverte physique des traces du passé. 
3 C'est sur cette double dimension, qui fait de l'excursion archéologique un vecteur privilégié de transmission - celle d'un savoir en voie d'unification et celle d'une poétique et d'une esthétique du paysage archéologique - qu'il convient de nous arrêter.

\section{Un préalable à la construction des savoirs antiquaires}

Si la promenade solitaire dans les ruines de l'ancienne France s'est, dès les lendemains immédiats de la Révolution, inscrite dans l'éventail des postures d'un romantisme conservateur nostalgique de l'ancien monde, la monarchie de Juillet, en donnant à l'inventaire historique et archéologique une dimension contraignante, rattrape cette pratique pour la corseter dans un cadre méthodologique qui en fait peu à peu la base de la construction d'un savoir raisonné. La diffusion, dans l'ensemble des sociétés d'antiquaires constituées à partir de 1830, d'un modèle de l'excursion archéologique, est une réponse à la forme spécifique d'exploration du territoire qu'implique la politique d'inventaire ${ }^{1}$. Dès la création, en 1824 , de la Société des antiquaires de Normandie, Arcisse de Caumont avait vanté les mérites de l'exercice.

"Les courses archéologiques ont toujours un heureux résultat, et il est à désirer que chacun de nous en fasse de fréquentes, afin que l'on connaisse bien ce qui n'a pas encore été exploré ou ce qui ne l'a été qu'imparfaitement ${ }^{2}$.»

5 C'est en 1835 que Guizot parachève la mise en place du dispositif d'encadrement scientifique des travaux menés par les érudits provinciaux dans le cadre de l'inventaire, en chargeant Albert Lenoir, Auguste Le Prévost, Prosper Mérimée et Charles Lenormant de rédiger des instructions relatives au relevé et à l'étude des monuments bâtis ${ }^{3}$. L'excursion archéologique devient alors l'occasion d'appliquer une méthode unifiée dont, quatre ans plus tard, Narcisse de Salvandy s'inquiète encore de ne pas percevoir les effets concrets.

«Une œuvre confiée à tant de mains à la fois ne manquera-t-elle pas d'ensemble et d'unité ? La science archéologique ne possède pas sa nomenclature. Que de disparates, que de contradictions et d'obscurités si chacun décrit les monuments avec une phraséologie particulière, s'il juge de leur antiquité d'après des systèmes différents? Cette bigarrure nous jetterait dans un vague et dans une indécision qu'un travail scientifique doit éviter à tout prix ${ }^{4}$. "

6 Les thèmes de l'exhumation des vestiges invisibles, de la révélation des richesses monumentales insoupçonnées dont résonnent les textes statutaires des sociétés d'antiquaires, renvoient à un imaginaire de la découverte qui apparente la figure de l'antiquaire à celle de l'explorateur. Le thème de l'endurance à la marche devient ainsi une figure récurrente des hommages posthumes. À sa mort en 1861, la Société archéologique de Nantes salue en Louis Bizeul l'infatigable arpenteur des voies romaines de la basse Bretagne.

"C'est ainsi qu'on le vit plus que sexagénaire / Partir toujours joyeux, le bâton à la main / À pied, guettant partout la borne milliaire / Ou le pied conquérant d'un lieutenant romain ${ }^{5}$."

Lorsque l'autorité s'impatiente des retards pris dans certaines régions par la statistique historique et archéologique, c'est précisément à une plus grande mobilité sur le terrain que sont invités les membres des sociétés savantes visées par les rappels à l'ordre. En juillet 1846, le préfet du Pas-de-Calais rappelle ainsi à ceux de la toute nouvelle commission des antiquités départementales, qu'il vient de créer, que la statistique monumentale implique que "le département entier soit exploré ${ }^{6} »$. Se défendant de 
l'accusation de léthargie dont l'Académie d'Arras fait alors l'objet en la matière, le président d'Héricourt proteste que ses membres «ne sont pas restés dans une molle oisiveté, [qu'] ils ont parcouru les campagnes, exploré les châteaux, les monastères, les pierres druidiques ${ }^{7} »$.

Inscrite dans les modalités du voyage savant, l'excursion archéologique joue avec ses multiples déclinaisons. Charles de Chergé, membre de la Société des antiquaires de l'Ouest, « persuadé qu'une promenade archéologique atteindrait rarement le but que se proposent les voyageurs antiquaires s'ils se bornaient à faire part des faits matériels qu'ils auraient observés ", rappelle en 1836 la nécessité de compléter les constatations faites sur le terrain par des recherches ultérieures dans les livres et sur les documents d'époque ${ }^{8}$. Ce qui suppose, parfois, une organisation collective, comme dans cette mission accomplie par l'antiquaire toulousain Alexandre Du Mège sur le site d'AiguesMortes en 1836 :

«J'étais accompagné dans cette exploration par mes dignes collègues à la Société archéologique, MM. Jules Boilly et Belhomme. Tandis que le premier dessinait, avec la facilité et le goût qui distinguent son talent, plusieurs vues d'Aigues-Mortes, le second parcourait les archives de cette ville et y recueillait des notions historiques d'un haut intérêt ${ }^{9}$.»

Rarement solitaire, l'exploration antiquaire d'un territoire nécessite souvent l'aide d'un cicérone local. L'image du "savant» contraint de subir les divagations parfois burlesques du demi-savant autochtone, si elle a été tournée en dérision par Mérimée dans sa correspondance ${ }^{10}$, n'est pas forcément de mise chez les auteurs de comptes rendus d'excursions destinés à paraître dans les pages des publications périodiques des sociétés savantes. Chergé se montre ainsi touché par l'aide que lui apporte, dans son exploration du département de l'Indre-et-Loire, l'hôte grâce auquel il peut étudier «le sol dans tous ses détails » et qui «joignit [ses] réflexions aux [siennes], [mêlant] ses regrets aux regrets qu'excitait en [lui] la vue des débris amoncelés par le vandalisme ${ }^{11}$ ».

\section{Une propédeutique du regard}

Progressivement, un modèle de compte rendu d'excursion archéologique se forge dans les pages des publications périodiques des sociétés d'antiquaires ou des commissions préfectorales d'antiquités, au point de s'imposer comme un vecteur privilégié de diffusion du savoir archéologique. S'y mêlent deux logiques d'exposition - celle, vivante et pédagogique de la restitution d'une progression physique, et celle, savante et statique, de la description archéologique -, deux logiques qui, conjuguées, concourent à une véritable éducation du regard.

11 Dès le début de la décennie 1840-1850, les termes « d'excursion » ou de " promenade » archéologique s'imposent dans les publications périodiques des sociétés savantes comme titres de notices dont l'objet principal est moins la relation des péripéties du voyage proprement dit que la description des édifices ou faits d'histoire locale qui émaillent le parcours. Au point qu'il devient souvent difficile de déterminer si l'auteur a réellement effectué le déplacement ou s'il a seulement utilisé comme une facilité pédagogique les ressorts d'une excursion fictive pour présenter un texte essentiellement nourri de références bibliographiques et d'emprunts à la statistique départementale. 
12 La métaphore du voyage contamine ainsi la rhétorique de l'archéologie descriptive, proposant au lecteur une véritable propédeutique du regard, qui l'implique dans la consommation visuelle d'un nouveau type de paysage, lequel est autant le champ d'une expérience savante que celui d'une délectation esthétique. Assimilé à un voyageur guidé par l'auteur de la notice, le lecteur est constamment invité à changer de point de vue à mesure qu'il progresse dans l'édifice et que se modifient, de ce fait même, ses impressions visuelles. Entraînant son lecteur dans la collégiale de Lillers, à laquelle il consacre en 1850 une notice en forme d'excursion lue à la commission des Antiquités du Pas-de-Calais, l'érudit artésien Charles de Linas joue de l'effet d'optique provoqué par l'inhabituelle clarté qui règne à l'intérieur de l'édifice roman.

«Au premier abord, les sensations changent complètement; et à l'aspect de ces murs blanchis à la chaux, de ces bas-côtés, de ces plafonnages modernes, on se demande si l'on n'est pas le jouet d'une illusion. Cependant l'œil s'habitue peu à peu à la lumière éclatante qui l'inonde [...] et après quelques secondes de réflexion, le spectateur voit l'harmonie la plus complète régner dans toutes les parties du monument ${ }^{12}$.»

13 Ainsi mis en condition, l'œil du lecteur-spectateur, guidé par des formules qui se font plus injonctives au fil de la progression de la visite, est ensuite orienté vers des détails architecturaux de plus en plus précis, décrits sur un mode de plus en plus technique: «Pénétrons maintenant dans l'intérieur de l'église [...]. Après avoir traversé la croisée [...], entrons dans le chœur ", écrit Linas, qui attire alors l'attention de son lecteur sur une " arcature intersectée dont les pleins cintres s'entrelacent et forment des ogives ", puis sur « une triple archivolte décorée, la supérieure de violettes, l'intermédiaire d'un double tore chevronné accompagné d'un besant dans chaque angle, et l'inférieure d'un chapelet au cordon louangé13 ${ }^{13}$. La déambulation est ici posée comme purement fictive, la posture de voyageur n'étant plus qu'une commodité stylistique offerte par l'auteur à un lecteur que rebuterait sans doute l'exposé purement descriptif et technique d'une monographie classique. L'artifice supplée en même temps à l'absence ou à l'indigence de l'illustration.

Dans le même ordre d'idée, le récit d'excursion archéologique concourt à la promotion du panorama. Panorama virtuel, évidemment, puisque le lecteur est invité à imaginer une scène qu'il ne voit que par le truchement du compte rendu d'excursion, et qui permet d'exploiter tous les avantages de la vision panoptique. L'érudit toulousain Alexandre Du Mège, rendant compte d'une excursion archéologique réalisée en 1834 à Aigues-Mortes, invite ainsi son lecteur à prendre de la hauteur :

«Pour embrasser l'ensemble du système, il faut se placer sur la tour de Constance. De ce point, l'œil voit en entier et le château et l'intérieur des remparts, aucun édifice n'interpose sa masse architecturale entre le spectateur et les fortifications ${ }^{14}$. »

Mais l'élévation du point de vue ne fait pas que contribuer au caractère panoptique de la vision de la scène archéologique. Elle est aussi introduction au travail de remémoration. En 1834, de ce même sommet de la tour Constance, Alexandre Du Mège qui, dans la touffeur des marais camarguais, a déjà été la proie de mirages, sollicite l'imagination du lecteur afin de faire revivre la cité dans sa splendeur du XIII ${ }^{\mathrm{e}}$ siècle.

«Réunissez par la pensée de nombreux soldats sur le parapet, sur le chemin de ronde; donnez à ces guerriers des corps étincellans [sic], de longues arbalètes, de brillantes pertuisanes ; arborez sur les tours les enseignes de la cité de saint Louis et celles de la vieille France; rendez au port et sa profondeur et ses vaisseaux; suspendez aux mâts de longues banderolles [sic] ; que sur les poupes dorées flottent 
en vastes replis les pavillons ornés du signe de la rédemption, et l'illusion sera complète, et Aigues-Mortes vous apparaîtra, parée de tout l'éclat de sa jeunesse, de toutes ses pompes navales, religieuses et guerrières. Vous comprendrez alors toute la puissance de la foi de nos aïeux ${ }^{15}$... »

On note ainsi la proximité du compte rendu d'excursion avec ce que François Guillet a appelé la "littérature d'espace ", qui diffuse à la même époque, à destination des voyageurs en tous genres, un ensemble de savoirs, notamment historiques, sur le territoire ainsi qu'une culture du déchiffrement de la topographie. Dans l'ensemble de la production écrite que le siècle a consacrée à la diffusion des savoirs sur le local, le compte rendu d'excursion archéologique apparaît ainsi comme un genre intermédiaire entre la monographie savante, dont elle est une déclinaison plus pédagogique, et le guide touristique, dont elle développe essentiellement les aspects culturels.

\section{La diffusion d'une poétique et d'une esthétique du paysage archéologique}

17 Pour autant, les auteurs des comptes rendus n'oublient guère que l'excursion archéologique s'inscrit aussi dans la gamme des modes sensibles d'appréhension du territoire que le premier xIX ${ }^{\mathrm{e}}$ siècle a déclinés et dont les érudits provinciaux se sont délectés : « Nous explorions ensemble les environs, nous allions parfois fort loin visiter de nos yeux et toucher de nos mains les découvertes signalées à notre attention ${ }^{16} »$, se souvient avec un grand plaisir en 1871 le chanoine Van Drival, président de la commission des Antiquités du Pas-de-Calais.

18 Le compte rendu d'excursion archéologique est un genre d'autant plus facilement transmissible auprès d'un public élargi qu'il transite précisément aux frontières de la littérature de voyage, de l'album pittoresque et de la production érudite.

19 Au récit de voyage, il emprunte un certain nombre de topoï, comme, par exemple, ceux liés à la poétique de la découverte de la ruine cachée, qui suppose souffrance du corps et ténacité morale. Encore fortement marqué par la culture de la lenteur propre aux mobilités réduites de l'Ancien Régime, le premier XIX ${ }^{\mathrm{e}}$ siècle reste celui des progressions pénibles et des jouissances visuelles conquises de haute lutte : relatant une excursion archéologique effectuée en 1835 dans le Poitou, Charles de Chergé, membre de la Société des antiquaires de l'Ouest, évoque « une marche assez longue et assez pénible à travers des sables montueux et brûlants, sur un espace de trois mortelles lieues de pays, [qui] semblait devoir [lui] faire payer cher [sa] curiosité et le plaisir [qu'il pouvait] espérer ». Mais, poursuit-il, "nous fûmes bientôt amplement dédommagés par la beauté du spectacle qui s'offrait à nos regards ${ }^{17}$ ».

20 La ruine castrale ne paraît accessible qu'au terme d'une progression pénible, faite de raidillons à monter, de fourrés inextricables à traverser, de fossés remplis de ronces à franchir, comme si la nature environnante participait au rejet de l'image historique associée à ce type de monument. À Penne, dans le Tarn-et-Garonne, Alexandre Du Mège est confronté à cette inaccessibilité :

« Un rocher escarpé, et très élevé au-dessus de l'Aveyron, supporte des tours à demi renversées, des murs couronnés de créneaux et percés de longues meurtrières. Leurs débris jonchent les lieux voisins, et ce n'est qu'en surmontant quelques difficultés que l'on peut parvenir dans l'intérieur de cet édifice, où je n'ai trouvé que de faibles traces de son ancienne magnificence ${ }^{18}$. » 
21 Si le thème de l'isolement de la ruine castrale s'érige en stéréotype dans les notices et comptes rendus d'excursions, c'est qu'elle constitue un vestige éminemment politisé. L'état d'abandon dans lequel la trouvent la plupart des antiquaires se donne à lire comme une expression de l'obsolescence d'un ordre social honni. Machine de guerre, le château mutilé, démantelé, laissé à l'abandon, ne porte finalement que les stigmates d'une juste punition. Rendant compte en 1846 d'une excursion archéologique à Souchez, l'archéologue arrageois Auguste Terninck écrit :
«L'histoire de Souchez est donc remplie, comme on le voit, d'épisodes sanglants qui furent causés surtout par son château fort qui, redoutable et bien placé, était exposé à la convoitise de tous ceux qui se disputaient notre province. Renversé et rebâti plusieurs fois, il tomba encore à la Révolution de 1793, et ne laissa plus après lui que des ruines aujourd'hui bien faibles et qui tous les jours s'amoindrissent et disparaissent ${ }^{19}$.»

Un scénario qui devient un poncif de la relation de la découverte de la ruine castrale s'offrant partout au regard dans cette esthétique de l'opposition, qui en fait un lieu éminemment contradictoire : fortifié et béant, inexpugnable mais lézardé, redoutable mais conquis par un irrévérencieux envahissement végétal. Cette esthétisation de l'arrogance féodale vaincue se retrouve, comme une figure convenue, dans toute la littérature antiquaire de l'époque. Charles de Chergé voit ainsi dans celui de Chinon :

«Un vieux château démantelé [qui] semblait étaler encore avec orgueil son immense squelette, ses pans de murailles en ruines, découpures grisâtres et colossales que le temps, destructeur impitoyable, a seul pu faire de sa faux implacable ${ }^{20}$.»

Cette image s'inscrit dans une généalogie facile à reconstituer. Elle prend d'abord corps dans la littérature archéologique savante - celle par exemple d'un Arcisse de Caumont qui, dans son Cours d'antiquités monumentales de 1835, établit que " les anciens châteaux demeurés aujourd'hui ne se trouvent assez souvent que dans des lieux stériles, au milieu des bois ou sur des éminences escarpées que l'homme s'est hâté d'abandonner ${ }^{21}$ ». Elle se diffuse dans les comptes rendus d'excursions archéologiques - comme par exemple dans celui que donne Alexandre Hermant en 1840 à la Société des antiquaires de la Morinie. Il note que c'est à peine si l'on trouve « quelques débris des châteaux des puissants barons, maîtres de la terre, dans les forêts et les marais non cultivables [... et que] lorsque les ruines s'y laissent voir, c'est dans un tel état de dégradation qu'il est presque toujours impossible d'en tirer quelque fruit pour l'intérêt de la science $\operatorname{archéologique~}^{22} »$.

24 Elle se diffuse ensuite dans la littérature de voyage. C'est ainsi qu'on la retrouve, par exemple, chez Flaubert. Parcourant la Bretagne avec Maxime Du Camp au printemps 1847, il évoque en ces termes, dans Par les champs et par les grèves, sa découverte du château de Clisson :

«Rien, rien! Le vent qui passe, l'herbe qui pousse, le ciel à découvert. Pas d'enfant en guenilles gardant une vache [...], pas même comme ailleurs une chèvre solitaire sortant sa tête barbue par une crevasse de remparts [...], pas un oiseau chantant, pas un nid, pas un bruit! Ce château est comme un fantôme, muet, froid, abandonné dans cette campagne déserte; il a l'air maudit et plein de ressouvenances farouches ${ }^{23}$. »

Une esthétique à la fois littéraire et iconographique, qui, par son caractère convenu, véhicule une forme de savoir historique fortement lestée d'idéologie: dans l'abandon des sites castraux et l'état de déliquescence du château fort se lit toute l'ambiguïté du 
rapport du premier XIX siècle avec le Moyen Âge féodal, à la fois symbole d'un ordre social que la Révolution a aboli et réceptacle emblématique de la nostalgie de l'ancienne France. Un motif littéraire qui renvoie aussi à l'iconographie des voyages pittoresques illustrés dont le genre, en marge de la grosse entreprise éditoriale du baron Taylor et de Charles Nodier, se diffuse dans la première moitié du XIX siècle $^{24}$.

Il y a en effet, dans les voyages pittoresques publiés avant 1830, plus d'un emprunt explicite tant à la littérature descriptive qu'à l'érudition locale, telle que celle-ci s'exprime tant à travers la statistique départementale que les comptes rendus d'excursions archéologiques. Simples jeux de recopiage, parfois, comme dans ce Voyage pittoresque dans le bocage de la Vendée publié en 1817 par le peintre Claude Thiénon, qui reprend in extenso le passage des Mémoires de Mme de La Roche Jacquelin, que cette dernière avait elle-même emprunté à la description du département de la LoireInférieure réalisée par le sous-préfet de l'arrondissement de Bressuire ${ }^{25}$. Ou encore, comme chez le Boulonnais Pierre Hédouin qui, en 1828, commence la relation de ses Souvenirs historiques et pittoresques $d u$ Pas-de-Calais, entreprise qu'il dit avoir voulu calquer sur celle de Taylor et Nodier, par une description transcrite de celle qui figurait dans les annuaires départementaux de l'époque impériale.

Il arrive aussi que d'authentiques érudits s'essaient au genre pittoresque. Comme, par exemple, l'historien breton Edmond Richer (1792-1834), figure dominante des milieux savants nantais et collaborateur du Lycée armoricain. Son Voyage pittoresque dans le département de la Loire-Inférieure, publié en $1823^{26}$, est précédé d'un Précis historique de la Bretagne que lui avait réclamé l'éditeur Camille Mellinet ainsi que d'une dissertation intitulée « Du genre descriptif », dans laquelle il analyse la poésie descriptive depuis le $\mathrm{xVI}^{\mathrm{e}}$ siècle jusqu'à Goethe et Byron ${ }^{27}$.

L'excursion archéologique apparaît ainsi comme la déclinaison pédagogique du savoir qui, sous la monarchie de Juillet, commence à se construire au sein du monde restreint des sociétés savantes. Sa filiation avec l'inventaire, qui pèse comme un couvercle fécondant sur l'activité historienne du premier XIXe siècle, en fait aussi - et c'est sans doute là une autre dimension de sa transmissibilité - un vecteur privilégié de la diffusion des savoirs sur le local. En cela, elle participe des stratégies de valorisation des patrimoines autochtones qui, en marge de l'entreprise centralisée conçue par le régime de Juillet, nourrit les sentiments d'appartenance et enrichit le processus de genèse et d'épanouissement des images régionales. Autour de la dialectique des hauts lieux et des trésors cachés, le compte rendu d'excursion archéologique fixe en effet un modèle descriptif des territoires provinciaux. Celui-ci se fonde sur les arguments dont se nourrissent, jusqu'à la fin du siècle, les discours de promotion touristique : la densité des vestiges monumentaux, leur degré d'ancienneté - dont Mérimée a la malice de noter la propension des antiquaires provinciaux à l'exagérer fortement - leur accessibilité au voyageur, ainsi que les formes de leur inscription dans l'environnement naturel et humain. 


\section{BIBLIOGRAPHIE}

\section{Sources}

AURAIX-JONCHIÈRE Pascale, « Le château », dans Bernard-Griffiths Simone, Glaudes Pierre, Vibert Bertrand (dir.), La fabrique du Moyen Âge au XIXe siècle : représentations du Moyen Âge dans la culture et la littérature françaises du XIX ${ }^{e}$ siècle, Paris, Honoré Champion, 2006, p. 541-552.

CAUMONT Arcisse de, Cours d'antiquités monumentales : histoire de l'art dans l'ouest de la France depuis les temps les plus reculés jusqu'au XVI ${ }^{e}$ siècle, t. V, Caen, Chalopin, 1830-1841.

CHARMES Xavier, Le Comité des travaux historiques et scientifiques : histoire et documents, Paris, Imprimerie nationale, 1886.

CHERGÉ Charles de, «Promenade archéologique faite en 1836 dans une partie du département d'Indre-et-Loire ", Mémoires de la Société des antiquaires de l'Ouest, t. I, 1835, p. 55-377.

DU MÈGE Alexandre, Voyage littéraire et archéologique dans le département du Tarn-et-Garonne par M. Alexandre Du Mège de la Haye, Paris, Treuttel et Wurtz, 1828.

DU MÈGE Alexandre « Aigues-Mortes », Mémoires de la Société archéologique du midi de la France, t. I, 1834-1835, p. 25-51.

HÉDOUIN Pierre et HESSE P., Souvenirs historiques et pittoresques du Pas-de-Calais, Paris, Dondey-Dupré, 1828.

HÉRICOURT Achmet d', « Rapport sur les travaux de l'académie », Mémoires de l'Académie d'Arras, t. XXIII, 1846, p. 24-33.

HERMANT Alexandre, « Notice sur le château de Rioult ", Mémoires de la Société des antiquaires de la Morinie, t. V, 1839-1840, p. 233-280.

LINAS Charles de, «L'église collégiale, aujourd'hui paroissiale de Lillers », Statistique monumentale du Pas-de-Calais, t. I, Arras, Commission des antiquités départementales.

RICHER Edmond, Voyage à Clisson [le faux titre porte : Voyage pittoresque dans le département de la Loire-Inférieure, lettre troisième], in-quarto de 11 feuilles, Nantes, Mellinet, 1823.

TERNINCK Auguste, « Souchez et Ablain-Saint-Nazaire », Mémoires de la Société des antiquaires de la Morinie, t. VII, 1844-46, p. 39-40.

THIÉNON Claude, Voyage pittoresque dans le bocage de la Vendée ou vues de Clisson et de ses environs dessinées d'après nature et publiées par C. Thiénon, Paris, Didot l'Aîné, 1817.

VAN DRIVAL Eugène, « Notice biographique de M. le Comte A. d'Héricourt par M. le chanoine Van Drival », Bulletin de la Commission des antiquités du Pas-de-Calais, t. III, p. 134.

\section{Études}

GUIOMAR Jean-Yves, Le bretonisme : les historiens bretons au XIXe siècle, Rennes, Société d'histoire et d'archéologie de la Bretagne, 1987. 
PARSIS-BARUBÉ Odile, La province antiquaire : l'invention de l'histoire locale en France, 1800-1870, Paris, Éditions du CTHS, 2011.

PARSIS-BARUBÉ Odile, «La province et les provinciaux dans la correspondance de Prosper Mérimée ", Cahiers Mérimée, n 5, 2013, p. 159-178.

PARSIS-BARUBÉ Odile, « En marge de Taylor et Nodier : les petits voyages pittoresques et la réinvention romantique de la province ", dans Antoine Philippe, Méaux Danièle, Montier JeanPierre (dir.), La France en albums, Paris, Hermann, 2017, p. 31-44.

\section{NOTES}

1. O. Parsis-Barubé, La province antiquaire: l'invention de l'histoire locale en France, 1800-1870, p. 285.

2. A. de Caumont, "Rapport sur les travaux de l'année 1825 », Mémoires de la Société des antiquaires de Normandie, t. I, 1825, p. CV.

3. «Rapport au roi sur l'état des travaux relatifs à la recherche et à la publication de documents inédits concernant l'histoire de France, 2 décembre 1835 ", dans $\mathrm{X}$. Charmes, Le Comité des travaux historiques et scientifiques: histoire et documents, t. II, p. 49.

4. N. de Salvandy, "Circulaire relative à l'envoi d'instructions rédigées par le Comité ", 1839, cité dans X. Charmes, Le Comité des travaux historiques et scientifiques: histoire et documents, p. 95-96.

5. Cité par J.-Y. Guiomar, Le bretonisme : les historiens bretons au XIXe siècle, p. 295.

6. Bulletin de la Commission des antiquités du Pas-de-Calais, t. I, p. 11.

7. A. d'Héricourt, « Rapport sur les travaux de l'académie », p. 26.

8. C. de Chergé, «Promenade archéologique faite en 1836 dans une partie du département d'Indre-et-Loire », p. 355.

9. A. Du Mège, « Aigues-Mortes ", p. 27.

10. O. Parsis-Barubé, «La province et les provinciaux dans la correspondance de Prosper Mérimée ».

11. C. de Chergé, «Promenade archéologique faite en 1836 dans une partie du département d'Indre-et-Loire », p. 355.

12. C. de Linas, Statistique monumentale du Pas-de-Calais, t. I, p. 3.

13. Ibid., p. 2-4.

14. A. Du Mège, « Aigues-Mortes », p. 50.

15. Ibid., p. 50.

16. E. Van Drival,« Notice biographique de M. le comte A. d'Héricourt par M.le chanoine Van Drival », p. 134.

17. C. de Chergé, «Promenade archéologique faite en 1836 dans une partie du département d'Indre-et-Loire », p. 356.

18. A. Du Mège, Voyage littéraire et archéologique dans le département du Tarn-et-Garonne par M. Alexandre Du Mège de La Haye, p. 79.

19. A. Terninck, « Souchez et Ablain-Saint-Nazaire », p. 39-40. 
20. C. de Chergé, «Promenade archéologique faite en 1836 dans une partie du département d'Indre-et-Loire », p. 357.

21. A. de Caumont, Cours d'antiquités monumentales : histoire de l'art dans l'ouest de la France depuis les temps les plus reculés jusqu'au XVI siècle, t. V, p. 6-7.

22. A. Hermant, « Notice sur le château de Rioult », p. 233.

23. G. Flaubert, Par les champs et par les grèves, Paris, Charpentier, 1886, p. 490 . Sur la représentation du château fort dans la littérature du XIX siècle, voir P. AuraixJonchière, « Le château ».

24. O. Parsis-Barubé, «En marge de Taylor et Nodier : les petits voyages pittoresques et la réinvention romantique de la province ».

25. C. Thiénon, Voyage pittoresque dans le bocage de la Vendée ou vues de Clisson et de ses environs dessinées d'après nature et publiées par $C$. Thiénon, p. 2-8. Le voyageur romantique se félicite d'ailleurs de trouver dans ce passage "le style élégant et facile d'un observateur et d'un administrateur éclairé » (p. 8) et donne, quelques pages plus loin, une description du musée de Clisson reprise de l'Annuaire statistique du département de la Loire-Inférieure (p. 11-14).

26. E. Richer, Voyage à Clisson.

27. J.-Y. Guiomar, Le bretonisme : les historiens bretons au XIXe siècle, p. 26-27.

\section{RÉSUMÉS}

Fille du «voyage pittoresque et romantique », l'excursion archéologique en devient, sous la monarchie de Juillet, une déclinaison scientifique. La systématisation de l'inventaire monumental impose en effet, dans les années 1830, une inflexion des modes d'arpentage des territoires locaux. Les publications périodiques des sociétés d'antiquaires deviennent dès lors le lieu de la consignation littéraire des signes de ce basculement de la promenade vers la mission scientifique. Pour autant, l'excursion archéologique, dans la forme que lui donnent les antiquaires du milieu du XIx siècle, n'en demeure pas moins une expérience sensible. Son compte rendu, qui s'érige en "genre » où se fixe la rhétorique de l'archéologie descriptive, est aussi le lieu où s'exprime, dans une poétique qui n'est pas sans rappeler celle du voyage romantique, l'émotion qui saisit l'antiquaire au détour du chemin et l'entraîne, au-delà de ses velléités scientifiques, vers la méditation.

\section{AUTEUR}

\section{ODILE PARSIS-BARUBÉ}

Membre associé du laboratoire IRHiS (CNRS UMR 8529), membre de la section Histoire contemporaine et du temps présent du CTHS 


\title{
Interruption dans le processus de transmission du savoir : exemple des grottes préhistoriques de Montmaurin (Haute-Garonne) fouillées par Louis Méroc (1904-1970)
}

\author{
Amélie Vialet
}

1 Si l'histoire de l'archéologie préhistorique s'est évidemment construite sur la dynamique des recherches sur le terrain, il faut constater qu'elle s'accompagne aussi d'un processus d'oubli à l'égard de certains sites. Le succès qu'ils connaissent à un moment donné, leur tombée dans l'oubli comme leur redécouverte sont des indicateurs du mouvement de la science, depuis la construction du savoir jusqu'à d'éventuelles préoccupations mémorielles. C'est pourquoi nous postulons que reconstituer cette histoire est l'une des méthodes qui permettent de suivre l'évolution des questions scientifiques au sein de la communauté des préhistoriens ainsi que les relations entre ses membres, impliquant continuités et ruptures. Pour illustrer ce propos, nous avons choisi les grottes préhistoriques de Montmaurin, dans les Petites Pyrénées, dont nous reprenons les fouilles aujourd'hui, parce qu'elles se révèlent emblématiques de ce processus: ayant joué un rôle essentiel pour répondre aux préoccupations des préhistoriens de l'après-Seconde Guerre mondiale, elles sont oubliées à la mort de leurs principaux prospecteurs, faute d'héritiers scientifiques et du fait du renouvellement des problématiques scientifiques.

\section{Les grottes préhistoriques de Montmaurin}

2 Le village de Montmaurin est situé en Haute-Garonne, à 75 kilomètres au sud-ouest de Toulouse. Il est perché sur un promontoire calcaire d'altitude modeste (400 mètres) 
bordé par deux cours d'eau qui confluent au nord-est du massif : la Save à l'est, affluent de la Garonne, et la Seygouade à l'ouest. Dès le début du xxe siècle, ce territoire fut exploré par les préhistoriens, tels Émile Cartailhac (1845-1921) et le comte René de Saint-Périer (1877-1950), qui en révélèrent le grand potentiel archéologique. Ainsi furent découverts les gisements paléolithiques de la grotte des Rideaux (Lespugue), au bord de la Save, et de la grotte Boule (dite anciennement grotte de Montmaurin), sur la rive droite de la Seygouade.

Juste après la Seconde Guerre mondiale, l'exploitation de carrières sur le flanc nordouest du massif de Montmaurin met au jour plusieurs grottes et révèle la richesse de leur remplissage, ce qui provoque la visite « officielle », le 21 septembre 1945, de l'abbé Henri Breuil (1877-1961) et du comte Henri Bégouën (1863-1956), qui en confient les fouilles à Louis Méroc (1904-1970). Ce dernier, docteur en droit, est alors substitut du procureur général à la cour d'appel de Toulouse et se dédie à la préhistoire sur son temps libre. Il a suivi les cours du comte Bégouën, dont il est certifié dès 1923, et met en application les conseils prodigués par l'abbé Breuil, tant pour nourrir sa formation que pour mener des prospections archéologiques, notamment sur les terrasses de la Garonne, qui livrent de nombreux quartzites taillés. En 1942, il prendra la relève du comte Bégouën en assurant le cours de préhistoire à la faculté des lettres de Toulouse, et l'assistera dans ses fonctions au muséum d'histoire naturelle de Toulouse. En 1946, il lui succèdera à la tête de la $\mathrm{X}^{\mathrm{e}}$ circonscription des Antiquités préhistoriques.

4 À Montmaurin, les grottes sont situées sur trois niveaux karstiques (fig. 1) situés à flanc de colline, entre 4 et 40 mètres de haut. Ces niveaux correspondent aux stades d'enfoncement de la rivière en relation avec l'étagement des terrasses de la Garonne, elles-mêmes corrélées avec les glaciations du Quaternaire. Méroc s'est concentré sur la grotte de Coupe-Gorge (étage moyen), dans laquelle il a effectué des fouilles de 1946 à 1961. Il s'est également intéressé à la grotte Boule, au niveau supérieur, où des sondages ont été effectués en 1947, 1948 et 1956 et, à proximité, à la grotte-abri de La Terrasse, entièrement fouillée entre 1947 et 1957. Les quatre grottes du Putois (étage inférieur), menacées de destruction, ont été fouillées rapidement en 1953. 
Fig. 1. - Le massif de Montmaurin dans les années 1950.

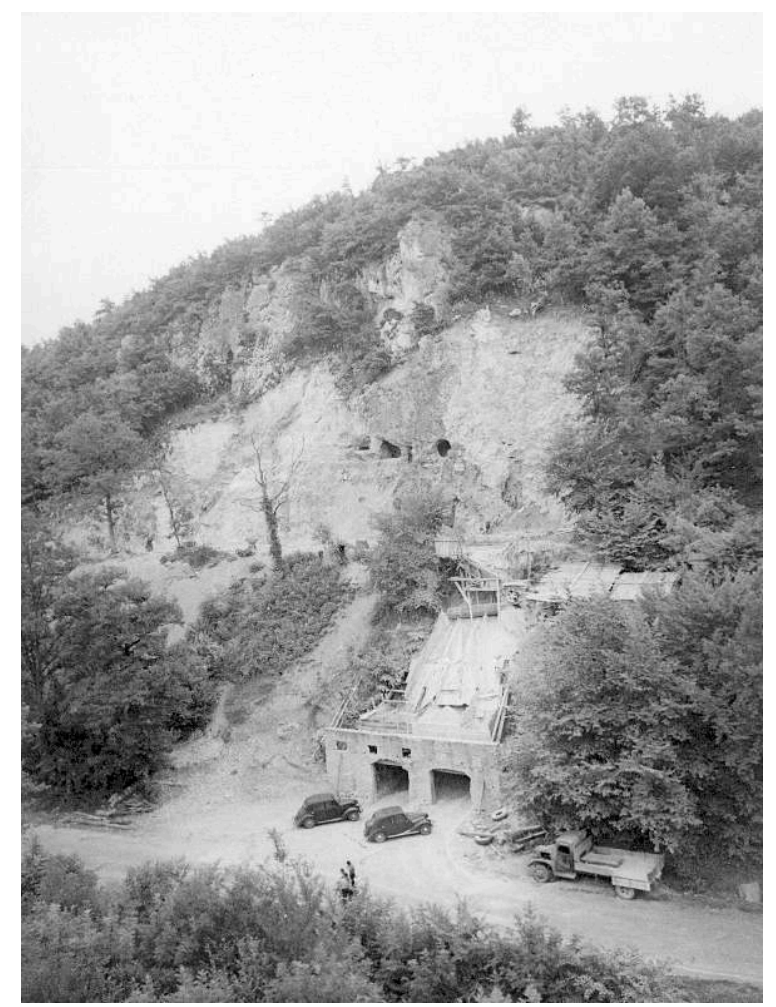

L'exploitation de la carrière a mis au jour les cavités de Coupe-Gorge et de La Niche (ouvertures visibles au milieu du massif). La Terrasse et la grotte Boule se situent à l'étage supérieur. Extrait de Baylac et al., 1950, p. 263.

(c) Babiel. D.R

\section{Montmaurin aujourd'hui}

5 Après l'arrêt des fouilles et la mort de Méroc en 1970, les sites ne seront que peu évoqués dans la littérature scientifique. Le but de cet article est d'en comprendre les raisons et de questionner la valeur heuristique de l'ensemble de ce processus. Il nous faut commencer par sonder ce qui est parvenu jusqu'à nous. En effet, la production du savoir et sa pénétration dans les communautés est comme une onde de choc dont l'intensité varie au cours du temps. Peut-on encore la percevoir aujourd'hui dans le cas des sites de Montmaurin? Autrement dit, quelle est la répercussion de ces travaux au sein de la communauté scientifique actuelle? Elle semble relever de trois ordres: scientifique, technique et politique.

6 En premier lieu, cette répercussion est scientifique, via la mandibule humaine provenant du site de La Niche qui, parce qu'elle est toujours accessible (elle est conservée au musée de l'Homme), est intégrée à de nombreuses études et s'inscrit dans un débat d'actualité depuis les années 1990, celui de la définition de l'espèce Homo heidelbergensis (Arsuaga et al. 1997, Rightmire 1998, Rosas et Bermúdez de Castro 1998, Mounier et al. 2009, Vialet et al. 2018). Il est intéressant de noter que ce fossile est pourtant à la marge des travaux de Méroc, qui n'est pas à l'origine de sa découverte. Ensuite, d'un point de vue historiographique, Montmaurin est associé à une méthode de fouilles inédite à l'époque, car conçue et utilisée pour la première fois par Méroc. 
Enfin, depuis plus d'une dizaine d'années, plusieurs chercheurs ont été sollicités pour témoigner de l'intérêt archéologique et patrimonial des sites de Montmaurin. L'enjeu devient alors politique : il s'agit de lutter localement contre la reprise de l'exploitation des carrières dont l'activité, qui a cessé en 2007, menace de reprendre (Marin 2008, Delpoux 2014).

7 Finalement, les fouilles de Méroc à Montmaurin (grotte Boule, La Terrasse, CoupeGorge et grottes du Putois) semblent avoir eu un impact modeste, qui n'a pas survécu au passage du temps, et leur apport apparaît plus technique (méthode de fouille) que strictement scientifique (connaissance des préhistoriques). Pour comprendre ce paradoxe, revenons sur le contexte historique dans lequel s'inscrivent ces recherches.

\section{L'organisation de l'archéologie préhistorique dans la deuxième moitié du $\mathrm{xx}^{\mathrm{e}}$ siècle}

Après la Seconde Guerre mondiale, le cadre législatif des pratiques de l'archéologie préhistorique a changé (Hurel 2007) avec la loi Carcopino du 27 septembre 1941 pour la régulation des fouilles et la protection des vestiges, et la mise en œuvre de cette loi par la création de dispositifs nouveaux. Le Centre national de la recherche scientifique (CNRS) est doté d'une section archéologique pour l'autorisation des fouilles $\left(\mathrm{XV}^{\mathrm{e}}\right.$ commission), avec la distinction entre les circonscriptions des antiquités historiques et préhistoriques et, pour ces dernières, une division administrative de la France en douze régions.

«L'État est devenu l'acteur majeur. Il prend la place des individus isolés et des institutions savantes traditionnelles [...]. Les amateurs se trouvent de fait marginalisés, et une nouvelle génération de chercheurs est en train d'émerger grâce à la refonte du CNRS et à la refonte académique. » (Hurel 2011, p. 398).

9 En effet, en 1948, en Sorbonne, Louis-René Nougier (1912-1995) soutient une thèse d'État en préhistoire et obtient l'année suivante une maîtrise de conférence d'archéologie préhistorique à la faculté des lettres de Toulouse, ce qui deviendra la première chaire de préhistoire en 1955 (Hurel 2011). Enfin, la revue Gallia est créée en 1943 par le CNRS pour la publication régulière des résultats de fouilles. L'appareil est donc en place pour assurer l'ensemble du processus, des recherches sur le terrain à leur publication, sans oublier la protection des sites via la loi du 2 mai 1930, qui réorganise la protection des monuments naturels et des sites de caractère artistique, historique, scientifique, légendaire ou pittoresque et renforce la loi sur les paysages de 1906, dite loi Beauquier (Hurel 2007).

10 Le rapport au terrain a changé lui aussi, impliquant la mise en œuvre de fouilles permettant une lecture tout autant horizontale de la répartition spatiale des vestiges que verticale de la stratigraphie.

«Un transfert s'opère peu à peu : le cœur de l'archéologie préhistorique n'est plus l'objet et une préhistoire typologique, mais le fait archéologique objectif lui-même, dont le gisement restitue une image dynamique [...]. La fouille en tant que telle devient donc le centre de la production du savoir scientifique et la condition première de sa validité. » (Hurel 2007, p. 247-248). 


\section{Louis Méroc, le « bon élève »}

11 Dans ce contexte, la méthode de fouille que Méroc adopte pour les grottes de Montmaurin (à Coupe-Gorge d'abord, puis à La Terrasse et à Boule) ne surprend guère. Même s'il est fort de son expérience dans la grotte de Labouiche, en Ariège, il s'interroge en écrivant à l'abbé Breuil au début de l'année 1946 :

«Ce qui me préoccupe, c'est la façon d'attaquer cette coupe absolument verticale. Je pourrais évidemment me borner à la fouille de chacune des grandes divisions stratigraphiques que j'y ai déjà reconnues [...]. Mais, sur un remplissage de $6 \mathrm{~m}$ de puissance, certaines des couches ainsi établies arriveraient à $2 \mathrm{~m}$ d'épaisseur. Aussi je crois qu'il faudrait les subdiviser artificiellement pour commencer tout au moins en tranches de $0,50^{1}$.»

12 Mais quelques mois plus tard, il semble sûr de sa méthode, qu'il décrit le 7 mai 1946 dans une autre lettre ${ }^{2}$. Il y explique le système de carroyage qu'il a établi, découpant la zone de fouille en carrés d'un mètre de côté formant des secteurs numérotés transversalement, qui s'inscrivent dans des bandes longitudinales portant des lettres (fig. 2). Méroc précise :

«Chaque fouilleur, ayant son carnet, devait fouiller chaque couche carré par carré et mentionner sur son carnet la position de chaque objet recueilli, tant en plan qu'en profondeur. Ainsi, au laboratoire, nous pourrons retrouver la position à peu près exacte de chaque objet ${ }^{3}$. »

Fig. 2. - Lettre de Louis Méroc à Henri Breuil, 7 mai 1946 (extrait).

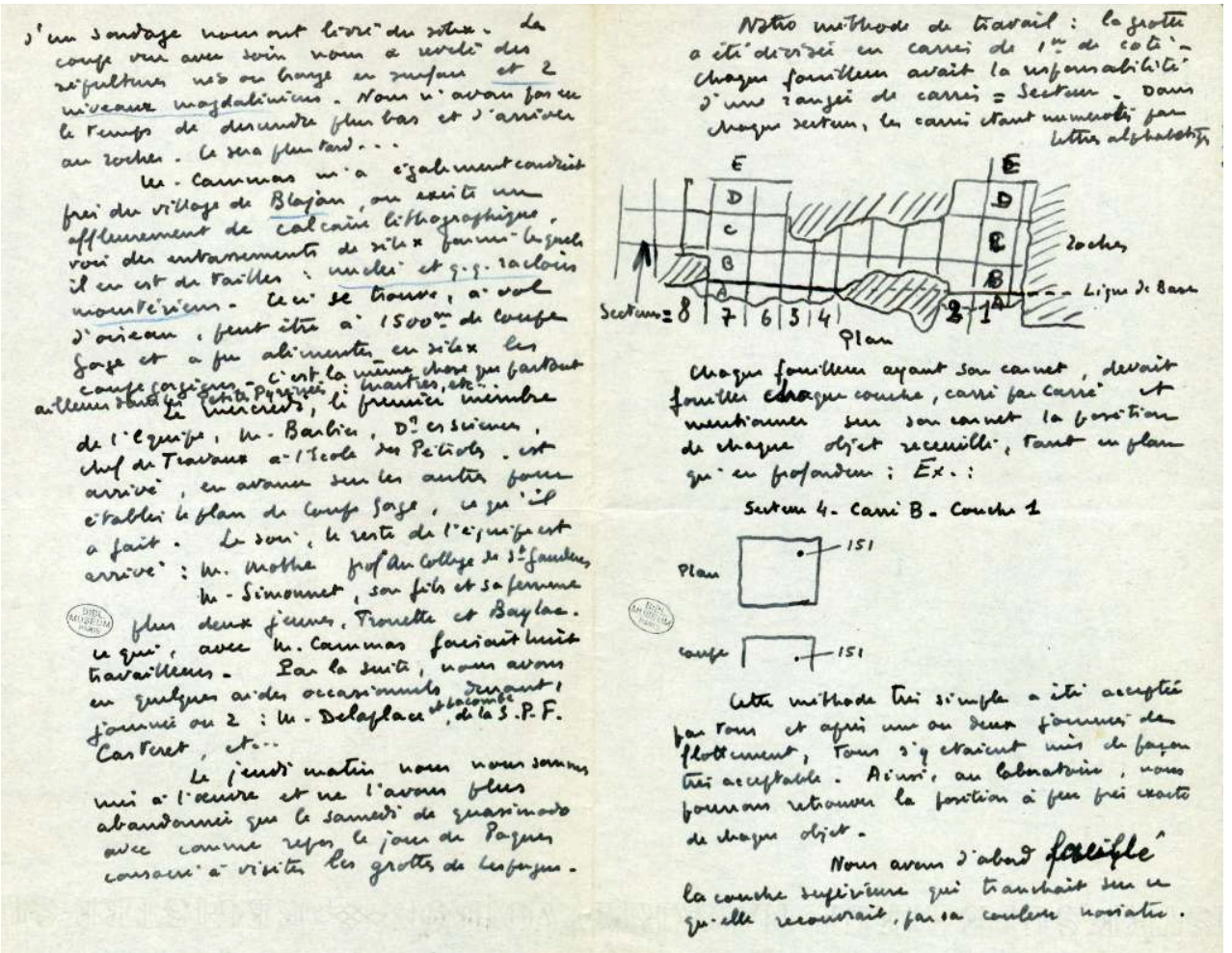

Paris, Bibliothèque centrale du Muséum national d'histoire naturelle, fonds Breuil, $\mathrm{Br} 37$, avec l'aimable autorisation des ayants droit.

(c) Muséum national d'histoire naturelle. 
13 Par cette méthode, Méroc répond à ses préoccupations stratigraphiques. En effet, si les fouilles de Coupe-Gorge l'intéressent tant, c'est parce que depuis quelques années la question de l'attribution chronologique des quartzites taillés des terrasses de la Garonne est dans l'impasse (Simonnet 2010). Seule l'association d'une telle industrie avec des ossements de faune permettrait la construction d'un cadre chronostratigraphique fiable. C'est un enjeu qu'il partage avec l'abbé Breuil, qui le soutient pour obtenir l'autorisation et le financement de ses fouilles.

Cependant, Méroc n'est pas le seul à avoir pensé les modalités d'une nouvelle pratique. André Leroi-Gourhan (1911-1986), qui entreprend des recherches dans les grottes d'Arcy-sur-Cure (Yonne) dès 1946, au même moment, en publiera une première synthèse en 1961, dans laquelle il précisera en note de bas de page le nom des membres de son équipe et ses méthodes de fouilles et d'analyse (Leroi-Gourhan 1961). Dès 1950, Leroi-Gourhan a fait paraître un petit ouvrage de 88 pages à destination des archéologues amateurs, intitulé Les fouilles préhistoriques (techniques et méthodes), manuel rassemblant l'enseignement dispensé dans son "école de fouilles» (Leroi-Gourhan 1950). On y lit en introduction :

«Il faut que tous les préhistoriens, même non fouilleurs, sachent faire la critique des recherches et distinguer une bonne fouille d'une mauvaise: on évitera ainsi rapidement le gaspillage des richesses et cette dangereuse illusion qu'un homme qui bouleverse vingt sites par an et qui remue tout seul cinquante mètres cubes de terre est un vrai préhistorien. »

Même si ces mises en garde semblent entendues, elles doivent encore être plus largement diffusées, comme le précise Méroc:

«Vaufrey a eu vent de nos méthodes de fouilles et m'a demandé de les exposer dans L'Anthropologie. J'ai accepté car cela pourra inciter des gens à nous imiter dans une voie que je crois la bonne $e^{4}$."

C'est sans doute ce qui l'oblige à publier son article «Application des coordonnées cartésiennes à la fouille d'un gisement", sous l'impulsion de Georges Laplace (1918-2004), qui participe aux fouilles de Montmaurin depuis 1947. Cet article contient «le minimum indispensable que devrait s'imposer tout fouilleur soucieux de voir son travail servir au progrès de l'archéologie préhistorique " (Laplace-Jauretche et Méroc 1954, p. 66).

17 Ainsi, les fouilles de Méroc et de ses collaborateurs sont exemplaires et les sites sur lesquels elles s'appliquent, les grottes de Montmaurin, constituent un véritable terrain d'expérimentation méthodologique. Elles se déroulent « dans une conception collective de recherche en équipe, ce qui est alors une grande nouveauté » (Simonnet 2010, p. 94), qu'il affirme en choisissant un ordre alphabétique des auteurs pour le premier article de synthèse qu'il rédige (Baylac et al. 1950). Faire école est une autre préoccupation de Méroc, qui accueille volontiers des étudiants et des «préhistoriens chevronnés de la région » sur le chantier de Coupe-Gorge devenu "école de fouilles ${ }^{5}$ », ce qui n'est pas sans rappeler le fonctionnement du Centre de documentation et de recherches préhistoriques créé par André Leroi-Gourhan en 1946 avec son école de fouilles (Soulier 2003). Ce principe va se généraliser, comme en témoigne pour le nord de la France la création en 1957 par Bernard Edeine (1908-1999) de l'école internationale de fouilles du mont Joly (Watté 2016).

18 Méroc n'a pas oublié non plus les autres directives de son époque: il publie régulièrement les résultats de ses recherches dans la revue Gallia et s'occupe du 
classement des sites de Montmaurin aux Monuments historiques (14 décembre 19496). La nécessité de cette dernière opération s'impose très vite, du fait de l'activité de la carrière qui, si elle a mis au jour les gisements, les a également en partie détruits. Enfin, lorsque c'est possible (à Coupe-Gorge et dans la grotte Boule), Méroc ne vide pas totalement les gisements, laissant un remplissage témoin pour des études futures.

Notons que l'œuvre de Méroc, qui fait figure de bon élève, se développe dans un contexte favorable, voire effervescent. Il est soutenu par des personnalités influentes, tels le comte Bégouën et l'abbé Breuil. Ce sont les figures emblématiques de la construction de la préhistoire dans la première moitié $d u x^{e}$ siècle. Le comte Bégouën a découvert avec ses fils, sur sa propriété de Montesquieu-Avantès, la grotte d'Enlène, celle du Tuc d'Audoubert livrant les fameux bisons modelés dans l'argile, et la cavité ornée dite des Trois-Frères (Bégouën et al. 2014); l'abbé Breuil a, quant à lui, grandement contribué à la question de l'art pariétal mais également à celle des cultures paléolithiques et à leur classification. Enfin, ce sont tous deux des " officiels ", le comte Bégouën ayant pris la suite d'Émile Cartailhac au muséum comme à la faculté des lettres de Toulouse, et l'abbé Breuil occupant la première chaire de préhistoire au Collège de France dès 1929.

Localement, à Montmaurin, c'est l'émulation entre Louis Méroc et Georges Fouet (1922-1993), son alter ego œuvrant à la mise au jour de spectaculaires vestiges galloromains sur la commune. Tous deux bénéficient de la complicité de Raymond SaintMartin (1913-2000), maire de Montmaurin de 1944 à 1989. La presse locale se fait régulièrement l'écho de leurs nombreuses découvertes, pour la préhistoire comme pour le gallo-romain ${ }^{7}$, et du passage de visiteurs de marque, comme à l'occasion de l'excursion organisée dans le cadre du $78^{\mathrm{e}}$ Congrès national des sociétés savantes en avril 1953. En quelques années, les sites de Montmaurin sont devenus incontournables, et c'est tout naturellement qu'ils font partie de l'excursion dans les Pyrénées orientales et centrales du VIII ${ }^{e}$ Congrès de l'International Union for Quaternary Research (INQUA) en 1969 (Méroc, 1969).

\section{La portée scientifique des sites de Montmaurin}

Ainsi toutes les conditions de la réussite scientifique étaient réunies ; mais quelle futelle réellement? Finalement, la portée des travaux de Méroc semble limitée. Ils sont connus essentiellement par de courtes parutions dans Gallia entre 1947 et 1954 (Méroc 1947, 1948, 1952, 1954).

La découverte qui fera grand bruit provient d'une cavité à laquelle Méroc s'intéresse pourtant peu, celle de La Niche. C'est dans cette dernière qu'est découverte une mandibule humaine, le 18 juin 1949. Elle a été mise au jour fortuitement par Raoul Cammas (1905-1987), huissier de justice à Boulogne-sur-Gesse qui, habitant à proximité, passe régulièrement vérifier le front de la carrière et notamment cette "niche", diaclase remplie de sédiments, à proximité de Coupe-Gorge. La mandibule de La Niche est alors considérée comme le plus ancien fossile de France; elle est décrite comme "pré-néandertalienne » de par sa morphologie archaïque. Étudiée par Henri-Victor Vallois (1889-1981), cette mandibule a eu une portée internationale, notamment via sa publication dans l'American Journal of Physical Anthropology en 1956 (Vallois 1956). L'étude détaillée, publiée quelque vingt ans plus tard (Billy et Vallois 1977), va définitivement installer ce fossile dans le paysage paléo-anthropologique. 
Si Méroc avait négligé la cavité de La Niche, c'est parce qu'« il n'y apparaissait pas de stratigraphie ${ }^{8}$ ». En effet, considérant le remplissage comme provenant d'un soutirage du niveau supérieur (La Terrasse notamment), Méroc n'a pas jugé bon d'y effectuer des fouilles en appliquant sa méthode rigoureuse d'enregistrement des "coordonnées cartésiennes ». Conscient que cette découverte est la plus importante de toutes celles effectuées dans les différentes cavités du massif, c'est autour de sa datation qu'il va organiser son article de synthèse paru en 1963. Il y explique que la mandibule provient sans doute "d'une très vieille couche à Rhinocéros de Merck, de la grotte-abri de La Terrasse » (Méroc 1963, p. 515). Sur ce point, Raoul Cammas semble avoir eu une autre intuition. Il a noté consciencieusement la provenance de chaque pièce découverte à La Niche, et grâce à une étude réalisée tardivement avec André Tavoso, a démontré la séquence stratigraphique en position primaire du remplissage où trois autres restes humains ont été mis au jour : deux vertèbres et un tibia (Cammas et Tavoso 1986).

Si la portée des découvertes effectuées dans les sites préhistoriques de Montmaurin est faible (excepté pour La Niche), c'est aussi, voire surtout, parce que l'étude en est inachevée. Quand Méroc arrête les fouilles en 1961, il a conscience du travail conséquent qui reste à accomplir. En effet, 27 campagnes à Coupe-Gorge, les fouilles complètes de La Terrasse et des grottes du Putois, ainsi que des opérations plus ponctuelles à Boule, ont permis d'accumuler un matériel archéologique immense, dont l'étude est à peine entamée. Beaucoup reste à faire. Et cette étape est essentielle. Elle est la justification du travail de terrain d'envergure qui a été réalisé grâce à un investissement important. Elle en constitue l'aboutissement. Mais Méroc manque de moyens. Dans ses lettres à Breuil, il se plaint régulièrement des problèmes de lieux et de conditions de conservation pour le matériel archéologique issu de ses fouilles. Méroc ne trouvera pas de solution satisfaisante, ce qui conduira à une dispersion des collections : aujourd'hui les principaux fonds sont à Toulouse, à Tautavel et aux Eyziesde-Tayac. Il mentionne également le problème du manque de chercheurs :

«L'étude systématique des matériaux réunis (de la faune en particulier), retardée par le défaut de locaux suffisants et de collaborateur technique, est ou va être entreprise.» (Méroc 1963, p. 514).

Pourtant, à la mort de Méroc en 1970, la situation n'a pas changé.

\section{Montmaurin « oublié »}

On peut en effet s'étonner de l'isolement de Méroc à la fin de sa vie. Lui qui a conçu ses chantiers de fouilles comme des écoles de terrain n'a pas un élève pour prendre la relève. Georges Simonnet (1905-1987) fait exception. Impliqué dans les fouilles de Montmaurin dès la première campagne de 1946, il achèvera son œuvre sur d'autres terrains, notamment à partir de 1963, occupant alors le poste d'agent technique de la direction des Antiquités préhistoriques de Midi-Pyrénées (Vaquer 2010). Il faut préciser que Louis Méroc n'a pas passé sa thèse ; il n'a pas trouvé le temps, dans cette vie déjà bien remplie, de la rédiger. C'est une question qui le tourmente et qu'il évoque régulièrement dans sa correspondance avec Henri Breuil, modifiant à plusieurs reprises le titre et le plan de son sujet de recherche. Breuil en est d'ailleurs bien conscient lorsqu'il décrit Méroc comme "trop pris par ses fonctions de magistrat " (Breuil 1957, p. 80). Or, sans ce prérequis, Méroc ne peut saisir l'occasion de gagner une position académique lorsqu'elle se présente, en 1949. C'est Louis-René Nougier qui obtient la 
maîtrise de conférence à la faculté des lettres de Toulouse. Il tente alors de se rapprocher des préhistoriens de la région, et rencontre des difficultés avec Méroc, ce qui sera «à l'origine d'une regrettable et préjudiciable coupure entre l'université et la circonscription préhistorique »(Clottes 2010, p. 102).

De plus, les relations de Méroc avec les plus jeunes, ou tout du moins avec Georges Laplace, se sont dégradées. Ce dernier s'est émancipé, il s'est distingué en tant que premier préhistorien membre de l'École française de Rome en 1956 et sera promu, en 1968, maître de recherches au CNRS (Plutniak 2017). Après une dispute à propos de la publication des fouilles menées dans la grotte des Abeilles, Méroc ne convie plus Laplace à Coupe-Gorge. Dans une lettre du 16 mai 1960, Méroc est bien conscient de la situation, faisant allusion à son jeune collègue : «J'ai eu le tort de ne pas mourir, ce sur quoi certains avaient tablé9 ".

Ce désaccord n'est qu'un épiphénomène. En effet, c'est une différence dans les enjeux scientifiques qui semble opposer Méroc et Laplace. Elle est perceptible très tôt, dès 1954, dans l'article qu'ils publient ensemble, dans lequel Georges Laplace indique avoir "perfectionné» la méthode de traitement des «coordonnées cartésiennes » en collaboration avec François Bordes, en multipliant les coupes, diagrammes et leur recoupement, la faisant passer d'un "système de repérage " dans l'espace à "un instrument pratique d'analyse et de compréhension graphiques d'une couche archéologique et de ses rapports avec la stratigraphie " (Laplace-Jauretche et Méroc 1954, p. 58-59). Il devient clair que si Méroc est innovant pour les méthodes de fouille, faisant souvent face à des situations d'urgence (sites néolithiques de VilleneuveTolosane et de Saint-Michel-du-Touch à partir des années 1960), son questionnement reste essentiellement stratigraphique, alors que Georges Laplace et les préhistoriens de sa génération vont s'intéresser à l'analyse spatiale et au traitement des données. D'une façon générale, dès les années 1950, les sciences de l'homme sont tournées vers la mise en évidence des structures sociales, et les outils méthodologiques antérieurs ne semblent plus opérants.

29 À la fin de sa vie et malgré son immense contribution, Méroc semble en dehors du système, par manque de reconnaissance officielle. Il est assimilé aux « anciens », tels le comte Bégouën et avant lui Cartailhac. Déjà, à propos de ce dernier, Marcellin Boule notait ce paradoxe entre production scientifique et reconnaissance académique, en précisant dans une élogieuse nécrologie : "ses appointements annuels de chargé de cours à la faculté des lettres progressèrent lentement jusqu'à la somme de 2000 francs, moins que le prix actuel d'une bonne à tout faire ! (Boule 1921, p. 601).

Bien sûr, Méroc occupa jusqu'au bout la fonction de directeur de la $\mathrm{X}^{\mathrm{e}}$ circonscription des Antiquités préhistoriques, qui lui avait été confiée par Bégouën et Breuil en 1946. Mais après deux décennies, le contexte a changé, les écoles de pensées se sont territorialisées autour de chercheurs en poste au CNRS ou à l'université, tel André Leroi-Gourhan à Paris, Henri de Lumley à Marseille, ou encore François Bordes à Bordeaux. En définitive, Méroc, «l'un des derniers directeurs de circonscription non professionnels », clôt le « temps des amateurs » (Simonnet 2010, p. 90 et 97).

31 Les fouilles menées par Louis Méroc dans les grottes préhistoriques de Montmaurin entre 1946 et 1961 sont représentatives des aspirations scientifiques d'une époque qui a 
vu l'archéologie préhistorique se réguler et se professionnaliser. Elles ont été parmi les premières fouilles méthodiques à faire l'objet de l'enregistrement de la position des vestiges dans l'espace et ont constitué un terrain d'expérimentation pour améliorer ces nouvelles pratiques. Trop liées à cette quête méthodologique à visée stratigraphique, elles ne présenteront pas d'intérêt pour la génération suivante, dont les questionnements sont d'un autre ordre, portés sur l'analyse statistique des corpus (typologie lithique, représentations pariétales...) et palethnographique des vestiges par l'étude de leur répartition spatiale.

Il semble que ce soit le sort de beaucoup de gisements, qui sont oubliés avec le changement de paradigme ou à la mort de leur inventeur. Cependant, lorsqu'ils sont préservés, au moins en partie, et qu'une recherche archivistique permet de les documenter (fouilles, sort des pièces mises au jour etc.), ils peuvent à nouveau être questionnés dans un cadre conceptuel et des pratiques renouvelés (Hurel et al. 2016). Nous espérons que ce sera le cas des sites de Montmaurin, dont nous reprenons l'étude.

\section{BIBLIOGRAPHIE}

ARSUAGA J. L., MARTínEZ I., GRACIA A., LORENZO C., 1997, « The Sima de los Huesos crania (Sierra de Atapuerca, Spain) : a comparative study ", Journal of Human Evolution, vol. 33, nº 2-3, p. 219-281.

BAYLAC P., CAMMAS R., DELAPLACE E., LACOMBE P., LAPLACE-JAURETCHE G., MÉROC L., MOTHE L., SIMONNET G., SIMONNET R., TROUETTE L., 1950, « Découvertes récentes dans les grottes de Montmaurin (HauteGaronne) », L'Anthropologie, vol. 54, n 3-4, p. 262-271.

BÉGOUËN R., CLOTTES J., FERUGLIO V., PASTOORS A. (dir.), 2014, La caverne des Trois-Frères : anthologie d'un exceptionnel sanctuaire préhistorique, Paris, Somogy éditions d'art.

BILLY G. et VALLOIS H.-V., 1977, « La mandibule pré-rissienne de Montmaurin », L'Anthropologie, vol. 81, $\mathrm{n}^{\circ} 2$, p. 273- 312 et vol. 81, $\mathrm{n}^{\circ} 3$, p. 411-458.

BOULE M., 1921, «Émile Cartailhac », L’Anthropologie, vol. 31, p. 587-608.

BREUIL H., 1957, « Henri Bégouën (1863-1956) », Bulletin de la Société préhistorique de France, vol. 54, $\mathrm{n}^{\circ} 1-2$, p. $78-81$.

CAMmAS R. et TAvoso A., 1986, " Nouveaux restes humains issus du remplissage de La Niche (Montmaurin, Haute-Garonne) », Comptes rendus de l'Académie des sciences, série 2, vol. 302, $\mathrm{n}^{\circ} 8$, p. 609-614.

CLOTTES J., 2010, « Louis-René Nougier (1912-1995) », dans Bon F., Dubois S., Labails M.-D. (dir.), Le muséum de Toulouse et l'invention de la préhistoire, Toulouse, Éditions du muséum de Toulouse, p. 101-102.

DELPOUX M., 2014, « Le site archéologique et naturel de Montmaurin (Haute-Garonne) : histoire du débat pour sa sauvegarde et sa sanctuarisation », Mémoires de l'Académie des sciences, inscriptions et belles-lettres de Toulouse, $19^{\mathrm{e}}$ série, vol. 5, nº 176, p. 109-131.

HUREL A., 2007, La France préhistorienne : de la Révolution à 1941, Paris, CNRS Éditions. 
HUREL A., 2011, L'abbé Breuil : un préhistorien dans le siècle, Paris, CNRS Éditions.

HUREL A., BAHAIN J.-J., MONCEL M.-H., VIALET A., ANTOINE P., AUGUSTE P., CHARLIER P., COYE N., FAVIN-LÉVÈQUE J.C., FROMENT A., LEBON M., LIMONDIN-LOZOUET N., ORLIAC R., TOMBRET O., VERCOUTÈRE C., VOINCHET P., ZAZZO A., 2016, « Moulin Quignon : la redécouverte d'un site », L'Anthropologie, vol. 120, n 4, p. 428-438.

LAPLACE-JAURETCHE G. et MÉROC L., 1954, « Application des coordonnées cartésiennes à la fouille d'un gisement ", Bulletin de la Société préhistorique de France, vol. 51, nº 1-2, p. 58-66.

LEROI-GOURHAN A., 1950, Les fouilles préhistoriques (techniques et méthodes), Paris, Picard.

LEROI-GOURHAN A., 1961, « Les fouilles d'Arcy-sur-Cure (Yonne) », Gallia préhistoire, vol. 4, p. 3-16.

MARIN A., 2008, « Motion pour la sauvegarde de l'intégrité d'un site naturel et archéologique majeur : les gorges de la Seygouade et de la Save à Montmaurin-Lespugue ", Mémoires de la Société archéologique du midi de la France, séance du $1^{\mathrm{er}}$ avril 2008, vol. 68, p. 26-34.

MÉROC L., 1947, « X ${ }^{e}$ circonscription préhistorique. Grotte de Coupe-Gorge, commune de Montmaurin (Haute-Garonne)», Gallia, vol. 5, p. 192-194.

MÉROC L., 1948, « Les grottes de Montmaurin (Coupe-Gorge, Montmaurin, Zubiate, Les Abeilles) », Gallia, vol. 6, p. 409-412.

MÉROC L., 1952, « Informations archéologiques : Montmaurin (grotte de Coupe-Gorge) », Gallia, vol. 10 , p. 93.

MÉROC L., 1954, «Informations archéologiques : Montmaurin (grotte de Coupe-Gorge, station de plein air dite de La Terrasse, grottes du Putois) », Gallia, vol. 15, nº 3, p. 95-97.

MÉROC L., 1963, « Les éléments de datation de la mandibule humaine de Montmaurin (HauteGaronne) », Bulletin de la Société géologique de France, vol. 7, p. 508-515.

MÉROC L., 1969, « Les grottes de Montmaurin », dans VIII Congrès INQUA, livret-guide de l'excursion A6, Pyrénées orientales et centrales, Roussillon, Languedoc occidental, p. 28-31.

MOUNIER A., MARCHAL F., CONDEMI S., 2009, «Is Homo heidelbergensis a distinct species ? New insight on the Mauer mandible ", Journal of Human Evolution, vol. 56, p. 219-246.

PLUTNIAK S., 2017, « The professionalisation of science, claim and refusal : discipline building and ideals of scientific autonomy in the growth of prehistoric archaeology. The case of Georges Laplace's group of typologie analytique, 1950s-1990s ", Organon, vol. 49, p. 105-153.

RIGHTMIRE G. P., 1998, « Human evolution in the middle Pleistocene : the role of Homo heidelbergensis », Evolutionary Anthropology, vol. 6, p. 218-227.

ROSAS A. et BERMÚDEZ DE CASTRO J. M., 1998, « The Mauer mandible and the evolutionary significance of Homo heidelbergensis ", Geobios, vol. 31, p. 687-697.

SIMONNET R., 2010, « Louis Méroc (1904-1970) », dans Bon F., Dubois S., Labails M.-D. (dir.), Le muséum de Toulouse et l'invention de la préhistoire, Toulouse, Éditions du muséum de Toulouse, p. $90-97$.

SOULIER P., 2003, « André Leroi-Gourhan et l'anatomie humaine : de la craniologie à la fouille des sépultures ", Revue archéologique de Picardie, vol. 21, p. 33-50.

VALLOIS H. V., 1956, « The premousterian human mandible from Montmaurin », American Journal of Physical Anthropology, vol. 14, p. 319-324.

VAQUER J., 2010, « Georges Simonnet (1905-1987) », dans Bon F., Dubois S., Labails M.-D. (dir.), Le muséum de Toulouse et l'invention de la préhistoire, Toulouse, Muséum de Toulouse, p. 98-100. 
VIALET A., MODESTO-MATA M., MARTINÓN-TORRES M., MARTÍNEZ DE PINILLOS M., BERMÚDEZ DE CASTRO J. M., 2018, "A reassessment of the Montmaurin-La Niche mandible (Haute-Garonne, France) in the context of European Pleistocene human evolution », PLoS One, vol. 13, n ${ }^{\circ} 1$. DOI : 10.1371/journal.pone. 0189714.

WATTÉ J.-P., 2016, « Enseigner la préhistoire à l'école de fouilles du Mont-Joly, commune de MontSaint-Quentin (Calvados) ", dans Éduquer et instruire en Normandie, actes du $21^{e}$ Congrès des sociétés historiques et archéologiques de Haute-Normandie, Le Havre, Fédération des sociétés historiques et archéologiques de Normandie, p. 493-501.

\section{NOTES}

1. Lettre de L. Méroc à H. Breuil du 14 janvier 1946, Bibliothèque centrale du Muséum national d'histoire naturelle (BCM), fonds Breuil.

2. Lettres de L. Méroc à H. Breuil du 25 mars et du 7 mai 1946, BCM, fonds Breuil.

3. Lettre de L. Méroc à H. Breuil du 7 mai 1946, BCM, fonds Breuil.

4. Lettre de L. Méroc à H. Breuil du 31 novembre 1948, BCM, fonds Breuil.

5. Lettre de L. Méroc à H. Breuil du 5 juillet 1949, BCM, fonds Breuil.

6. Grotte dite de Montmaurin ou Boule, abri chantier de La Terrasse, grotte de CoupeGorge et Niche du Néanderthal : classement par arrêté du 14 décembre 1949, propriété de la commune.

7. Les ruines d'une villa gallo-romaine, propriété de l'État, ont été classées par arrêté du 5 décembre 1949.

8. Lettre de L. Méroc à H. Breuil du 25 juin 1949, BCM, fonds Breuil.

9. Lettre de L. Méroc à H. Breuil du 16 mai 1960, BCM, fonds Breuil.

\section{RÉSUMÉS}

La construction du savoir en préhistoire prend sa source sur le terrain, et sa validité dépend des conditions dans lesquelles s'effectuent les recherches. Dans la seconde moitié $d u x^{e}$ siècle, l'application de la nouvelle réglementation des fouilles en France et l'utilisation de méthodes d'enregistrement spatial des vestiges témoignent de cet enjeu visant à la compréhension de la dynamique de mise en place et d'occupation des sites. Les travaux de Louis Méroc (1904-1970) dans les différentes cavités du massif de Montmaurin, en Haute-Garonne, entre 1946 et 1961, s'inscrivent clairement dans ce contexte. C'est pourquoi le rôle modeste qu'ils ont joué par la suite peut étonner. Il se comprend par une série de facteurs, dont l'absence de relève scientifique et un changement de paradigme (les deux phénomènes étant en partie liés), que cet article propose d'examiner en détail. 


\section{AUTEUR}

\section{AMÉLIE VIALET}

Maître de conférences au Muséum national d'histoire naturelle (UMR 7194, Histoire naturelle de l'homme préhistorique, université de Perpignan - Via Domitia), membre de la section Sciences, histoire des sciences et des techniques et archéologie industrielle du CTHS 
Le rôle des sociétés de publication de documents dans la transmission des savoirs : l'exemple de la Société des archives historiques de la Saintonge et de l'Aunis

\author{
Pascal Even
}

Dans le cadre de la transmission des savoirs, thème d'étude choisi par le Comité des travaux historiques et scientifiques (CTHS) pour le congrès de 2018, le rôle et les activités des sociétés de publication de documents historiques méritent d'être soulignés. Il ne s'agit pas d'évoquer l'activité des sociétés savantes en général, mais de celles qui ont pour but et principale fonction de publier des documents inédits, sur le modèle du CTHS dont on ne rappellera jamais assez que l'un des buts, et peut-être le premier, qui lui ont été assignés par ses fondateurs, était de publier les documents inédits de l'histoire de France.

Dans la seconde moitié du XIX siècle, nombreuses ont été les sociétés fondées en province dans un but analogue: publier et rendre accessibles à la recherche des documents non connus, et souvent même non encore conservés dans les collections publiques, mais demeurés propriété de particuliers. Force est de constater que cent cinquante ans plus tard, rares sont les sociétés qui poursuivent encore cette activité ; celles qui s'étaient donné comme seul objectif la publication de documents ont pour la plupart disparu; les autres sont devenues des sociétés savantes publiant travaux et études, et la publication de documents inédits n'entre que ponctuellement dans le programme de leurs activités et de leurs travaux ${ }^{1}$.

3 Les raisons de cette décadence sont multiples et ont déjà été analysées ${ }^{2}$. Le développement à partir de la fin du XIX ${ }^{e}$ siècle d'institutions patrimoniales concernées au premier chef par la conservation des documents anciens et leur mise en valeur, services d'archives et fonds patrimoniaux des bibliothèques, l'essor des recherches universitaires et de la recherche scientifique, qui ont facilité l'identification des 
documents pertinents pour la recherche et les moyens de leur mise à disposition, ont changé la donne. Les sociétés savantes ont été affectées également par la diminution sensible de leur public et du nombre de leurs adhérents après la Première Guerre mondiale ; leurs publications se sont espacées et la plupart d'entre elles ont vécu dans l'entre-deux-guerres une crise qui s'est révélée fatale pour un certain nombre.

4 La Société des archives historiques de la Saintonge et de l'Aunis n'a pas échappé à cette évolution, mais après plusieurs décennies de sommeil, elle est revenue à la vie et a retrouvé le rythme de ses publications. Dans un contexte social et économique bien évidemment différent, sa résurrection semble montrer que la publication de documents inédits conserve encore une utilité.

\section{Un rouage de l'érudition saintongeaise au tournant du $x x^{e}$ siècle}

5 La Société des archives historiques de la Saintonge et de l'Aunis a été créée en avril 1874, quelques années seulement après l'incendie dramatique en 1871 de l'hôtel de ville de Saintes, qui conservait la bibliothèque et les archives de la cité. La perte documentaire entraînée par l'incendie était considérable; en quelques heures disparaissait en effet une large partie de la mémoire non seulement de la cité, mais encore de la province. Cet incendie constitue le « déclic fécondant » de l'apparition de la société, pour reprendre l'expression d'un historien contemporain de la Saintonge ${ }^{3}$. Certes, il existait au chef-lieu du département un service d'archives, mais son organisation scientifique restait récente et ses moyens très limités. Il n'avait pas encore engagé de campagne de sauvegarde des archives communales, et il est fort peu probable, au demeurant, que la ville de Saintes aurait accepté à l'époque de verser ses dossiers anciens au service des archives départementales.

6 Ce traumatisme, parce qu'il faut vraiment parler de traumatisme pour les érudits locaux et les historiens de la Saintonge, explique le succès de la création de la Société des archives historiques par Louis Audiat, le malheureux bibliothécaire de Saintes. Les circonstances du drame qui avait entraîné la disparition des manuscrits et archives rassemblés dans l'hôtel de ville donnaient presque à la fondation de la société et à son fondateur l'auréole de la légende, mais les faits étaient avérés. Louis Audiat, désespéré, s'était élancé au milieu des flammes pour tenter de leur arracher quelques manuscrits parmi ceux qu'il jugeait les plus précieux et les avait lancés par les fenêtres, avant d'être obligé par les pompiers de quitter les lieux, quelques instants seulement avant l'effondrement des toitures.

7 Le bibliothécaire, qui avait vu disparaitre ses collections et pouvait mesurer la perte enregistrée, avait proposé immédiatement sa démission, qui avait été refusée. Audiat restera marqué par l'événement et à partir de ce moment toute son énergie consistera d'une part à reconstituer la bibliothèque et d'autre part à sauvegarder par l'édition les témoins de l'histoire de la Saintonge, c'est-à-dire les papiers et archives qui pouvaient être encore en mains privées, mais également ceux déjà déposés dans des institutions patrimoniales, l'expérience montrant que le dépôt dans une institution publique ne constituait pas une garantie suffisante. Très vite, il acquiert la conviction que la publication de ces textes dans une collection de volumes imprimés largement diffusés constitue la meilleure sauvegarde. Naît alors le projet de créer une société qui aurait 
pour vocation la publication des documents inédits relatifs à l'histoire des deux anciennes provinces de l'Ancien Régime, la Saintonge et l'Aunis, qui forment approximativement le département de la Charente-Inférieure. Ce sera le combat de sa vie que d'animer jusqu'à sa mort cette société des archives qu'il avait créée et de multiplier les éditions de textes.

Quelques observations doivent cependant être faites. Le vocable de "société des archives historiques » semble être, tout au moins selon la liste publiée dans les statistiques de la «France savante » du CTHS comme une particularité de l'ouest de la France, et plus particulièrement du Sud-Ouest. Indépendamment de la Société des archives historiques du Maine, qui s'appelle également Société historique de la province du Maine, créée en 1883, n'y figurent en effet que quatre sociétés qui portent le nom de société des archives historiques : celle du Limousin, celle de la Gironde, celle du Poitou et enfin la Société des archives historiques de la Gascogne, fondée à Auch et active de 1883 à $1914^{4}$.

9 Sans doute, toutes ces sociétés s'inspirent de la Société des archives historiques du département de la Gironde, la plus ancienne puisqu'elle a été créée en 1859. On remarquera que la Société des archives historiques du Poitou apparait l'année même de l'incendie de la bibliothèque de Saintes, en $1871^{5}$. On notera également que depuis la dernière réorganisation territoriale, toutes ces anciennes sociétés relèvent de la région Nouvelle-Aquitaine. Convient-il pour autant de parler de spécificité locale? Peut-être. Tout au moins peut-on constater que le principe et le modèle des sociétés de publication de documents inédits connaît un véritable succès dans le Sud-Ouest dans la seconde moitié du xIX siècle.

10 Pour en revenir à la Société des archives historiques de la Saintonge et de l'Aunis, il paraît évident que, pour les initiateurs de la nouvelle société réunis autour de Louis Audiat, la Saintonge était considérée comme l'élément principal de ses activités et le ressort géographique principal. Le titre adopté par la société est symptomatique. L'Aunis, l'ancienne province du nord du département, avec ses deux ports de La Rochelle et de Rochefort, est placée en deuxième position. Il est vrai que ni La Rochelle, ni à plus forte raison Rochefort ne peuvent prétendre à la richesse du passé antique de Saintes; mais il faut sans doute voir dans cette primauté accordée à la Saintonge une revanche sur La Rochelle, qui aux yeux des Saintongeais et des Saintais avait usurpé le titre de chef-lieu du département depuis la décision prise par Napoléon, en 1810, d'y transférer le siège de la préfecture initialement fixé à Saintes. Les Saintais n'avaient cessé, tout au long du siècle, de réclamer en vain le retour du chef-lieu du département dans la capitale de la Saintonge. Les initiateurs de la nouvelle société réunis autour de Louis Audiat étaient indiscutablement saintais ou saintongeais, ce qui explique le rôle secondaire dévolu à l'Aunis, non seulement dans l'intitulé de la société mais surtout dans le contenu des publications réalisées. En majorité, ces dernières portent en effet sur la Saintonge. Et pourtant, les érudits rochelais ne sont pas moins actifs à l'époque que ceux de Saintes ${ }^{6}$.

11 Mais ce que revendiquent Louis Audiat et ses associés, c'est la Saintonge historique, avec la partie de l'ancienne province - l'élection de Cognac - qui avait été dévolue au département de la Charente pendant la Révolution, lors de la création des départements. L'article 1 des statuts de la société le précise tout de suite :

«La société des Archives historiques de la Saintonge et de l'Aunis, fondée en 1874, a pour but, en même temps que la gestion de ses collections, la publication des 
documents inédits relatifs aux deux anciennes provinces d'Aunis et Saintonge, à la généralité de La Rochelle, et aux anciens diocèses de La Rochelle et de Saintes. [...] Elle a son siège à Saintes, point central de la circonscription. »

12 La Société et ses publications connurent un rapide succès. Louis Audiat, fondateur et premier président de la société, fit des Archives historiques de la Saintonge et de l'Aunis le rouage des études historiques dans un département qui ne possédait pas d'université et où les sociétés savantes d'envergure se bornaient encore à la Société d'archéologie de Saintes ${ }^{7}$, fusionnée avec la commission des Arts et des monuments historiques du département pour la partie saintongeaise de ce dernier ${ }^{8}$, et à l'Académie des belles-lettres, sciences et arts de La Rochelle pour l'Aunis ${ }^{9}$. La ville de Rochefort avait certes possédé une société savante, créée au début du XIX ${ }^{\mathrm{e}}$ siècle, mais tombée en décadence, et la Société de géographie de Rochefort qui lui succéda, axée sur le monde maritime et colonial, ne prétendait pas concurrencer le presque monopole saintais, puisque ses buts visaient la défense et l'accroissement du domaine colonial français ${ }^{10}$.

13 Au sein du conseil d'administration de la Société des archives historiques, qui bénéficia dès 1886 d'une reconnaissance d'utilité publique, prirent place les principaux érudits de l'époque, et le bilan des publications de la société reste impressionnant. Au rythme d'un par an, cinquante volumes furent publiés au cours de cette première période.

La Première Guerre mondiale porte un coup décisif aux activités de la société ; elle interrompt ses publications et le rythme annuel de ces dernières ne reprendra pas. Si quatre volumes sont encore publiés jusqu'en 1935, la campagne d'édition de textes s'essouffle $^{11}$. Les raisons de ce déclin sont multiples: transformation de la société française, affaiblissement du cercle des érudits et des chercheurs, diminution du nombre des adhérents et des subventions publiques. La société, qui avait compté jusqu'à 500 adhérents au tournant du siècle, peine désormais à trouver de nouveaux membres; ses ressources diminuent et les soutiens officiels se dérobent. Cette évolution est, au demeurant, identique à celle que connaissent la plupart des sociétés savantes du pays.

15 Complexe personnalité que celle d'Audiat; il avait donné à son association une orientation résolument conservatrice, lui-même ne cachant pas ses idées monarchistes, et la revue figurait sur toutes les tables des châtelains et notables conservateurs de l'époque ${ }^{12}$. Il savait au demeurant recruter en dehors du département, et jusque dans les sphères nationales; on trouve ainsi l'écrivain polémiste Paul Déroulède parmi les membres de la société. Toutefois, parmi ses adhérents membres de l'aristocratie locale, figurait la comtesse Charlotte de La Redorte, épouse en premières noces du général Camille Antoine Callier ; elle prit le parti d'Alfred Dreyfus et entretint avec Salomon Reinach une abondante correspondance, récemment étudiée ${ }^{13}$. Mais la comtesse de La Redorte vivait à Paris et ne séjournait qu'à La Rochelle lorsqu'elle résidait en CharenteMaritime.

16 L'orientation conservatrice de la société fut renforcée après la disparition d'Audiat par son successeur à la présidence, le baron Amédée Oudet, ardent partisan des idées bonapartistes, particulièrement bien implantées dans le département jusque très tard dans le $\mathrm{XIX}^{\mathrm{e}}$ siècle.

Consciente sans doute du caractère quelque peu aride de ses volumes d'archives, la société avait lancé, quatre années après sa fondation, la publication d'un bulletin qui, très rapidement, prit l'aspect d'une véritable revue de société savante, dans laquelle étaient publiés des articles historiques; il avait paru en effet nécessaire de disposer 
d'une véritable revue historique à côté des volumes de documents inédits. En dépit de l'intérêt qu'ils représentaient pour les chercheurs scientifiques, ces derniers ne pouvaient retenir l'attention des adhérents habituels. Le bulletin ne se bornait pas à publier des articles historiques; il laissait une large place aux notes de lecture, aux questions-réponses de lecteurs curieux et surtout à la chronique familiale des notables saintongeais, atout indispensable pour conforter l'audience de la Société des archives historiques dans la société saintongeaise. Les bulletins contiennent ainsi une série extrêmement précieuse de notices nécrologiques, qui ne concernent pas uniquement les adhérents de la société, mais s'étendent à toutes les notabilités du département. Les mariages des membres de cette société étaient fidèlement rapportés et donnaient lieu, pour Audiat et ses collègues, à la réalisation de savantes généalogies familiales, toujours très bien accueillies par les lecteurs.

Audiat et ses successeurs avaient par ailleurs, comme dans les autres sociétés savantes, organisé des sorties et excursions généralement appréciées, surtout lorsqu'elles permettaient d'avoir accès à des demeures privées ordinairement fermées aux visiteurs. Louis Audiat s'était déjà illustré, par ailleurs, dans des commémorations réussies, comme l'érection d'une statue au Saintais Bernard Palissy, en 1868, ou encore les fêtes de Samuel Champlain, à Saintes, en 1893, qui connurent une audience nationale et même internationale.

\section{La renaissance de la Société des archives historiques}

On conviendra facilement que la société a beaucoup changé depuis un siècle et que les supporters contemporains de la Société des archives historiques, pour reprendre un terme moderne, ne se recrutent plus dans l'aristocratie et la haute bourgeoisie saintongeaise. Il n'en demeure pas moins que la société, après avoir connu une période de long endormissement qui s'est étendue des années trente aux années quatre-vingtdix du siècle dernier, a retrouvé son dynamisme et le rythme de ses publications depuis une vingtaine d'années. Ce qui avait paru à l'origine une simple boutade du président du conseil général de l'époque : "La secte des érudits relance les Archives historiques ", est devenu une réalité, et la qualité des publications réalisées depuis vingt ans témoigne du travail accompli. Bien sûr, la société ne publie plus de bulletin, rôle dévolu désormais à la Revue de la Saintonge et de l'Aunis, organe de la Fédération des sociétés savantes de la Charente-Maritime, qui publie des travaux historiques depuis 1975, mais elle se consacre exclusivement à la publication de documents inédits. Son public, sans atteindre les sommets observés lors de la période faste du début du $\mathrm{xx}^{\mathrm{e}}$ siècle, reste stable; sans doute les adhérents n'attendent-ils pas avec impatience l'assemblée générale annuelle pour pouvoir bénéficier de la distribution du volume édité au cours de l'année ; du moins sont-ils heureux de participer aux sorties organisées deux fois par an, à la fin du printemps et au début de l'automne.

Quelles sont les raisons de ce renouveau? Il tient en premier lieu à l'existence d'un petit cercle d'érudits et de chercheurs locaux de bonne tenue qui, formés pour certains d'entre eux par Jean Glénisson ou ayant travaillé avec lui, se sont pris au jeu de la publication des documents. Ils ont été rejoints par des universitaires, et la collaboration ainsi mise en place permet la sortie de volumes irréprochables sur le plan scientifique. Des décimes ecclésiastiques aux comptes médiévaux, en passant par les visites pastorales des évêques de La Rochelle - celles de l'évêché de Saintes ayant été 
malheureusement détruites - de la correspondance des négociants de Cognac au XVIII ${ }^{\mathrm{e}}$ siècle aux mémoires des médecins des Lumières, le bilan des publications des vingt dernières années est éloquent et, en dépit de la diminution progressive puis de la disparition des subventions des collectivités publiques, la société continue à sortir un volume de 350 pages en moyenne par an.

21 La plupart des documents publiés sont conservés désormais dans les collections publiques, mais il s'agit souvent de documents mal connus ou mal identifiés, ou encore difficilement accessibles. Rappelons les torrides négociations rendues nécessaires pour la publication du dénombrement de 1685 portant sur la population, le bétail et les terres de lîle de Ré, malencontreusement conservé dans le fonds patrimonial de la médiathèque de Saintes, fermé depuis de nombreuses années déjà pour une mystérieuse opération de désinfection dont l'achèvement n'est toujours pas programmé. Plusieurs manuscrits récemment publiés sont conservés dans les institutions patrimoniales de la capitale, comme le manuscrit de la topographie médicale de la ville de La Rochelle, rédigée par le médecin Guillaume Martin Destrapières en 1777, conservé à la bibliothèque de l'Académie de médecine à Paris.

C'est ce bilan qui permet à la Société des archives historiques de retrouver aujourd'hui dans le domaine de la recherche historique relative aux deux anciennes provinces d'Aunis et de Saintonge la place qui a été autrefois la sienne au moment de sa fondation. En effet, elle participe directement à la constitution d'un corpus de textes qui, rendus désormais accessibles, deviennent, aujourd'hui plus que jamais, des textes de référence alimentant les recherches non seulement des érudits locaux mais également des chercheurs universitaires.

En dépit de leur diffusion limitée, les volumes des Archives historiques de la première période, qu'il s'agisse des volumes d'archives ou des bulletins, étaient déjà devenus des ouvrages de référence, et l'on peut affirmer sans exagérer qu'aucune étude historique sérieuse sur le département ne peut être effectuée sans avoir recours, à un moment ou à un autre, aux volumes de la Société des archives historiques de la Saintonge et de l'Aunis. Il en est aujourd'hui de même pour les volumes publiés depuis 1997. La numérisation par la Bibliothèque nationale de France, dans le cadre de la campagne de numérisation des publications des sociétés savantes, à la fois des volumes d'archives de la Société des archives historiques et de son bulletin, contribue évidemment à rendre plus accessibles encore les publications de la société, mais aussi à les faire connaître en France et à l'étranger ${ }^{14}$.

Chaque année, de nouveaux textes sont ainsi mis à la disposition de la communauté scientifique, et il n'y a aucune raison de penser qu'ils seront moins exploités que les précédents par les chercheurs universitaires. C'est un vœu que l'on peut formuler, mais nullement une certitude. En effet, si une université de plein droit a été créée à La Rochelle en 1993 par la volonté de Michel Crépeau, alors son maire et son député, les réformes successives introduites dans les enseignements ont sensiblement réduit le public universitaire qui s'adresse aux archives, c'est-à-dire aux matériaux de l'histoire. Il est loin le temps où l'on demandait aux étudiants en maîtrise de dépouiller une série de dossiers d'archives pour les "apprivoiser " à l'utilisation des sources manuscrites. Seuls les doctorants ont désormais un réel contact avec les documents, et le nombre des chercheurs en histoire médiévale et en histoire moderne a aujourd'hui considérablement diminué. Cette évolution n'est évidemment pas propre à l'université de La Rochelle ; force est de constater que la recherche historique dans notre pays tend 
aujourd'hui à se concentrer et à se limiter à quelques grands pôles qui disposent des ressources humaines et des compétences pour animer cette recherche.

De la même façon, l'enseignement de la paléographie a été tout aussi considérablement réduit, lorsqu'il n'a pas été purement et simplement supprimé, dans beaucoup d'universités petites et moyennes. Par conséquent, les étudiants éprouvent beaucoup de difficultés à lire les documents conservés dans les fonds patrimoniaux, et bien souvent les jeunes professeurs se trouvent tout autant démunis devant des manuscrits à l'écriture difficilement déchiffrable. Au-delà de ce constat peu optimiste, on peut s'interroger désormais sur l'utilisation à des fins universitaires des fonds anciens conservés dans les services d'archives ou des manuscrits des bibliothèques dans une grande partie du territoire, en particulier en dehors des métropoles régionales. On peut certes regretter une telle évolution, mais il paraît peu probable que de nouvelles orientations soient définies et adoptées dans ce domaine.

De fait, pour les chercheurs universitaires aussi bien que pour les érudits qui s'aventurent encore aujourd'hui dans des recherches sur l'histoire locale, l'existence d'un corpustel que celui que s'efforcent de constituer les sociétés de publication de documents présente un intérêt renouvelé. Ils disposent ainsi de sources qu'ils auraient bien de la peine à identifier dans les institutions patrimoniales et à utiliser.

Les sociétés de publication peuvent-elles, de ce fait, retrouver le rôle qui a été le leur au $\mathrm{XIX}^{\mathrm{e}}$ siècle et leur audience passée ? S'agit-il au contraire d'une illusion, d'un excès d'optimisme? Il est vrai que parler de recherche historique et de campagnes de publication de documents inédits par les sociétés savantes de province peut paraître en 2019 terriblement suranné. Maintenir de telles publications à l'ère du numérique parait quelque peu démodé, voire obsolète, et constitue un véritable défi renouvelé chaque année. Il n'en demeure pas moins qu'en poursuivant son travail d'édition de textes inédits - et dans ce domaine les sources ne manquent pas - la Société des archives historiques de la Saintonge et de l'Aunis, comme ses homologues, participe à l'élaboration de l'histoire locale et contribue, à la hauteur de ses moyens, à une meilleure connaissance du passé des deux anciennes provinces qui forment le département de la Charente-Maritime.

\section{BIBLIOGRAPHIE}

DUCHÊNE Hervé, « La comtesse dreyfusarde : à propos de la correspondance de Charlotte de La Redorte avec Salomon Reinach », Revue de la Saintonge et de l'Aunis, t. XXXVII, 2011, p. 143-164. FLOURET Jean, «Érudits rochelais contemporains de Louis Audiat », Revue de la Saintonge et de l'Aunis, t. XXXIII, 2007, p. 227-234.

JULIEN-LABRUYÈRE François, L'alambic des Charentes, Paris, Le Croît vif, 1989. 
JULIEN-LABRUYÈrE François " Audiat, homme de caractère ", Revue de la Saintonge et de l'Aunis,

t. XXXIII : «Actes du colloque Audiat », p. 183-192.

\section{NOTES}

1. Il serait souhaitable que le CTHS réactualise et rende publics les résultats de l'enquête qu'il avait lancée il y a quelques années sur les activités des sociétés de publication de documents inédits.

2. Sur le plan local, le lecteur pourra consulter les ouvrages suivants: F. JulienLabruyère, L'alambic des Charentes; Dictionnaire biographique des Charentais, notes sur les érudits.

3. F. Julien-Labruyère, L'alambic des Charentes, p. 66.

4. La Société des archives historiques du Limousin, créée en 1891, continue les deux collections lancées auparavant sous le titre d'« Archives historiques de la Marche et du Limousin » (1887) et des « Archives révolutionnaires de la Haute-Vienne » (1889).

5. La société publie 14 volumes à Poitiers, sur les presses de l'imprimeur Oudin, entre 1881 et 1958.

6. J. Flouret, «Érudits rochelais contemporains de Louis Audiat », p. 227-234.

7. La Société d'archéologie de Saintes, ancêtre de l'actuelle Société d'archéologie et d'histoire de la Charente-Maritime, avait été fondée en 1839 par plusieurs érudits saintais. La Société d'archéologie et d'histoire de la Charente-Maritime a été reconnue d'utilité publique en 1976.

8. La Commission des arts et monuments historiques du département de la CharenteInférieure a été créée à Saintes par arrêté préfectoral du $1^{\mathrm{er}}$ mars 1860 , conformément au vœu du conseil général du 25 avril 1859. Elle se composait de 30 membres titulaires et d'un nombre illimité de membres correspondants élus par la commission. Elle œuvrait pour la préservation des monuments du département et publiait dans son Recueil de nombreux travaux historiques. Ses statuts furent révisés en 1880.

9. L'Académie de La Rochelle a été créée en 1732. Après avoir été supprimée comme toutes les autres académies pendant la Révolution, elle se reconstitue sous le Premier Empire, mais ses activités restent limitées jusqu'au Second Empire, époque à laquelle la société littéraire, héritière de l'académie, fédère les différentes sociétés savantes locales, comme les sociétés d'agriculture, des sciences, des amis des arts, de la médecine... Après la Première Guerre mondiale, les différentes sociétés retrouvent leur indépendance.

10. La Société de littérature, sciences et arts de Rochefort avait été fondée en 1806 ; elle devint en 1834 la Société d'agriculture, littérature, sciences et arts de Rochefort. La Société de géographie, fondée pour sa part en 1879 , resta active jusque dans les années 1930, avant de trouver un nouveau départ en 1967.

11. Assez curieusement, un dernier volume, le $n^{\circ} 50$, consacré au censif du prieuré de Saint-Vivien-les-Saintes et édité par le docteur L. H. Hude, paraît en 1967 sur les presses de l'imprimerie Taffard, à Bordeaux.

12. F. Julien-Labruyère, « Audiat, homme de caractère ». 
13. H. Duchêne, «La comtesse dreyfusarde : à propos de la correspondance de Charlotte de La Redorte avec Salomon Reinach ».

14. Actuellement sont disponibles sur Gallica les 50 volumes d'archives de la Société des Archives historiques de la Saintonge et de l'Aunis de 1874 à 1935 ainsi que les 24 numéros du bulletin, de 1876 à 1914.

\section{RÉSUMÉS}

Née d'une catastrophe documentaire, l'incendie de la bibliothèque de Saintes et de ses riches archives, la Société des archives historiques de la Saintonge et de l'Aunis, créée en 1874, a connu le sort de la plupart des sociétés savantes : croissance jusqu'à la Première Guerre mondiale, puis lent déclin et assoupissement jusqu'aux années 1990, qui l'ont vue renaître et reprendre ses publications. Mais au-delà des péripéties propres à toutes les sociétés savantes, on peut s'interroger sur le rôle que peut jouer aujourd'hui une société vouée à la publication de documents inédits, non seulement dans les travaux des érudits locaux mais également dans la recherche universitaire contemporaine. À une époque où dans les programmes universitaires, la recherche en histoire locale tend à s'effacer et où l'absence d'enseignement de la paléographie aboutit à rendre presque impossible le recours aux archives, de la période médiévale notamment, la mise à la disposition des chercheurs de nouvelles sources et la transmission de la mémoire locale constituent un véritable défi.

\section{AUTEUR}

\section{PASCAL EVEN}

Conservateur général honoraire du patrimoine, membre de la section Histoire du monde moderne, de la Révolution française et des révolutions du CTHS 
Savoirs oraux, savoirs écrits, archives 


\title{
Entre l'oral et l'écrit : la transmission des contes et récits populaires en Alsace
}

\author{
Marie-Noële Denis
}

À la mémoire de Marie-Claude Groshens

1 Il est de tradition d'admettre que la transmission de la littérature populaire s'est faite oralement, à la campagne, par la voix des conteurs, lors des veillées. Mais en fait l'écrit intervint très tôt dans la mémorisation des récits, contes et légendes. Dès le XIV siècle, les moines et les chroniqueurs, puis au XIX ${ }^{e}$ siècle les travaux des folkloristes, ont assuré une transmission écrite de ces textes.

\section{La tradition orale des contes et récits populaires}

2 Il est de coutume d'attribuer la tradition orale des contes populaires aux longues veillées d'hiver qui réunissaient tour à tour, dans l'une ou l'autre maison, tous les voisins d'un même quartier rural. En effet, le lieu par excellence du récit populaire était la veillée. Il s'agissait d'une forme particulière de sociabilité paysanne, qui touchait surtout les fermes d'élevage de montagne, et beaucoup moins les populations des villages et des vallées. Les invitations tournaient de ferme en ferme, pendant les longues soirées d'hiver. La fête n'était pas improvisée. La pièce à vivre (le pal dans les Vosges, la Stub en dialecte germanique) servait de cadre aux veillées. On préparait du pain, des brioches, et les invités arrivaient dès 5 heures du soir. Chacun s'activait: les hommes réparaient leurs outils, jouaient aux cartes et buvaient autour de la table, les femmes filaient ou travaillaient à des ouvrages de broderie ou de tricot autour du poêle, tous émondaient des noix. Souvent un conteur venait distraire la soirée avec un répertoire d'histoires merveilleuses ou fantastiques de l'ancien temps. Loups et sorcières étaient destinés à effrayer les jeunes filles qui repartaient ainsi chez elles sous la protection de leur galant. Mais cette transmission orale, par des personnes plus ou 
moins reconnues, était depuis longtemps soutenue par une transmission écrite, surtout en ville.

\section{Les exempla}

3 Les exempla sont des récits populaires recueillis et transcrits par les religieux à l'usage des grands prédicateurs, qui en assurent la diffusion. Les sermons de Geiler de Kaysersberg, qui prêchait à la cathédrale de Strasbourg, recueillis par Pauli, en sont un bon exemple. Ces contes moraux mettent en scène les différentes classes de la société du temps. Ils opposent maîtres et compagnons, bourgeois et domestiques. Les récits sur les femmes sont nombreux et le clergé même est ridiculisé. Ces histoires, diffusées oralement lors des prédications, se développent surtout après la Réforme et sont reprises par les conteurs.

\section{Les chroniques}

4 Dès la fin du XIV et jusqu'au XVIII ${ }^{e}$ siècle, les contes populaires vont s'inspirer des chroniques. Les chroniqueurs sont nombreux. On peut citer Closener (†1384 ?), Koenigshoven (1346-1420), Schadaüs (1384- $\uparrow$ ?), Schould Buheler, Trausch (1578-1636), Daniel Specklin (1536-1589), Künart (1589- $\uparrow$ ?), Kleinlauel, Schelter et A. Silbermann (1752-1797).

5 Il est difficile de distinguer, dans leurs textes, outre leurs propres inventions, les éléments populaires authentiques des vérités historiques. Mais il est un fait, par exemple, que les récits du Wasigenstein et la légende de Trebeta sont les témoignages d'un va-et-vient entre l'oral et l'écrit, entre le populaire et le savant.

6 Le combat des héros au Wasigenstein est considéré comme la version populaire du Waltharius, poème en latin du $\mathrm{x}^{\mathrm{e}}$ siècle, lié à la geste de Gauthier d'Aquitaine. Siegfried aurait été tué par Hagen dans les Vosges. Selon la deuxième légende, la ville de Strasbourg aurait été fondée par Trebeta, fils de Ninus, roi d'Assyrie. Pour fuir l'amour de sa belle-mère Sémiramis, Trebeta aurait pris un grand bateau avec ses serviteurs et abordé à l'embouchure du Rhin, où il aurait fondé Trèves, baptisée d'après son nom. Toutes sortes de peuples, parlant toutes sortes de langues, se joignirent à lui et construisirent successivement les villes de Cologne, Worms, Strasbourg et Bâle'

7 Closener et Koenigshoven cherchèrent à fixer la tradition historique à partir de textes écrits, de " on-dit » et de témoignages. Au XVIII ${ }^{\mathrm{e}}$ siècle, la recherche de la vérité se précise avec l'abbé Grandidier² (1752-1787). Toutes ces chroniques, où se mêlent à la fois récits légendaires et références savantes, sont récupérées de manière fragmentaire par les conteurs populaires, qui les diffusent oralement. Puis le goût des récits populaires en tant que tels apparaît et donne naissance à un genre littéraire nouveau.

\section{Un nouveau genre littéraire : les contes alsaciens}

Au début du XIX ${ }^{e}$ siècle, le mouvement romantique, influencé en Allemagne par Herder, réveille dans la classe moyenne et supérieure cultivée, en particulier dans les milieux protestants, le goût des expressions populaires. Une nouvelle littérature se crée, où les auteurs enchâssent des propos entendus dans la rue et des observations directes. Il 
fallait, dans un but politique, créer une communauté bien identifiée par une culture spécifique. Dès le milieu du XvIII ${ }^{\mathrm{e}}$ siècle, Schoepflin et son disciple Oberlin ${ }^{3}$, en rapport avec les milieux allemands et suisses, avaient initié ce mouvement. Arnold (1780-1829) avait déjà fourni aux frères Grimm des contes alsaciens pour leur propre recueil, et Jacob Grimm entretint toute sa vie des relations avec les intellectuels de la région, notamment avec le jeune pasteur Auguste Stoebler (1808-1884). Celui-ci publie en 1836 un petit recueil de légendes, avec des compléments de son frère Adolphe, Alsa-Bilder. En 1842, un recueil plus ample portera le titre de Elsässisches Sagenbuch; puis paraîtra de 1852 à 1858 Die Sagen des Elsasses, légendes et traditions d'Alsace pour la première fois recueillies et expliquées d'après les souvenirs du peuple, chroniques et autres sources imprimées ou manuscrites ${ }^{4}$.

9 Auguste Stoeber travaille scientifiquement, dans l'esprit des frères Grimm, avec l'aide de l'archiviste-bibliothécaire Louis Schneegans, et applique leur principe de fidélité : ne rien ajouter à ce qui a été recueilli « de la bouche même du peuple». En fait, il combine aux souvenirs des conteurs les récits des chroniqueurs. Il y a aussi chez lui une part de reconstitution à partir de la tradition orale, bien que son style essaye de se conformer à l'expression populaire de son temps.

Du côté catholique, l'abbé Braun publie les Légendes du Florival en $1866^{5}$ et l'abbé Kramer le manuscrit Contes s'il en fut en 1848.

11 Les folkloristes ont contribué à réinjecter leur littérature dans le corpus des contes populaires. Les thèmes des chroniqueurs, qui se présentaient sous forme de longs récits, ont été découpés par eux en courts textes légendaires. Leurs recueils vont être le conservatoire de la littérature orale populaire, à laquelle ils assurent ainsi une matérialité.

12 Certaines catégories de population, surtout urbaines mais pas seulement, produisirent aussi à cette époque des textes diffusés oralement : pamphlets, complaintes, chansons de métiers, chroniques, légendes hagiographiques. Dans les campagnes, les colporteurs et les vagabonds, nombreux au $\mathrm{xIX}^{\mathrm{e}}$ siècle, vendent des petites feuilles appelées « canards ». Des lectures collectives ont lieu sur les places des villages. Les complaintes sont reprises chaque jour dans un nouveau lieu, transformées par les rencontres, par le public, par le chanteur, réécrites le soir à l'auberge. C'est la prise de parole du monde des paysans, des artisans des bourgs, du peuple des villes, parole populaire s'il en est. À Strasbourg, les échanges sont constants entre peuple et lettrés.

\section{Des formes modernes de transmission au $\mathrm{XX}^{\mathrm{e}}$ siècle}

\section{L'édition}

$13 \mathrm{Au} \mathrm{Xx}^{\mathrm{e}}$ siècle, on observe une pléthore, aussi bien régionale que nationale, dans l'édition des contes et récits populaires. Jean Variot publie en 1936 les Contes populaires et traditions orales de l'Alsace, qui sont en partie une traduction française des textes d'Auguste Stoeber. Après lui, les auteurs les plus connus furent Joseph Lefftz, qui a publié des récits en dialecte dans la revue Elsassland de 1924 à 1935, Anselme Pfleger, qui a écrit en allemand pour cette même revue, en 1939, et en français dans la Revue d'Alsace. Des éditeurs nationaux sont intéressés, comme en témoignent les Contes et légendes d'Alsace ${ }^{6}$ parus chez Nathan en 1957 et les volumes de la collection « Récits et 
contes populaires » chez Gallimard en $1979^{7}$. Dans cette très abondante littérature, les textes souvent se copient les uns les autres.

\section{Les nouveaux médias}

14 Les médias modernes vont donner une nouvelle chance à la littérature orale, inspirée, en grande partie de ces éditions. Ils vont favoriser la naissance d'une nouvelle forme d'oralité. La chaîne de radio régionale créée en 1945 pour assurer la réintégration de l'Alsace à la France va développer le genre à travers les émissions de Martin Alheilig. La chaîne de télévision régionale FR3 Alsace (créée en 1975) en prendra le relais avec des émissions consacrées aux arts et traditions populaires. Radio et télévision assureront la diffusion des nombreux recueils de contes, récits et légendes édités jusque-là.

\section{Qu'en est-il aujourd'hui de la littérature orale ?}

15 Si l'on a pu se réjouir récemment d'un regain d'intérêt pour les conteurs professionnels sollicités par les écoles, les théâtres et les centres culturels, quels sont aujourd'hui les authentiques informateurs de la littérature orale populaire ? À Strasbourg, nous avons rencontré sur ce thème ${ }^{8}$ des agents du tourisme relativement marginaux, comme un sacristain de la cathédrale, le rédacteur d'un guide de Strasbourg, et de vieilles Strasbourgeoises de souche appartenant à la bourgeoisie protestante. À la campagne, les personnes compétentes sont aussi des gens instruits et âgés: institutrices, religieuses, et plus généralement les habitants de forte tradition catholique ou protestante. Leur inspiration doit beaucoup à des récits de tradition orale locale, qui s'appuient sur des éléments immuables de leur environnement: châteaux forts, fontaines, pierres dressées, monuments divers. Les conteurs populaires se sont approprié ces récits. Les enquêtes contemporaines permettent de constater que les thèmes abordés, les longs textes des chroniques, se trouvent de nos jours fragmentés dans les catégories classiques de la littérature orale : contes, légendes, contes moraux ou facétieux, anecdotes, devinettes.

16 Cette réappropriation populaire se manifeste aussi par la langue. Les textes écrits au $\mathrm{XIX}^{\mathrm{e}}$ siècle le sont en allemand, les recueils plus récents généralement en français. Les conteurs contemporains les traduisent souvent en dialecte ou en patois vosgien (le welsche), leur redonnant ainsi une certaine authenticité.

17 On a accusé longtemps le curé, le pasteur et l'instituteur, qui luttaient contre la superstition, d'avoir accéléré la disparition de la littérature orale populaire, alors qu'ils ont été parmi les premiers folkloristes à s'y intéresser. On a accusé aussi la presse, la radio et la télévision de distraire leur public par une large ouverture sur le monde. Pourtant, les émissions régionales et les journaux tels que Elsassland, la Revue d'Alsace ou la Revue du Club vosgien ont œuvré pour la conservation et la transmission de ce type de récits.

On assiste néanmoins à la fin d'une culture locale ancienne. Les contes oraux supposaient un univers clos, immobile, où l'on disait dans les mêmes termes les mêmes récits, où chacun reconnaissait son identité dans une connivence réciproque. Les 
nouvelles formes de diffusion vers un large public sont différentes, mais donnent à penser que la littérature populaire, orale ou écrite, est en renouveau, dans une démarche d'affirmation d'une identité régionale forte. Enfin, l'expression orale ne doit pas être comprise comme une exclusion radicale de l'écrit. C'est grâce à un va-et-vient continu entre les deux modes d'expression que perdure, depuis le XIve siècle, la transmission de ce type de récits jusqu'à nos jours.

\section{BIBLIOGRAPHIE}

BRAUN Charles (abbé), Légendes du Florival ou la mythologie allemande dans une vallée d'Alsace, Guebwiller, impr. J. B. Jung, 1866.

GRANDIDIER Philippe André (abbé), Essais historiques et topographiques sur la cathédrale de Strasbourg, Strasbourg, Berger-Levrault, 1762.

GROSHENS Marie-Claude, DENIS Marie-Noële, LUCIUS Henriette, Récits et contes populaires d'Alsace, Paris, Gallimard, 1979.

GROSHENS Marie-Claude, DENIS Marie-Noële, LUCIUS Henriette, L'Alsace contée, Thionville, Klopp, 1986.

HINZELIN Émile, Contes et légendes d'Alsace, Paris, Nathan, 1957.

KOENIGSHOVEN J. T. von, Die älteste teusche, so wohl allgemeine, als insonderheit Elsässische und Strassburgische Chronik von Iacob von Königshoven, Strasbourg, Jonas Städd, 1698.

LIPOWSKY Günter et MORGEN Daniel, Die Sagen des Elsasses : les légendes d'Alsace, anthologie bilingue d'après Auguste Stoeber accompagnée d'une documentation complémentaire, Strasbourg, J. J. Do Bentzinger, 2009.

OBERLIN Jean-Jacques, Essai sur le patois lorrain, Strasbourg, J. F. Stern, 1795.

STOEBER Auguste, Elsässisches Sagenbuch, Strasbourg, Schuler, 1842.

STOEBER Auguste, Die Sagen des Elsasses : légendes et traditions d'Alsace pour la première fois recueillies et expliquées d'après les souvenirs du peuple, chroniques et autres sources imprimées ou manuscrites, SaintGall, Scheitlin und Zollikefer, 1858.

STOEBER Auguste, Légendes et traditions orales de l'Alsace, Paris, Grès, 1920.

STOEBER Auguste et STOEBER Adolphe, Alsa-Bilder : Vaeterlaendische Sagen und Geschichten, mit Anmerkungen, Strasbourg, 1836.

\section{NOTES}

1. J. T. von Koenigshoven, Die älteste teusche, so wohl allgemeine, als insonderheit Elsässische und Strassburgische Chronik von Iacob von Königshoven.

2. P. A. Grandidier, Essais historiques et topographiques sur la cathédrale de Strasbourg. 
3. J.-J. Oberlin, Essai sur le patois lorrain.

4. Au. Stoebler et Ad. Stoebler, Alsa-Binder; Au. Stoebler, Elsässisches Sagenbuch; Die Sagen des Elsasses.

5. C. Braun, Légendes du Florival.

6. É. Hinzelin, Contes et légendes d'Alsace.

7. M.-C. Groshens et al., Récits et contes populaires d'Alsace.

8. Dans le cadre des enquêtes pour l'édition des ouvrages Récits et contes populaires d'Alsace et L'Alsace contée, par M.-C. Groshens, M.-N. Denis et H. Lucius.

\section{RÉSUMÉS}

Il est de tradition d'admettre que la transmission de la littérature populaire se faisait oralement, à la campagne, par l'intermédiaire de conteurs, lors des veillées d'hiver. Mais l'écrit intervint très tôt dans la diffusion de ces récits. Ce fut le cas avec les folkloristes, nourris de romantisme et de "gothique » allemands, tel Auguste Stoeber (1808-1884), qui, à l'imitation des frères Grimm, se préoccupèrent de recueillir ce matériel inédit de manière scientifique et littéraire. En milieu urbain, le passage à l'écrit est encore plus ancien. Dès le XIV siècle, les chroniqueurs spécialistes de l'histoire légendaire les recueillent, tel Koenigshoffen (1346-1420), et jusqu'à l'abbé Grandidier (1752-1787). Il faut y ajouter les exempla illustrant les sermons oraux des grands prédicateurs, par exemple Geiler de Kaisersberg (1445-1510), qui prêchait à la cathédrale de Strasbourg. De nos jours, outre les multiples publications qui font office de conservatoire, le récit oral renaît par l'intermédiaire de nouveaux conteurs, qui maîtrisent la forme parlée de la narration et utilisent les canaux médiatiques modernes (la chaîne de télévision FR3 par exemple) pour diffuser largement leur savoir et recréer une communauté culturelle bien identifiée.

\section{AUTEUR}

\section{MARIE-NOËLE DENIS}

Chargée de recherche honoraire au CNRS 


\title{
Mémoires orales du canal de Suez
}

\author{
Philippe Joutard
}

1 L'Association du souvenir de Ferdinand de Lesseps et du canal de Suez est née en 1978, à l'initiative de Jacques Georges-Picot, dernier directeur général de la Compagnie universelle du canal maritime de Suez, puis président de la Compagnie financière de Suez. Arnaud Ramière de Fortanier, son président, décrit ainsi les activités de l'association :

« Il est apparu que l'œuvre de Ferdinand de Lesseps n'était pas une chose du passé, domaine des historiens, mais que le canal vivait en Égypte et, selon le vœu de son fondateur, continuait à accueillir, chaque jour, les navires du monde entier. Il est également apparu que cette œuvre était au plus haut point une réalisation francoégyptienne et que dès lors, au-delà d'antagonismes lointains dépourvus aujourd'hui de portée, le canal constituait un lien tangible entre les deux pays. C'est dans ces conditions que se sont instaurées des relations étroites avec l'Autorité du canal de Suez. L'association tient chaque année une réunion de son conseil d'administration à Ismaïlia, elle est reçue à la Résidence, elle est associée au projet de musée du canal à Ismaillia. De même, à Paris, une collaboration permanente unit l'association à

l'ambassade d'Égypte et, notamment, à son bureau culturel. »

2 À l'approche du cent cinquantième anniversaire de l'inauguration du canal de Suez, le 19 novembre 2019, l'association a lancé dès 2017 une grande enquête sur les mémoires orales du canal. L'histoire du canal de Suez bénéficie d'une bibliographie abondante et de grande qualité ${ }^{1}$; il ne s'agissait donc pas de prétendre la remplacer en offrant une autre vision. Plus modestement, cette enquête s'est proposé un double objectif: compléter les très riches archives sur le sujet confiées aux Archives nationales du monde du travail de Roubaix ${ }^{2}$ et accompagner, sous forme de courts documentaires de trois à six minutes, les expositions et manifestations qui doivent célébrer cet anniversaire, en particulier les expositions organisées par l'Institut du monde arabe à Paris et par le musée d'Histoire de Marseille, sans parler d'autres manifestations prévues en Égypte en 2019. Cette enquête s'est insérée dans le cadre du Centre d'études alexandrines ${ }^{3}$, qui en assure la logistique.

3 A-t-on besoin de rappeler l'intérêt des sources orales qui, en dialoguant avec les sources écrites et iconographiques, offrent une autre approche de la réalité ${ }^{4}$ ? Les mémoires ne doivent pas se confondre avec l'histoire, mais elles lui fournissent une 
matière précieuse et indispensable. Elles donnent la parole à des témoins et des acteurs qui n'ont pas l'habitude de s'exprimer; par l'oral, elles révèlent l'affectivité et l'imaginaire, créateurs d'histoire eux aussi, et qu'exprimera rarement l'écrit; sans oublier les représentations et le ressenti des acteurs, difficiles à percevoir par les sources classiques de l'historien. Certes, les mémoires peuvent aussi engendrer le légendaire, les déformations, véhiculer les rumeurs les plus folles; mais plus encore, elles manifestent une grande faculté d'oubli, voire d'occultation. Et leurs faiblesses bien connues, à condition de les repérer soigneusement et de les analyser rigoureusement, sont une chance pour mieux comprendre une sensibilité, une mentalité, une culture.

\section{Les conditions de l'enquête}

4 L'enquête a commencé en Égypte, en février 2017, au Caire, à Port-Saïd et à Alexandrie. Elle s'est continuée à Athènes en octobre de la même année, et s'est terminée à Paris en janvier et février 2018. La méthode utilisée a été celle de l'histoire orale, l'entretien semi-directif accompagné de l'observation participante couramment utilisée par les ethnologues. L'enquêteur prend soin de poser des questions très générales qui n'induisent pas la réponse et laisse parler librement son interlocuteur, n'intervenant que s'il s'éloigne trop du sujet de l'enquête, et admettant donc parfaitement les digressions significatives. Il s'intéresse aussi à l'environnement, au contexte, à l'implicite.

5 Au total, 48 personnes ont été enregistrées et filmées, 14 femmes et 34 hommes : 20 de nationalité égyptienne, dont 6 femmes ; 17 de nationalité française, dont 4 femmes ; 11 de nationalité grecque, dont 4 femmes aussi. Nées entre 1922 et 1945 (à une exception près), elles appartiennent à des milieux sociaux très variés, de cadres supérieurs à modestes ouvriers.

658 entretiens ont été réalisés, 2 personnes ayant été interrogées trois fois, et 7 interrogées deux fois. Chaque entretien, à de rares exceptions près, dépassait une heure. Inutile de préciser que nos interlocuteurs étrangers maîtrisaient parfaitement la langue française. Lorsqu'il y avait le moindre doute, nous avons préféré utiliser la langue arabe, ce qui sera aussi utile pour présenter des versions adaptées au public égyptien.

7 L'entreprise a pu bénéficier de l'aide de M. Yehia El-Sadr, président des Anciens Ismaïliotes, fils du premier pilote égyptien ${ }^{5}$, né à Ismaïlia, profondément nourri de la mémoire du canal ; avant même notre rencontre, il animait un réseau Facebook sur les originaires d'Ismaïlia, avec des correspondants dans le monde entier. Non seulement il a fourni une mémoire très riche au cours de trois entretiens, mais il a à son tour interrogé en arabe plusieurs de ses compatriotes. Il nous a accompagnés aussi en Grèce, retrouvant avec émotion de très anciens camarades de classe. À ce propos, précisons que ces « vacances grecques » sont le résultat de notre séjour égyptien. Nous y avons pris conscience de l'importance du phénomène grec ${ }^{6}$ à la fois dans la longue durée de l'histoire du canal, mais à plus forte raison pour le temps court, avec le tournant capital de 1956.

8 Cette communication ne peut prétendre présenter la richesse des conclusions qu'offre déjà cette cinquantaine d'entretiens. Tout au plus s'efforce-t-elle de suggérer quelques 
pistes de réflexion. C'est un bilan très provisoire, qui devra être approfondi et peut-être même susciter d'autres enquêtes.

\section{«Une jolie mémoire »}

Une première réflexion doit être mise en avant : les mémoires orales du canal de Suez sont fortes et " heureuses ", quelle qu'en soit l'origine, égyptienne, française ou grecque. Elles entraînent des identités affirmées qui apparaissent sous différentes formes. Le phénomène est assez rare pour être souligné d'entrée de jeu. La plupart du temps en effet, les mémoires fortes naissent d'un traumatisme; ici, rien de tel. Même les moments dramatiques, en particulier la rupture de 1956, avec l'Expédition de Suez ${ }^{7}$, et à plus forte raison la Seconde Guerre mondiale, n'ont pas empêché la vision d'un monde privilégié, préservé, générateur d'une profonde nostalgie et d'une non moins grande identité. La facilité à faire parler nos interlocuteurs, leur plaisir à le faire, à proposer d'autres personnes, à conserver de nombreux témoignages de l'époque, sont autant de signes de cette mémoire heureuse. Une expression d'une interlocutrice grecque résume bien ce sentiment : " Nous possédons une jolie mémoire. »

C'est précisément en Grèce que nous avons le mieux perçu la force de cette identité. Les Grecs ayant vécu en Égypte ont créé une grande association de plus de trois mille personnes, l'Association des Égyptiens grecs; celle-ci possède en plein centre-ville d'Athènes de spacieux locaux sur plusieurs étages, avec un restaurant et un cuisinier égyptien (!). Elle organise chaque semaine différentes activités. Certes, les Grecs du canal de Suez ne sont pas les seuls, ceux d'Alexandrie sont aussi très présents et certainement plus nombreux ; mais les gens du canal compensent leur nombre moindre par leur dynamisme, se regroupant par ville: Port-Saïd, Port-Fouad, Ismaillia, Suez. Dans les locaux de l'association, une grande armoire vitrée montre des objets de mémoire. L'un des souvenirs les plus forts révélés par notre enquête, c'est le commentaire fait par le président du groupe de la ville de Suez sur la cloche de son école, soigneusement conservée. Il publie un bulletin diffusé dans le monde entier.

11 Tour à tour, chaque communauté de Grecs d'Égypte se met en scène. Ils ont même réussi à transmettre cette identité à certains de leurs enfants. Ils sont intarissables sur leur séjour sur le canal. Ces Grecs nous ont montré des photos, raconté des anecdotes et expliqué la place qu'ils ont tenue aussi bien avant 1956 que lors de la crise, pendant laquelle ils ont joué un rôle important, remplaçant les Français à côté des Égyptiens durant une dizaine d'années; le gouvernement grec leur avait d'ailleurs conseillé de rester. De tous les gens du canal, ils sont les meilleurs polyglottes, maîtrisant à côté de leur langue natale, le français, l'arabe et l'anglais, quand ce n'est pas l'italien. Un demisiècle plus tard, ils sont encore capables de parler arabe avec notre ami Yehia El-Sadr, qui réalise l'entretien sur l'esprit du canal dans cette langue. Il est vrai que cette diversité linguistique fut un atout puissant lors de leur retour forcé en Grèce en 1967, causé par le contexte international et la politique de Nasser, et suscita la jalousie des Grecs restés en Grèce, beaucoup moins préparés à l'ouverture au monde.

Cette mémoire heureuse, nous l'avons retrouvée chez les Égyptiens du canal, qui ont pourtant vécu la rupture de la gestion du canal et trois guerres successives, en particulier en 1956, l'« Expédition de Suez », menée par les Français, les Britanniques et les Israéliens. Peu de ressentiment, ni de rancœur : ainsi le trésorier de l'Alliance française, qui a vu à l'âge de douze ans sa maison détruite par les soldats anglais, nous 
raconta son histoire calmement; il en parlait pour la première fois. L'ensemble de nos témoins égyptiens explique tout aussi calmement comment ils ont déjoué les pronostics de la Compagnie de Suez en faisant fonctionner le canal sans la présence des "Occidentaux ». Les récits sont nombreux et détaillés sur la prise de pouvoir de la gestion du canal et sa réussite, y compris dans la négociation finale, ce qui avait déjà été confirmé dans un entretien plus ancien avec son responsable français, fondateur même de l'Association du souvenir de Ferdinand de Lesseps et du canal de Suez, JeanPaul Calon. Sur ce point, le sentiment de continuité l'emporte largement sur celui de rupture et de révolution.

13 Les Français eux-mêmes, qui ont pourtant connu un départ brutal et une rupture forte, ont une vision nostalgique de leur jeunesse au canal. Il est vrai qu'ils bénéficiaient de conditions de vie privilégiées et préservées : la Compagnie universelle du Canal maritime de Suez mettait à leur disposition des loisirs pour tous, même si la hiérarchie était présente dans ces activités. La rupture a été bien plus fortement ressentie dans le monde adulte, avec les conditions parfois brutales du retour en France. Les Français interrogés sont parfaitement lucides sur les limites de cette vie dorée : la société du canal restait fermée sur elle-même, sans lien profond avec le reste de l'Égypte, sinon avec Le Caire. Ainsi, ils nous ont indiqué que leurs parents n'étaient pas intéressés par la civilisation égyptienne, même la plus ancienne ; la plus grande partie d'entre eux n'était jamais allés en Haute Égypte. En revanche, des amateurs français de la génération suivante sont revenus plusieurs fois dans le pays, en s'intéressant aux différentes périodes de la civilisation égyptienne.

\section{Un cosmopolitisme totalement assumé}

14 Pourtant, si les gens du canal de Suez possèdent cette mémoire heureuse, ce n'est pas uniquement à cause du sentiment d'avoir vécu là une vie privilégiée, quel qu'ait été leur statut social ; c'est aussi pour avoir connu une expérience originale et unique, celle de la coexistence culturelle et religieuse. Vision idéalisée ? Sans doute, un peu. Mais les témoignages sont suffisamment nombreux, concordants, avec des détails concrets, des exemples précis, pour qu'il y ait une grande part de vérité dans cette impression.

Lorsque les gens du canal, adolescents, le traversaient à la nage par bravade, ils disaient qu'ils allaient d'Afrique en Asie et d'Asie en Afrique. Combien de fois avons-nous entendu cette phrase ! À Port-Saïd, le Dr Moussa nous expliquait que dans sa maison, toutes les religions étaient représentées; chacun assistait aux repas des fêtes religieuses des voisins, chacun goûtait les plats élaborés à cette occasion dans une concurrence joyeuse. À Ismaïlia, une Grecque, Tassoula, orthodoxe, participait à la rupture du jeûne de son amie musulmane, et celle-ci suivait volontiers la procession orthodoxe du Vendredi saint. La diversité culturelle et religieuse s'apprenait dans les escaliers des maisons, dans la rue et à l'école. Nous n'avons jamais eu besoin de le suggérer : le mot cosmopolitisme est apparu souvent au détour de la conversation, sans aucun sens péjoratif et comme un titre de gloire. Ce cosmopolitisme, que l'on voyait défiler chaque jour en regardant passer les bateaux de tous les continents. Voilà pourquoi aujourd'hui, les enfants du canal sont dispersés dans les quatre coins du monde, mais par nostalgie, beaucoup continuent à dialoguer par l'intermédiaire de Facebook. 
C'est une part importante révélée par les mémoires orales du canal de Suez. Ce n'est pas la seule. Nous aurions pu mettre en valeur des traditions orales qui remontent à cette époque légendaire, évoquer la Seconde Guerre mondiale avec les Français libres de Suez, revenir sur les pratiques de la Compagnie universelle du Canal maritime de Suez. Nous pourrons en parler à l'occasion de l'exposition au musée d'Histoire de Marseille, "Marseille et l'épopée du canal de Suez », du 19 octobre 2018 au 31 mars $2019^{8}$, et des rencontres de 2019.

\section{BIBLIOGRAPHIE}

ALMEIDA Fabrice et MARÉCHAL Denis (dir.), L’histoire orale en question, Paris, INA, 2014.

CROSNIER-LECONTE Marie-Laure, GHITANI Gamal, NAGUIB Amin (dir.), Port-Saïd : architectures XIX ${ }^{e}$-XX siècles, Le Caire, IFAO, 2006.

DALACHANIS Angelos, The Greek exodus from Egypt : diaspora politics and emigration (1937-1962), New York, Berghahn Books, 2017.

DESCAMPS Florence, L'historien, l'archiviste et le magnétophone : de la constitution de la source orale à son exploitation, Paris, Comité pour l'histoire économique et financière de la France, 2001.

GAUTHIER Gilles (dir.), L'épopée du canal de Suez, catalogue d'exposition, Paris, Gallimard / Institut du monde arabe / musée d'Histoire de Marseille, 2018.

JOUTARD Philippe, Ces voix qui nous viennent du passé, Paris, Hachette, 1983.

JOUTARD Philippe, Histoire et mémoires, conflits et alliances, Paris, La Découverte, 2015.

PARFOND Paul, Pilotes de Suez, Paris, France-Empire, 1957.

PIATON Claudine (dir.), Ismailia : architectures, Le Caire, IFAO, 2008.

PIATON Claudine (dir.), Suez : histoire et architecture, Le Caire, IFAO, 2011.

PIATON Claudine (dir.), L'isthme et l'Égypte au temps de la Compagnie universelle du canal maritime de Suez (1858-1956), Le Caire, IFAO, 2016.

PIQUET Caroline, La Compagnie du canal de Suez : une concession française en Égypte (1888-1956), Paris, Sorbonne université presses, 2008.

PIQUET Caroline, Le canal de Suez : une voie maritime pour l'Égypte et le monde, Paris, Erik Bonnier, 2018.

\section{NOTES}

1. Voir C. Piaton (dir.), Suez: histoire et architecture; L'isthme et l'Égypte au temps de la Compagnie universelle du canal maritime de Suez (1858-1956); Ismailia : architectures; 
C. Piquet, La Compagnie du canal de Suez: une concession française en Égypte (1888-1956) et : Le canal de Suez: une voie maritime pour l'Égypte et le monde; M.-L. Crosnier-Lecomte et al. (dir.), Port-Saïd : architectures XIX ${ }^{e}-\mathrm{XX} \mathrm{X}^{e}$ siècles.

2. L'association est propriétaire - en fait sinon en droit - des archives de la Compagnie financière de Suez, accumulées depuis sa création jusqu'en 1956, soit pendant cent ans. Ces archives ont été inscrites en 1997 sur le Registre de la mémoire du monde par l'Unesco. À ces archives s'ajoute une importante collection de tableaux, statues et maquettes, de documents, de lettres et de souvenirs.

3. Le Centre d'études alexandrines (CEAlex, unité de service et de recherche du CNRS), créé en 1990 avec le soutien du CNRS, du ministère des Affaires étrangères et de l'IFAO, a pour mission d'étudier l'histoire d'Alexandrie (Égypte) à travers tous les documents qui illustrent son destin exceptionnel.

4. Voir F. Almeida et D. Maréchal (dir.), L'histoire orale en question; F. Descamps, L'historien, l'archiviste et le magnétophone: de la constitution de la source orale à son exploitation; P. Joutard, Ces voix qui nous viennent du passé.

5. Voir P. Parfond, Pilotes de Suez.

6. Voir A.Dalachanis, The Greek exodus from Egypt: diaspora politics and emigration (1937-1962).

7. La crise du canal de Suez, parfois appelée Expédition de Suez, Guerre de Suez, Campagne de Suez ou Opération Kadesh, est une guerre qui éclata en 1956 en territoire égyptien. Le conflit opposa l'Égypte et une alliance actée par le protocole de Sèvres, formée par l'État d'Israël, la France et le Royaume-Uni, à la suite de la nationalisation du canal de Suez par l'Égypte le 26 juillet 1956.

8. Voir G. Gauthier (dir.), L'épopée du canal de Suez, catalogue d'exposition.

\section{RÉSUMÉS}

À l'occasion du $150^{\mathrm{e}}$ anniversaire de l'inauguration du canal de Suez (17 novembre 2019), l'Association du souvenir de Ferdinand de Lesseps et du canal de Suez a entrepris une enquête sur les mémoires orales du canal. L'originalité de ce travail est de croiser les souvenirs d'Égyptiens, de Français et de Grecs, hommes et femmes, de différentes générations et milieux sociaux, ayant vécu autour du canal des années 1940 à celles de 1970. La confrontation de ces mémoires différentes offre une surprenante convergence, autour d'une grande nostalgie («une jolie mémoire ", selon une informatrice), au-delà de quelques tensions, alors que la région a été profondément marquée par plusieurs conflits (Seconde Guerre mondiale, 1956, 1967 et 1973) et par un bouleversement institutionnel (nationalisation de la gestion du canal). Cette communication s'interrogera sur cette convergence. 
AUTEUR

PHILIPPE JOUTARD

Professeur émérite d'histoire moderne à Aix-Marseille Université 


\title{
Le Panthéon et la transmission des
} savoirs sur Marie Curie : enjeux et
apports d'une nouvelle forme de
médiation

\author{
Ginette Gablot
}

«Madame, à quelques pas d'ici, dans cette rue qui porte désormais le nom de vos parents, s'élèvent les deux pavillons de l'Institut du radium où s'acheva le destin de votre mère. [...] À une faible distance de là était l'humble hangar de la rue Vauquelin où fut isolé le radium. Entre ces deux lieux et le Panthéon, si proches les uns des autres, que de chemin parcouru, que d'épreuves et que de gloire ${ }^{1}$ !»

1 Ainsi s'adressait François Mitterrand, président de la République, à la fille de Pierre et de Marie Curie, Éve Labouisse-Curie, lors du transfert des cendres de ses parents au Panthéon, le 20 avril 1995.

\section{Le Quartier latin et la mémoire du couple Curie}

Dans le $5^{\mathrm{e}}$ arrondissement parisien, de la rue Cuvier, où Pierre Curie est né, à la rue qui porte son nom et celui de son épouse, ce quartier de la montagne Sainte-Geneviève consacré à l'enseignement et à la recherche recèle de nombreux lieux qu'ils ont fréquentés. Aujourd'hui, le public intéressé par l'histoire de ce couple célèbre n'a accès qu'au Panthéon et au musée Curie. Pour les plus curieux, le pavillon Curie de la rue Cuvier peut être visité sur demande grâce à l'association Parcours des sciences.

\section{Au Panthéon, la première femme honorée pour ses propres mérites}

Le 11 février 1992, dans un entretien avec le journaliste Bruno Mazure, Hélène Carrère d'Encausse, de l'Académie française, Simone Veil, député européen et Françoise Gaspard, chercheuse et écrivaine, commentaient le courrier qu'elles venaient d'adresser au président de la République pour que «soient honorées des femmes qui 
par leurs actions, leurs talents, leurs découvertes, ont servi la démocratie, le progrès ou les arts ${ }^{2}$ », et demandaient que Marie Curie (1867-1934) soit admise au Panthéon.

Trois ans plus tard, le transfert de ses cendres honora à la fois la femme et la science, et associa à ce geste Pierre Curie (1857-1906) « au même titre » que son épouse. En 2006, à l'occasion du centenaire de la mort de ce dernier, l'exposition consacrée à ce «savant précoce » reçut 1274000 visiteurs. Ceux qui venaient pour en savoir plus sur Marie Curie furent déçus, comme en témoigne le livre d'or ${ }^{3}$. Aujourd'hui, un seul des parcours proposés par le Centre des monuments nationaux, celui qui est consacré aux scientifiques dans le Panthéon, accorde une place spécifique au couple Curie.

\section{Un musée dans le laboratoire Curie}

5 En 1964, à la veille de la commémoration du trentième anniversaire de la découverte de la radioactivité artificielle par la fille de Marie Curie, Irène, et son mari Frédéric Joliot au laboratoire Curie de l'Institut du radium, les «anciens » décidèrent de créer un musée consacré à ces deux prix Nobel de chimie $1935^{4}$. Un lieu de mémoire destiné aux chercheurs de passage et aux scolaires était né. Il incluait également le laboratoire de chimie personnel de Marie Curie et le bureau directorial.

6 Au début des années 1990, face à la demande grandissante d'un public plus large, curieux et sensible à l'atmosphère du lieu, des visites guidées ont été mises en place. Ainsi que nous l'avons souligné en 1994 au musée des Arts et métiers dans le cadre du séminaire sur les lieux de mémoire, l'émotion ressentie devant les lunettes de vue utilisées par Marie Curie n'est pas différente de celle éprouvée devant la cafetière de Balzac, à Saché : qui oserait rompre le charme et dire qu'il n'a jamais lu le Lys dans la vallée ? À l'opposé, au musée Curie, le questionnement est de mise.

7 Aujourd'hui, les locaux de l'ancien laboratoire Curie, cédés en 1993 par l'université Paris VI à l'Institut Curie, abritent le musée Curie. Au terme de deux rénovations, « la figure de Marie Curie s'est propulsée à la tête du musée Curie, contraignant la figure des Joliot-Curie à rester dans la sphère étroite de la physique nucléaire ${ }^{5}$ ».

\section{"Parcours culturels à travers la recherche scientifique française sur la montagne Sainte-Geneviève »}

8 L'association Parcours des sciences est née en 1998 au terme d'une recherche-action ${ }^{6}$ soutenue par le ministère chargé de la recherche. Elle s'inspire de l'esprit des centres d'interprétation nord-américains et de celui des écomusées. Pour répondre à la demande de "science en contexte", son propos entremêle réseaux de compétences, lieux de convivialité, débats scientifiques, prises de position politiques et transformations urbaines. L'intérêt du public pour cette approche validée du point de vue historique ne s'est jamais démenti, pas plus que le souhait d'être accompagné par un conférencier ou de disposer d'un guide de promenade pour découvrir le quartier à son rythme.

9 L'offre de visites commentées reste fortement marquée par l'ancrage géographique d'origine de l'association. Les institutions et les grandes figures scientifiques du Quartier latin au $\mathrm{xx}^{\mathrm{e}}$ siècle, comme les Curie et les Joliot-Curie, y tiennent une très grande place. Au fil du temps, la figure de Marie Curie se popularise et s'étoffe, comme 
en témoignent les questions du public au fait des dernières parutions la concernant et qui suit l'actualité de la santé et du nucléaire. Sur 32 questions relevées en 2015 et 2016, 7 ont porté sur les travaux sur la radioactivité ; 7 sur les dangers de ces recherches; 5 sur l'enfance en Pologne de Marie Curie ; 4 sur son mari Pierre et leurs enfants ; 3 sur ses études à la Sorbonne ; 3 sur le traitement du cancer ; 2 sur la place faite aux femmes dans le monde universitaire et scientifique; 1 sur son action pendant la Première Guerre mondiale.

\section{Enjeux et apports d'une célébration} s'annonçait devait être l'occasion pour le Panthéon de rappeler les valeurs d'engagement de Marie Curie et de faire lien avec une institution de recherche proche, l'Institut Curie, et son musée. Pour Parcours des sciences, l'enjeu était d'offrir au public une approche originale de Marie Curie et de son temps et de mieux intégrer le Panthéon dans le territoire qui est le sien.

11 L'exposition rétrospective "Marie Curie, une femme au Panthéon ", préparée par le Centre des monuments nationaux et l'Institut Curie, était conçue comme «une immersion inédite dans l'univers scientifique, intime et familial [à la suite de laquelle le public est invité à visiter la crypte et] plus particulièrement le caveau VIII, où reposent Marie et Pierre Curie, et enfin à se rendre au musée Curie, situé à cinq minutes à pied ${ }^{7}$ ».

Pour sa part, l'association Parcours des sciences, en partenariat avec le Centre des monuments nationaux, proposait de bâtir une visite commentée intitulée "Marie Curie, le Panthéon et le quartier ». Dans la crypte, le propos du guide convoquerait tour à tour les «grands hommes" qui ont influencé les Curie ou qui les ont connus. La deuxième partie serait consacrée à la découverte de ce quartier gagné par la science.

\section{Qu'apporte à Marie Curie une visite commençant au Panthéon ?}

Dans la crypte, les influences et sympathies, voire les inimitiés qui ont pu exister au sein de «ce cercle des talents et vertus de la République » sont évoquées au regard des archives des Curie et des Joliot-Curie... et du plan du quartier !

Rien n'atteste que les Curie soient jamais entrés dans le Panthéon, qui faisait partie de leur paysage quotidien. Néanmoins, il n'est pas interdit de penser que le $1^{\mathrm{er}}$ juillet 1894 , Maria Skłodowska, qui habite à deux pas, remarque les tentures noires qui drapent le monument, où vont être conduits les restes du président de la République Sadi Carnot.

Revenons aux hôtes de cet "Élysée visible ${ }^{8}$ " mentionnés dans les écrits du couple Curie. Il y a fort à parier que Pierre, qui a cité Le Roi s'amuse ${ }^{9}$ dans son journal intime, se félicite de voir le Panthéon rendu au culte républicain à l'occasion de l'hommage rendu à Victor Hugo le $1^{\text {er }}$ juin 1885 . Émile Zola fait aussi partie du paysage intellectuel de Pierre, lui qui note à l'attention de Maria, retournée en Pologne pendant l'été 1894 : «J'ai lu Lourdes, de Zola. Quand mes parents auront fini l'ouvrage, je vous l'enverrai. J'y ai retrouvé vos propres opinions sur la religion ${ }^{10} »$. Plus tard, le couple Curie, qui fait partie du groupe des dreyfusards, compte parmi ses collaborateurs un filleul d'Alexandrine Zola, Albert Laborde. Dans ces conditions, on peut penser que la 
translation des cendres de Zola au Panthéon le 6 avril 1908 et le coup de feu tiré contre Alfred Dreyfus lors de la cérémonie n'échappent pas à Marie Curie. En ce qui concerne l'opinion de Marie Curie sur un autre hôte du Panthéon, Jean Jaurès, un seul indice : le post-scriptum d'une de ses lettres, adressée le $1^{\text {er }}$ août 1914 à sa fille Irène, en vacances en Bretagne : « Tu as vu que ce pauvre Jaurès a été assassiné. C'est triste et abominable ${ }^{11}$ ».

Pour ce qui est des savants, Marie Curie voit entrer au Panthéon deux personnalités qu'elle apprécie sans doute différemment. En 1907, Marie peut-elle oublier que Marcellin Berthelot, ce spécialiste de la thermochimie, a plusieurs fois douté de la qualité des travaux des "radioactivistes", allant jusqu'à envoyer un chercheur étranger de passage rencontrer Pierre Curie "pour faire une enquête et voir s'il n'y avait pas de fraude dans le dégagement de chaleur du radium ${ }^{12}$ " ? Rien de tel en 1933 avec Paul Painlevé, qui l'avait défendue lors des attaques portées contre elle en 1911 et qui, plus tard, comme membre du gouvernement, n'avait pas manqué de soutenir le laboratoire qu'elle dirigeait.

Après la mort de Marie Curie en 1934, deux amis proches du couple rejoignent le Panthéon en 1948: Jean Perrin, lauréat du prix Nobel de physique en 1926, qui l'a soutenue à la mort de Pierre, et Paul Langevin, plus célèbre aujourd'hui pour sa liaison avec Marie que pour ses travaux sur la théorie des électrons, la relativité, le magnétisme et le sonar développé à Toulon en 1917.

À la fin de la visite, qui se termine devant les caveaux du couple Curie, une question se pose. Toutes les personnalités illustres rencontrées ici ont en commun d'avoir fréquenté le Quartier latin. Elles sont de celles qui font que Mona Ozouf compare le Panthéon à "un musée $\mathrm{III}^{\mathrm{e}}$ République, une docte réunion de prix d'excellence ${ }^{13}$ ". Pourtant, Henri Poincaré et quelques autres savants éminents sont absents. À l'évidence, la qualité des travaux réalisés ne suffit pas pour être admis dans ce haut lieu de la mémoire nationale. Pour y accéder, il vaut mieux, semble-t-il, avoir été ministre, comme Berthelot, voire président du Conseil, comme Painlevé, ou engagé au nom de la science, comme Perrin et Langevin. Alors pourquoi y admettre les époux Curie?

Pour le public de nos visites, comme pour une grande partie de l'opinion, la décision d'honorer une femme " pour ses propres mérites " relève d'une obligation morale trop longtemps différée. Ce sentiment d'évidence oblitère la dimension politique du choix qui, sous la $V^{e}$ République, est l'apanage du président, après avoir été celui des parlementaires. Le projet de panthéonisation des années 1930, découvert dans les archives du musée Curie et dans celles d'Irène Curie à l'occasion de la préparation de cette visite, illustre bien le cadre d'une telle décision.

\section{Qu'apporte Marie Curie au Panthéon ? Le projet de transfert des années 1930}

20 Dès le lendemain de l'annonce de la mort de Marie Curie, le 4 juillet 1934, la presse parle déjà d'un éventuel transfert des époux Curie au Panthéon. Mais la "grande savante, [la] grande Française, qui avait pétri son idéal de patriotisme et d'humanité ${ }^{14}$ " veut être enterrée à Sceaux, près de son mari. Ce souhait suscite alors des propos calomnieux envers la défunte. Selon Le Journal,

"[Elle aurait] refusé tous les honneurs posthumes auxquels lui donnait droit la gloire d'avoir été la collaboratrice et la continuatrice de l'homme de génie que fut 
son mari. [...] En dépit de son penchant - qui fut assez vif - pour le pacifisme intégral et ses apôtres, [elle] n'oubliait certainement pas que la libération de sa patrie était due, pour une part assez importante, au chef des armées alliées. [...] C'est dans la volonté de ne pas se soumettre à l'usage, dans le mépris des hommages traditionnels, qu'il y a de l'orgueil - et un immense, me semble-t-il ${ }^{15}$. »

21

En réponse à ce billet, Ève Curie précise :

«L'idée qu'on lui destinât des honneurs posthumes [ne lui] avait même pas traversé l'esprit. De 1914 à 1918, délaissant ses travaux, elle s'était entièrement dévouée à son pays d'adoption ${ }^{16}$.»

À la rentrée, en première page de l'Excelsior du 14 septembre 1934, il est de nouveau question de la translation au Panthéon des cendres des époux Curie, qui aurait lieu en octobre suivant. Juxtaposée à cette information, la longue déclaration de Jean Perrin sur les « besoins immédiats de la recherche scientifique » est des plus explicites:

«Nous comptons bien demander prochainement à l'opinion, à l'occasion de l'hommage solennel que la nation va prochainement rendre à Marie Curie et à Pierre Curie, et comme le monument le plus digne d'eux qui puisse leur être élevé, de faciliter une souscription nationale analogue à celle de la Journée Pasteur, qui suffira, nous l'espérons, pour donner [...] les possibilités d'action désirables ${ }^{17}$. »

La mort de Marie Curie sert à médiatiser un objectif qu'un intertitre de l'article rend dans toute sa trivialité : il faut obtenir «dix sous par Français, par an, pour les recherches ".

La figure du couple Curie participe alors à la campagne en faveur de la science. Pas étonnant donc que ce projet de transfert au Panthéon réapparaisse sous le Front populaire. «Je veux savoir si le corps de votre mère va être transféré au Panthéon, et quand ${ }^{18}$ ", demande en 1936 Missy Meloney, l'amie américaine de Marie Curie, alors que Jean Perrin vient de remplacer la fille des Curie, Irène, au poste de sous-secrétaire d'État à la recherche scientifique.

\section{Un quartier qui requiert une médiation}

Le public inscrit à la visite "Marie Curie, le Panthéon et le quartier » souhaite découvrir un quartier méconnu, que Marie Curie a vu se transformer avec la construction de la Nouvelle Sorbonne et de son annexe rue Cuvier, la démolition du couvent des Dames de Saint-Michel qui a laissé place à « une cité scientifique » - le futur campus Curie -, l'ouverture d'une rue portant le nom de son mari, et enfin avec la destruction du «hangar de la découverte " lors de l'agrandissement de l'École municipale de physique et de chimie industrielles (ESPCI aujourd'hui), que dirigeait Paul Langevin.

De nos jours, les cours anglaises de la rue Brossolette rappellent l'importance des professions ouvrières qui occupaient les ateliers à l'entresol des laboratoires. Rue Rataud, la plaque à l'emplacement des établissements Beaudouin, disparus en 1970, et les visuels que présente le guide lors de la visite font revivre les souffleurs de verre, les marchands de produits chimiques et les constructeurs d'appareils scientifiques sans qui l'activité des laboratoires aurait été impossible.

La visite du «campus Curie », où Marie Curie s'est installée en juillet 1914, permet de rappeler que son laboratoire accueillit de très nombreux chercheurs étrangers et qu'il était aussi ouvert aux jeunes femmes, comme celui de Jean Perrin, devenu son voisin en 
1926. Le parcours se termine par l'évocation de ces savants reconnus qui militèrent pour la reconnaissance du travail de recherche et participèrent à la campagne de sensibilisation du monde politique et de l'opinion publique aux besoins de la recherche scientifique, une campagne qui conduisit à la création du Centre national de la recherche scientifique en 1939.

Les treize visites du quartier effectuées de novembre 2017 à février 2018 ont rassemblé 251 personnes. Ce chiffre est tout à fait honorable, mais sans commune mesure avec la fréquentation très importante de l'exposition au Panthéon et au musée Curie. Ce succès dû à la volonté du Centre des monuments nationaux de mettre en avant une personnalité honorée dans la crypte s'inscrit pleinement dans la politique culturelle préconisée en 2013 par son président, Philippe Bélaval, pour «faire entrer le Peuple dans le Panthéon ${ }^{19}$ ".

Contrairement au public qui fréquente habituellement le monument, celui des visites de l'association Parcours des sciences était très majoritairement constitué de Français, actifs ou retraités, qui revenaient dans le monument, principalement motivés par le parcours en extérieur.

Les commentaires très favorables recueillis soulignent l'intérêt de s'appuyer sur les ressources de ce haut lieu pour renouveler, au plus près des archives, la saga propre à Marie Curie et offrir au public une médiation distincte de celle du Panthéon et des propositions du musée Curie. Commencer la visite par présenter Marie Curie au regard du Panthéon, pour mieux la suivre ensuite dans le quartier, introduit une réelle continuité entre un "monument que l'on contourne plus volontiers que l'on n'en franchit le seuil ${ }^{20}$ » et les rues qu'il domine. Pour le public d'admirateurs de Marie Curie et de curieux de science qui cherche à découvrir ce quartier scientifique méconnu, Marie Curie est une médiatrice.

\section{BIBLIOGRAPHIE}

BÉLAVAL Philippe, Pour faire entrer le Peuple au Panthéon : rapport à Monsieur le Président de la République, Paris, Présidence de la République, 2013.

BLANC Karin, Pierre Curie : correspondances, Saint-Rémy-en-l'Eau, Monelle Hayot, 2009.

EIDELMAN Jacqueline, GABLOT Ginette, BENOIT Serge, Parcours culturels à travers la recherche scientifique française sur la montagne Sainte-Geneviève, contrat MRES/CNRS n ${ }^{\circ} 93$ H 6332, Paris, Parcours des sciences, 1996, 2 vol.

LANGEVIN-JOLIOT Hélène et BORDRY Monique (dir.), Marie Curie et ses filles, Paris, Pygmalion, 2011. Ozouf Mona, « Le Panthéon : l'École normale des morts », dans Pierre Nora (dir.), Les lieux de mémoire, t. I : République, Paris, Gallimard (Bibliothèque illustrée des histoires), 1984, p. 139-166. 
SAURIER Delphine, La fabrique des illustres : Proust, Curie, Joliot et lieux de mémoire, Paris, Non Standard (SIC Recherches en sciences de l'information et de la communication), 2013.

\section{NOTES}

1. F. Mitterrand, extrait du discours prononcé lors du transfert des cendres des époux Curie au Panthéon le 20 avril 1995, disponible sur https://fr.wikisource.org/wiki/ Discours_du_transfert_des_cendres_de_Pierre_et_Marie_Curie_au_Panthéon_(consulté le 21/01/2018).

2. Institut national de l'audiovisuel, images d'archives, journal télévisé de la chaîne Antenne 2, 11/07/1992. Disponible sur: https://www.youtube.com/watch? v=D_8FZutyyiw (consulté le 5/05/2017).

3. Centre des monuments nationaux, «Pierre Curie, l'homme, le scientifique : bilan», non paginé, coll. part.

4. D. Saurier, La fabrique des illustres : Proust, Curie, Joliot et lieux de mémoire, p. 47.

5. Ibid., p. 214.

6. J. Eidelman et al., «Parcours culturels à travers la recherche scientifique française sur la montagne Sainte-Geneviève ».

7. Centre des monuments nationaux / musée Curie, dossier de presse, 9 octobre 2017.

8. Quatremère de Quincy, cité par M. Ozouf dans «Le Panthéon: l'École normale des morts ", p. 150.

9. Pièce de Victor Hugo ; voir K. Blanc, Pierre Curie : correspondances, p. 21.

10. Ibid., p. 55.

11. Lettres, Marie Curie et ses filles, p. 53.

12. Ibid., p. 457, 275-276.

13. M. Ozouf, «Le Panthéon : l'École normale des morts ", p. 140, même si ces "grands hommes » n'ont pas tous fréquenté la rue d'Ulm.

14. Arch. musée Curie, RDP-PMC/1934, 5 juillet 1934, Paris-soir.

15. Arch. musée Curie, RDP-PMC/1934, 9 juillet 1934, Le Journal ; C. Vautel, « Mon film ».

16. Arch. musée Curie, RDP-PMC/1934, 11 juillet 1934, Le Journal, È. Curie.

17. Arch. musée Curie, RDP-PMC/1934, J. Perrin, «Ce que sont en France les besoins immédiats de la recherche scientifique ".

18. BNF / musée Curie, arch. Irène Curie, I 46, dossier Co pr USA, fol. 10 ; lettre de $\mathrm{M}^{\text {me }}$ Meloney à I. Curie, 14 octobre 1936 : «I want to know if your mother's body is to be moved to Pantheon, and when?".

19. P. Belaval, Pour faire entrer le Peuple au Panthéon: rapport à Monsieur le Président de la République.

20. Ibid., p. 7. 


\section{RÉSUMÉS}

La visite commentée « Marie Curie, le Panthéon et le quartier », créée en 2017 par l'association Parcours des sciences, avait pour enjeu d'offrir au public une approche originale de Marie Curie et de son temps et d'intégrer le Panthéon dans le territoire de la montagne Sainte-Geneviève du Quartier latin, dans le $5^{\mathrm{e}}$ arrondissement de Paris. Dans la crypte, de Victor Hugo à Paul Langevin, la mémoire des " grands hommes » présents dans divers fonds d'archives permet d'esquisser un réseau d'influences et de sympathies qui interpelle les savoirs et les représentations de Marie Curie. Sur cette base, le public s'engage ensuite à explorer ce quartier marqué par la recherche scientifique au $\mathrm{Xx}^{\mathrm{e}}$ siècle. La découverte dans les archives d'une campagne de presse en faveur de la panthéonisation du couple Curie, menée de 1934 à 1936 par Jean Perrin, éclaire la procédure de la translation des cendres et rappelle le caractère politique de ces décisions. Admirateur de Marie Curie ou curieux de science, le public s'est inscrit pour découvrir un quartier qu'il connaît mal.

\section{AUTEUR}

\section{GINETTE GABLOT}

Ingénieur d'étude honoraire au CNRS 


\title{
Transmission des savoirs et
} pratiques des archives dans les familles nobles du Portugal d'Ancien Régime

\author{
Filipa Lopes
}

1 Depuis les années 90 du siècle dernier, les archives familiales sont un objet d'étude très prisé dans plusieurs pays européens ${ }^{1}$. Au Portugal, au cours de la dernière décennie, des progrès très importants furent réalisés dans l'étude de ce genre d'archives, soit dans le domaine de la recherche historique, soit dans celui de la recherche archivistique. Pour cela, deux groupes de chercheurs jouèrent un rôle clé : d'une part ceux qui étaient associés à la Universidade do Porto, et d'autre part ceux qui appartenaient à deux laboratoires de recherche de la Universidade Nova de Lisboa; ces derniers développèrent des recherches croisant les perspectives de l'histoire et celles de l'archivistique ${ }^{2}$. Ils se concentrèrent surtout sur l'étude des archives de familles nobles de l'Ancien Régime, c'est-à-dire d'ensembles de documentation produite, reçue et conservée par les familles nobles elles-mêmes et transformés par celles-ci en archives transmises à travers les générations jusqu'à la fin de l'Ancien Régime ou, parfois, jusqu'à aujourd'hui.

2 À partir de l'analyse des conclusions de ces recherches, ainsi que d'un ensemble d'inventaires d'archives de familles nobles portugaises qui furent étudiées dans le projet international Invent.arq ${ }^{3}$, nous nous proposons de faire une synthèse et une brève réflexion sur l'actuel état des connaissances sur la transmission des savoirs archivistiques et des pratiques d'archivage dans les familles nobles sous l'Ancien Régime au Portugal. Il ne s'agit pas d'exposer une théorie générale qui explique l'évolution de tous ces savoirs et pratiques depuis la fin du Moyen Âge jusqu'à la fin de l'Ancien Régime, ni d'une recherche exhaustive sur toutes les archives familiales connues au Portugal, qu'elles soient privées ou déposées dans les institutions publiques $^{4}$. 
3 En ce qui concerne la chronologie, nous nous concentrerons sur la période $\mathrm{XVI}^{\mathrm{e}}-\mathrm{XIX}^{\mathrm{e}}$ siècle; nous étendrons notre analyse à une période de transition allant de la Révolution libérale (1820) jusqu'à la décennie 1860, qui marque l'abolition des majorats ${ }^{5}$ (et des vincules en général), comme on le verra plus loin.

4 À partir des études citées, nous tenterons d'apporter une réponse aux questions suivantes : comment peut-on appréhender l'organisation de ces archives et identifier les savoirs qui lui sont sous-jacents? Qui organisait et inventoriait ces archives, quelle formation avaient-ils? Quels critères utilisèrent-ils? Quels furent les changements survenus avec la création d'une chaire de diplomatique annexe à l'Université de Coimbra et avec l'apparition des premiers experts paléographes à partir la fin du XVIII siècle? Quelle influence eurent-ils dans l'organisation de ces archives?

5 Cet article se divise en trois parties. La première est consacrée à une brève contextualisation des savoirs archivistiques et des pratiques d'archivage en général. La deuxième partie se tourne vers les premières pratiques d'archivage, la mobilisation et l'éventuelle transmission de savoirs dans les archives des maisons nobles au Portugal. La troisième se concentre sur les changements apportés sous l'influence des modèles rationalistes développés à partir des $\mathrm{XVII}^{\mathrm{e}}$ et $\mathrm{XVIII}{ }^{\mathrm{e}}$ siècles, sur le travail des premiers archivistes paléographes dans ces archives, ainsi que sur le contexte familial, économique et politique qui amena leur réorganisation à cette époque et au siècle suivant.

\section{Savoirs archivistiques et pratiques d'archivage : une brève contextualisation}

6 La constitution des premières archives dans les anciennes civilisations obéit à des formules intuitives, sans être influencée par la dimension technique ou conceptuelle qui marqua, en premier lieu, les règlements et la littérature « archivistique » après le $\mathrm{XVI}^{\mathrm{e}}$ siècle et, plus tard, l'archivistique scientifique à partir du xIX $\mathrm{x}^{\mathrm{e}}$ siècle. Selon $\mathrm{A}$. M. Silva et al., savoir et pratique étaient déjà étroitement liés à ces époques; avant l'existence de textes normatifs pour étayer les "savoirs archivistiques", ceux-ci existaient et ils s'exprimèrent lors de la première organisation systématique des documents, lors de la préparation des premiers étiquettes, listes et/ou inventaires ${ }^{6}$. Les mêmes auteurs soulignent que les premiers textes plus cohérents sur ces savoirs et ces pratiques, apparus aux $\mathrm{xVI}^{\mathrm{e}}$ et $\mathrm{XVII}{ }^{\mathrm{e}}$ siècles, furent - ce n'est pas par hasard - les règlements et les guides pratiques conçus par ceux qui travaillaient dans les chancelleries et les archives ${ }^{7}$. À partir de cette époque, la publication de manuels d'archivistique et de diplomatique ${ }^{8}$ permit une plus grande diffusion de ces savoirs et pratiques liés au rangement (l'organisation physique d'un ensemble de documents dans un certain lieu et dans une certaine "unité d'installation»), au classement (en choisissant des critères précis pour la division des documents en classes), à l'inventaire et à la cotation des archives.

$7 \mathrm{Au} \mathrm{xVI}$ siècle, à côté de l'administration centrale ${ }^{9}$, le fonctionnement des seigneuries laïques ou ecclésiastiques exigea aussi que les documents soient de plus en plus organisés en archives capables de répondre aux besoins de la gestion, dans un contexte de croissante complexité de la vie institutionnelle et économique et, par conséquent, d'accroissement de la production documentaire ${ }^{10}$. Des concentrations d'archives eurent 
lieu à cette époque non seulement dans les entités gouvernementales, qui encouragèrent la production de textes réglementaires ${ }^{11}$, mais aussi à cause des réformes institutionnelles de l'Église catholique post-Trente. Au cours de cette période, l'organisation de nombreuses archives privées atteignit des niveaux de qualité comparables à celle de l'administration centrale ${ }^{12}$. Le concept d'archive et les pratiques n'évoluèrent pas beaucoup, mais il y eut une maturation du système traditionnel d'organisation archivistique, une amélioration de la réglementation et la création de nouveaux instruments administratifs ${ }^{13}$. En tout cas, un critère de classification organique prédominait ${ }^{14}$.

8 Pendant les $\mathrm{XVII}^{\mathrm{e}}$ et $\mathrm{XVIII}^{\mathrm{e}}$ siècles, on commença à assister à des changements dans les méthodes de rangement et de classification, liés à une demande de plus en plus importante de conservation des archives, non seulement pour leur valeur première c'est-à-dire la valeur juridique et administrative -, mais aussi pour leur valeur secondaire, historique et culturelle. Il s'avère que diverses collections furent reclassées selon des critères thématiques. Il s'agit de classifications méthodiques, influencées bien évidemment par le rationalisme des Lumières, et qui altérèrent la structure originale des archives ${ }^{15}$.

9 Au Portugal, une fois ancré un ensemble de pratiques, développées au XviII siècle et fortement influencées par la tradition, il y eut a posteriori des tentatives de théorisation sur le rangement et le classement et la description des documents d'archive. A. Rodrigues et A. M. Silva ont étudié les propositions du moine bénédictin Francisco de São Luís (1766-1845) et de l'historien et diplomatiste João Pedro Ribeiro $(1758-1839)^{16}$.

10 Le premier a donné des conseils sur la préservation et le bon traitement des documents, recommandant un bon choix du lieu d'archivage et des modalités de stockage; il proposa un ordre et un "rangement méthodique " à donner aux titres. Pour le frère Francisco, les documents pouvaient être rangés selon quatre méthodes différentes : par thème, par ordre chronologique, par ordre géographique, ou selon un critère mixte, un mélange des précédents, qui serait dans la plupart des cas préférable. Le bénédictin appliqua ces principes aux chartriers de son ordre, ainsi qu'aux archives nationales, dont il fut le responsable (guarda-mor) entre 1834 et $1836^{17}$.

11 Quant à João Pedro Ribeiro, il étudia de près plusieurs archives locales et chartriers ecclésiastiques et proposa des méthodes de stockage pour éviter la détérioration des documents et un plan pour les ordonner. Pour cet érudit, la méthodologie devait s'adapter à la nature des actes et aux exigences de leur utilisation. Pour les documents en vrac, Ribeiro préférait le critère géographique, qui pouvait être combiné avec d'autres critères ; pour la documentation reliée, le classement devait être fait en accord avec la nature des livres (la thématique ou la typologie des documents) et par ordre chronologique. La dernière étape de l'arrangement du chartrier consistait à élaborer un index permettant l'accès et le contrôle de l'information ${ }^{18}$.

12 C'est en 1796 qu'une chaire de diplomatique fut créée à l'Université de Coimbra et confiée à João Pedro Ribeiro. En 1801, elle fut transférée à Torre do Tombo ${ }^{19}$. Cette discipline devint obligatoire pour tous ceux qui voulaient intégrer le service des archives royales ou exercer la fonction de notaire ${ }^{20}$.

13 Nous ne présenterons pas en détail toute cette évolution, mais donnerons un panorama général permettant de poser un ensemble de questions à propos de la transmission des 
savoirs archivistiques et des pratiques d'archivage dans les familles nobles sous l'Ancien Régime.

\section{Autour des premières pratiques d'archivage familial au Portugal}

L'organisation des archives seigneuriales - c'est le cas des archives de familles nobles est connue surtout à partir du xIV ${ }^{\mathrm{e}}$ siècle. À cette époque, l'affirmation d'une conscience généalogique, observée un peu partout en Europe occidentale, et l'émergence de formes successorales plus structurées, comme c'est le cas du majorat (morgadio) au Portugal, favorisèrent la conservation des documents familiaux ${ }^{21}$. La transformation de ces documents en archives, avec l'attribution de nouveaux usages, significations et fonctions au fil du temps, fut l'écho d'un changement et d'une complexification du fonctionnement des groupes familiaux, qui manifestèrent la conscience d'une identité et d'un projet commun partagé par ses membres ${ }^{22}$. En plus d'être des instruments d'administration et de gestion de la propriété, ces archives jouèrent également un rôle fondamental dans la réclamation de droits et de prérogatives, dans la sollicitation de grâces, charges et privilèges, dans l'exercice de fonctions professionnelles par ces membres, dans la transmission d'instructions ou codes de conduite aux descendants, et enfin dans l'affirmation de la mémoire, de l'identité et du pouvoir de ces groupes ${ }^{23}$.

À partir des cas étudiés, on peut conclure que la mobilisation de savoirs archivistiques et l'usage de certaines pratiques d'archivage, loin d'être une chose simple, uniforme et imitative, répondait à des besoins et à des circonstances particulières liées aux parcours sociaux des familles.

M. J. Sousa, dans son étude sur les archives de la maison de Belmonte ${ }^{24}$, essaya de comprendre l'organisation des documents des Figueiredos, entre le xvI siècle et 1722, la date du premier inventaire connu pour ces archives. Bien qu'elle n'ait pas pu dégager les critères régissant les tout premiers arrangements, elle se rendit compte que les documents étaient pliés et probablement rangés en liasses (maços), avec des notes apposées sur le verso, notamment de courts résumés permettant une identification rapide du contenu, et qu'à un certain moment des listes de documents de divers types commencèrent à être rédigées. C'est une forme d'organisation et de repérage de l'information assez répandue, utilisée déjà au Moyen Âge, par exemple, dans les chartriers ecclésiastiques ${ }^{25}$, et pratiquée aussi dans d'autres chartriers familiaux, comme celui de la maison de Mateus ${ }^{26}$.

Dans le cas de la maison de Mateus, il y eut une grande production documentaire dans la première moitié du XVII ${ }^{e}$ siècle, à cause des nombreuses acquisitions immobilières du chef de la maison et de l'institution du majorat de Mateus en 1643. Il existe des vestiges d'une première organisation du chartrier, coïncidant avec le registre d'un ensemble de terres dans des tombos ${ }^{27}$ au début du $\mathrm{XVIII}^{\mathrm{e}}$ siècle. Cette organisation utilisa le critère géographique et une numérotation fut ajoutée au verso des documents. Des index incomplets et des livres de comptes produits à cette époque montrent des entrées organisées selon ce critère ${ }^{28}$.

18 À mesure que le volume de documentation augmentait et que les archives devenaient plus complexes, il devint nécessaire de procéder à des réorganisations répondant à de nouvelles réalités - comme l'incorporation de nouvelles propriétés et majorats, le décès 
de chefs de famille et l'existence d'héritiers mineurs, les conflits à propos de l'attribution du statut de représentant de la maison, ou à propos de ses biens -, réalités parfois représentées dans les inventaires ou autres instruments de repérage d'information.

19 Contrairement à ce qu'on pourrait penser, les inventaires ne sont pas un miroir des archives; ils sont fréquemment des instruments véhiculant stratégies internes et externes, de reproduction, de défense des droits, d'accroissement du prestige, et somme toute, de pouvoir ${ }^{29}$. Néanmoins, ils sont une pièce du puzzle (et parfois la seule, quand les archives familiales ont été complètement dispersées ou perdues) qui peut nous donner accès aux modes d'organisation passés et aux modèles de représentation et de repérage des documents en vigueur au moment de leur production.

20 En ce qui concerne les pratiques d'inventaire, M. L. Rosa et R. C. Head soutiennent que, pour les cas déjà étudiés d'inventaires d'archives de familles nobles de l'Ancien Régime, il est difficile d'envisager une progression de ces pratiques par étapes. Comme pour les institutions ecclésiastiques, mais avec une chronologie plus tardive, on observe dans ces archives le passage d'une prédominance du modèle « inventaire-cartulaire » à celle du modèle "inventaire-liste de documents"; mais il est peu probable que cette tendance soit liée à une évolution purement technique, puisqu'on continue à trouver des documents mixtes coexistant encore longtemps avec ces listes ${ }^{30}$. Du XVI ${ }^{\mathrm{e}}$ siècle au début du XVII ${ }^{e}$ sont élaborés des livres contenant des copies d'actes authentifiés, comme celui de Rui Teles de Meneses, produit après 1583, ou le « cartulaire » de Pero Anes do Canto de 1515 ; parallèlement sont produits des listes comme le Catálogo do Cartório da Casa (autour de 1542) et des instruments plus complexes combinant listes et résumés de documents avec des récits historiques et généalogiques, comme le Livro da fazenda do senhor meirinho-mor (1588-1609) et la Tabuada do cartório da Casa de Sortelha (1609) ${ }^{31}$.

Il est souvent difficile de déceler qui furent les responsables de l'organisation des pièces d'archives ou de la rédaction des inventaires, surtout avant le XviII siècle. Il pouvait s'agir des seigneurs eux-mêmes, des administrateurs de leurs biens, ou de clercs, souvent proches de la famille ${ }^{32}$. Seule une étude approfondie de plusieurs archives familiales pourrait clarifier ce point, sachant qu'une certaine proximité avec la famille était importante, ainsi qu'une connaissance plus ou moins approfondie des biens et du territoire et des compétences en paléographie, en droit et en généalogie.

Il faut garder aussi en tête qu'une proximité de ces familles avec l'Église et le service du roi pouvait influencer leurs pratiques de gestion par l'écrit et les usages qu'ils faisaient de leurs archives (et, en conséquence, l'organisation qui leur fut donnée). C'était apparemment le cas de la famille Brito-Nogueira, qui possédait une importante tradition de pratiques de gestion par l'écrit quand elle s'allia avec les Limas. Le travail de réorganisation et de description des archives entrepris alors influença celui qui serait mené plus tard pour la maison des vicomtes de Vila Nova de Cerveira, selon une hypothèse en cours d'étude ${ }^{33}$. On retrouve cette même problématique dans le cas d'autres chartriers: comment l'incorporation d'archives bien organisées dans celles d'une famille sans tradition de gestion par l'écrit développée a-t-elle influencé les futurs rangements, classements ou inventorisations des archives de la maison qui les recevait? 


\section{Entre l'influence des modèles rationalistes et les besoins familiaux dans un monde en mutation}

Comme on l'a vu, à partir du XVII et du XvIII ${ }^{\mathrm{e}}$ siècle, le rationalisme émergent stimula une reclassification de la documentation pour des raisons de «bon ordre » - pour un accès rapide à l'information et pour une gestion optimale des familles - ou en raison d'un intérêt pour la dimension historique des documents. Au Portugal, ce mouvement émergea au sein des institutions religieuses ${ }^{34}$ et de là s'étendit progressivement aux grandes maisons nobles. A. M. Silva et A. Rodrigues soulignent que beaucoup de maisons réorganisèrent leurs chartriers à la lumière de cette littérature technique, en recourant souvent, à partir de la fin du XVIII ${ }^{\mathrm{e}}$ siècle, à des professionnels des archives, les experts paléographes ${ }^{35}$. On en connaît bien quelques exemples.

La maison de Bragança perdit une part considérable de ses archives pendant le tremblement de terre de Lisbonne en 1755 et les incendies qui suivirent. Pour cette raison, le roi Joseph $\mathrm{I}^{\mathrm{er}}$ demanda une copie des documents qui étaient à Torre do Tomboou dans d'autres lieux d'archivage du royaume et confirmant la possession de toutes les donations, biens et privilèges de la maison de Bragança. Ainsi commença en 1756 une importante réforme, avec Manuel António de Ataíde, qui ordonna les titres chronologiquement dans des codex thématiques en accord avec la typologie des documents : contrats, donations, forais ${ }^{36}$, etc. ${ }^{37}$

Le chartrier de la maison de Mateus fut lui aussi profondément réorganisé entre 1772 et 1798. Avec Luís António de Sousa Botelho Mourão furent créées les gavetas (tiroirs), un modèle d'organisation de la documentation administrative et des comptes, résultat du contexte d'ascension sociale des membres de la maison de Mateus, qui créa une augmentation exponentielle de la documentation concernant l'acquisition de propriétés, l'institution de majorats, l'occupation de charges de magistrats, d'ecclésiastiques ou de militaires dans le royaume et dans l'empire ${ }^{38}$.

Des raisons identiques, de caractère essentiellement administratif, mèneront la maison de Belmonte à une réorganisation de ses archives au début du XvII siècle, aboutissant à la préparation du premier inventaire connu de ce type d'archives, un instrument composé qui incluait en plus des listes de documents - classés géographiquement ou par typologie du document -, toutes les informations sur les propriétés, leurs revenus et leurs obligations ${ }^{39}$. Cet inventaire était probablement en vigueur jusqu'à la préparation d'un nouvel inventaire en 1807, à la veille des invasions françaises et du départ de la famille au Brésili ${ }^{40}$.

Dans ces deux cas, comme dans le chartrier de la maison de Povolide ${ }^{41}$, on assiste à l'adoption de l'armoire à tiroirs pour le stockage des documents, grâce à sa grande capacité et sa facilité d'accès. Les chartriers d'autres familles nobles suivirent ces tendances «rationalistes" dans leur organisation, comme la maison de Lafões ${ }^{42}$ ou la maison de Calheiros - une organisation avec des critères thématiques, appliquée encore au XVII ${ }^{\mathrm{e}}$ siècle ${ }^{43}$.

Il n'est pas toujours possible de savoir qui a conçu ces organisations. Il s'agissait probablement d'administrateurs ou de secrétaires des membres de la maison ou, surtout à partir de la fin du xviII ${ }^{\mathrm{e}}$ siècle, d'experts paléographes. Le prêtre João Filipe da Cruz (c. 1798-1827) était un de ces experts. Ayant suivi les enseignements de la chaire de diplomatique et composé un manuel sur ce thème, il espérait un poste aux archives 
royales, dont l'attribution fut reportée à cause des invasions napoléoniennes et de l'exil de la famille royale portugaise. Pour vivre, il travailla dans des archives privées et fit l'inventaire de sept archives familiales ${ }^{44}$. R. Nóvoa et M. Leme analysèrent une partie de son travail et conclurent qu'il ne pratiqua pas un unique modèle archivistique: il trouva des solutions multiples pour la réorganisation physique et/ou pour la préparation d'instruments de repérage d'information ${ }^{45}$. Ce spécialiste mit son expertise et son expérience archivistique au service de plusieurs maisons nobles; pourtant, malgré ses tendances rationalistes, le résultat final de ces arrangements et inventaires dépendit toujours des circonstances et des besoins de chaque maison.

Il en est de même pour Francisco de São Luís qui, dans la deuxième décennie du XIX ${ }^{\mathrm{e}}$ siècle, reclassa le chartrier de la maison de Sá. Les membres de cette maison avaient intérêt à bien connaître les documents pour mieux gérer les biens familiaux et pour valoriser l'héritage symbolique de la famille. Le travail fut réalisé vers 1811, après les invasions françaises, et lorsque l'administrateur était au Brésil. On utilisa une méthode mixte, avec des liasses thématiques qui contenaient des chemises ou des papiers cousus. Ce travail fut complété par la mise en place d'un index, qui se perdit ${ }^{46}$.

Dans le cas du chartrier de la maison de Lapa, le cistercien José de Almeida Vasconcelos ordonna le chartrier dans des liasses et des boîtes en carton, et produisit l'Index général (1804-1805) $)^{47}$, conçu pour avoir une fonction plus large que le simple accès et le repérage d'information. Cet instrument fournissait, en plus de la description et de la localisation des documents du registre, un récit historique, moraliste et politique sur les chefs et les membres des maisons en général ${ }^{48}$.

On constate qu'à la fin du XVIII et au XIX ${ }^{e}$ siècle, cette tendance est continue : intérêt des maisons nobles ou même obligation légale d'organiser des chartriers. Le contexte le demandait: à partir de 1769 sortirent les premières lois qui réglementaient et restreignaient le fonctionnement des majorats, et qui obligèrent les propriétaires à confirmer l'origine et la possession de plusieurs de leurs propriétés. Ainsi, l'un des principaux instruments disponibles pour garantir les moyens de subsistance et la cohésion de ces familles fut remis en cause. De la législation pombaline à la première législation libérale, ce processus fut mis en marche jusqu'à l'abolition totale des majorats en $1863^{49}$. Les familles recoururent à leurs archives pour se défendre contre les impositions de la Couronne, ce qui déclencha leur réorganisation. Un contexte spécifique peut créer une demande d'inventaire ou d'un autre instrument n'ayant pas une fonction directe de repérage, mais une fonction mémorielle, d'affirmation symbolique $^{50}$.

En fait, le majorat était au centre de nombreuses archives familiales et son importante production documentaire explique en grande partie la longue durée de vie de ces chartriers ${ }^{51}$. Plusieurs exemples d'archives et d'inventaires organisés qui donnent un relief particulier aux majorats peuvent être cités, comme celui de la maison des vicomtes de Vila Nova do Souto d'El-Rei en $1835-36^{52}$; les archives des Gama Lobo, réorganisées en partie autour de $1774^{53}$ en fonction des majorats et vincules existants ; du chartrier de Belmonte, l'inventaire déjà cité produit en $1807^{54}$. L'arrangement des archives des Castro-Nova Goa en est un cas représentatif : menacée de perdre ses majorats, la famille Castro, qui résidait en Inde depuis des siècles, se vit très probablement contrainte d'organiser (ou de reconstruire) ses archives; l'administrateur des biens, de retour au Portugal, demanda plusieurs copies pour faire la preuve des biens et des privilèges familiaux. La structure de l'inventaire produit dans 
ce contexte vers 1854-1864 nous donne la vision d'une organisation conditionnée par ces propriétés, leur nature et leur origine ${ }^{55}$.

Dans ce genre d'archives, on eut recours à des pratiques archivistiques multiformes. Les logiques qui sont derrière leurs organisations vont au-delà d'une simple évolution de la technique archivistique, des savoirs et des pratiques d'archivage. Il est important de les connaître et de comprendre les influences du milieu ecclésiastique ou même de l'administration centrale. Cependant, il faut mettre en évidence la "complexité sociale» de ces pratiques ${ }^{56}$ et les interpréter toujours en contexte. Comme le dit A. Rodrigues, reconstituer virtuellement ces arrangements et les comprendre implique $d^{\prime}$ '« entrer dans la sphère privée des familles ${ }^{57}$ ».

\section{BIBLIOGRAPHIE}

COELHo Maria de Fátima, " O instituto vincular, sua decadência e morte: questões várias », Análise Social, 16 (61-62), 1980, p. 111-131.

FREITAS Cristina, « Dos cartórios da Ordem Beneditina ao Real Archivo da Torre do Tombo: o périplo de Frei Francisco de São Luís Saraiva », Boletim do Arquivo da Universidade de Coimbra, 31 (1), 2018, p. 103-123.

GOMES Saul, In limine conscriptionis: documentos, chancelaria, cultura no mosteiro de Santa Cruz de Coimbra (séc. XII-XIV), Coimbra, Palimage, 2007.

HENRIQUES Luís et ROSA Maria de Lurdes, «O Arquivo da Casa da Lapa (1804-1832) e os seus inventários: gestão dos bens e memória dos antepassados ", Boletim do Arquivo da Universidade de Coimbra, 29, 2016, p. 89-132.

MARQUES Patrícia, «The Archive Castro-Nova Goa and its inventory: between proof and memory. A (re)construction of the 19th century ", dans Rosa Maria de Lurdes et Head Randolph C. (éd.), Family archives inventories, 15th-19th centuries: from management and proof to lost memories. Rethinking the pre-modern archive, Lisbonne, IEM, 2015, p. 89-95.

MORSEL Joseph, « Médiations ou déviations ? Les inventaires, entre archives et historiens », dans Rosa Maria de Lurdes et Head Randolph C. (éd.), Family archives inventories, 15th-19th centuries: from management and proof to lost memories. Rethinking the pre-modern archive, Lisbonne, IEM, 2015, p. 23-30.

NAVARRO BONILLA Diego, La imagen del archivo: representación y funciones en España (s. XVI y XVII), Gijón, Trea, 2003.

NóvOA Rita, « O Arquivo Gama Lobo Salema e a produção, gestão e usos dos arquivos de família nobre nos séculos XV-XVI ", thèse de doctorat en archivistique historique, Lisbonne, Faculdade de Ciências Sociais e Humanas da Universidade Nova de Lisboa, 2016. 
NóVOA Rita et LEME Margarida, «The expert paleographer João Filipe da Cruz (c.1798-1827) », dans Rosa Maria de Lurdes et Head Randolph C. (éd.), Family archives inventories, 15th-19th centuries: from management and proof to lost memories. Rethinking the pre-modern archive, Lisbonne, IEM, 2015, p. 77-82.

NóvoA Rita et Rosa Maria de Lurdes, «O estudo dos arquivos de família de Antigo Regime em Portugal: percursos e temas de investigação », Revista Brasileira de História, 38 (78), 2018, p. 75-95.

PESTANA Manuel Inácio, A reforma setecentista do cartório da Casa de Bragança, Lisbonne, Fundação da Casa de Bragança, 1985.

RIBEIRO Fernanda, "O acesso à informação nos arquivos ", thèse de doctorat en archivistique, Porto, Faculdade de Letras da Universidade do Porto, 1998.

RIBEIRo Fernanda, «O ensino da Paleografia e da Diplomática no curso de bibliotecárioarquivista ", dans Estudos em Homenagem ao Professor Doutor José Marques, vol. 2, Porto, Faculdade de Letras da Universidade do Porto, 2006, p. 47-63.

RODRIGUES Abel, « Entre o Público e o Privado: a génese do Arquivo do Conde da Barca (1754-1817) », mémoire de master en histoire, Braga, Universidade do Minho, 2007.

RODRIGUES Abel, «O Arquivo da Família Melo (Séc. XIV-XIX): do “arranjamento” iluminista à integração no Sistema de Informação Casa de Mateus ", dans Casa Nobre: um património para o futuro (Congresso Internacional Casa Nobre, 3, Arcos de Valdevez, 2011), Arcos de Valdevez, Câmara Municipal, 2013, p. 478-497.

RODRIGUES Abel, « Os arquivos pessoais e familiares em Portugal: uma reflexão crítica dos últimos vinte anos ", dans Actas do I encontro da Fundación Olga Gallego: arquivos privados de persoas e familias, Vigo, Fundación Olga Gallego, 2018, p. 31-50.

RODRIGUES Abel et SILVA Armando Malheiro da, « A criação das Gavetas na Casa de Mateus: um modelo iluminista de gestão da informação », dans Rosa Maria de Lurdes (dir.), Arquivos de Família, séculos XIII-XX: que presente, que futuro? Lisbonne, IEM / CHAM / Caminhos Romanos, 2012, p. 597-650.

ROSA Maria de Lurdes, O morgadio em Portugal, sécs. XIV-XV, Lisbonne, Estampa, 1995.

ROSA Maria de Lurdes, «Problemáticas históricas e arquivísticas actuais para o estudo dos arquivos de família portugueses (Épocas medieval e moderna) », Revista de História da Sociedade e da Cultura, 9, 2009, p. 9-42.

ROSA Maria de Lurdes, « Os espelhos e os seus outros lados. Inventários e gestão da informação documental do Viscondado de Vila Nova de Cerveira / Marquesado de Ponte de Lima e família Brito-Nogueira, séculos XV-XIX ", dans Rosa Maria de Lurdes (dir.), Arquivos de Família, séculos XIII-XX: que presente, que futuro? Lisbonne, IEM / CHAM / Caminhos Romanos, 2012, p. 571-596.

ROSA Maria de Lurdes et HEAD Randolph C. (éd.), Family archives inventories, 15th-19th centuries: from management and proof to lost memories. Rethinking the pre-modern archive, Lisbonne, IEM, 2015.

ROSA Maria de Lurdes et HEAD Randolph C., « Delineating the social complexity of archival practices : the objectives and the results of the INVENT.ARQ project on family archives inventories ", dans Rosa Maria de Lurdes et Head Randolph C. (éd.), Family archives inventories, 15th-19th centuries: from management and proof to lost memories. Rethinking the pre-modern archive, Lisbonne, IEM, 2015, p. 9-22.

SILVA Armando Malheiro da, RIBEIRo Fernanda, RAMOs Júlio, REAL Manuel (dir.), Arquivística: teoria e prática de uma ciência da informação, Porto, Afrontamento, 2009. 
SouSA Maria João, «O Arquivo da Casa de Belmonte, séculos XV-XIX: identidade, gestão e poder », thèse de doctorat en archivistique historique, Lisbonne, Faculdade de Ciências Sociais e Humanas da Universidade Nova de Lisboa, 2017.

VENTURA Isabel, « O Arquivo Paço de Calheiros: uma abordagem sistémica », mémoire de master en science de l'information, Porto, Faculdade de Letras da Universidade do Porto, 2011.

\section{NOTES}

1. M. L. Rosa, « Problemáticas históricas e arquivísticas actuais... », p. 24-25.

2. Sur l'état de ces recherches, voir R. Nóvoa et M. L. Rosa, «O estudo dos arquivos de família de Antigo Regime em Portugal...»; A. Rodrigues, «Os arquivos pessoais e familiares em Portugal... ».

3. Projet mené dans le cadre de l'Instituto de Estudos Medievais (Universidade Nova de Lisboa, 2014-2015). Les 36 inventaires et autres instruments de description archivistique étudiés, datant $\mathrm{du} \mathrm{XV}^{\mathrm{e}}$ au $\mathrm{XIX}^{\mathrm{e}}$ siècle, et leur description sont disponibles en ligne (http://www.inventarq.fcsh.unl.pt/index.php/), et dans le catalogue publié dans M. L. Rosa et R. C. Head (éd.), Family archives inventories..., p. 97-173.

4. On n'en connaît pas l'intégralité, car aucun recensement de ces archives n'a encore été fait au Portugal: R. Nóvoa et M. L. Rosa, "O estudo dos arquivos de família de Antigo Regime em Portugal... », p. 89.

5. Morgadio ou majorat: forme d'organisation familiale créant une lignée, régentée par un code pour désigner les successeurs, statuts et comportements. Un ensemble de biens fonciers ou de rentes était inaliénable et indivisible après la mort de son titulaire, et transmis en règle générale au fils aîné ou à d'autres successeurs désignés dans le document fondateur. La totalité de la propriété constituait un vínculo ou vincule, puisque ces biens étaient liés à la perpétuation du pouvoir économique, politique et symbolique de la famille dont ils faisaient partie, au cours des générations successives. Voir M. L. Rosa, O morgadio em Portugal, sécs. XIV-XV.

6. A. M. Silva et al., Arquivística: teoria e prática de uma ciência da informação, p. 45 et 93-94; pour un panorama diachronique de l'évolution de l'archivistique jusqu'au début du XIX ${ }^{\mathrm{e}}$ siècle, voir p. 45-100.

7. Ibid., p. 94.

8. Science qui a pour objet l'étude des documents officiels, en analysant leur structure interne et externe et sa variation au cours des époques, afin de déterminer leur authenticité.

9. A. M. Silva et al., Arquivística: teoria e prática de uma ciência da informação, p. 87.

10. Ibid., p. 91.

11. Ibid., p. 87-93. Pour le cas castillan, voir D. Navarro Bonilla, La imagen del archivo, p. 137-143.

12. A. M. Silva et al., Arquivística: teoria e prática de uma ciência da informação, p. 94-95.

13. Ibid., p. 79-81.

14. Ibid., p. 93 ; D. Navarro Bonilla, La imagen del archivo, p. 147.

15. F. Ribeiro, « O acesso à informação nos arquivos », p. 30. 
16. Voir A. Rodrigues et A. M. Silva, "A criação das Gavetas na Casa de Mateus... ", p. 599-617. Les auteurs y analysent Dois objetos se devem ter prezentes, quando se trata de qualquer cartório... du frère Francisco et les Observações historicas e criticas para servirem de memorias ao systema da diplomatica portugueza... (1798) de J. P. Ribeiro.

17. A. Rodrigues et A.M. Silva, "A criação das Gavetas na Casa de Mateus...", p. 599-601; C. Freitas, « Dos cartórios da Ordem Beneditina ao Real Archivo da Torre do Tombo... », p. 110-116.

18. A. Rodrigues et A.M. Silva, "A criação das Gavetas na Casa de Mateus...", p. 602-607.

19. Torre do Tombo était le nom d'une tour du château de Lisbonne où, à la fin du XIV e siècle, furent réunies pour la première fois les archives de la Couronne. Les archives furent déménagées après le tremblement de terre de 1755 qui détruisit la tour, mais l'institution responsable des archives conserva ce nom. À partir du xixe siècle, l'institution élargit ses fonctions et devint le site de conservation des archives nationales.

20. F. Ribeiro, « $O$ ensino da paleografia e da diplomática no curso de bibliotecárioarquivista », p. 50.

21. M. L. Rosa, « Problemáticas históricas e arquivísticas actuais... », p. 30-32.

22. R. Nóvoa et M. L. Rosa, "O estudo dos arquivos de família de Antigo Regime em Portugal... ", p. 83.

23. Ibid., p. 83-84 ; M.L. Rosa et R.C. Head, «Delineating the social complexity of archival practices... ", p. 10-14.

24. M. J. Sousa, «O Arquivo da Casa de Belmonte... », p. 220-226.

25. Voir l'exemple du chartrier du monastère de Santa Cruz de Coimbra, étudié dans

S. Gomes, In limine conscriptionis: documentos, chancelaria, cultura no mosteiro de Santa Cruz de Coimbra (séc. XII-XIV), p. 263.

26. A. Rodrigues et A. M. Silva, "A criação das Gavetas na Casa de Mateus... », p. 619.

27. Tombos: inventaires authentiques contenant la description des biens immobiliers, notamment leurs démarcations.

28. Ibid., p. 620-621.

29. J. Morsel, "Médiations ou déviations? Les inventaires, entre archives et historiens », p. 26-28.

30. M.L.Rosa et R.C.Head, " Delineating the social complexity of archival practices... ", p. 15-21.

31. Les descriptions sont disponibles ici: http://www.inventarq.fcsh.unl.pt/ index.php/, et dans M. L. Rosa et R. C. Head (éd.), Family archives inventories..., p. 102, $108,114,116$ et 120 .

32. Ibid., p. 120 ; l'auteur de cet inventaire fut un prieur, proche de la maison de Sortelha. C'est probablement aussi le cas pour le Catálogo do Cartório da Casa: voir M. L. Rosa, «Os espelhos e os seus outros lados... », p. 593.

33. Pour une étude préliminaire, voir ibid., p. 591-596. Nous sommes en train d'approfondir l'étude de ces archives en doctorat.

34. F. Ribeiro, " $O$ acesso à informação nos arquivos", p. 358-449. Les chartriers bénédictins sont ainsi réformés, en particulier dans le dernier quart $\mathrm{du} \mathrm{xVIII}^{\mathrm{e}}$ siècle, 
ainsi que le chartrier du chapitre de la cathédrale de Braga dans la seconde moitié du siècle. Pour les institutions de l'État, Manuel da Maia réforme les archives de Torre do Tombo par la création du Corpo Cronológico (A. Rodrigues et A. M. Silva, «A criação das Gavetas na Casa de Mateus... », p. 611-613).

35. Ibid., p. 614.

36. Foral (pl. forais) : document délivré par le roi ou par un seigneur laïc ou ecclésiastique à une ville ou un village; il établissait les relations entre les habitants de la communauté et ceux de l'entité qui octroyait le document, en stipulant les privilèges et les devoirs de chacun. Il pouvait également réglementer les relations entre le cheflieu de la ville et son termo (l'espace autour de la ville qui dépendait de sa juridiction).

37. M. I. Pestana, A reforma setecentista do cartório da Casa de Bragança, p. 14, 27-33.

38. A. Rodrigues et A.M. Silva, "A criação das Gavetas na Casa de Mateus... », p. 617-627.

39. M. J. Sousa, «O Arquivo da Casa de Belmonte, séculos XV-XIX... », p. 234-235.

40. Ibid., p. 261-263.

41. Ibid.,p. 243-244.

42. A. Rodrigues et A. M. Silva, " A criação das Gavetas na Casa de Mateus... », p. 615.

43. I. Ventura, « $O$ arquivo Paço de Calheiros: uma abordagem sistémica », p. 39.

44. R. Nóvoa et M. Leme, "The expert paleographer João Filipe da Cruz (c. 1798-1827)»; A. Rodrigues, «O arquivo da família Melo (séc. XIV-XIX)... », p. $480-483$.

45. R. Nóvoa et M. Leme, «The expert paleographer João Filipe da Cruz (c. 1798-1827) », p. 81.

46. Sur la méthodologie appliquée dans la réforme du chartrier de la maison de Sá, voir A. Rodrigues, Entre o público e o privado..., p. 127-137, notamment le tabl. 2.

47. L. Henriques et M. L. Rosa, "O Arquivo da Casa da Lapa (1804-1832) e os seus inventários... ", p. 92-102.

48. Ibid., p. 94.

49. M. F. Coelho, « O instituto vincular, sua decadência e morte: questões várias ».

50. M. L. Rosa et R.C.Head, " Delineating the social complexity of archival practices... », p. 18-21.

51. Ibid., p. 10.

52. La description de l'inventaire est disponible ici : http://www.inventarq.fcsh.unl.pt/ index.php/indice-geral-do-cartorio-do-visconde-de-vila-nova-do-souto-do-rei.

53. R. Nóvoa, «O Arquivo Gama Lobo Salema... », p. 50-51.

54. M. J. Sousa, «O Arquivo da Casa de Belmonte... », p. 259-277.

55. P. Marques, «The Archive Castro-Nova Goa and its inventory... ", p. 89-94.

56. M. L. Rosa et R.C.Head, «Delineating the social complexity of archival practices... », p. 15-21.

57. A. Rodrigues, « $O$ arquivo da família Melo... », p. 492. 


\section{RÉSUMÉS}

Nous proposons une brève réflexion sur la transmission de savoirs archivistiques et les pratiques de gestion des archives des familles nobles sous l'Ancien Régime au Portugal. Comment peut-on appréhender l'organisation de ces archives et identifier les savoirs sous-jacents? Qui organisait et qui inventoriait ces archives? Quelle formation avaient ceux qui s'en chargeaient, quels critères utilisèrent-ils ? Quels furent les changements survenus avec la création d'une chaire de diplomatique annexe à l'université de Coimbra et l'apparition des premiers experts paléographes à partir de la fin du XVIII ${ }^{\mathrm{e}}$ siècle, quelle influence eurent-ils dans l'organisation de ces archives ? Pour essayer de répondre à ces questions, on privilégiera l'analyse des conclusions des recherches qui, au cours de la dernière décennie, furent réalisées sur ce genre d'archives au Portugal.

\section{AUTEUR}

\section{FILIPA LOPES}

Chercheur à la Universidade Nova de Lisboa, Instituto de Estudos Medievais, Centro de Humanidades (CHAM - FCSH/NOVA-UAç) et à l'université PSL, École nationale des chartes, centre Jean-Mabillon ; boursière de la Fundação para a Ciência e a Tecnologia (SFRH/BD/114873/2016) 


\title{
La double médiation archivistique des savoirs
}

\author{
Jean-Marie Yante
}

1 Quelle que soit la forme d'écriture retenue, la transmission des savoirs résulte d'une démarche archivistique en deux temps, le qualificatif «archivistique » étant pris dans son acception la plus large. Des travaux récents ont rappelé la distinction fondamentale entre documents et archives ${ }^{1}$. Les sources dont dispose ou disposera l'historien sont en effet la résultante de deux opérations: la production documentaire d'abord, son archivage ensuite.

2 En premier lieu, les détenteurs d'un savoir événementiel, philosophique, artistique, technique ou autre, doivent être conscients de l'intérêt et de l'importance de celui-ci ou y être sensibilisés, et éprouver le besoin et avoir la possibilité de le transmettre aux générations futures en le confiant à l'écriture ou à tout autre support mémoriel (image, son...). C'est le stade de la production d'une archive. Avec les nouvelles technologies, le sort dévolu aux documents peut ou doit être déterminé dès la création, voire antérieurement à celle-ci. Force toutefois est de reconnaître qu'il s'agit là d'une évolution toute récente et que la «mise en archives» reste à considérer comme une opération à part entière.

3 La seconde médiation archivistique intervient ultérieurement par l'intermédiaire des professionnels chargés du repérage, de la collecte, de la sélection, de la préservation, de l'inventaire, de la consultation et de la valorisation des témoignages du passé. Des évolutions techniques et sociétales vulnérabilisent aujourd'hui les archives: fragilité des nouveaux supports, nécessité de transferts périodiques, coût de la sauvegarde...

\section{Fabriquer de l'archive}

4 Très tôt, l'homme a éprouvé le besoin de poser des empreintes afin de transmettre des informations. L'art pariétal en est la plus belle illustration. Et l'on connaît le goût immodéré des Égyptiens pour l'enregistrement et l'archivage. Dans le secteur économique, pour se limiter à un seul aspect, des archives d'entreprises remontent 
vraisemblablement au ve siècle avant notre ère : elles concernent un organe de gestion de biens fonciers apparenté à une banque et établi à Nippur, près de Babylone. On sait aussi que des archives d'entreprises, avec un certain contrôle par l'État, existaient dans la Rome républicaine ${ }^{2}$.

On s'accorde aujourd'hui à reconnaître que l'archiviste n'« hérite " plus ou très peu (en ce qui concerne les archives strictement contemporaines), mais qu'il devient davantage, de jour en jour, le constructeur du patrimoine archivistique de demain. Il doit intervenir en amont du processus créateur des documents, dialoguer avec les concepteurs de systèmes informatiques afin qu'ils introduisent des spécifications et des normes rendant automatiques et faciles la rétention ou la destruction de documents ${ }^{3}$. On attend pareillement qu'il intervienne en cours de production et soit associé à des modifications de logiciels. La nécessité s'avère de plus en plus évidente de déterminer ex ante le cycle de vie de chacune des typologies documentaires.

6 Associé à la construction du patrimoine archivistique de demain, le praticien cesse d'agir, ainsi que l'écrivait le Canadien Jean-Pierre Wallot, " comme un "conservateur objectif" pour pénétrer de plain-pied dans l'univers des valeurs, du relatif, du subjectif, de tout ce qui préside à une hiérarchie dans l'univers documentaire ${ }^{4} »$. On peut même aller plus loin, comme le fait a été exposé à propos des archives universitaires :

"Le rôle nouveau de l'archiviste consiste à élucider son temps et à observer le réel anthropologique pour donner aux générations suivantes, en faisant exister les archives nécessaires, les conditions d'une mémoire juste ${ }^{5}$.»

\section{L'archivage}

7 L'archivage proprement dit se décline en plusieurs opérations.

\section{Le repérage et la collecte documentaires}

8 À l'heure actuelle, où les ressources financières disponibles sont proportionnellement moindres qu'il y a quelques années, la sauvegarde d'archives - spécialement d'archives non institutionnelles - implique impérativement la conception et la mise en œuvre d'une planification des acquisitions. Celle-ci passe par un repérage systématique des fonds présentant un intérêt historique, par la définition de priorités, par une sensibilisation et un démarchage auprès des détenteurs et de donateurs potentiels, par la collecte de moyens financiers et par une collaboration étroite avec des instituts de recherche spécialisés, des associations jouissant d'une audience reconnue et d'autres organismes susceptibles d'intervenir en matière de préservation documentaire ${ }^{6}$.

\section{La sélection et l'intérêt historique}

On perçoit aujourd'hui l'évaluation des documents, préalable au tri et à l'élimination, comme une intervention majeure de l'archiviste. "D'aucuns vont même jusqu'à affirmer qu'elle est la plus importante, la plus noble ${ }^{7}$. " Il s'agit d'une démarche au niveau de la constitution patrimoniale. L'archiviste contemporain a mandat de définir ce qui constituera la mémoire d'une institution ou d'une organisation. Selon la formule consacrée, il a droit de vie et de mort sur les documents. Ceci suppose bien sûr qu'il soit au courant des tendances actuelles de la recherche, idéalement qu'il soit lui-même 
partie prenante dans celle-ci. Il convient toutefois que l'archiviste n'agisse pas en vertu de préoccupations strictement contemporaines, mais il doit livrer aux historiens et aux hommes de demain autre chose que sa propre vision du temps, en étant attentif à la fois au quantitatif et au qualitatif. L'élargissement de la problématique et l'extraordinaire essor des sciences humaines, spécialement au cours des dernières décennies, l'y invitent impérativement ${ }^{8}$.

Dans un contexte de (sur)patrimonialisation du passé, de multiplication des " usagers » de celui-ci, la mémoire est devenue un devoir : « tout est archive ou est potentiellement destiné à l'être ${ }^{9}$ » La volonté de tout garder est assurément une chimère. Les États, gardiens traditionnels du patrimoine mémoriel, ne peuvent faire face seuls à de tels enjeux.

11 Des solutions " miracles ", assurant de substantiels gains de place et dispensant dès lors d'accroître à l'infini la capacité des dépôts, se sont révélées des mirages. Dans la décennie 1960, le microfilm apparaissait comme la réponse adéquate au problème de la croissance exponentielle des archives, mais il s'est avéré que ces copies ne pouvaient pas remplacer les originaux dans un grand nombre de cas. Et toute campagne de microfilmage exige une lourde préparation préalable des pièces. De la même façon, la numérisation (au sens de traitement post-production des documents) est rapidement apparue une illusion en termes de conservation pérenne à moindre coût. Le processus est chronophage et coûteux, tant au stade de la réalisation que de la maintenance. Par ailleurs, le caractère éphémère de certaines archives contemporaines, le raccourcissement de la durée de vie active de l'information, la diversité des supports et la prompte obsolescence d'un certain nombre d'entre eux imposent aux archivistes d'intervenir au plus vite dans le processus documentaire, idéalement d'anticiper le flux lui-même ${ }^{10}$.

12 On sait que « l'intérêt historique est une notion qui se modifie, qui évolue » dans le sens de l'élargissement, qu'il est « une subjectivité commune à tous les hommes d'une même époque ». C'est au nom de l'intérêt historique, poursuit l'archiviste belge Renée Doehaerd en 1947, que «nous conserverons peut-être, [...] nous ne détruirons jamais ${ }^{11}$ ». Un demi-siècle plus tard, en 1999, François Monnier écrit :

«L'intérêt historique est une construction de l'historien, qui le fabrique en fonction de ses soucis présents. Par suite, l'intérêt historique se déplace. On fait l'histoire de l'eau au xix ${ }^{e}$ siècle en fonction de l'actuel mouvement écologiste. On fait l'histoire de la corruption d'hier au regard des "affaires" d'aujourd'hui. »

13 Et, pour celui qui présidait alors la section des sciences historiques et philologiques de l'École pratique des hautes études :

«Le mot tri, en fonction de l'intérêt historique, est un contresens. Il est restrictif, "totalitaire". [...] Il n'est pas possible de laisser aux seuls professionnels de l'histoire, aux archivistes et aux historiens, le soin de définir l'intérêt historique, cet intérêt culturel, normatif, contingent, marqué par l'époque dans laquelle ils vivent. On ne peut leur demander d'éviter les destructions inconsidérées, eux qui sont aveuglés par leurs habitudes, leurs routines, leurs méthodes présentes de travail ${ }^{12}$."

14 On s'abstient de souscrire totalement à ce propos.

15 En matière de sélection, doivent être prises en considération les attentes sociétales nouvelles, non seulement des historiens professionnels et d'amateurs avertis, des chercheurs en sciences humaines, mais aussi (et surtout ?) du citoyen, du public qui fréquente les salles de lecture et, de plus en plus, retient l'attention des autorités, des 
bailleurs de fonds. On pense immédiatement aux généalogistes. Les interrogations et les demandes se multiplient, se diversifient, dépassent la recherche des filiations pour atteindre les milieux sociaux, les parcours professionnels, les moments d'existence plus ou moins intenses (par exemple les périodes de guerre ou de crise économique), les cadres et lieux de vie, les maisons et leur histoire...

La première qualité de l'archiviste est d'avoir du recul. On attend qu'il prenne suffisamment de distance pour avoir dans son champ de vision et de réflexion et les documents dans le contexte de leur production, et l'utilisateur d'aujourd'hui ou de demain, "en vivant pleinement l'instant de sa problématique et de son besoin d'archives ${ }^{13}$ ». Ce recul est essentiellement affaire d'anticipation.

Il convient de garder à l'esprit le précepte formulé par Hans Booms : avoir un maximum d'informations dans un minimum de documents ${ }^{14}$. Ne pas évaluer pour éliminer, comme les Anglais l'ont fait dans un premier temps, mais, à l'instar des archivistes allemands, évaluer pour conserver ${ }^{15}$. On ne peut que souscrire à l'affirmation prudente, réaliste et de bon sens de Bruno Delmas :

«Ce n'est pas en [...] détruisant toujours plus qu'une réponse sera donnée aux besoins de la société du futur. Il faudrait donc sans doute conserver sinon plus, du moins mieux qu'on ne le fait ${ }^{16}$.»

Les tableaux de tri disponibles sont améliorables et doivent être adaptés à des évolutions récentes. L'une de leurs grandes faiblesses, affirme-t-on, est de ne pas " prendre en compte l'imprévisible ${ }^{17}$ ", mais est-il légitime de reprocher aux archivistes ce que l'on n'est pas en mesure d'exiger des prévisionnistes économiques et des hauts responsables politiques? Comme le notait très justement Jean Favier, « effectuées avec discernement et scrupule, les éliminations et destructions de documents n'en demeurent pas moins des mesures arbitraires et irréparables ${ }^{18} »$.

19 À propos de l'évaluation, du choix des pièces, l'archiviste doit documenter ses successeurs ainsi que les utilisateurs actuels et futurs sur les opérations effectuées, les échantillonnages et les modalités de traitement d'un fonds.

\section{Conservation-préservation et restauration}

20 La préservation est perçue dans sa définition englobante, à savoir comme "un ensemble d'activités hiérarchisées, planifiées et articulées de manière à assurer la durabilité de l'information ${ }^{19}$ ", quel qu'en soit le support. La restauration, quant à elle, consiste en un des domaines ou une des facettes de la conservation matérielle, laquelle inclut également la conservation préventive, qui consiste à agir sur l'environnement sans toucher aux documents, ainsi que le transfert de support ${ }^{20}$.

21 La notion de restauration comporte une ambiguïté profonde. Le désir d'embellir, parfois de rajeunir ou encore de réhabiliter les documents a longtemps prévalu sur toute autre considération. Toutefois, à partir des années 1960, les réflexions de Cesare Brandi ont singulièrement enrichi le débat ${ }^{21}$. Trop longtemps, la restauration a été perçue comme une remise à neuf. On ne peut que proscrire ce retour ou prétendu retour à l'état d'origine, car c'est nier que le document a vécu et que, de ce fait, il est porteur de toute une histoire liée à son utilisation, à l'intérêt que les générations successives lui ont accordé, ou au contraire au mépris et aux maltraitances ayant engendré ou accéléré sa dégradation. Les taches de cire ou de graisse de doigts, les coins arrondis constituent autant d'indices de l'utilisation d'un livre ou d'un registre. 
situe en fait au sein d'une évolution dans la perception et la définition du document d'archives. Longtemps, l'attention a été réservée au contenu intellectuel. On reconnaît aujourd'hui l'importance de la partie matérielle de la pièce d'archives ou du livre, même si certains jugent obsolètes les termes « contenu » et « contenant ${ }^{22}$ ".

De nos jours certes, pour d'aucuns, l'archive (au singulier), l'archive sentie, l'archive touchée, bénéficie d'un attrait particulier. D'où, sous la plume d'Arlette Farge, un certain regret face à la modernité, aux techniques de reproduction et aux supports de substitution ${ }^{23}$.

nnité, intégrité et compréhension sont les trois objectifs poursuivis par toute restauration. S'y ajoutent à présent, de plus en plus, un acquis intellectuel non négligeable et l'obligation de limiter au maximum les interventions irréversibles ${ }^{24}$.

Maintenir l'intégrité d'un document, c'est conserver scrupuleusement toutes les informations qu'il véhicule, directement ou indirectement. Certaines dégradations n'engagent nullement la survie de la pièce ${ }^{25}$. On ne peut délester les archives de leur patine, pas davantage qu'un sanctuaire roman ne peut, par une simple volonté administrative ou architecturale, être spolié d'un habit baroque surimposé. C'est le priver d'un précieux témoignage, celui de la vitalité d'une communauté paroissiale ou religieuse ${ }^{26}$.

\section{Communication et communicabilité}

L'accès aux archives s'inscrit dans une longue évolution allant de la confidentialité la plus stricte à une communication fort libérale, voire outrancière. Au Moyen Âge, la communication des documents est extrêmement limitée. Les pièces n'intéressent que les membres des institutions qui les ont produites ou reçues et en assurent la conservation. Au début du $\mathrm{xv}^{\mathrm{e}}$ siècle, le sénat de Venise constate que «[ses] registres d'impôt de l'île de Crète ne sont pas tenus comme ils devraient l'être [et] peuvent être vus par presque tous ceux qui le veulent, ce qui n'est pas bon ${ }^{27}$ ». Il décide dès lors leur mise sous clé. C'est à Simancas, en 1588, que les archives s'affirment comme un véritable service public. Bientôt l'idée de la communicabilité des pièces est de plus en plus largement admise. Faut-il rappeler que l'on a beaucoup exagéré la portée de la loi promulguée par les révolutionnaires français le 25 juin 1794, concernant la «publicité des archives ${ }^{28}$ ».

«La perception de la communicabilité des documents dépend de la tradition politique, administrative, juridique et culturelle de chaque pays. [...] C'est un domaine de réflexion mouvant que les événements et les mentalités peuvent bouleverser rapidement ${ }^{29}$."

La revendication d'une communication universelle de l'information et celle du « droit de savoir " comme fondement et préalable à l'exercice des libertés démocratiques s'affirment de plus en plus à l'aube du XXI ${ }^{\mathrm{e}}$ siècle $^{30}$.

Quand refus de communication il y a, les archivistes doivent aujourd'hui en expliquer la raison aux chercheurs, qu'ils appartiennent au milieu universitaire ou scientifique, ou satisfassent, à titre privé ou autre, une légitime et honorable curiosité. 


\section{La valorisation}

29

Qu'on la considère ou non comme la finalité même de l'archivistique, la communication, mieux, la valorisation de l'héritage culturel est quelque chose d'essentiel. C'est toute la question, vitale à terme, de la notoriété et de la visibilité des archives auprès des décideurs, des financeurs, publics ou privés.

Depuis quelques années, l'univers archivistique, les métiers du secteur et les attentes auxquelles ils sont confrontés vivent un tournant assurément inédit. On ne peut toutefois parler de révolution, mais bien « d'évolutions qui, selon le degré de maturité de l'organisation, peuvent être longues et difficiles ». À la suite d'autres praticiens, on constate que « les fondamentaux archivistiques ne sont pas remis en question, [que] la gestion des risques est parfaitement applicable, [que] les bonnes pratiques informatiques sont adaptables ${ }^{31} »$.

31 Suggérés depuis plusieurs années, souvent plus théoriques que réels, les partenariats entre producteurs et gestionnaires d'archives doivent se muer en collaboration de tous les instants, tant au niveau du repérage documentaire que du traitement des fonds (notamment au stade de la sélection) et de la valorisation de ceux-ci ${ }^{32}$. L'archiviste est appelé à y assumer le rôle « d'initiateur, d'animateur et de cheville ouvrière ${ }^{33}$ ".

Force cependant est de constater que l'histoire est et restera " connaissance mutilée ${ }^{34}$ ", chronologiquement, géographiquement et/ou thématiquement. En 1939, Henri-Irénée Marrou (sous le pseudonyme d'Henri Davenson) n'intitulait-il pas un article «Tristesse de l'historien » ?La médiation archivistique des savoirs demeure plus que jamais à l'ordre du jour, à un moment où évoluent le positionnement sociétal et les responsabilités de l'archiviste, cet homme ou cette femme au profil par essence hybride, au service de plusieurs maîtres. Son action, inscrite dans les valeurs de son époque, l'amène à opérer sur trois temps: le passé, le présent et le futur. Des attentes et besoins sociétaux inédits, de nouveaux supports de l'information, dès lors des savoirs, et de foisonnantes évolutions technologiques imposent un aggiornamento et une revalorisation de ses missions et responsabilités traditionnelles. D'autant plus que les archives actuelles ne peuvent plus être réduites à leur dimension historique, mais ont retrouvé leur utilité pratique que l'historicisme du XIX ${ }^{\mathrm{e}}$ siècle avait quelque peu estompée ${ }^{35}$. Au seuil du XXI siècle, l'archiviste intervient pour garantir la sécurité de l'information et gérer le risque $^{36}$. L'univers numérique rend à la diplomatique classique toute son actualité et la place au cœur des responsabilités du praticien intervenant comme tiers de confiance ${ }^{37}$.

\section{BIBLIOGRAPHIE}

Abrégé d'archivistique : principes et pratiques du métier d'archiviste, Paris, Association des archivistes français, 2004. 
ANHEIM Étienne et PONCET Olivier, « Présentation : fabrique des archives, fabrique de l'histoire », dans Fabrique des archives, fabrique de l'histoire, Paris, Éditions rue d'Ulm, 2004, p. 1-14.

BAILLARGEON Diane, « De quelle sorte d'archivistes aurons-nous besoin en 2030 ? ", dans Servais Paul et Mirguet Françoise (dir.), Archivistes de 2030 : réflexions prospectives, Louvain-la-Neuve, Academia / L'Harmattan, 2015, p. 19-32.

BANAT-BERGER Françoise, DUPLOUY Laurent, HUC Claude, L'archivage numérique à long terme : les débuts de la maturité ?, Paris, Documentation française, 2009.

BERDUCOU Marie (dir.), La conservation en archéologie : méthodes et pratiques de la conservationrestauration des vestiges archéologiques, Paris, Masson, 1990.

воомS Hans, « Society and the formation of a documentary heritage: issues in the appraisal of archival sources ", Archivaria, 24, 1987, p. 69-107.

BRANDI Cesare, Théorie de la restauration, Paris, Allia, 2011.

CHABIN Marie-Anne, Je pense doncj'archive : l'archive dans la société de l'information, Paris, L'Harmattan, 1999.

COUTAZ Gilbert, «L'archiviste entre le droit à l'information et la protection des informations réservées ", Janus, 1998, p. 205-218.

COUTURE Carol, «L'évaluation », dans Couture Carol (dir.), Les fonctions de l'archivistique contemporaine, Sainte-Foy, Presses de l'université du Québec, 1999, p. 103-143.

DAVENSON Henri [i. e. Marrou Henri-Irénée], « Tristesse de l'historien », Esprit, avril 1939, p. 11-47. DELMAS Bruno, La société sans mémoire : propos dissidents sur la politique des archives en France, Paris, Bourin, 2006.

DELSAlle Paul, Une histoire de l'archivistique, Sainte-Foy, Presses de l'université du Québec, 1998. DESCHAUX Jocelyne, « La restauration », dans Oddos Jean-Paul (dir.), La conservation : principes et réalités, Paris, Cercle de la librairie, 1995, p. 305-340.

DOEHAERD Renée, «À propos des archives contemporaines », Archives, bibliothèques et musées de Belgique, 18, 1947, p. 75-79.

DURANTI Luciana, «From digital diplomatics to digital records forensics », Archivaria, 68, 2009, p. 39-66.

DURANTI Luciana, « Authentification des archives numériques : l'archiviste en tant qu'expert judiciaire », dans Delpierre Nicolas, Hiraux Françoise, Mirguet Françoise (dir.), Les chantiers du numérique : dématérialisation des archives et métiers de l'archiviste, Louvain-la-Neuve, Academia / L'Harmattan, 2012, p. 115-123.

FARGE Arlette, Le goût de l'archive, Paris, Points, 1997.

FAVIER Jean, Les archives, Paris, Presses universitaires de France (Que sais-je ?, 805), 1991. GAGNON-ARGUIN Louise, «La création », dans Couture Carol (dir.), Les fonctions de l'archivistique contemporaine, Sainte-Foy, Presses de l'université du Québec, 1999, p. 69-101.

GRANGER Christophe (dir.), À quoi pensent les historiens ? Faire de l'histoire au XXI ${ }^{e}$ siècle, Paris, Autrement, 2013.

GRIMARD Jacques, « De la gouvernance de la préservation : cadre légal, éthique et technologique de gestion de la préservation », dans Lemay Yvon et Gagnon-Arguin Louise (dir.), L'archiviste, 
constructeur, gardien et communicateur : mélanges en hommage à Jacques Grimard, 1947-2007, Québec, Presses de l'université du Québec, 2009, p. 247-269.

HIRAUX Françoise, « Des voix et des visages pour mémoire : la création de documents audiovisuels par les Archives de l'Université catholique de Louvain », dans Schoukens Cathy (dir.), Archives, universités, monde étudiant : une mémoire en construction, Louvain-la-Neuve, Bruylant / Academia, 2003, p. 107-121.

MONNIER François, « De l'intérêt historique : à propos d'un projet de loi sur les archives », Revue administrative, 52 année, 309, mai-juin 1999, p. 227-229.

La numérisation au service de la préservation et de la valorisation des archives, journée d'études de la direction des Archives de France (Châlons-en-Champagne, 25-27 juin 1997), Paris, Documentation française, 1998.

PIRON Jonathan, « Les archives, au défi de leur expansion », dans Dubois Marie-Laurence et Zareba Szymon (dir.), Écologie : les archives en mouvement, Namur, Etopia / Éditions namuroises, 2013, p. 11-19.

SERVAIS Paul et YANTE Jean-Marie, « Pour des partenariats efficaces producteurs / gestionnaires d'archives : quelques balises ", dans Actes ( 8 e Congrès de l'Association des cercles francophones d'histoire et d'archéologie de Belgique et $\mathrm{LV}^{\mathrm{e}}$ Congrès de la Fédération des cercles d'archéologie et d'histoire de Belgique, Namur, 28-31 août 2008), t. v, Namur, 2011, p. 1691-1698.

VEYNE Paul, Comment on écrit l'histoire, Paris, Le Seuil, 1996.

WALLOT Jean-Pierre, «La macroévaluation aux Archives nationales du Québec », dans Daelemans Frank (dir.), Miscellanea in honorem Caroli Kecskeméty, Bruxelles, 1998, p. 559-571.

YANTE Jean-Marie, « L'archiviste face à la numérisation : rigueur et pragmatisme, préalables et perspectives », dans De Keyzer Walter et Van Overstraeten Daniel (dir.), Actes de la $11^{e}$ Journée d'étude franco-belge sur les aspects juridiques et archivistiques de la numérisation des archives (Charleroi, 7 juin 2001), Bruxelles, Archives générales du Royaume, 2003, p. 33-45.

YANTE Jean-Marie, « Balises pour un profil de l'archiviste », dans Vandevoorde Évelyne (dir.), La formation des archivistes : pour relever les défis de la société de l'information, Louvain-la-Neuve, Bruylant / Academia, 2006, p. 155-166.

YANTE Jean-Marie, « Nouveaux métiers et formation des archivistes », dans Delpierre Nicolas, Hiraux Françoise, Mirguet Françoise (dir.), Les chantiers du numérique ; dématérialisation des archives et métiers de l'archiviste, Louvain-la-Neuve, Academia / L'Harmattan, 2012, p. 175-183.

YANTE Jean-Marie, « Mémoires collectives, mémoires individuelles : pour concilier l'inconciliable? », dans Hiraux Françoise et Mirguet Françoise (dir.), Les archives personnelles : enjeux, acquisition, valorisation, Louvain-la-Neuve, Academia / L'Harmattan, 2013, p. 61-70.

YANTE Jean-Marie, "Conserver et restaurer sans altérer ni appauvrir », dans Hiraux Françoise et Mirguet Françoise (dir.), De la préservation à la conservation : stratégies pratiques d'archivage, Louvain-la-Neuve, Academia / L'Harmattan, 2014, p. 169-177.

YANTE Jean-Marie, « Vers une sélection plus drastique et davantage de partenariats », dans Servais Paul et Mirguet Françoise (dir.), Archivistes de 2030 : réflexions prospectives, Louvain-laNeuve, Academia / L'Harmattan, 2015, p. 395-405.

YANTE Jean-Marie, « Entre valeur de transparence et déontologie du respect : quels équilibres ? ", dans Servais Paul et Mirguet Françoise (dir.), L'archive dans quinze ans : vers de nouveaux fondements, Louvain-la-Neuve, Academia / L'Harmattan, 2015, p. 131-141. 
YANTE Jean-Marie, «Les nouvelles responsabilités des archivistes : éclatement ou repositionnement du métier? ", dans Servais Paul et Mirguet Françoise (dir.), L'archiviste dans quinze ans : nouvelles attentes, nouvelles responsabilités, nouveaux défis, Louvain-la-Neuve, Academia / L'Harmattan, 2015, p. 91-102.

\section{NOTES}

1. É. Anheim et O. Poncet, «Présentation : fabrique des archives, fabrique de l'histoire », p. 3.

2. P. Delsalle, Une histoire de l'archivistique, p. 18 et 28.

3. J.-P. Wallot, « La macroévaluation aux Archives nationales du Québec », p. 560 et 564 ; L. Gagnon-Arguin, «La création», p. 82-85; J.-M. Yante, "Nouveaux métiers et formation des archivistes », p. 178.

4. J.-P. Wallot, «La macroévaluation aux Archives nationales du Québec », p. 560.

5. F. Hiraux, «Des voix et des visages pour mémoire: la création de documents audiovisuels par les Archives de l'Université catholique de Louvain », p. 110.

6. J.-M. Yante, « «Mémoires collectives, mémoires individuelles: pour concilier l'inconciliable?», p. 66-67.

7. C. Couture, «L'évaluation », p. 103.

8. J.-M. Yante, «Balises pour un profil de l'archiviste », p. 159-160.

9. J. Piron, "Les archives, au défi de leur expansion», p. 11 et 13-14; voir aussi C. Granger (dir.), À quoi pensent les historiens ? Faire de l'histoire au XXI siècle.

10. Voir notamment La numérisation au service de la préservation et de la valorisation des archives; J.-M. Yante, "L'archiviste face à la numérisation : rigueur et pragmatisme, préalables et perspectives", p. 33-45, et: "Vers une sélection plus drastique et davantage de partenariats ", p. 396-397.

11. R. Doehaerd, « À propos des archives contemporaines ", p. 76 et 79.

12. F. Monnier, « De l'intérêt historique : à propos d'un projet de loi sur les archives ", p. 228-229.

13. M.-A.Chabin, Je pense donc j'archive: l'archive dans la société de l'information, p. 102-104.

14. H. Booms, "Society and the formation of a documentary heritage: issues in the appraisal of archival sources ", p. 69-107.

15. C. Couture, « L'évaluation », p. 105.

16. B. Delmas, La société sans mémoire: propos dissidents sur la politique des archives en France, p. 176-177.

17. Ibid., p. 174-177.

18. J. Favier, Les archives, p. 52-53.

19. J. Grimard, «De la gouvernance de la préservation: cadre légal, éthique et technologique de gestion de la préservation ", p. 250.

20. Abrégé d'archivistique : principes et pratiques du métier d'archiviste, p. 191.

21. C. Brandi, Théorie de la restauration. 
22. J. Deschaux, « La restauration », p. 306.

23. A. Farge, Le goût de l'archive, p. 23.

24. À propos des objectifs de la restauration: M. Berducou (dir.), La conservation en archéologie: méthodes et pratiques de la conservation-restauration des vestiges archéologiques, p. 6 ; J. Deschaux, « La restauration », p. 309-310.

25. J. Deschaux, « La restauration », p. 326.

26. J.-M. Yante, « Conserver et restaurer sans altérer ni appauvrir », p. 172.

27. P. Delsalle, Une histoire de l'archivistique, p. 88 et 115-118.

28. Ibid., p. 155.

29. G. Coutaz, «L'archiviste entre le droit à l'information et la protection des informations réservées », p. 205.

30. J.-M. Yante, «Entre valeur de transparence et déontologie du respect: quels équilibres? », p. 131-141.

31. F. Banat-Berger et al., L'archivage numérique à long terme: les débuts de la maturité?, p. 195.

32. À propos des différentes facettes du partenariat: P. Servais et J.-M. Yante, "Pour des partenariats efficaces producteurs / gestionnaires d'archives : quelques balises », p. 1691-1698.

33. C. Couture, « L'évaluation », p. 121.

34. P. Veyne, Comment on écrit l'histoire, p. 26.

35. J.-M. Yante, «Les nouvelles responsabilités des archivistes: éclatement ou repositionnement du métier? », p. 93-95.

36. D. Baillargeon, « De quelle sorte d'archivistes aurons-nous besoin en 2030 ? », p. 23.

37. Voir notamment L. Duranti, «From digital diplomatics to digital records forensics ", p. 39-66, et: " Authentification des archives numériques : l'archiviste en tant qu'expert judiciaire », p. 115-123.

\section{RÉSUMÉS}

La transmission des savoirs par l'une ou l'autre forme d'écriture résulte d'une démarche archivistique en deux temps: la création documentaire d'abord, son archivage ensuite. Ce dernier se décline en plusieurs opérations. Au repérage et à la collecte documentaires est intimement liée la sélection posant la question de l'intérêt historique, concept éminemment fluctuant au fil des décennies et au sein des sociétés. Alors que la préservation vise à assurer la durabilité de l'information, la restauration ne peut conduire à une remise à neuf. Ce serait nier qu'un document est porteur de toute une histoire et privilégier le contenu par rapport au contenant. L'accès aux archives s'inscrit, quant à lui, dans une longue évolution allant de la confidentialité la plus stricte à une communication fort libérale, voire outrancière. Enfin, la valorisation est garante de la notoriété et de la visibilité des archives auprès des décideurs. 
AUTEUR

JEAN-MARIE YANTE

Professeur émérite de l'Université catholique de Louvain 
Les savoirs à l'épreuve de l'interculturel 


\title{
Transmettre l'art de transmettre : la grammaire latine entre Antiquité et Moyen Âge (IV ${ }^{\mathrm{e}}-\mathrm{IX}^{\mathrm{e}}$ siècle)
}

\author{
Michel Sot
}

1 Dans un congrès interdisciplinaire consacré à la transmission des savoirs, il m’a paru important d'aborder dans une communication le principal vecteur des savoirs: la langue. Une langue évolue, s'enrichit ou s'appauvrit, est en contact avec d'autres langues, avec lesquelles elle échange. C'est pourquoi il a été - et il est - nécessaire de la décrire, de l'expliquer et de la transmettre : c'est l'objet de la grammaire, la discipline qui à la fois rend compte de l'état de la langue et tente d'en discipliner l'expression, écrite ou orale.

2 À la fin de l'Antiquité et durant le haut Moyen Âge, la seule langue écrite en Occident est le latin. Dans le classement des disciplines, la grammaire est le premier des sept arts libéraux, suivie de la rhétorique et de la dialectique, qui lui sont étroitement liées comme sciences de la langue latine, vecteur de tous les savoirs. Quels savoirs? Nous sommes dans un monde devenu chrétien au $\mathrm{IV}^{\mathrm{e}}$ siècle, où la connaissance par excellence, celle vers laquelle convergent toutes les disciplines et toutes les sciences, est la connaissance de Dieu. Une connaissance à laquelle on accède par des Écritures, la Bible, que l'on lit en langue latine dans diverses traductions, dont celle qui se révélera la plus importante est celle de Jérôme au IV siècle, reprise par Alcuin à la fin du VIII ${ }^{\mathrm{e}}$ siècle, et que l'on désignera comme la Vulgate au Xvi ${ }^{\mathrm{e}}$ siècle. La grammaire est à la base de l'exégèse et de la théologie.

Mais la langue latine véhicule aussi tous les héritages savants. Pensons à l'héritage philosophique gréco-romain, dans le cadre duquel le christianisme s'est pensé depuis saint Paul, jusqu'à saint Augustin pour l'Occident latin. Pensons au savoir juridique : le droit romain est évidemment écrit en langue latine; le droit de l'Église ou droit canonique aussi ; quant aux droits dits "barbares ", ils sont aussi mis par écrit en latin. Pensons encore à l'héritage que nous appelons «littéraire", avec les œuvres des auteurs antiques, chrétiens et païens, abondamment exploités et cités. Pensons même 
aux connaissances que nous appelons «scientifiques»: la médecine et les mathématiques, l'astronomie ou la géographie, s'étudient dans des textes latins. Principale science de la langue, la grammaire est bien l'art de transmettre.

4 Je me propose d'examiner comment elle a, elle-même, été transmise entre Antiquité et Moyen Âge. Pour cela, je me placerai d'abord au premier grand moment de l'histoire de la culture médiévale, celui de la Renaissance carolingienne au $\mathrm{IX}^{\mathrm{e}}$ siècle. Puis je remonterai aux auteurs qui sont les références les plus invoquées de la grammaire latine: Donat, au $\mathrm{IV}^{\mathrm{e}}$ siècle, et Priscien, au $\mathrm{VI}^{\mathrm{e}}$ siècle; et j'examinerai finalement comment et par où leurs grammaires ont été transmises au Moyen Âge : par les pays méditerranéens bien sûr, mais aussi, plus surprenant et tout à fait décisif, par les îles Britanniques ${ }^{1}$.

\section{Renaissance carolingienne et grammaire}

On emploie depuis le $\mathrm{xIX}^{\mathrm{e}}$ siècle l'expression «Renaissance carolingienne » pour désigner le mouvement de retour à la culture antique dans la seconde moitié du VIII siècle et au IX ${ }^{e}$ siècle sous l'autorité de Charlemagne, roi des Francs en 767, couronné empereur en 800, et de ses successeurs. Au cœur de cette Renaissance de la culture et des savoirs, on observe la restauration d'une «bonne » langue latine, et donc d'une grammaire latine corrigée.

On en a de nombreux indices. Charlemagne lui-même, nous dit son biographe Éginhard, étudia la grammaire auprès du diacre Pierre de Pise, venu d'Italie après la soumission de cette région aux Francs en $774^{2}$. Dans le texte emblématique de la Renaissance carolingienne, le capitulaire appelé Admonitio generalis, émis en 789 , celui où le futur empereur ordonne l'institution d'écoles "dans tous les évêchés et monastères ", il est précisé que l'on doit y enseigner, avec d'autres disciplines, la grammaire. C'est la première fois que ce mot apparaît dans un texte législatif.

« [Enseignez] les Psaumes, les notes, le chant, le comput, la grammaire, dans chaque monastère et chaque évêché, et corrigez bien les livres catholiques; car souvent, alors que certains voudraient demander quelque chose à Dieu de bonne façon, ils le font mal à cause de livres non corrigés. Ne permettez pas à vos garçons de déformer ces livres, soit en les lisant, soit en les copiant; et s'il faut copier un évangile, un psautier ou un missel, que ce soient des hommes d'âge accompli qui les écrivent avec beaucoup de soin ${ }^{3}$.»

7 Il est donc précisé que les livres doivent être soigneusement copiés et corrigés (émendés) par des personnes suffisamment formées pour que ceux qui les lisent ne soient pas induits en erreur par des fautes de copiste. C'est grâce à la grammaire que l'on assure la bonne transmission des textes. Au moins trois textes confirment ces préoccupations de Charlemagne et l'on peut, à son propos, parler d'une véritable politique de la grammaire.

8 Il a donné entre 786 et 800 une lettre publiée sous le titre d'Encyclique sur la correction des livres et des offices ecclésiastiques ${ }^{4}$, dans laquelle il indique qu'il a fait corriger " tous les livres de l'Ancien et du Nouveau Testament corrompus par l'impéritie des copistes». On sait qu'il a de fait commandé aux savants Alcuin et Théodulfe une révision des différentes traductions latines des livres bibliques pour que l'on dispose d'un seul texte de référence qui conduise au Dieu unique. Charles a aussi demandé au savant lombard Paul Diacre de composer un nouveau lectionnaire destiné à l'office 
monastique, pour que l'on n'entende plus résonner «le couac discordant des solécismes ${ }^{5}$ » et que la prière des moines soit elle aussi unifiée. Dans les deux cas est affirmée la volonté de disposer de textes corrigés (ou émendés) pour lire et prier correctement.

Dans une autre missive à peu près contemporaine, publiée sous le titre Sur l'étude des lettres ${ }^{6}$ adressée dans les années 790 (ou avant 789 ?) à Baugulf, abbé du grand monastère de Fulda, le roi Charles exprime le même souci de correction de la langue pour les moines :

«Pendant que la règle [monastique] bien observée soutient l'honnêteté des mœurs, le soin d'apprendre et d'enseigner mettra l'ordre dans le langage, afin que ceux qui veulent plaire à Dieu en vivant bien ne négligent pas de lui plaire en parlant bien. »

Il s'agit de mettre de l'ordre dans la langue parlée, mais aussi dans la langue écrite :

«Nous avons commencé à craindre que si la science manquait dans la manière d'écrire, il n'y eut beaucoup moins d'intelligence qu'il ne faut dans l'interprétation des Saintes Écritures. »

Et il ajoute même des précisions techniques :

"Comme il y a dans les livres sacrés des figures, des tropes et d'autres particularités semblables, il n'est douteux pour personne que chacun en les lisant ne saisisse d'autant plus vite le sens spirituel qu'il s'y trouve mieux préparé par l'enseignement des lettres. » ... À commencer par celui de la grammaire.

13 Derrière ces textes se profile le principal conseiller de Charlemagne de 786 à 796 au moins, Alcuin, « venu de Bretagne et d'origine saxonne, l'homme le plus savant qui fut alors » nous dit Eginhard ${ }^{7}$. Alcuin, dans une œuvre abondante et quasi encyclopédique, a donné un De grammatica ${ }^{8}$, écrit ou au moins terminé à Tours, où il est abbé de SaintMartin entre 796 et sa mort en 804 . Né vers 730 en Northumbrie, il s'est formé à l'école d'York auprès d'Egbert, lui-même élève de Bède le Vénérable, qu'Alcuin désigne encore comme magister noster.

De la formation d'Alcuin et de la culture qu'il a acquise à York avant sa venue sur le continent, on a un témoignage remarquable dans un long poème qu'il consacre à l'éloge de son église de York' ${ }^{9}$. On y aperçoit le programme d'enseignement et le catalogue de la bibliothèque de la métropole du nord de l'Angleterre. Le cursus d'enseignement des arts libéraux commence normalement par la grammaire ${ }^{10}$. Dans la bibliothèque, les livres de grammaire occupent une large place, répartis entre ouvrages poétiques et ouvrages techniques. Viennent d'abord les poètes chrétiens, au nombre de neuf (Sedulius, Juvencus, Avitus, Prudence, Prosper d'Aquitaine, Paulin de Nole, Arator, Venance Fortunat et Lactance), puis les poètes païens, au nombre de trois (Virgile, Stace et Lucain). Alors seulement viennent les grammairiens, au sens technique du mot, où nous trouvons en particulier deux noms, celui de Donat et celui de Priscien (associés en Donatus-Priscianusve) mais aussi Probus, Phocas, Servius, Euticius, Pompée et Charisius $^{11}$.

Dans la tradition antique, les œuvres que nous appelons littéraires et celles que nous appelons grammaticales sont étroitement associées. On trouve dans les premières le fondement et la garantie de la grammaire comme technique, ce qui indique dans quel esprit Alcuin a appris à l'aborder. Mais on doit remarquer aussi que, dans cette bibliothèque d'York telle que la décrit Alcuin, tous les arts libéraux sont représentés. Au-dessus des arts «littéraires" du trivium, une large place est faite à ceux du 
quadrivium "scientifique", auxquels est ajoutée l'étude des êtres vivants (dont fait partie l'histoire), le tout conduisant à l'étude des Écritures, couronnement de l'ensemble. C'est dans cette perspective d'ouverture sur tous les savoirs qu'Alcuin a contribué au renouveau carolingien de la grammaire.

Son De Grammatica est présenté sous forme d'un dialogue entre deux jeunes élèves (Saxo et Franco) en présence d'un maître ${ }^{12}$. Dans un certain nombre de manuscrits, ce traité est précédé d'une introduction, qui a été publiée dans la Patrologie latine de Migne sous le titre Disputatio de vera philosophia. Ce préambule, qui introduit de fait à tous les arts libéraux, exprime l'enthousiasme du maitre et du disciple pour le savoir. La grammaire et les six autres arts sont présentés comme les sept colonnes qui soutiennent la Sagesse (selon le Livre des Proverbes) et ils sont rapprochés des sept dons de l'Esprit. Ils représentent aussi les sept degrés qu'il faut gravir pour accéder à la sagesse depuis la grammaire.

«Je vous montrerai, pour que vous les voyiez, les sept degrés par lesquels on accède à la philosophie, et tout en les gravissant, si Dieu me l'accorde et si la vie m'accompagne, je finirai, dans la mesure de mes facultés, par vous mener, avec le temps et si les circonstances s'y prêtent, jusqu'au sommet élevé de la connaissance contemplative [ad sublimiora speculativae scientiae ${ }^{13}$. »

Au-delà de cette introduction programmatique, c'est le professeur Alcuin qui s'exprime dans ce dialogue entre deux étudiants, dont le premier, Saxo («le Saxon», entendons "l'Anglo-Saxon »), âgé de quinze ans, est l'aîné du second, Franco (« le Franc»), âgé de quatorze ans seulement. On peut voir là un symbole des deux publics successifs d'Alcuin, les Saxons à York, les Francs à la cour de Charlemagne. C'est d'ailleurs Franco qui interroge son aîné et ce dernier lui répond, mais sous l'autorité du magister Albinus Alcuin lui-même - qui intervient de temps à autres, mais surtout dans la partie introductive du débat, pour bien orienter la disputatio et tenter de lui donner une dimension philosophique et pas seulement technique.

Le traité d'Alcuin, comme la plupart des manuels de grammaire carolingiens, est largement fondé dans ceux de Donat (IV siècle) dont nous allons parler plus loin. La majeure partie du texte est consacrée à l'étude des " parties du discours » (la partie II de l'Ars maior de Donat), dans l'ordre et souvent avec les mots mêmes de Donat (nom, pronom, verbe, adverbe, participe, conjonction, préposition, interjection). Mais Alcuin, par la bouche de Saxo, y injecte toutes sortes de notions fondamentales, tirées principalement de l'autre grammairien de référence, Priscien ( $\mathrm{vi}^{\mathrm{e}}$ siècle), auteur lui aussi d'une Ars grammatica, souvent appelée à tort Institutions grammaticales, en dix-huit livres. Ces deux auteurs représentent à peu près $80 \%$ des sources du De Grammatica selon Louis $\mathrm{Holz}^{14}$. Ils sont étroitement associés par Saxo, pour amener Franco à dépasser Donat et à découvrir Priscien, ce qui n'est pas acquis pour le jeune Franc.

On se souvient que dans l'énumération des livres de la bibliothèque d'York figurait Donatus Priscianusve: pour les parties communes aux deux grammairiens (Ars maior I et II et Institutions grammaticales I-XVI). Alcuin considère toujours Donat comme la base, mais il est pour lui inséparable des enrichissements apportés par Priscien, devenus indispensables. 


\section{Les deux phares de la grammaire latine entre Antiquité et Moyen Âge : Donat et Priscien}

\section{Donat et son Ars grammatica (apr. 350)}

Quand Alcuin donne son traité intitulé Ars grammatica, sa première référence est l'œuvre qu'un certain Donat a composée à Rome vers 350. Elle a été magistralement éditée et commentée par Louis Holtz en $1981^{15}$. On peut, avec ce savant, emprunter à Diomède, grammairien proche de Donat, une définition de la grammaire qui leur est commune :

«La grammaire se divise en deux parties, l'une que l'on appelle exégétique, l'autre horistique. L'exégétique a pour rôle l'explication et concerne les fonctions obligatoires de la lecture; l'horistique a pour tâche de définir [horos en grec $=$ définition] ; elle enseigne les règles et comporte deux aspects : les parties du discours, les défauts et les qualités du discours. La grammaire dans sa totalité consiste en l'interprétation des poètes et des écrivains, l'explication de ce qui fait la matière du texte [...], et dans les règles de correction du langage et de l'écriture ${ }^{16}$.»

21 Nous retrouvons la tension entre l'étude des textes littéraires (partie exégétique de la grammaire) et étude technique de la langue (partie horistique ou définitionnelle), avec à l'horizon l'exigence de correction à laquelle la Renaissance carolingienne sera si sensible. «Cette ambivalence de la grammaire et du grammaticus, commente Louis Holz, est le résultat d'un compromis entre la tradition des Alexandrins, très empiriques, et celle des Stoïciens plus tournés vers la théorisation ${ }^{17}$. » Pour Donat, l'Ars grammatica, dont il va maintenant être question, correspond à la partie définitionnelle (horistique) de la grammaire, les commentaires de textes à la partie exégétique.

Jérôme, le plus brillant élève de Donat à Rome, indique que son maître commentait Térence et Virgile, mais d'autres auteurs aussi dont Plaute, Lucrèce, Horace, Perse, Lucain et Salluste. C'est dans ce contexte culturel qu'a été composé le grand livre que l'on appelle l'Ars maior de Donat, duquel il tirera une Ars minor destinée à l'enseignement élémentaire. Il recueille et codifie un grand nombre des traditions grammaticales antiques avec une certaine perfection pédagogique et formelle, en les allégeant de toute référence aux grammairiens et aux auteurs cités. Si dans les exemples qu'il propose, la prépondérance de Virgile reste massive, le nom du poète n'apparaît jamais ${ }^{18}$. De fait, Donat a proposé une structuration de la grammaire en trois parties qui sont devenues canoniques et dont on peut résumer les principaux éléments. Un premier livre, en six chapitres, donne la description des éléments constitutifs du mot : les sons, les lettres, les syllabes, les pieds, les accents et la ponctuation. Ce sont les éléments nécessaires pour la lecture des textes, lecture qui implique l'identification des lettres, la mesure de la quantité des syllabes, le placement des accents et le respect des pauses.

Un second livre, en neuf chapitres, établit les différentes " parties du discours », c'està-dire les différentes catégories de mots, distingués par leurs caractères morphologiques. Ces catégories sont au nombre de huit: nom, pronom, verbe, adverbe, participe, conjonction, préposition et interjection.

Chaque catégorie est divisée en sous-catégories appelées "accidents» (accidentia $=$ attributs). Pour les noms (divisés en noms propres et noms communs), les « accidents » sont : le genre, le nombre, la forme (figura, simple ou composée) et le cas. 
Pour les pronoms, les accidents sont les mêmes, avec en outre la personne et la qualité (définis, indéfinis, démonstratifs et bien d'autres).

Le verbe se caractérise, en opposition au nom, par la référence à une personne (active ou passive) et par quatre accidents : la forme (simple, méditatif, fréquentatif, inchoatif), le mode (indicatif, impératif, optatif), la conjugaison (combinaison du temps et des personnes) et le genus (actif, passif, neutre ou déponent).

Le participe combine les caractéristiques des noms et des verbes.

L'adverbe se définit par son incidence à l'égard du verbe.

Les conjonctions relient et peuvent être copulatives (par exemple : et), disjonctives (par exemple : aut $=\mathrm{ou}$ ), explétives (si).

La préposition est anté-posée à un nom ou à un verbe. L'interjection exprime des affectus animae (des états de l'âme): elle n'a ni contenu conceptuel ni fonction grammaticale dans la phrase.

31 Ces catégories et sous-catégories de mots, appelées "parties du discours", ont constamment été reprises par la suite - nous l'avons vu à propos du De Grammatica d'Alcuin - et nous sont largement restées familières.

Un troisième livre, en six chapitres, contient « les défauts et les qualités de l'énoncé », c'est-à-dire les écarts par rapport à la correctio. Ces écarts peuvent être négatifs et l'on parle alors de vitia (fautes) : barbarisme et solécismes en particulier. Ils peuvent aussi être positifs, spécialement dans les textes poétiques, et l'on parle alors de virtutes: métaplasmes, figures et tropes.

De cet Ars maior en trois parties, Donat a lui-même tiré un manuel d'initiation réduit, que l'on désigne comme Ars minor, organisé sous la forme d'un dialogue entre un maître et son élève, transmis soit en tête de l'Ars maior, soit séparément, et très diffusé. « Mais dans l'esprit de l'auteur, il n'y a qu'une seule grammaire, avec un cours élémentaire et un cours supérieur ${ }^{19}$.»

\section{L'autre référence des grammairiens carolingiens : Priscien ( $\mathrm{Vl}^{\mathrm{e}}$ siècle)}

L'autre grand jalon de l'histoire de la grammaire antique telle qu'elle est recueillie au Moyen Âge par la Renaissance carolingienne est Priscien ${ }^{20}$, dont l'œuvre considérable devait éclipser celle de Donat - mais au-delà de l'époque carolingienne - pour devenir la grande référence de la grammaire scolastique aux $\mathrm{XII}^{\mathrm{e}}$ et $\mathrm{XIII}^{\mathrm{e}}$ siècles. Sans doute originaire d'Afrique (Césarée de Maurétanie), Priscien a enseigné le latin à Constantinople au début $\mathrm{du} \mathrm{VI}^{\mathrm{e}}$ siècle. Il s'adresse à des élèves hellénophones ou bilingues, à une époque où la langue latine est plutôt en régression dans l'empire d'Orient, alors qu'elle est la langue officielle de l'administration et du palais impérial. C'est aussi l'époque d'une grande effervescence intellectuelle en Occident, après que les Goths se furent établis en Italie et leurs élites largement ralliées au roi Théodoric. Priscien est en relation avec les nobles lettrés romains tels Symmaque († 504), consul en 391 , défenseur de la culture traditionnelle contre le christianisme, ou encore Boèce († 524), qui entend porter haut l'héritage helléniste.

Son ouvrage principal est souvent appelé les Institutions grammaticales, à tort puisque ce nom ne figure sur aucun manuscrit. Il s'agit d'une Ars grammatica, un traité de 
grammaire qui comporte dix-huit livres. Il est dédié au consul et patrice Julianus. Priscien a par ailleurs dédié à Symmaque trois opuscules : un sur les signes numériques (De figuris numerorum), un sur la métrique de Térence (De metris Terentii) et un sur la rhétorique (De praeexercitalentis rhetoricis). Enfin il a donné deux ouvrages pédagogiques, dont le premier connaîtra un grand succès: l'Institutio de nomine, pronomine et verbo, manuel résumé qui renvoie à son Ars en dix-huit livres. Le second est intitulé Partitiones duodecim versuum Aeneidos principalium. Notons la référence obligée, jusque dans les titres, à Virgile quand il s'agit de grammaire.

Le premier livre et la majeure partie du second de l'Ars de Priscien traitent des sons vocaux (vox) et des signes graphiques (litterae) qui leurs sont associés. De la fin du second livre jusqu'au seizième, il traite des parties du discours : 2-7, les noms ; 8-10, les verbes ; 11 , les participes ; $12-13$, les pronoms ; 14 , les prépositions ; 15 , les adverbes et interjections ; 16 , les conjonctions.

Les deux derniers livres, là où, suivant Donat, on attendrait l'exposé des vices et des vertus du langage, étudient la syntaxe. C'est là l'innovation majeure de Priscien, passer de la morphologie à la syntaxe, c'est-à-dire à la combinaison des parties du discours pour former des énoncés ou des phrases.

Cette œuvre ne connut pas un succès immédiat. « Vis-à-vis des maîtres qui enseignaient la grammaire à Rome ou en Italie, elle avait un côté provocateur et même polémique ", nous dit Louis Holtz ${ }^{21}$. De plus, les circonstances devinrent rapidement défavorables : l'aristocratie romaine rompit avec le roi ostrogoth Théodoric, qui fit exécuter Boèce en 524. La "guerre gothique» de conquête de l'Italie menée depuis Constantinople par l'empereur Justinien ruine le pays. De sorte que l'heure est à la conservation d'un héritage menacé et non à un renouvellement tel que l'envisage Priscien.

« Voilà pourquoi l'œuvre grammaticale de Priscien, la plus importante que nous ait livré le monde romain, a mis du temps à s'imposer... et cela en raison même du souffle nouveau qu'elle apportait ${ }^{22}$.»

Priscien est resté fidèle à la tradition grammaticale hellénistico-romaine : la lecture commentée de Virgile et de Térence, les deux grands classiques, reste à la base du travail de l'élève qui s'engage dans un cursus - c'est celui l'école antique - le conduisant à la rhétorique, pour laquelle le grammairien lui propose déjà des praeexercitamenta (titre de son traité de rhétorique).

40 Ajoutons que l'Ars de Priscien est de loin le plus long texte du genre, le plus riche en citations: il représente l'apogée de la science philologique d'alors. Sa lecture est difficile et lorsqu'Alcuin évoque "les buissons épineux de l'épaisse forêt grammaticale ", peut-être pensait-il particulièrement à l'Ars de Priscien ${ }^{23}$.

On ne sera pas surpris que le très savant Cassiodore fasse mention de Priscien. Mais il est le seul savant du vi ${ }^{\mathrm{e}}$ siècle à le faire. Si l'Ars de Priscien est dans la bibliothèque de son monastère de Vivarium, il en tire très peu de parti. Pour Cassiodore, en effet, c'est encore et toujours dans Donat qu'il convient d'étudier la grammaire latine, selon la solide tradition évoquée plus haut. D'ailleurs, Priscien lui-même avait dû composer avec la grammaire latine simplifiée en donnant, après les dix-huit livres de son Ars, l'ouvrage élémentaire déjà évoqué : l'Institutio de nomine, pronomine et verbo, que l'on a pu appeler la "Petite institution», qui se répandit plus vite que l'Ars. L'Institutio est souvent associée à l'Ars Donati dans les manuscrits. 


\section{Transmission et évolution de la grammaire latine du IV au IX ${ }^{\mathrm{e}}$ siècle : de la Méditerranée aux îles Britanniques et au royaume puis Empire franc}

Dans les régions méditerranéennes, berceau de la langue latine, la prééminence de la grammaire de Donat s'est maintenue. Parmi les savants qui l'ont transmise de l'Antiquité au haut Moyen Âge, une place importante revient d'abord aux Italiens que l'on vient d'évoquer: Boèce à la fin $d u v^{e}$ et au début $d u v^{e}$ siècle, puis Cassiodore (485-585) dans son monastère conservatoire de la culture antique qu'est Vivarium, en Italie du sud. Il donne un De orthographia et un De oratione et octo partibus orationis (Sur le discours et les huit parties du discours). Ces ouvrages renvoient aux deux premiers livres de l'Ars maior de Donat: les "lettres", qui font partie du premier sur les éléments constitutifs du mot ; les " parties du discours » (les mots), qui sont l'objet du deuxième.

En Espagne, Isidore de Séville, au début du $\mathrm{VI}^{\mathrm{e}}$ siècle, ouvre ses Étymologies, grande encyclopédie qui fera autorité jusqu'au $\mathrm{XII}^{\mathrm{e}}$ siècle au moins, par un chapitre "De grammatica", qu'il définit comme "scientia recte loquendi et origo et fondamentum liberalium litterarum» (science du bien parler, origine et fondement des savoirs libéraux). Lui aussi s'appuie principalement sur Donat. Priscien ne réapparaît qu'au VII siècle, mais c'est en Angleterre, dans l'œuvre d'Aldhelm de Malmesbury.

\section{Le détour par les îles Britanniques ( $\mathrm{VII} \mathrm{e}^{\mathrm{e}} \mathrm{VIII}{ }^{\mathrm{e}}$ siècles)} commentaires, voire des paraphrases de Donat; citons par exemple la grammaire $\mathrm{d}^{\prime} \mathrm{Asper}^{25}$, du second quart $\mathrm{du} \mathrm{VII}^{\mathrm{e}}$ siècle, qui est une «édition" irlandaise et christianisée de l'Ars minor. Asper, comme bien d'autres grammairiens, « convertit » les exemples empruntés par Donat à la culture antique païenne: pour les noms propres 
par exemple, Roma ou Tiberim (Rome ou le Tibre) deviennent Hierusalem ou Iordanis (Jérusalem ou le Jourdain). Quant aux noms de personnages, ils sont désormais empruntés à la Bible et non plus à l'histoire ou à la littérature antique. Des mots de la vie monastique sont substitués à des vocables profanes : sanctus remplace doctus; ieiunio ou oro («je jeûne» ou «je prie») remplacent lego («je lis»).Le manuel d'Asper est typique des ouvrages élémentaires à portée pratique, destinés avant tout aux copistes pour maintenir correcte la langue des Écritures. On s'est intéressé aussi en Irlande à une grammaire plus savante, celle de l'Ars maior de Donat, et aux commentaires qui en avaient été donnés par Servius à la fin du IV siècle ou, plus récemment, par Isidore de Séville et Julien de Tolède.

Mais le renouvellement de l'approche grammaticale est venu de la prise en compte de grammairiens postérieurs à Donat et très particulièrement de Priscien. Lui aussi, à Constantinople, s'était trouvé en position d'avoir à défendre et promouvoir la langue latine comme une langue presque «étrangère » dans un contexte de langue grecque dominante.

On connaît trois grands traités hiberno-latins, qui ont sans doute été écrits à Bobbio, en Italie du nord, mais dans le monastère fondé par saint Colomban: ils illustrent la culture grammaticale irlandaise. Le premier, appelé Ars Ambrosiana, a été composé avant 700. C'est un commentaire de Donat et il est édité sous le titre Commentum anonymum in Donati partibus maiores. Il n'ignore pas Priscien, mais ne l'utilise pas directement. Le second, l'Anonymus ad Cuimnanum, daterait des environs de 730 si le dédicataire Cuimnanus est bien l'abbé de Bobbio de ce nom. C'est aussi un commentaire de Donat mais avec, cette fois, un emprunt important à Priscien : le classement des noms en cinq déclinaisons selon le nominatif et le génitif. Enfin, dans l'Ars Bernensis (le manuscrit se trouve à la bibliothèque de Berne), Priscien est largement mis en œuvre.

En Angleterre, le premier utilisateur de Priscien a été Aldhelm (640-709), comme nous l'avons dit plus haut. Abbé de Malmesbury puis évêque de Sherbone, il invoque dans son De metris et enigmatibus et pedum regulis l'autorité de Priscien, dont il détient l'Ars en dix-huit livres et l'Institutio. Louis Holz a relevé 54 emprunts à l'Ars et 2 à l'Institutio ${ }^{26}$. Néanmoins, l'enseignement d'Aldhelm, comme celui de Bède le Vénérable et de tous les lettrés anglo-saxons, reposait avant tout sur Donat. Bède y fait très explicitement référence et compose un De orthographia, qui renvoie au livre I de l'Ars maior. Il donne aussi un De arte metricaet un De schematibus et tropis qui renvoient au livre III. S'il n'a pas traité des "parties du discours» (livre II de l'Ars maior), ses contemporains WynfrithBoniface et Tatwine témoignent de ce que la pédagogie des parties du discours, suivant de très près le livre II de Donat, était considérée comme prioritaire. Le premier, Wynfrith, originaire du Devon, la région la plus occidentale de l'île conquise par les Ango-Saxons, gagna le continent en 718-719, où le pape Grégoire II devait lui donner le nom de Boniface. Évangélisateur des régions germaniques, actif à la cour des maires du palais d'Austrasie et engageant la réforme de l'Église franque dans les années 740, il avait sans doute apporté avec lui une Ars grammatica et un De arte metrica qu'il avait composés naguère, en Angleterre. C'est dans les régions évangélisées, et à partir du monastère de Fulda fondé en son honneur en 742 , que son œuvre se répandit. Quant à Tatwine, moine devenu archevêque de Cantorbéry en 731, il joua un rôle plus effacé mais son Ars grammatica fut diffusée sur le continent au vIII ${ }^{\mathrm{e}}$ et au début du IX $\mathrm{I}^{\mathrm{e}}$ siècle, où l'on en connaît six manuscrits ${ }^{27}$. Chez Winfrith-Boniface comme chez Tatwine, la connaissance de Priscien semble limitée à l'Institutio, qu'ils utilisent sans la citer. Mais 
dans la lettre de dédicace de son Ars grammatica, Boniface désigne deux fois le couple Donat-Priscien (Donatus Priscianusve), comme le fait Alcuin dans son poème sur York, où il dresse un inventaire de la bibliothèque.

Le grammairien de Constantinople est donc connu dans les îles aux $\mathrm{VII}^{\mathrm{e}}$ et $\mathrm{VIII}{ }^{\mathrm{e}}$ siècles et la tradition de ses œuvres y a rejoint la tradition dominante de Donat. On peut penser que des manuscrits ont été apportés de Rome en Northumbrie lors des nombreux voyages de moines anglo-saxons ad limina, et on sait que les relations entre les monastères d'Irlande et celui de Bobbio sont restées étroites. Bède ( $† 735)$, dans son Histoire $d u$ peuple anglais, indique que de nombreux moines irlandais venaient en Angleterre et spécialement en Northumbrie pour instruire les moines anglais, et que nombre de ces derniers se rendaient en Irlande pour suivre les leçons de maîtres irlandais ${ }^{28}$. C'est par ces déplacements de personnes, et sans doute de manuscrits, que les traditions grammaticales se sont rencontrées dans les îles.

L'expérience insulaire de la pratique d'une grammaire latine "langue étrangère » aux cultures bretonnes ou germaniques, autochtones ou importées aux $\mathrm{v}^{\mathrm{e}}$ et $\mathrm{vI}^{\mathrm{e}}$ siècles, a obligé à penser la langue latine avec les catégories héritées de la grammaire antique, mais en les adaptant à des contextes nouveaux, différents de ceux dans lesquels elles avaient été élaborées. C'est assurément ce qui lui donne sa force au moment où les rois francs engagent la Renaissance carolingienne dans la seconde moitié du VIII siècle avec les Anglo-Saxons Boniface et Alcuin. Ces derniers ont été relayés au IX siècle par des Irlandais, au rôle desquels il faudrait consacrer une autre communication ${ }^{29}$.

Mais soulignons pour terminer que ce sont presque tous les savants carolingiens qui, pour les raisons que nous avons dites, on donné au moins un traité de grammaire, transmettant ainsi l'art de transmettre de l'Antiquité au Moyen Âge.

\section{BIBLIOGRAPHIE}

ALCUIN, The bishops, kings and saints of York, éd. et trad. anglaise Peter Godman, Oxford, Oxford University Press, 1982.

AUROUX Sylvain (dir.), Histoire des idées linguistiques, vol. 2, Le développement de la grammaire occidentale, Liège/Bruxelles, Mardaga, 1992.

BARATIN Marc, COLOMBAT Bernard, holtz Louis (dir.), Priscien, transmission et refondation de la grammaire de l'Antiquité aux modernes, Turnhout, Brepols, 2009.

BORETIUS Alfred (éd.), Admonitio generalis, I, Hanovre (Monumenta Germaniæ Historica, Leges), 1883.

CINATO Franck, Priscien glosé : l'Ars grammatica de Priscien vue à travers les gloses carolingiennes, Turnhout, Brepols, 2015. 
COZ Yann, Rome en Angleterre : l'image de la Rome antique dans l'Angleterre anglo-saxonne du VII siècle à 1066, Paris, Classiques Garnier, 2011.

ÉGINHARD, Vie de Charlemagne, texte, trad. et notes Michel Sot et Christiane Veyrard-Cosme, Paris, Les Belles Lettres, 2014.

HOLTZ Louis, Donat et la tradition de l'enseignement grammatical : étude sur l'Ars Donati et sa diffusion (IVe-IXe siècle) et édition critique, Paris, CNRS éditions, 1981.

HOLTZ Louis, «L'enseignement des maitres de grammaire irlandais sur le continent au IX siècle », dans Picard Jean-Michel (dir.), Ireland and Northern France AD 600-850 (Blackrock, 1991), Dublin, Four Court Press, 1991, p. 143-156.

HOLTZ Louis, « La grammaire carolingienne », dans Auroux Sylvain (dir.), Histoire des idées linguistiques, Liège / Bruxelles, Mardaga, 1992, p. 96-106.

HOLTZ Louis, « Alcuin et la renaissance des arts libéraux », dans Butzer Paul Leo, Kerner Max, Oberschelp Walter (dir.), Karl der Grosse und sein Nachwirken, 1200 Jahre Kultur und Wissenschaft in Europa, vol. 1, nº 1, Turnhout, Brepols, 1997-1998, p. 45-60.

HOLTZ Louis, « Alcuin et la redécouverte de Priscien à l'époque carolingienne », dans Auroux Sylvain, Koerner Ernst Frideryk Konrad, Niederehe Hans-Josef, Versteegh Kees (dir.), History of the language sciences, Berlin / New York, De Gruyter / Mouton, 2000, t. I, p. 525-532.

HOLTZ Louis, «Le dialogue entre Saxo et Franco », Annales de Bretagne et des pays de l'Ouest, vol. 111, $\mathrm{n}^{\circ} 3$ : Depreux Philippe et Judic Bruno (dir.), Alcuin de York à Tour, 2004, p. 133-145.

HOLTZ Louis, « Bède et la tradition grammaticale latine », dans Lebecq Stéphane et Perrin Michel (dir.), Bède le Vénérable, entre tradition et postérité, Lille, CEGES, 2005, p. 9-18.

HOLTZ Louis, « L'émergence de l'œuvre grammaticale de Priscien et la chronologie de sa diffusion », dans Baratin Marc, Colombat Bernard, Holtz Louis (dir.), Priscien, transmission et refondation de la grammaire de l'Antiquité aux modernes, Turnhout, Brepols, 2009, p. 37-55.

LAW Vivien, « La grammaire latine durant le haut Moyen Âge », dans Auroux Sylvain (dir.), Histoire des idées linguistiques, vol. 2, Le développement de la grammaire occidentale, Liège / Bruxelles, Mardaga, 1992, p. 83-95.

LAW Vivien, « The study of grammar » dans McKitterick Rosamond (dir.), Carolingian culture: emulation and innovation, Cambridge, Cambridge University Press, 1994, p. 88-110.

SZERWINIACK Olivier, «L'étude de Priscien par les Irlandais et les Anglo-Saxons durant le haut Moyen Âge », dans Baratin Marc, Colombat Bernard, Holtz Louis (dir.), Priscien, transmission et refondation de la grammaire de l'Antiquité aux modernes, Turnhout, Brepols, 2009, p. 65-75.

\section{NOTES}

1. Pour situer la grammaire dans l'histoire générale de la linguistique, nous renvoyons à S. Auroux (dir.), Histoire des idées linguistiques, vol. 2, Le développement de la grammaire occidentale, et plus particulièrement ici à V. Law, « La grammaire durant le haut Moyen Âge » et L. Holtz, « La grammaire carolingienne ».

2. Éginhard, Vie de Charlemagne, p. 59.

3. A. Boretius (éd.), Admonitio generalis, Monumenta Germaniae Historica, I, chap. 72, p. 59-60. 
4. Encyclica de emendatione librorum et officiorum ecclesiasticorum, Monumenta Germaniae Historica, Leges I, Hanovre, 1835, p. 44-45.

5. Ibid., p. 45 : «Inter sacra officia inconsonantes perstrepere solœcismos ».

6. Epistola de litteris colendis, Monumenta Germaniae Historica, Capitularia I, Hanovre, 1883, p. 78-79.

7. Éginhard, Vie de Charlemagne, p. 25. Sur le rôle d'Alcuin dans l'histoire de la culture, voir en particulier L. Holz, « Alcuin et la renaissance des arts libéraux ».

8. Patrologie latine, t. 101, c. 849-902, traduit et commenté par L. Holtz, «Alcuin et la renaissance des arts libéraux ", p. 54-55.

9. Alcuin, The bishops, kings and saints of York.

10. Ibid., v. 1434 à 1449.

11. Ibid., v. 1536 à 1562.

12. L. Holtz, « Le dialogue entre Saxo et Franco ».

13. Patrologie latine, 101, col.853, traduit et commenté par L. Holtz, "Alcuin et la renaissance des arts libéraux », p. 54-55.

14. L. Holtz, « Le dialogue entre Saxo et Franco », p. 144.

15. L. Holtz, Donat et la tradition de l'enseignement grammatical. Étude sur l'Ars Donati et sa diffusion (IVe-IXe siècle) et édition critique.

16. Diomède, 426, 16-20, cité par L. Holtz, Ibid., p. 24.

17. Ibid., p. 25.

18. Ibid., p. 95.

19. Ibid., p. 99.

20. Voir M. Baratin et al., Priscien, transmission et refondation de la grammaire de l'Antiquité aux modernes; F. Cinato, Priscien glosé: l'Ars grammatica de Priscien vue à travers les gloses carolingiennes.

21. L. Holtz, «Alcuin et la redécouverte de Priscien à l'époque carolingienne ».

22. Ibid.

23. F. Cinato, Priscien glosé..., p. 47.

24. Voir V. Law, «The study of grammar » et O. Szerwiniack, «L'étude de Priscien par les Irlandais et les Anglo-Saxons durant le haut Moyen Âge ».

25. Voir L. Holtz, Donat et la tradition de l'enseignement grammatical..., p. 272-284.

26. L. Holtz, «L'émergence de l'œuvre grammaticale de Priscien et la chronologie de sa diffusion », p. 40.

27. Cf. Y. Coz, Rome en Angleterre: l'image de la Rome antique dans l'Angleterre anglosaxonne, du VII siècle à 1066 ; sur la grammaire et les grammairiens, p. 130-159.

28. L. Holtz, «Bède et la tradition grammaticale latine ».

29. Renvoyons une fois encore à L. Holtz, «L'enseignement des maîtres de grammaire irlandais sur le continent au IX siècle ». 


\section{RÉSUMÉS}

La grammaire est la science fondamentale pour la compréhension et la transmission de la langue, vecteur de tous les savoirs. Dans les turbulences culturelles que connaît le monde romain d'Occident, l'Africain Donat a recueilli et systématisé (canonisé) les diverses traditions de la grammaire latine. Quatre siècles plus tard, les savants de la renaissance carolingienne restaurent et perfectionnent cette grammaire, qu'ils considèrent comme la base de toutes les sciences, celle qui permet d'accéder aux textes, et en particulier au texte par excellence : la Bible. Ainsi s'est mise au point la langue qui sera celle de la science médiévale, et pour partie moderne. On voudrait montrer comment la grammaire latine s'est installée au cœur du nouvel empire carolingien, via, bien sûr, l'Italie et l'Espagne, anciennes régions romanisées, mais aussi, ce qui est $a$ priori beaucoup plus surprenant, via les îles Britanniques et en particulier l'Irlande, qui n'a jamais été touchée par l'Empire romain et où le latin est « langue étrangère ».

\section{AUTEUR}

\section{MICHEL SOT}

Professeur émérite à Sorbonne université, membre de la section Histoire et philologie des civilisations médiévales du CTHS 


\title{
Astronomes voyageurs du XVII siècle : Cassini et les missions lointaines
}

\author{
Monique Gros
}

1 Dans la préface du premier volume de l'Histoire de l'Académie royale des sciences, on peut lire :

«Nous avons une Lune pour nous éclairer pendant nos nuits; que nous importe, dira-t-on, que Jupiter en ait quatre ? Pourquoy tant d'observations si penibles tant de calculs si fatiguans pour connoître exactement leur cours? Nous n'en serons pas mieux éclairés, et la Nature qui a mis ces petits Astres hors de la portée de nos yeux ne paroît pas les avoir faits pour nous. En vertu d'un raisonnement si plausible, on auroit dû négliger de les observer avec le Télescope et de les étudier, et il est sûr qu'on y eût beaucoup perdu. Pour peu qu'on entende les Principes de la Géographie et de la Navigation on sçait que depuis que ces quatre Lunes de Jupiter sont connues, elles nous ont été plus utiles par rapport à ces sciences que la nôtre ellemême; qu'elles servent et serviront toujours de plus en plus à faire des Cartes marines incomparablement plus justes que les anciennes et qui sauveront apparemment la vie à une infinité de Navigateurs ${ }^{1}$. "

2 La nouvelle Académie royale des sciences, créée fin 1666, montre ses priorités lors d'une de ses premières réunions, en janvier 1667, puisque dans les procès-verbaux des assemblées, le registre de mathématiques rapporte :

«Ce $11^{\mathrm{e}}$ de Janvier 1667. Mons. Auzout a présenté à l'Assemblée un mémoire des observations qu'il faudra faire a Madagascar, qui a été leu a la compagnie. [...] On donne ce Mémoire en gros seulement afin que chacun songe s'il y a quelque chose à adiouster et afin que ceux qui sont destines pour les faire puissent désicy se preparer pour cela. [...] On observera le plus exactement que l'on pourra toutes les Eclypses de Lune car pour celles du Soleil il ny en a point que nous puissions voir icy. On observera le plus souvent que l'on pourra les occultations et les emersions des Satellites de Jupiter pour correspondre aux observations qui s'en feront icy avec des Lunettes pareilles afin que de plusieurs observations conformes, on s'assure de la difference de longitude, apres quoy, on pourra faire plusieurs autres observations utiles ${ }^{2}$ » 
Ce mémoire, joint à la liasse des feuillets, précise les observations des astres à effectuer par les futurs voyageurs. Les feuillets 37 à 40 sont consacrés au "Mémoire des Instrumens et autres choses nécessaires dont il faudra fournir ceux qui iront à Madagascar ", présenté par Adrien Auzout (1622-1691); dans la description des observations relatives à la lune - feuillet 45 - il est précisé que les voyageurs à Madagascar n'y seront qu'en 1671. Cette liasse de feuillets jointes aux procès-verbaux des assemblées des académiciens couvre l'année 1667 et une partie de 1668, jusqu'à l'assemblée du 24 août 1668 ; d'autres mémoires y sont incorporés, mémoires qui ont été lus en séance, par exemple "Manière de trouver les lieux des étoiles fixes par le moyen d'une horloge à pendule et de filets comme aussi la réfraction »- feuillet 8 - par Christian Huygens (1629-1695).

Dans ce même registre, on peut consulter un rapport de l'abbé Jean Picard (1620-1682) relatif aux observations faites en 1666 des diamètres des planètes; à la suite de ce relevé, Picard décrit l'histoire des tables astronomiques, remontant aux toutes premières, celles dues à Ptolémée, puis à celles effectuées par les « soins et la libéralité d'Alfonse $9^{e}$ Roy de Castille ${ }^{3} »-$ les tables alphonsines - jusqu'aux tables plus récentes : il rappelle un des échecs les plus connus, celui de l'éclipse de soleil du 14 novembre 1659 , qui a commencé une demi-heure plus tôt qu'indiqué dans les tables rudolphines, les plus récentes alors utilisables. Il insiste ainsi sur le besoin de tables plus exactes.

Dans ce registre de mathématique, on décèle déjà le dessein de l'académie, à savoir monter des expéditions lointaines pour l'établissement de cartes modernes, et son souci de pédagogie à destination de ses membres par le nombre de mémoires et ouvrages lus en séance, dorénavant joints au registre des séances.

Le voyage à Madagascar, tel qu'il était programmé en ce mois de janvier 1667, n'eut pas lieu, le contexte politique ne s'y prêtant plus. Le souci d'obtenir des cartes géographiques plus modernes a néanmoins subsisté. Ainsi, plus tard, en 1668 :

«Le mesme jour mercredy 6è de Juin la Compagnie estant assemblée a la Bibliothèque du Roy Mr. de Carcavi a dit que sur ce quon avait resolu dans la dernière assemblée denvoyer une personne expres aux environs de Paris pour essayer la maniere la plus commode de faire des Cartes Geographiques [...] Mrs. de Roberval et Picard de prescrire au dit sieur [...] les lieux où il doit aller pour prendre les angles de position et la maniere dont il les doit prendre4.»

7 Une première assemblée, le mercredi 30 mai 1668, avait débattu de ce sujet et nommé Gilles Personne de Roberval (1602-1675) et Picard pour superviser l'opération; un instrument avait été défini, un cercle entier de 15 pouces de diamètre, et Jacques Buot (1603 ?-1684) désigné pour sa construction.

\section{Le contexte scientifique}

En 1668, Giovanni Domenico Cassini (1625-1712), astronome exerçant à Bologne, publie un ouvrage d'éphémérides des satellites de Jupiter: Ephemerides Bononieneses Mediceorum Siderum. Ces éphémérides, beaucoup plus précises que les précédentes, étaient attendues par les astronomes; dans l'analyse de cet ouvrage parue dans le numéro du Journal des sçavans du lundi 17 décembre 1668 se trouvent des explications sur les longitudes :

"Il est nécessaire de rapporter icy ce que l'auteur dit de la difficulté qui se rencontre à observer les longitudes, et des causes d'où elle procede ${ }^{5}$. » 

observations qui témoignent de la qualité des éphémérides fournies par Cassini. La recherche des longitudes se trouve alors facilitée; Cassini accepte la proposition de Colbert et Louis XIV de venir travailler à Paris. Il s'ensuit une longue période, quasiment un siècle, de présence d'astronomes de la lignée de Cassini exerçant leurs compétences astronomiques et géographiques dans le cadre de l'académie et à l'observatoire royal quand celui-ci sera construit, la première pierre ayant été posée et la méridienne tracée le jour du solstice d'été en juin 1667.

'en avril 1669, Jean-Dominique Cassini arrive à Paris, l'astronomie dispose des outils les plus modernes pour résoudre l'un des problèmes à l'origine de la création de l'Académie royale des sciences et de son observatoire: la modernisation des cartes géographiques.

11 La méthode : il s'agit d'observer un même événement astronomique à partir de deux lieux d'observation (méridiens différents). La différence d'heure locale de l'événement observé fournit la différence de longitude des deux lieux d'observation. L'événement astronomique a longtemps été une éclipse de lune ou de soleil ; ces événements étant relativement rares et d'observation délicate, la méthode la plus récente, au sens $d u X_{V I I}{ }^{\mathrm{e}}$ siècle, encouragée par Cassini, consiste à observer et noter l'heure de l'émersion ou de l'immersion des satellites de Jupiter - découverts par Galilée en 1609 - dans l'ombre de la planète. Cette méthode implique néanmoins des observations coordonnées et des mesures de temps précises.

Les instruments: en 1657, Huygens adapte le pendule comme régulateur du mouvement des horloges à roues crantées en usage jusqu'alors ; l'abbé Picard a mis au point le micromètre à fil mobile, qu'il a adapté aux grands instruments d'observation, lunettes et quarts de cercle. Disposant dorénavant d'éphémérides précises, les phénomènes à observer sont prévus, l'observateur peut se préparer à l'observation.

Peu de temps après son arrivée à Paris, en avril 1669, Cassini accompagne Picard dans la mission d'observations et de mesures des environs de Paris. Le registre des procèsverbaux de l'Académie indique ainsi :

«Le mercredi 31è jour de juillet 1669. [...] M. Picard, qu'on avait prié d'aller à Mareuil avec M.Cassini pour vérifier le travail de ceux qui font des cartes géographiques des environs de Paris, a lu un mémoire contenant la relation de son voyage en ces termes ${ }^{6}$."

14 Cette mention de Cassini semble être la première dans les procès-verbaux ; Cassini à son arrivée en France ne maîtrise pas encore la langue française. L'examen des procèsverbaux des réunions ultérieures de l'académie montre son implication de plus en plus grande dans les débats.

\section{Les missions astronomiques et géographiques}

15 La première mission astronomique et géographique organisée par l'Académie royale des sciences est donc effectuée aux environs de Paris. Elle a été décidée formellement lors de l'assemblée du 6 juin 1668. Peu de temps après son arrivée à Paris, en 1669, Cassini a participé à une vérification, en compagnie de l'abbé Picard, des observations et mesures effectuées dans les environs de Paris. Picard, en 1671, se déplaça à Uranibourg pour établir la différence de longitude entre l'observatoire d'Uranibourg, 
où Tycho Brahé avait effectué ses observations, et le tout nouveau Observatoire royal, tandis que Richer allait à Cayenne en 1671-1673. D'autres expéditions astronomiques furent entreprises, les unes pour améliorer le tracé des côtes et corriger la carte de France, les autres pour obtenir ou corriger les longitudes en des lieux lointains. Parmi les premières, on peut citer les observations faites à Brest et Nantes en 1672, le long des côtes de Bretagne en 1679, à Bayonne en 1680, en Flandres et Picardie en 1681, dans le Languedoc, en Provence et Lyon en 1682 : ces voyages permirent aux académiciensastronomes de mettre au point leurs méthodes d'observation, de tester leurs instruments et de vérifier les procédures. Ils impliquèrent Cassini, Philippe La Hire (1640-1718), Picard, Olaus Rømer (1644-1710), soit des académiciens profitant des congés de l'académie, ayant une pratique des observations et de l'astronomie, habitués à observer et à travailler de concert. Les expéditions les plus lointaines furent effectués par des observateurs qu'il fallut former aux bases de l'astronomie, aux observations astronomiques et aux procédures.

Il n'est que de rappeler le commentaire de Picard dans son compte-rendu du voyage à Uranibourg (1680) :

«Je partis de Paris au mois de Juillet 1671 avec un ayde nommé Estienne Villiard que j'avais dressé aux observations [...] pendant que le célèbre astronome M. Cassini travaillerait aussi de concert à l'observatoire Royal ${ }^{7}$."

Parmi les voyages lointains qui se sont succédé à partir du XVII siècle, celui aux îles Canaries, pour la mesure du méridien origine, et la mission des jésuites mathématiciens du roi à la Chine peuvent être distingués : ils sont les premiers à avoir été entrepris par des observateurs étrangers à l'Académie, qu'il aura fallu former à l'observation et à la mesure astronomique.

\section{Le voyage aux îles Canaries}

Le 14 décembre 1680, Cassini présente un rapport à l'académie, "L'Invention des longitudes vérifiée par les observations nouvelles par M. Cassini » :

«Sur le projet que je donnay au public l'an 1668 la mesme année que j'eus l'honneur d'estre appellé en France au service de sa Majesté les Astronomes de l'Académie Royale des Sciences travaillent presentement a la determination des longitudes necessaires a la perfection des Cartes de Géographie et de la Navigation. [...] Nous nous servons aujourd'hui des eclipses des Satellites de Jupiter qui sont fort frequentes et qui se determinent avec une grande précision sans hesiter d'un quart de minute [...]. Il y a douze ans que mes tables sont publiées et pendant ce temps Jupiter ayant fait une revolution entière par le Zodiaque je les ay toujours comparées aux observations faites par toutes les parties de son orbe pour les perfectionner davantage ${ }^{8}$. "

Il s'ensuit la liste des voyages déjà effectués, avec des mesures ayant permis la validation de la méthode employée et la justification d'un futur voyage à l'île de Fer, partie occidentale des îles Canaries et lieu par où passe le méridien origine défini par Ptolémée et conservé par un décret de Louis XIII. C'est lors de l'assemblée du 14 juin 1681 que cette mission est décrite et son avancement présenté :

« [...] Monseigneur ayant donné ordre a Mr. Cassini d'instruire une personne qu'on puisse envoyer en ces isles pour y faire les observations necessaires, il a instruit depuis plusieurs mois et exercé continuellement Mr Varin qui luy a été proposé par quelques uns de l'Academie, et qui se tient prest pour executer les ordres de Monseigneur quand il luy plaira de les donner ${ }^{9}$. » 


\section{reprises :}

«M. Cassini a fait son rapport de ce que le Roy lui avoit fait l'honneur de luy dire touchant le dessein qu'on a pris d'observer les longitudes et il luy a ordonné de luy faire son rapport quand il y aura quelque chose de nouveau. [...] M. Cassini a leu un projet qu'il a donné au R. P. de Fontaney pour observer les longitudes dans le voyage qu'il medite dans la Chine dont suit la copie ${ }^{10}$.»

Puis Cassini a commencé à lire un traité sur la correction des cartes géographiques :

«Projet pour les observations géographiques. [...] Après avoir envoyé par ordre de sa Majesté deux Mathématiciens aux Canaries pour y establir le premier meridien auquel il faut rapporter toutes les longitudes des autres lieux de la Terre, il ne se pouvoit présenter une occasion plus favorable pour pousser bien loin ce grand ouvrage que le projet qu'on fait presentement d'envoyer des habiles mathematiciens pour missionaires a la Chine ${ }^{11}$. »

Le voyage aux Canaries n'a pas encore eu lieu, mais déjà une expédition de jésuites mathématiciens en Chine est envisagée :

«Les RP Jésuites qui font profession de ces sciences et ont l'entrée dans ces missions sont très propres pour travailler a l'exécution de ce grand dessein, non seulement dans la Chine mais dans tout l'orient. Et le R. P. De Fontaney, Professeur de Mathématiques dans le Collège de Clermont, qui depuis longtemps a communication d'observations avec l'Académie Royale, y peut servir particulièrement ${ }^{12}$. »

Plusieurs recommandations techniques sont prescrites par Cassini; surtout, il insiste sur la coopération devant s'établir entre les observateurs, ainsi que sur leur formation :

«Comme ce travail est fondé principalement sur des observations concertées, ils formeront entre eux un corps qui agira toujours de concert, tantost ensemble, tantôt separement, tantost par eux mesmes, tantost par des personnes qu'ils instruiront sur les lieux et ils auront le soin de le remplir toujours de bons observateurs afin que ce qui ne pourra etre exécuté par les uns le soit par les autres dans la suite des temps ${ }^{13}$."

Un autre moyen de s'instruire et de vérifier la validité des mesures est de maintenir le contact entre les astronomes de l'observatoire royal et les observateurs partis en mission :

«Dans les occasions qui se présenteront du retour des vaisseaux en Europe, ils envoyeront leurs observations et relations a l'Académie Royale des Sciences avec laquelle ils entretiendront la correspondance plus frequente qu'il sera possible afin que comparant leurs observations a celles qu'on pourra faire en mesme temps dans les autres parties du monde, on puisse dresser la description exacte de toute la Terre $^{14}$.»

Jusqu'à la fin de l'année 1681, quasiment à chaque assemblée de l'académie, Cassini lit ses instructions en vue du voyage de Varin et Deshayes: le 13 décembre, ce sont les "Instructions particulières pour le voyage des Canaries ${ }^{15}$ ", en plus des instructions qu'il avait fournies lors du voyage à Cayenne ; le 20 décembre, "Instruction generale pour les observations geographiques a faire dans les voyages ", document de sept pages, précisant l'ensemble des réglages et opérations à effectuer avec, en premier point : « Avant le depart on reglera les pendules a celle de l'observatoire ${ }^{16}$. "

Le 17 janvier 1682, Cassini continue à informer ses collègues académiciens de l'avancement - ou plutôt du retard, et même de la modification de l'expédition :

«Mrs Varin et Deshayes ne pouvant aller aux Canaries a cause des Corsaires iront au Cap Verd en Afrique ou ils feront les observations pour la Longitude et la 
latitude et y attendront Mr De Glos qui les y doit joindre pour aller tous ensemble observer dans l'isle de St Thome sous la ligne equinoxiale suivant les memoires qu'on leur a donnés ${ }^{17}$. " observations astronomiques et physiques de MM. Varin, Des Hayes et de Glos faites à l'île de Gorée au Cap-Vert, dont la copie est jointe au procès-verbal sous le titre « Relation des observations de Mrs Varin Deshayes et DeGlos faites a la Gorée proche du cap vert ${ }^{21} »$. Trois rapports individuels sont joints. Le samedi 6 mars 1683 :

"Messieurs Varin, Deshayes et De Glos sont venus pour faire leur rapport des observations qu'ils ont faites. MrCassini a parlé de leurs observations Astronomiques. On a arresté que l'on feroit une seance a l'Observatoire pour verifier la longueur du pendule a secondes qui estoit moindre a la Gorée au cap vert et proche de la ligne ${ }^{22}$.» (longitude) entre deux lieux d'observation est présenté par Cassini le samedi 3 avril 1683 ; la méthode est jointe au registre de la séance : "Methode pour déterminer les longitudes par les observations des eclipses des satellites de Jupiter faites en un lieu comparées aux calculées pour un autre lieu ou on a fait d'autres observations avant et apres $^{23}$ ». Les déterminations de longitudes à la Guadeloupe et à la Martinique ont pu bénéficier, après vérification, de cette facilité.

Cassini, le véritable organisateur de cette expédition, en retient quelques leçons : les trois voyageurs ont réussi à remplir au mieux les objectifs scientifiques, en dépit d'un long et périlleux voyage entrepris par trois personnes de bonne volonté, sans affinité particulière, pour ne pas dire antagonistes, qu'il a fallu former puis accompagner par courrier. Le 19 juin 1683, Cassini présente un projet de prolongation de la méridienne d'une mer à l'autre (Méditerranée / océan Atlantique) approuvé par Colbert. Dans ce long mémoire, il énonce quelques points dont le quatrième, concernant plus spécialement la tenue des observations et des règles à suivre par les observateurs, résulte certainement de ce qu'il a appris du voyage en Afrique et aux îles d'Amérique et des difficultés attenantes ${ }^{24}$. 
«4 $4^{\circ}$ L'Academie employera en ces preparations des personnes habiles qu'elle instruira et exercera et acheminera aux operations. On fera le journal de toutes les operations qu'on envoiyera chaque semaine pour en scavoir tousjours l'estat et pour donner les instructions et les avis que la suite monstrera estre necessaires $5^{\circ}$ Ceux de l'Academie qui auront la direction de cette affaire iront sur les lieux pour commencer la preparation et aux temps des vacances ils y retourneront pour faire les operations qui demandent la derniere exactitude ${ }^{25}$. "

On mesure ainsi l'attention qu'a apportée Cassini - et apparemment lui seul parmi les académiciens - à ce voyage en Afrique et en Amérique, le soin qu'il a mis à instruire les futurs observateurs en leur fournissant par écrit toutes les instructions à chaque étape de leur périple, en leur précisant les opérations techniques à effectuer et en informant ses collègues académiciens de chaque avancée du projet.

L'examen de son journal d'observations, conservé à la bibliothèque de l'observatoire de Paris, témoigne également de l'implication constante, jour après jour, de Cassini dans l'organisation de l'expédition. Outre ses observations, il a l'habitude de noter quelques faits du jour, correspondance, incidents liés aux observations, visites - par exemple, « Ventus agitabat telescopium ${ }^{26} »$. On trouve ainsi mention de l'heure de l'immersion d'un satellite de Jupiter : "D23 Varin telescopio 19 ped $^{27}$ ", ce qui montre que Varin était présent ce jour à l'observatoire et participait aux observations.

35 Le $1^{\text {er }}$ janvier 1682 , Cassini rapporte :

«Je reçus une ltre de M Varin du 30 de decembre de Diepe. Le vent toujours contraire a empeche le vaisseau qui le doit porter au Cap vert de se mettre à la rade. Il faut attendre encore la maree de la nouvelle lune suivante ${ }^{28}$.

Le lendemain, 3 janvier 1682, on lit :

" J'ecrivis à MMs Varin et des Hayes a Diepe et Mg Gallois a S. Germain de l'interest de ces MMs pour poursuivre leur voyage ${ }^{29}$."

À la date du 10 janvier, Cassini écrit :

«J'écrivis a MM Varin et Deshayes la methode d'observer les longitudes par les hauteurs correspondantes de la lune. [...] Le matin Mons. d'Ancourt directeur general de la compagnie dAfrique y devant aller en peu de temps me vint trouver s'offrant d'y amener les matematiciens que Monsg Colbert a dessein d'y envoier a faire des observations astronomiques Jallay pour cela voir Mr de la Hire Mes Coubart et Agarat. Le lendemain j'allay pour le mesme dessein voir Mr Picard ${ }^{30}$.»

\section{Le 13 janvier :}

«J'allay à S.Germain proposer a Monseigneur Colbert le voyage d'Afrique et les sieurs pour y envoier. Il l'approuva et m'ordonna de faire venir d'Honfleur Monsieur de Glos et de tenir pres Ms Agara et Coubart. Il m'ordonna d'en parler a $\mathrm{Mg}$ Galloys auquel il aurait donne les depeches necessaires ${ }^{31}$. »

\section{Agara et Coubart, de futurs assistants?}

Le 15 janvier, Cassini note :

«Je prescrivis a M de Glos a Honfleur de se rendre a Paris pour prendre des instructions. [...] Ms Agarat et Coubart vinrent s'exercer a l'Observatoire. [...] M L'Abbe Galois me mit entre les mains un ordonance du Roy de 2000 livres payables au Tresor Royal pour MM Varin et des Hayes en antedonation [?] des voyages a faire par eux au Cap vert a l'Isle de S. Thome et au Canaries ${ }^{32}$. »

\section{Le 16 janvier :}

«Ayant represente a Monseigneur Colbert que le depart de Mr Dancourt est trop presse pour pouvoir suffire aux preparatifs de ces MMs qu'on a dessein d'envoier en 
Afrique Monseigneur a establi que MMs Varin et Deshayes iroient a l'Isle de $\mathrm{S}$ Thome et ces mes s'ensuivraient pour aller aux Canaries et que $\mathrm{M}$ de Glos iroit joindre Ms Varin et Deshayes au Cap Vert pour aller a l'Isle de S Thome ${ }^{33}$. »

En date du 17 janvier, on lit :

«M Bartillac [?] me paya le $2000 \mathrm{l}$ que le Roy a ordonne a MM Varin et Deshayes je les porteray a M Valensi qui se charge de le leur faire servir a Diepe par une ltre de change donc ils n'auront paye qu'un pour $100^{34}$. »

\section{Le 18 janvier :}

« $\mathrm{M}^{\mathrm{r}}$ Dancourt partit aujourd'hui pour Brest et vint à l'observatoire solliciter le départ de ceux qui doivent aller observer en Afrique. Je recus la response de M. de Glos qu'il sera parti de Honfleur le 25 de ce mois ${ }^{35}$. »

\section{Le 30 janvier :}

« Mons de Glos vint a l'Observatoire. Je le presentay a Mg l'Abbe Galois et ensuite à monseig Colbert pour recevoir ses ordres pour le voyage de l'isle de S Thome. Monseigneur ordonna que je lui donnasse les instructions necessaires et que je l'exercasse aux observations et que visite $\mathrm{mr}$ l'Abbe Gallois pour ses depeches qu'il auroit delivrees ${ }^{36}$. »

Le $1^{\text {er }}$ février, en fin de journée :

"J'écrivis a Monsieur Galois pour soliciter les depeches de $\mathrm{M}$ de $\mathrm{Glos}^{37}$. »

Puis, le 3 février :

"Japris de Mr le Theologal que Mr Dancourt devait arriver ce soir a Brest et qu'il fallait soliciter le depart de $\mathrm{M}$ de $\mathrm{Glos}^{38}$.»

\section{Le 4 février :}

«J'ecrivay a MMs Varin et Deshayes l'ordre de monseigneur Colbert pour aller observer a l'Isle de S.Thomay. [...] Je presentay Mr de Glos a l'Académie ${ }^{39}$. »

Le 9 février :

«J'apprens par ltres de MMs Varin et Deshayes que le vent changea a Dieppe le 7 de fevrier a sudest et qu'ils allaient alors s'embarquer pour l'Aphrique. Il semble que depuis six mois le mesme vent a este a Dieppe et a Paris ${ }^{40}$."

Le 12 février :

«Mr Daincourt par une ltre du 6 de ce mois me fait savoir son arrivee a Brest le matin du 4 ayant mis 16 jours en voyage a cause du mauvais temps qu'il ne sera en estat de mettre a la voile que le 3 de mars. Il solicite le depart de M de Glos ${ }^{41}$. »

\section{Le 13 février :}

«Je presentays de nouveau Mr de Glos a Monseigneur Colbert qui lui fit un ordonnance de 2300 livres pour aller à la Goree et a L'Isle de S. Thome ${ }^{42}$. »

\section{Le 25 février :}

«Mr de Glos partit pour Brest avec un sextant de 3 pieds, une lunette de 18 un cercle d'un pied et un anneau astronomique et une pendule ${ }^{43}$."

52 À plusieurs reprises, les $1^{\mathrm{er}}, 2,6,8$ février 1682 , des mesures sont explicitement rapportées par Cassini comme étant effectuées par de Glos; exceptionnellement, le 2 février, il est précisé « Mr De Glos prit les hauteurs suivantes [... ${ }^{44}$ ».

Quelques jours plus tard, le 14 mai :

«Messieurs Agarat et Coubarc vinrent prendre conge a l'Academie pour partir le premier pour Rochefort le second pour Brest. Je me chargay de leur faire avoir des instruments pour observer dans leur navigation ${ }^{45}$. 

des jésuites en Chine en tant que mathématiciens chargés de faire des observations astronomiques ont fait l'objet de nombreux travaux. Ils reçurent leurs lettres de patente le 20 décembre 1684 ; peu de temps après leur nomination, ils ont été mis en relation avec les académiciens. Cette mission a été considérée comme très importante. Elle avait été envisagée de longue date: le samedi 29 novembre 1681, lors de l'assemblée hebdomadaire de l'académie, Cassini, après avoir fait le point sur le projet de voyage aux Canaries, mentionnait déjà un projet de voyage pour «des habiles mathématiciens ${ }^{48}$ » en Chine. Dans le projet qu'il lit à ses collègues académiciens, Cassini propose deux groupes d'observateurs, l'un passant par la route de la Méditerranée pour aller à Alep et de là passer en Perse pour se rendre à Ormuz, l'autre prenant la route de l'océan et faisant le tour de l'Afrique. Un jésuite, le père Jean de Fontenay (1643-1710) a déjà observé les astres; il a communiqué avec les académiciens à plusieurs reprises.

«Le Samedi dernier de fevrier 1682 [...] Mrs Cassini, Picard et de la Hire ont confere leurs observations de la dernière Eclipse de lune qu'ils ont faites separement et les ont comparees aussi avec les observations du P. de fontaney et toutes se sont trouvées fort conformes. Ils en donneront une Copie pour mettre dans les Registres ${ }^{49}$.»

Plus tard, le 23 juillet 1682 : 
«Cassini [...] a leu aussi un projet qu'il a donne au P. de Fontaney professeur de Mathematiques au college de Clermont pour observer les longitudes dans le voyage qu'il medite dans la Chine ${ }^{50}$. " novembre 1681. C'est plus tard que l'expédition s'effectue: dans le procès-verbal de l'assemblée du 16 décembre 1684, on lit :

«Le samedy seiziesme de Decembre 1684 la Compagnie estant assemblée Mr Cassini a continué la lecture de sa Preface. Mr l'Abbé De L'anion luy a donné ses Remarques. Mr De La Chapelle a dit à la Compagnie que l'intention de Monseigneur De Louvois que le Pere Fontenay et les autres missionnaires que les Peres Jesuites envoyent a la Chine conferent avec Mrs De l'Academie avant que de partir et particulierement que Mrs Cassini et De La hire qu'ils observent et qu'ils conferent ensemble ${ }^{51}$. »

La réception à l'Assemblée des Jésuites mathématiciens envoyés par le roi en Chine eut lieu la semaine suivante ; elle est rapportée comme suit :

«Le Mercredy vingtiesme de Decembre 1684. [...] Le P. De Fontenay est venu avec trois Peres de sa Compagnie qui vont dans la Chine et qui souhaittent avoir Correspondance avec l'Academie tant pour les observations astronomiques que pour les experiences de Physique. Mr Cassini et Mr De La hire leur donneront des Memoires pour faire des observations tant a la Chine que dans les lieux par ou ils passeront, particulierement des eclipses des satellites de Jupiter ; Mr Dodard leur donnera aussi un Memoire pour les Plantes, et pour les prier d'observer ce qu'ils jugeront de plus curieux pour la physique ${ }^{52}$.»

Peu de temps après :

«Le Mercredy dixseptiesme de janvier 1685, La Compagnie estant assemblee le P. fontenay est venu a l'Assemblée avec les cinq Peres Jesuites qui vont a la Chine. On a leu un memoire des principales choses que les Pères doivent observer pour l'astronomie, et la Physique, qui leur a esté donné de la part de Monseigneur de Louvois ${ }^{53} \cdot »$

Le journal d'observations de Cassini témoigne, le 7 décembre 1684, d'une visite à l'Observatoire des observateurs jésuites: «[...] ceux de Siam vinrent à l'observatoire ${ }^{54}$. »; le 21 décembre, juste après la description presque minute après minute d'une éclipse de Lune et la mention, à $4 \mathrm{~h} \mathrm{11}$, de l'immersion du premier satellite dans l'ombre de Jupiter, les noms des astronomes jésuites apparaissent au bas de la page « Joannes de Fontaney S. J., Claudius Visdelou S. J., Joachimus Bonnet, Guido Tachard J. S. ${ }^{55}$ ", ces derniers ayant probablement observé l'éclipse de ce jour.

Le 25 décembre 1684, c'est à Cassini de se déplacer :

«J'allay a Versaille pour presenter au Roy l'observation de l'eclipse de lune Sa Mté

la recut le matin et m'ordonna de retourner pour lexpliquer apres dine et celle la considera de nouveau et me parla des Jesuites qui vont a la Chine ${ }^{56}$."

Le père de Fontaney, mathématicien aux compétences déjà reconnues, rencontra Cassini à l'observatoire à plusieurs reprises: le 9 décembre 1680, à propos de l'observation de la comète de $1680^{57}$; le 21 février 1682, à propos d'une horloge apportée à l'observatoire par le père de Fontanay: «[...] Je la reglay a 6 heures a la mienne ${ }^{58} »$; de même, en octobre 1684 :

« Le 3 octobre serein mais diverses occupations m'empecherent de rien observer. Je comparay les constellations chinoises aux nostres en compagnie du P. Fontenay. Mr de xxx [illisible] m'envoia la dissertation du P. Adam sur la Cronologie chinoise que j'examinay ${ }^{59}$. » 

ce que la carte du monde soit établie et que la querelle sur la figure de la Terre soit résolue; mais les expéditions astronomiques lointaines ont continué plus longtemps : observation de phénomènes astronomiques particuliers, à des instants privilégiés passages de Vénus devant le soleil, éclipses totales de soleil -, avec l'utilisation de télescopes spécifiques. Quel que soit le but de la mission, sont encore nécessaires une organisation solide, une formation sur l'objet du voyage, des instructions quant à l'instrument à utiliser pour les observations. Finalement, former des observateurs n'a peut-être pas beaucoup changé : lire des documents, modes d'emploi divers, apprendre des collègues astronomes déjà experts, pratiquer et échanger expérience et résultats.

\section{BIBLIOGRAPHIE}

CASSINI Jean-Dominique, Ephemerides Bononieneses Mediceorum Siderum..., Bologne, Emilio Maria

Manolesso et frères, 1668. 
CASSINI Jean-Dominique, Recueil d'observations faites en plusieurs voyages par ordre de sa Majesté, pour perfectionner l'astronomie et la géographie. Avec divers traitez astronomiques, Paris, Imprimerie royale, 1693.

DEW Nicholas, « Scientific travel in the Atlantic world: the French expedition to Gorée and the Antilles, 1681-1683 », British Journal for the History of Science, 43 (1), 2009, p. 1-17.

DUMONT Simone et GROS Monique, «Les premiers astronomes-cartographes dans les îles », dans Pelletier Monique (dir.), Les îles : du mythe à la réalité, 2002, Paris, Éditions du CTHS, p. 131-147.

FEUILLÉE Louis, Journal des observations physiques, mathematiques et botaniques, faites par l'ordre du Roy sur les côtes orientales de l'Amerique meridionale, \& dans les Indes occidentales, depuis l'année 1707 jusques en 1712, t. I, Paris, P. Giffard, 1714.

PICARD Jean, Voyage d'Uranibourg ou Observations Astronomiques faites en Dannemarck, Paris, Imprimerie royale, 1680 .

TACHARD Guy, Voyage de Siam des Peres jesuites envoyez par le Roy aux Indes \& à la Chine: avec leurs observations astronomiques, et leurs remarques de physique, de géographie, d'hydrographie, \& d'histoire, Paris, A. Seneuze et D. Hortemels, 1686.

VARIN, DESHAYES Jean, CASSINI Jean-Dominique, GLOS Guillaume de, Les Élémens de l'astronomie vérifiez par M. Cassini par le rapport de ses Tables aux observations de M. Richer faites en l'isle de Caïenne. Avec les observations de MM. Varin, Des Hayes et de Glos faites en Afrique et en Amérique, Paris, Imprimerie royale, 1684 .

VARIN, DESHAYES Jean, GLOS Guillaume de, « Voyages au Cap Verd en Afrique et aux Isles de l'Amérique ", dans Mémoires de l'Académie royale des sciences, 1729, t. VII, p. 431-459.

wOLF Charles, Histoire de l'Observatoire de Paris de sa fondation à 1793, Paris, Gauthier-Villars, 1902.

\section{NOTES}

1. Histoire de l'Académie royale des sciences, MDCXCIX, préface, p. IV.

2. Académie royale des sciences, Procès-verbaux, t. III, 11 avril 1668-27 mars 1669, registre de mathématique, 11 janvier 1667, fol.155, 43, 47. https://gallica.bnf.fr/ark:/12148/ bpt6k55678s/f560.

3. Ibid., fol. 31 .

4. Académie royale des sciences, Procès-verbaux, t. III, 1667-avril 1668, Registre de mathématique, 6 juin 1668, fol.52-53. https://gallica.bnf.fr/ark:/12148/bpt6k55678s/ f560.

5. Journal des Scavans, lundi 17 décembre 1668, p. 154-156.

6. Académie royale des sciences, Procès-verbaux, t. 88, 1669, Registre de mathématique, 31 juillet 1669, fol. 126. https://gallica.bnf.fr/ark:/12148/bpt6k55764c.

7. J. Picard, Voyage d'Uranibourg ou Observations Astronomiques faites en Dannemarck, p. 2.

8. Académie royale des sciences, Procès-verbaux, t. 9, 18 novembre 1679-29 juin 1683, Registre de mathématique, 14 décembre 1680, fol.89-90. https://gallica.bnf.fr/ark:/ 12148/bpt6k556852.

9. Ibid., 14 juin 1681 , fol. 107.

10. Ibid., 29 novembre 1681, fol. 123-124. 
11. Ibid., 29 novembre 1681, fol. 125.

12. Ibid., 29 novembre 1681, fol. 125.

13. Ibid., 29 novembre 1681, fol. 126-127.

14. Ibid., 29 novembre 1681, fol. 127.

15. Ibid., 13 décembre 1681, fol. 134-137.

16. Ibid., 20 décembre 1681, fol. 141, 145.

17. Ibid., 17 janvier 1682, fol. 148.

18. Ibid., février 1682, fol. 150-154.

19. Ibid., 23 juillet 1682, fol. 168 .

20. Ibid., 14 novembre 1682, fol. 180 .

21. Ibid., 21 novembre 1681, fol. 181.

22. Ibid., 6 mars 1683, fol. 191.

23. Ibid., 3 avril 1683, fol. 205.

24. Voir N. Dew, Scientific travel in the Atlantic world: the French expedition to Gorée and the Antilles, 1681-1683 ; S. Dumont et M. Gros, « Les premiers astronomes-cartographes dans les îles, du mythe à la réalité », p. 131-147.

25. Académie royale des sciences, Procès-verbaux, t. 9, 18 novembre 1679-29 juin 1683, Registre de mathématique, 19 juin 1683, fol.222-223. https://gallica.bnf.fr/ark:/12148/ bpt6k556852.

26. «Le vent a fait bouger la lunette », Observatoire de Paris, J.-D. Cassini, « Journal des observations faites à l'Observatoire royal de Paris, $1^{\mathrm{er}}$ janvier 1680-25 décembre 1683 ", D1/7, p. 46. https://bibnum.obspm.fr/ark:/11287/1j0RP.

27. « $23^{\mathrm{e}}$ jour [de septembre], Varin, avec la lunette de 23 pieds... », ibid., 23 septembre 1681 , p. 50.

28. Observatoire de Paris, J.-D. Cassini, « Journal des observations faites à l'Observatoire

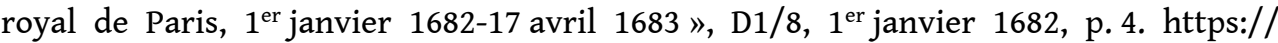
bibnum.obspm.fr/ark:/11287/rdNQf.

29. Ibid., 3 janvier 1682, p. 5.

30. Ibid., 10 janvier 1682, p. 8.

31. Ibid., 13 janvier 1682, p. 9.

32. Ibid., 15 janvier 1682 p. 10-11.

33. Ibid., 16 janvier 1682, p. 11.

34. Ibid., 17 janvier 1682, p. 11.

35. Ibid., 18 janvier 1682, p. 12.

36. Ibid., 30 janvier 1682, p. 17.

37. Ibid., $1^{\text {er }}$ février 1682, p. 17.

38. Ibid., 3 février 1682, p. 18.

39. Ibid., 4 février 1682, p. 18.

40. Ibid., 9 février 1682, p. 21.

41. Ibid., 12 février 1682, p. 22.

42. Ibid., 13 février 1682, p. 22. 
43. Ibid., 25 février 1682, p. 34.

44. Ibid., 2 février 1682, p. 18.

45. Ibid., 14 mai 1682, p. 37.

46. C. Wolf, Histoire de l'Observatoire de Paris de sa fondation à 1792, p. 122.

47. Histoire de l'Académie royale des sciences, t. VII, partie II, 1729.

48. Cf. supra, note 11.

49. Académie royale des sciences, Procès-verbaux, t. 9, 18 novembre 1679-29 juin 1683, Registre de mathématique, dernier samedi de février 1682, fol. 149. https://gallica.bnf.fr/ ark:/12148/bpt6k556852.

50. Ibid., 23 juillet 1682, p. 169.

51. Académie royale des sciences, Procès-verbaux, t. 11, 23 juin 1683-20 avril 1686, Registre de physique, décembre 1684, fol.114. https://gallica.bnf.fr/ark:/12148/bpt6k55687r/ f230.

52. Ibid., 20 décembre 1684, fol. 115.

53. Ibid., 17 janvier 1685, fol. 116.

54. Observatoire de Paris, J.-D. Cassini, « Journal des observations faites à l'Observatoire de Paris et au château de Thury, 6 juin 1684-3 mai 1685 et 3 mars 1685-31 mai 1685 ", 3/2A et 3/2B, 7 décembre 1684, p. 116. https://bibnum.obspm.fr/ark:/11287/2p8hB.

55. Ibid., 21 décembre 1684, p. 137.

56. Ibid., 25 décembre 1684, p. 140.

57. Observatoire de Paris, J.-D. Cassini, « Journal des observations faites à l'Observatoire royal de Paris, $1^{\text {er }}$ janvier 1680-25 décembre 1683 ", D1/7, 9 décembre 1680, p. 30. https://bibnum.obspm.fr/ark:/11287/1j0RP.

58. Observatoire de Paris, J.-D. Cassini, « Journal des observations faites à l'Observatoire royal de Paris, $1^{\mathrm{er}}$ janvier 1682-17 avril $1683 »$, D1/8, 21 février 1682, p. 30. https:// bibnum.obspm.fr/ark:/11287/rdNQf.

59. Observatoire de Paris, J.-D. Cassini, « Journal des observations faites à l'Observatoire de Paris et au château de Thury, 6 juin 1684-3 mai 1685 et 3 mars 1685-31 mai 1685 ", 3/2A et 3/2B, 3 octobre 1684, p. 89. https://bibnum.obspm.fr/ark:/11287/2p8hB.

60. L. Feuillée, Journal des observations physiques, mathematiques et botaniques, faites par l'ordre du Roy sur les côtes orientales de l'Amerique meridionale, \& dans les Indes occidentales, depuis l'année 1707 jusques en 1712, t. I, épître, p. 2.

\section{RÉSUMÉS}

Depuis la découverte des satellites de Jupiter par Galilée (1564-1642) et leur exploitation qu'il a suggérée pour la détermination des longitudes, depuis les travaux de Christian Huygens (1629-1695) et de Jean-Dominique Cassini (1625-1712), les astronomes ont disposé des outils nécessaires à une amélioration des cartes des côtes du royaume et de celles des pays et 
continents en cours d'exploration. Louis XIV et Colbert ont encouragé cet effort de modernisation par la création, en 1666, de l'Académie royale des sciences et la construction, dès 1667 , de ce qui sera très vite l'observatoire royal. Les académiciens et astronomes, JeanDominique Cassini en particulier, s'impliquent dans l'organisation de multiples expéditions, que ce soit le long des côtes du royaume ou dans des pays lointains, impliquant des observations astronomiques effectuées par des voyageurs ayant été instruits sur les procédures. Toute une technicité est nécessaire: les ouvrages rédigés par les voyageurs ayant effectué de multiples observations astronomiques instruisent sur l'aide qu'ils ont reçue des académiciens et astronomes. Ma communication portera sur quelques témoignages, imprimés et manuscrits, d'origines diverses, sur l'instruction des voyageurs-observateurs.

\section{AUTEUR}

\section{MONIQUE GROS}

Sorbonne Université et CNRS (UMR 7095), Institut d'astrophysique de Paris 


\title{
Transmettre le savoir à travers la
} traduction : interprètes européens et chinois auprès de la maind'œuvre chinoise employée en France pendant la Première Guerre mondiale

\author{
Yuan Hua Liu-Honvault
}

1 La traduction d'œuvres depuis une langue étrangère vers le chinois a commencé par celle des textes sacrés du bouddhisme, puis s'est déployée vers les œuvres scientifiques. À partir de la seconde guerre de l'Opium intervient une troisième vague de traductions, avec les œuvres littéraires. Quand les traducteurs ne maîtrisaient pas suffisamment la langue du livre à traduire, ils étaient assistés par des interprètes. Ces interprètes étaient à l'origine des étrangers habitant près des frontières ou leurs descendants ; peu à peu, la fonction d'interprète s'étendit en Chine à différents domaines de la vie économique, politique, religieuse ou sociale ${ }^{1}$.

2 L'augmentation des déplacements et du commerce, le développement de la colonisation et du champ des relations internationales se sont déployée tout au long du XIx siècle, mais les progrès techniques des moyens de transport et l'intensification des échanges, qui augmentaient les contacts entre États et populations, se sont heurtés aux différences de langue. Le recours à l'interprète s'imposa souvent, et il devint un personnage clef dans de nombreuses situations commerciales, fiscales, militaires ou politiques. Leur nombre augmenta très sensiblement, avec des niveaux de professionnalisation différents : à côté des interprètes occasionnels, aux capacités approximatives, dans les villages ou les quartiers, apparurent des interprètes professionnels libéraux et des interprètes fonctionnaires. 
3 Parallèlement, des formes de regroupement linguistique existent. En Chine, la langue chinoise contemporaine se divise en grandes zones de dialectes et une zone de mandarin ; la zone du mandarin est formée par différents guan hua (mot qui désigne la «langue des officiels", c'est-à-dire la prononciation standard du chinois, utilisée au niveau des couches supérieures et dans les textes religieux). Les dialectes issus de cette zone du mandarin sont plus faciles à comprendre que les dialectes régionaux utilisés dans les zones de dialectes régionaux (comme le cantonais). Durant la Grande Guerre, $80 \%$ des ouvriers chinois (recrutés dans le Nord) sont originaires de cette zone du mandarin.

4 La Première Guerre mondiale, en se généralisant, élargit le champ des personnels mobilisés, notamment les soldats ou les salariés coloniaux ou extra-européens, et celui des langues qu'ils devaient utiliser. Elle prolongea en les accentuant les tendances amorcées au siècle précédent. Ainsi, au milieu du XIX siècle, le gouvernement anglais avait nommé des student interpreters ${ }^{2}$ affectés en Chine. Il s'agissait à l'origine d'un poste de premier échelon dans le service diplomatique et consulaire britannique et américain de certains pays. Le Foreign Office britannique avait nommé les student interpreters après l'ouverture de la Chine et du Japon au milieu du xIX ${ }^{e}$ siècle pour apprendre la langue du pays, dans le but de développer un corps consulaire s'exprimant couramment dans les langues locales. Ces fonctionnaires consulaires devaient rester dans le pays choisi pendant toute leur carrière. La naissance de l'interprétariat diplomatique avait ainsi déjà créé ce besoin d'interprètes spécialisés. Quand les gouvernements français, puis britannique, décidèrent de recruter de la main-d'œuvre auxiliaire en Chine, la question de l'interprétariat devint cruciale.

5 Les sources dont nous disposons sur ce sujet sont relativement dispersées. Les principaux dossiers d'archives se partagent entre la Chine, la France, la GrandeBretagne et les États-Unis. Pour le personnel chinois recruté par la France, les dossiers du Service historique de la Défense constituent un point de départ ${ }^{3}$. Aux archives nationales britanniques, les documents du Foreign office évoquent les difficultés d'embauche des interprètes chinois et européens, tandis que ceux du War Office mettent plus l'accent sur la compétence insuffisante de candidats inexpérimentés et ses effets sur la discipline et le rendement des ouvriers ${ }^{4}$.

6 Dans la littérature imprimée, on trouve des informations sur les interprètes chinois dans des ouvrages qui décrivent pour la plupart de jeunes étudiants venant de Chine, manquant d'expérience sociale et professionnelle ${ }^{5}$. Quant aux officiers européens parlant chinois, l'analyse sur leurs capacités linguistiques est limitée et les conditions de leur recrutement sont rarement évoquées. Ceux venant de Chine sont issus de plusieurs horizons ${ }^{6}$. Les différents emplois des interprètes dans les compagnies chinoises en Europe n'ont pas été bien identifiés ${ }^{7}$. Un des premiers ouvrages académiques importants sur le sujet des travailleurs chinois en France est rédigé en anglais et analyse leur venue en France sous l'angle de l'immigration ${ }^{8}$. Par ailleurs, un certain nombre d'ouvrages d'époque ont été repris et enrichis par des travaux contemporains ${ }^{9}$.

7 Avec le recrutement massif d'ouvriers chinois à partir de 1916 (plus de 100000 en quelques mois), la question de la langue devint capitale pour leur transmettre des ordres et encourager leur productivité. Pour y répondre, on pouvait imaginer le recrutement soit de nombreux officiers et sous-officiers interprètes britanniques parlant le chinois; soit le recrutement d'un certain nombre d'interprètes chinois, en 
leur confiant des fonctions d'encadrement (officiers ou sous-officiers interprètes chinois); soit l'association d'officiers interprètes britanniques en nombre limité et d'un certain pourcentage d'interprètes chinois ayant le rang de contremaîtres pour assurer la liaison. C'est la troisième solution qui a prévalu, avec des nuances entre les Britanniques et les Français.

Il est nécessaire de s'interroger sur les raisons qui ont guidé les choix effectués par les états-majors, le statut de ces personnels disposant d'une qualification d'interprète et l'efficacité générale du dispositif retenu, aussi bien du côté des interprètes que des ouvriers chinois et de l'état-major. Nous nous proposons d'examiner successivement le nécessaire recrutement de personnel bilingue pour accompagner la main-d'œuvre chinoise, une première étape consistant à recruter des "officiers interprètes " européens, puis une seconde étape, complémentaire, le recrutement d'interprètes chinois.

\section{Un nécessaire recrutement de personnel bilingue pour accompagner la main-d'œuvre chinoise}

9 La France embauche différents types de main-d'œuvre, par le biais de deux administrations différentes : le Service de la main-d'œuvre étrangère (SMOE), géré par le ministère de l'Armement, qui encadre les travailleurs européens, et le Service d'organisation des travailleurs coloniaux (SOTC), assuré par le ministère de la Guerre, qui encadre les travailleurs coloniaux et les travailleurs chinois. Ces derniers sont embauchés par un accord officiel franco-chinois signé en mai 1916. Comme la Chine n'est pas encore en guerre, la matérialisation des contrats passés est réalisée par des sociétés privées; une mission officielle dirigée par le lieutenant-colonel Truptil parraine le recrutement, finalisé par la société Huimin, fondée par un consortium bancaire. Le nombre d'ouvriers souhaité par les Français est de 50000 ; le nombre réel embauché est de 40000 environ. Les zones d'embauche correspondent aux lieux d'installation des entreprises filiales du groupe Huimin: à Tianjing, Hong Kong, Shanghai Pukou et Qingdao (province du Shandong).

La même année, en octobre, le gouvernement britannique adopte une stratégie d'embauche consistant à lancer le recrutement dans sa concession chinoise de Wei-HaiWei, sans en avertir officiellement le gouvernement chinois, puis dans la ville proche de Qingdao et dans la province voisine du Zhili (aujourd'hui Hebei); Shandong et Zhili représentent l'essentiel des zones d'embauche britanniques. Le nombre initial de recrutements prévu est de 15000 , mais en réalité près de 100000 ouvriers sont engagés.

11 En 1917, la Chine entre en guerre officiellement aux côtés des Alliés. Les dernières arrivées de contingents chinois en France ont lieu au mois de mai 1918. Les Français comme les Anglais privilégient les capacités des Chinois du Nord, plus résistants aux froids du front ouest. Il s'agit pour la plupart de paysans dépourvus d'instruction. On constate qu'il y a plus de Chinois du Sud chez les Français que chez les Anglais, ce qui va augmenter le nombre de parlers chinois à gérer pour les employeurs dans l'Hexagone.

12 Les effectifs chinois employés par la Grande-Bretagne auprès de son corps expéditionnaire en France augmentent rapidement après 1916, la Grande Guerre nécessitant de plus en plus de main-d'œuvre, notamment pour préparer les opérations 
(logistique, travaux de tranchées etc. ${ }^{10}$ ). Les ouvriers et manœuvres chinois dépendent d'une structure militaire spécifique, le Chinese Labour Corps, composé d'un peu moins de 200 compagnies en fin de période. La plupart de ces compagnies sont constituées de main-d'œuvre non qualifiée, les compagnies explicitement «qualifiées » représentant moins de $3 \%$ du total de l'effectif. Une majorité (120 sur 192) des compagnies est affectée à l'état-major et aux transports, pour des tâches principalement logistiques ${ }^{11}$. Le besoin en interprètes augmente arithmétiquement avec le nombre d'ouvriers chinois. Au niveau de l'encadrement, quand le nombre des ouvriers chinois est devenu plus important en France, les problèmes de compréhension se sont également aggravés.

Du côté français, durant l'année 1916, on compte 5976 travailleurs chinois débarqués au port de Marseille, puis durant l'année 1917, l'arrivée de 18000 autres. À la manufacture d'armes de Châtellerault, le manque d'interprètes militaires français se fait alors sentir. Pour le maintien de l'ordre et de la discipline dans les cantonnements, le SOTC renforce l'encadrement disciplinaire, avec deux sergents et quatre caporaux par groupement, dont au moins un qui soit apte aux fonctions de comptable; mais ils ne disposent pas de vraies connaissances en langue chinoise. Les employeurs français et britanniques constatent rapidement que la barrière de la langue constitue une limite à la discipline, mais surtout un réel obstacle aux gains de productivité.

De même, les besoins de personnel auxiliaire pour appuyer les mouvements et l'approvisionnement de l'armée britannique en France ne cessent d'augmenter. En janvier 1917, dans la perspective des opérations du printemps, le gouvernement de Londres envisage un remplacement des personnels ouvriers britanniques par des troupes étrangères ou d'origine coloniale et programme un projet de « réduction de la force britannique en France par l'introduction de troupes de couleur ${ }^{12}$ ». Les effectifs nécessaires sont évalués à un total de 223000 hommes pour les troupes opérant en France ${ }^{13}$. Le processus est dénommé "substitution", sur le modèle du mouvement de remplacement ou de compensation de main-d'œuvre masculine par la main-d'œuvre féminine dans les ateliers et les usines du Home front ${ }^{14}$.

16 L'Army Council et le Field-Marshal Douglas Haig réagissent de manière mitigée à ce plan. Le personnel britannique qu'il est prévu de remplacer est souvent qualifié et polyvalent ${ }^{15}$. L'Army Council pointe les questions qui peuvent se poser : la qualification du personnel recruté, la question de la langue pour ce nouveau personnel étranger ou encore les réticences des syndicats ${ }^{16}$. Les lacunes linguistiques et culturelles et le peu de temps disponible pour former correctement les interprètes ne semblent pas créer des conditions favorables à une organisation raisonnable et efficace du processus de substitution. Certains postes ne peuvent pas être occupés sans une formation préalable ; mais pour être opérationnelle en avril 1917, cette substitution dispose d'un temps de formation trop court, sans compter la nécessité d'installations ou d'établissements supplémentaires pour les dispenser.

Du côté des compétences, le Field-Marshal Haig estime que les décalages de qualification rendraient l'opération difficile. Pour réussir cette substitution, il faudrait classer les demandes des employeurs et différencier les unités des ouvriers non européens («coloured») selon leur qualification professionnelle et leur statut militaire. Dans l'armée britannique en France, la main-d'œuvre est classée en trois catégories : a pour des unités techniques (secteur d'opération), b pour des unités spécialisés et c pour les actifs non qualifiés (« unskilled») et ceux qui ne pouvaient pas être inclus dans les 
catégories $\mathrm{a}$ et $\mathrm{b}$. Les unités $\mathrm{c}$ étant destinées à compléter le travail des catégories $\mathrm{a}$ et $\mathrm{b}$, le personnel non européen du $\mathrm{C}$ ne peut pas remplacer les Britanniques dans les catégories $\mathrm{a}$ et $\mathrm{b}$ dans les unités prévues pour la substitution ${ }^{17}$. Pour être qualifiés, il leur faudrait passer des examens, ce qui complique le projet.

Cette question de la qualification n'est pas secondaire. Eu égard aux effectifs chinois salariés, plus de 100000 recrues masculines de vingt à quarante ans, le rôle des officiers et sous-officiers britanniques dévolus devient essentiel. Eux-mêmes doivent bénéficier d'une amélioration de leurs compétences militaires, techniques et linguistiques, pour augmenter la productivité des compagnies qu'ils commanderont ${ }^{18}$.

Les cinq armées ne disposent que de 66,5 compagnies non qualifiées (" unskilled»); état-major et logistique de transport associent compagnies non qualifiées et semiqualifiées, et on ne compte que 5,5 compagnies qualifiées, un peu moins de $3 \%$ du total, pour l'ensemble des effectifs chinois recrutés. Par nombre d'affectations, les plus importants «employeurs » britanniques d'ouvriers chinois sont le Grand Quartier général et les communications (120 compagnies), puis les différentes armées (66 compagnies), d'où se détachent la seconde armée (23) et la $4^{\mathrm{e}}(16)$, car les $1^{\text {ère }}, 3^{\mathrm{e}}$ et $5^{\mathrm{e}}$ armées emploient moins d'interprètes (tabl. 1).

Tabl. 1. - Répartition des 192 compagnies chinoises du Chinese Labour Corps employées par la British Expeditionary Force en France au 27 juillet 1918, à l'apogée de leurs effectifs.

\begin{tabular}{|c|c|c|c|c|c|c|c|}
\hline Locations of companies & Unskilled Cie & Unskilled Cie & Unskilled Cie & Unskilled Cie & Unskilled Cie & Unskilled and Semi-Skilled Cie & $\begin{array}{l}\text { Skilled } \\
\text { Cie }\end{array}$ \\
\hline & I st Army & II nd Army & III rd Army & IV th Army & $\mathrm{V}$ th Army & $\begin{array}{c}\text { Lines of Communication (LoC) } \\
\text { and G.H.Q. }\end{array}$ & NA \\
\hline Defences & 6 & 8 & 5 & 11 & 5 & & \\
\hline Royal Engineers (construction) & 0,5 & 0,5 & & & 0,5 & 16,5 & 3 \\
\hline Railways & & 4 & 1,5 & 0,5 & & 19,5 & \\
\hline Depots on Lines of Communication & & & & & & 34,5 & \\
\hline Docks & & & & & & 27,5 & \\
\hline Forests & 0,5 & 6 & 2 & 2 & & 2 & \\
\hline Roads & 0,5 & & 0,5 & 0,5 & 0,5 & & \\
\hline Ammunition Depots, Railheads, Dumps & 0,5 & & & 2 & 0,5 & & \\
\hline Quarries & 1,5 & & & & 0,5 & & \\
\hline Laundries & & 1 & & & & 0,5 & \\
\hline Directorate Gen. of Transportation & & 1,5 & & & & 1 & \\
\hline Burials & & & 0,5 & & & & \\
\hline Unspecified & 1,5 & 2 & & & & 0,5 & \\
\hline Workshops & & & & & & 2 & \\
\hline Royal Air Force and Tank Corps & & & & & & 3,5 & \\
\hline Railway Maintenance and Shops & & & & & & 13 & \\
\hline \multicolumn{8}{|l|}{ Royal Air Force and Tank Corps } \\
\hline Total & 11 & 23 & 9,5 & 16 & 7 & 120,5 & \\
\hline Grand total & & & & 192 & Labo & our Companies & \\
\hline
\end{tabular}

D'après N. J. Griffin, «The use of Chinese labour by the British army, 1916-1920 », 1973, p. 261.

Dans une compagnie d'ouvriers et de manœuvres figurent des officiers « militaires » et des officiers « techniques ». Au début, lors de l'arrivée des ouvriers chinois, les qualités militaires sont considérées comme de plus grande valeur que les qualités techniques, parce qu'elles permettent de gérer les hommes en cas d'urgence. Les choses ont évolué ensuite.

Ces officiers ou sous-officiers disposant de compétences militaires, techniques ou linguistiques travaillent avec les Chinois en seconde ou troisième position, derrière les lignes tenues par les armées britanniques sur le front ouest. Les effectifs salariés non européens de substitution ne sont pas nécessairement équivalents aux effectifs britanniques à remplacer ${ }^{19}$ : une partie du personnel britannique auxiliaire peut travailler dans des parties plus avancées et plus exposées du front, ce qui serait plus difficile pour des ouvriers étrangers sous contrat. 
22 Le Field-Marshal Haig prend aussi en considération la composante climatique du recrutement et considère que seuls les Chinois septentrionaux sont à même de supporter l'hiver du nord de la France.

Ce plan de substitution britannique est différent de celui de l'envoi de travailleurs chinois en substitution à des effectifs armés conçu par Liang Shiyi ${ }^{20}$, un des négociateurs d'un accord d'embauche franco-chinois signé en mai 1916, qui envisage l'embauche de 50000 Chinois uniquement employés à l'exécution de travaux industriels, agricoles, publics ou privés en France, en Algérie ou au Maroc.

Il y a alors beaucoup de types différents de travailleurs dans l'armée anglaise en France, les principaux étant les ouvriers britanniques et les ouvriers chinois ${ }^{21}$. La durée des contrats est différente selon les types de main-d'œuvre; si pour certaines catégories, elle est de l'ordre de quelques semaines ou quelques mois, par exemple d'un an pour les Sud-Africains et les Indiens, celle des Chinois est de trois ans. Au fur et à mesure de l'avancement du conflit, il y a aussi de plus en plus de prisonniers allemands; en juillet 1918, environ 120 compagnies de prisonniers de guerre sont employées pour les différents travaux de la British Expeditionary Force, la quasi-totalité étant affectée à la Line of Communication (LoC).

\section{Une première solution : les « officiers interprètes » européens}

Pour encadrer cette main-d'œuvre, on peut imaginer plusieurs solutions, aux effets variables en termes de coût ou d'efficacité. La première consiste à lier commandement et transmission linguistique, avec des officiers et des sous-officiers européens parlant le chinois ; c'est le principe des « officiers interprètes » européens. La seconde peut être de dissocier les deux fonctions, avec des officiers et des sous-officiers européens ne parlant pas le chinois, assistés d'interprètes chinois. La troisième est de recruter des Chinois avec qualité d'interprètes et de leur confier des fonctions d'encadrement, au moins comme sous-officiers, ce qui reprend la première solution, mais en créant un corps d'officiers ou de sous-officiers chinois interprètes ${ }^{22}$.

La première solution permet à moindre frais d'encadrer la main-d'œuvre et de contrôler le travail, les conditions de vie des ouvriers ainsi que les mouvements souterrains de propagande antimilitariste. Dans ce cas, on aurait affaire à des " interprètes militaires ", qui disposent d'une connaissance de la langue étrangère en tant qu'officiers ou sous-officiers. Ce recrutement de personnel européen est prévu dans un premier temps par la légation britannique à Pékin, ciblant des Britanniques parlant la langue chinoise et résidant en Chine ${ }^{23}$, où il sont affectés pour des missions temporaires, comme lieutenants d'infanterie et capitaines dans les corps de coolies. Ce projet repose sur une estimation initiale d'encadrement hiérarchique et linguistique de 13 officiers pour 1000 hommes, soit un total arrondi de 200 officiers interprètes, et la majorité des capitaines et des lieutenants peuvent être recrutés en Chine ${ }^{24}$.

Pour être officier, la compétence exigée par l'attaché militaire à Pékin, le lieutenantcolonel David Stephen Robertson, est l'expérience militaire; comme pour les commandants de bataillons chinois, les candidats doivent être des officiers de l'armée régulière expérimentés, ou d'anciens officiers. Pour lui, la sélection des candidats doit être traitée de manière uniforme et méthodique. En revanche, il n'est pas question de 
négocier le salaire, car le tarif de rémunération a déjà été convenu avec les intermédiaires de recrutement ou les missionnaires ${ }^{25}$.

Pour disposer de meilleurs candidats interprètes chinois, le War office garantit à l'avance la prise en charge des frais de transport de Pékin à Wei-Hai-Wei après leur présélection. En Grande-Bretagne même, le War Office recrute aussi par annonces dans la presse anglaise et cible des hommes ayant dépassé l'âge du service militaire, parlant la langue chinoise "certificat à l'appui » et disposant d'une expérience avec les coolies chinois. Cela pose la question du certificat, innovation récente pour l'apprentissage du chinois ; certains certificats sont délivrés en Chine par l'école linguistique attachée à la chambre de commerce britannique à Shanghai, avec trois niveaux: avancé, intermédiaire et élémentaire ${ }^{26}$. Le vivier disponible pour ces officiers-interprètes est très circonscrit ${ }^{27}$. En décembre 1916, selon la légation britannique à Pékin, il n'y a que 260 sujets britanniques (dont 158 sont des missionnaires) qualifiés d'interprètes dans l'ensemble de la Chine et donc pouvant être recrutés comme officiers. À la date du 10 février 1918, en Chine, les sujets britanniques d'âge militaire connaissant la langue chinoise, y compris les missionnaires, sont 30 dans la classe A (aptes pour le combat) et 200 dans la classe B.

Du côté français, certains régiments utilisent également des militaires comme interprètes ou commandants de groupe, mais le niveau linguistique en chinois d'une partie des candidats est très limité.

Pour des non-Chinois, apprendre le chinois à la fin $d u$ XIX siècle ou au début du $\mathrm{Xx}^{\mathrm{e}}$ peut procéder de raisons multiples, religieuses, diplomatiques ou commerciales, mais reste une compétence encore peu répandue, non seulement parce que les communautés européennes en Chine ne sont pas nombreuses, mais encore parce que les contacts avec la Chine n'ont pas l'importance des échanges entre l'Europe et l'Amérique ou entre la Grande-Bretagne et l'Inde, par exemple. En Chine même, les formes d'apprentissage de la langue chinoise par des Britanniques sont en grande partie le fruit de l'expérience, par le jeu des échanges courants avec les habitants, les commerçants ou le personnel salarié. Un stade plus élaboré consiste à prendre des cours particuliers avec un enseignant chinois, comme à Tch'ong-King (Chongqing), où des jeunes Britanniques ont commencé à étudier la langue chinoise avec un enseignant chinois, ou encore auprès des dispositifs éducatifs existant quand le nombre d'étrangers est plus important ${ }^{28}$. On constate cependant qu'il existe peu d'unités d'enseignement supérieur pour la langue chinoise en Chine : l'université de Nanjing et la North China Union Language School, à Pékin ${ }^{29}$. Cette dernière utilise une nouvelle méthode d'enseignement, ne s'appuyant pas sur des manuels inégalement mis à jour, mais enseignant directement en chinois l'actualité et les coutumes du pays.

31 Même si l'attaché militaire anglais à Pékin pense que les conditions d'embauche manquent d'attractivité financière et sociale pour les candidats de haut niveau en langue chinoise, la légation britannique en chine décide d'envoyer quelques représentants en France. Pour le Foreign Office, à Londres, l'utilisation d'hommes hautement qualifiés comme interprètes des contingents chinois n'est pas complètement adaptée ${ }^{30}$. En effet, leurs compétences les rendent capables par ailleurs d'occuper des fonctions importantes et des responsabilités dans beaucoup d'autres domaines, ce qui fait hésiter l'état-major à les employer uniquement pour encadrer des unités de salariés. 

passent pas bien, selon un rapport d'un commandant du Chinese Labour Corps ${ }^{31}$, à cause de l'atmosphère dégradante liée à la violence de la guerre ; les nouveaux officiers manquent d'expérience et les Chinois sont incapables de se faire comprendre de leurs supérieurs. Pormation militaire informelle, donnee par le commandant pendant la duré de formation militaire informelle, donnée par le commandant pendant la durée de leur voyage par mer. Au dépôt chinois de Noyelles-sur-Mer, une formation est également prévue pour instruire les officiers et sous-officiers, mais peu d'entre eux peuvent se rendre en pratique dans l'établissement. En France, la pénurie extrême d'officiers dans les unités de travailleurs nécessite la création d'une école de cadets à Boulogne-surMer. Après leur formation, ils sont affectés directement aux unités de travailleurs en France. Pour différentes raisons, cette école est fermée, puis remplacée par une nouvelle. La nouvelle école se concentre sur le mode d'enseignement d'un cours de dix jours pour les officiers et les sous-officiers : cinq jours de formation théorique et cinq jours de stage, avec des connaissances techniques augmentées d'une certaine quantité d'instruction militaire ${ }^{32}$. La difficulté rencontrée pour développer ces cours est identique à celle rencontrée par d'autres formations : le nombre des participants reste faible à cause des contraintes de travail, car il n'est pas possible de dispenser ces officiers et sous-officiers de toutes leurs autres activités.

Ces chantiers de guerre exigent toujours un meilleur rendement; en 1917, parmi les ouvriers chinois, on assiste à un certain nombre de troubles. L'armée britannique pourrait les réprimer par des mesures disciplinaires draconiennes, voire par les armes, mais le risque de faire des victimes dans son propre camp et les impératifs d'image officielle de la Grande-Bretagne auprès de son alliée, la Chine, ne permettent pas d'aller si loin. Dans certains cas, chefs d'équipes et interprètes tyrannisent les ouvriers ordinaires. Améliorer la situation s'avère alors nécessaire.

Pour l'acquisition et la consolidation de la langue chinoise des officiers britanniques, l'outil principal de formation est un livret bilingue, A Chinese phrase book for Chinese labour. Ce livret de 90 pages a été publié sous la direction du major R. L. Purdon, du Chinese Labour Corps $^{33}$. Bien que ce livre ait été approuvé en octobre 1917, ce n'est qu'en mars 1918 que des exemplaires sont délivrés aux compagnies ${ }^{34}$. Les compagnies sont encouragées à organiser des classes d'enseignement de langue au moment qu'elles jugent opportun. On trouve dans ce manuel le vocabulaire et des phrases indispensables pour donner confiance aux ouvriers et améliorer leurs performances. Il s'agit de phrases en langage simple, proche de celui des coolies, mais d'une bonne qualité grammaticale en mandarin, comme :

- «Pourquoi ne viens-tu pas travailler aujourd'hui ?»

- «Est-ce que cette méthode est bonne?»

- «Actuellement je n'ai pas d'argent, je t'en donnerai après-demain. »

Le vocabulaire est réduit, les sons difficiles à prononcer pour un officier anglais évités le plus possible; l'orthographe phonétique ou romanisée est en concordance avec le système Wide, inventé en 1859. La méthode d'apprentissage recommande d'abord d'apprendre " comme un perroquet ", puis de s'améliorer en écoutant la prononciation des interprètes chinois. Le dictionnaire est indispensable pour l'apprentissage de la langue et la traduction: les autorités conseillent le dictionnaire anglais-chinois édité par H. A. Giles, publié en $1892^{35}$. 
37 Au cours des opérations de 1918, l'offensive allemande oblige des ouvriers à se déplacer d'ouest en est, dans des territoires très proches des zones tenues par les armées ennemies. Le 21 mars, l'armée allemande lance sa grande attaque sur les $3^{\mathrm{e}}$ et $5^{\mathrm{e}}$ armées anglaises. Celles-ci opèrent leur retrait en compagnie de la main-d'œuvre, y compris la main-d'œuvre chinoise. Grâce à un effort de préparation et d'entraînement, un système de protection mobile pour la main-d'œuvre non militaire est progressivement élaboré. L'idée est de s'assurer que les ouvriers soient au bon endroit et sachent exactement ce qu'il faut faire en cas d'attaque ennemie, dans des conditions de communication et de transport difficiles ${ }^{36}$. Une partie des réflexes à déployer est déjà acquise par l'expérience vécue des ouvriers chinois chez les Britanniques. En septembre 1918, les opérations deviennent plus acharnées, les mouvements de main-d'œuvre se situant alors plus profondément au sein des zones ennemies, ce qui expose parfois les compagnies d'ouvriers presque en première ligne. La rapidité de la contre-offensive alliée à partir de juillet 1918 pousse les Allemands à abandonner avec précipitation leurs positions, jonchées de morts et remplies d'armes et d'équipements laissés sur place, compliquant le travail de la main-d'œuvre étrangère ${ }^{37}$.

\section{Une solution complémentaire : le recrutement d'interprètes chinois}

Recruter des interprètes chinois en Chine constitue l'autre versant des solutions choisies pour assurer la liaison entre les officiers britanniques et la main-d'œuvre. Cette orientation nécessite la définition de leur statut et commence à se réaliser avec le projet anglais de créer une classe d'interprètes officiers chinois. Selon les instructions du War Office et de l'état-major, il n'est pas possible d'appliquer les grades militaires anglais aux Chinois du Chinese Labour Corps, bien que l'embauche anglaise dans le nord de la Chine se soit avérée un succès du point de vue militaire et politique. Parmi les obstacles figure tout simplement le fait que la Chine n'est pas en guerre à ce moment-là. La légation britannique à Pékin songe alors à élargir la prospection et le recrutement à la région septentrionale chinoise, où des ouvriers ont déjà été engagés par le Chinese Labour Corps ${ }^{38}$. Elle propose aussi au ministère de former 100 interprètes officiers chinois au grade de second lieutenant pour les compagnies chinoises, et de leur accorder la possibilité d'aller ensuite étudier dans une université en Angleterre après leur service en France.

Mais cette solution rencontre rapidement des obstacles. Le War Office pense en décembre 1917 que les compétences des interprètes chinois en France ne donnent pas d'exemples suffisamment convaincants pour pouvoir leur accorder un statut d'officier. D'autres arguments accompagnent ces réticences: dans la tradition militaire anglaise, il n'existe pas de sous-officiers britanniques placés sous les ordres d'un officier chinois ; innover dans ce domaine poserait des problèmes d'égalité sociale entre officiers chinois et officiers britanniques. Par ailleurs, même si cela devait théoriquement poser moins de difficultés, les coolies accepteraient-ils pour autant l'autorité d'officiers chinois ${ }^{39}$ ?

Dans le Chinese Labour Corps, on ne nomme pas d'« officiers interprètes »; à l'origine est prévu un poste d'interprète anglais par bataillon chinois, mais la solution finalement retenue est celle d'un lieutenant britannique possédant une connaissance du chinois parlé, aidé par un adjoint administratif, un Chinese interpreter clerk. 
41 Avec l'augmentation des besoins d'encadrement linguistique, le War Office n'écarte plus l'appui d'interprètes chinois et cherche à trouver de meilleurs candidats chinois comme interprètes principaux et interprètes en second. Les candidats interprètes doivent disposer de capacités orales et d'une écriture élégante en chinois et en anglais, ainsi que d'une expérience de traduction des documents. Les interprètes en second, capables de parler l'anglais de terrain, doivent savoir gérer des ouvriers ; leur poste est équivalent à celui de chef d'équipe de première classe. Il n'est donc pas pour eux question d'être officiers, mais leur statut les assimile assez logiquement à celui des contremaîtres.

42 En parallèle, chez les Français des solutions similaires sont trouvées pour résoudre le problème du commandement et de la langue auprès des 40000 Chinois embauchés par l'armée de terre française, qui travaillent principalement dans l'industrie. Dans l'encadrement français, qui occupe aussi des ouvriers chinois, on compte environ un interprète pour 125 ouvriers. Ces interprètes doivent lire et écrire correctement le chinois et avoir des connaissances suffisantes en langue française. Leur travail est de transmettre des ordres et des instructions concernant les travaux aux chefs d'équipe chinois $^{40}$, qui assurent ensuite l'exécution des demandes de l'encadrement par les ouvriers. Les interprètes sont également assimilés à des contremaîtres.

Si ces interprètes maîtrisent leur propre langue dans un registre linguistique suffisant pour encadrer des ouvriers, ils ne disposent pas toujours d'une bonne connaissance de la langue de l'employeur, le français dans ce cas. Pour y remédier, les interprètes chinois ont été conduits à assister au moins à une heure d'étude quotidienne de la langue française ${ }^{41}$.

44 Dans l'armée française, l'organisation de la main-d'œuvre contractuelle étrangère diffère de celle de l'armée britannique. Les compagnies chinoises sont plus dispersées, l'envoi des Chinois dans des zones d'opérations françaises étant seulement de quelques "groupes", environ 200 personnes par compagnie. Les ouvriers chinois travaillent souvent par sections de 50,100 , voire 200 sur un chantier ${ }^{42}$, et le nombre d'interprètes n'est pas suffisant. Il semble cependant indispensable, dans l'intérêt de la discipline et du bon rendement, que chaque compagnie soit pourvue d'un interprète, alors que pour les cinq compagnies chinoises (cinq compagnies représentaient un "groupe ») qui ont été créés dans la zone d'opérations nord, il n'y a que deux interprètes ${ }^{43}$. Les candidats interprètes sont rares, et leur niveau en langue chinoise n'atteint pas le niveau d'attente de l'armée. En mars 1918, quatre interprètes militaires sont envoyés par l'état-major dans cette zone ; deux d'entre eux possédent une connaissance linguistique du chinois très limitée, qui handicape la transmission des directives en cas d'urgence. En conséquence, l'état-major demande des militaires parlant vraiment le chinois du nord ou la langue « koan-koa » (Guanhua, mandarin), au besoin les dialectes du Nord et les dialectes du Sud (cantonais) et étant capables de commander ${ }^{44}$.

45 Du côté de la main-d'œuvre sont organisés des cours de français pour les futurs ouvriers-interprètes chinois dans des usines de guerre. Mais pour disposer de suffisamment d'interprètes, l'état-major a prévu également que des officiers et des hommes de troupes français soient détachés de leur corps pour être affectés dans les groupements chinois et nommés soit "chefs de groupement", soit "interprètes", selon leur niveau hiérarchique et leur connaissance de la langue chinoise.

Toutefois, la compréhension du chinois parlé est souvent freinée par la présence de dialectes; l'enseignement du français au public chinois semble plus facile à gérer. Le 
général Pierre Famin, directeur des ouvriers indigènes et chinois, amorce au second semestre 1916 la mise en place de cours avec pour objectif de former des "ouvriers interprètes » chinois en trois à six mois. Les cours portent sur la connaissance des mots et locutions usuels concernant l'exécution du travail. Le but est que non seulement les ouvriers soient capables de faire leur travail sans l'assistance d'un interprète, mais qu'à leur tour, ils servent d'interprètes entre contremaîtres et ouvriers ${ }^{45}$. On choisit des candidats parmi ceux qui parlent déjà un peu le français, ceux qui ont la vivacité d'esprit nécessaire pour apprendre, ou ceux qui sont intéressés par l'étude de la langue française. Le cours est d'une heure par jour à la fin du travail (sans diminution de salaire), les enseignants sont des interprètes français ${ }^{46}$. Un examen trimestriel a lieu devant une commission spécifique.

47 Au bout de quelques mois, on se rend compte que l'intensité du travail et les mutations fréquentes des ouvriers chinois les empêchent d'assister régulièrement à ces cours et d'y participer correctement. Le général Famin insiste sur l'importance de ces cours. On regroupe donc les candidats chinois autant que possible dans les mêmes équipes de travail, de façon à ne dispenser qu'un seul cours par groupement.

Dans la manufacture d'armes de Châtellerault, en novembre 1916, on compte 25 ouvriers chinois assistant au cours de français d'une heure par jour ; en août 1917, on identifie 12 élèves au cours de français qui dure deux heures, de 15 à $17 \mathrm{~h}$ (le passage d'une à deux heures étant récent); la direction de la manufacture pense qu'il est nécessaire de leur donner une légère prime en plus de leur salaire normal, pour les encourager ${ }^{47}$. Bien que le pourcentage de participants et le taux de réussite restent encore faibles dans ce programme, cette solution permet à l'établissement d'améliorer en partie la productivité de la main-d'œuvre. Une dimension supplémentaire, demandée plusieurs fois par la direction du SOTC, est que les interprètes jouent également le rôle de collaborateurs des chefs d'atelier et des chefs de groupement pendant et en dehors du travail pour maintenir la discipline et pour éviter les menus incidents qui se sont déjà produits.

La dimension matérielle et pécuniaire de l'interprétariat mérite d'être abordée, car elle a pu aussi contribuer à attirer les candidats.

Dans les instructions militaires, on souligne qu'il ne faut pas traiter les interprètes chinois comme des coolies. Les différentes compétences des interprètes sont comptabilisées sur leur qualification salariale : $1,50 \mathrm{~F}, 2,50 \mathrm{~F}$ ou $5 \mathrm{~F}$ par jour en France, et une paie mensuelle en Chine de 15, 30 et 60 dollars mexicains. Les interprètes les mieux rémunérés gagnent plus de trois fois la solde des interprètes les moins qualifiés. Comme ils sont nourris et logés, et qu'il s'agit d'une rétribution « additionnelle » (une prime plus qu'un salaire de salarié), ces chiffres sont difficilement comparables aux salaires des ouvriers français non mobilisés. Pour esquisser toutefois une comparaison, le salaire horaire moyen à Paris passe de 0,88 F de l'heure en 1911 à 3,53 F en 1921, ce qui représente une moyenne approximative de $1,80 \mathrm{~F}$ à $2,20 \mathrm{~F}$ en $1916^{48}$. Dans les départements, où les salaires sont alors 40 à $50 \%$ en moyenne moins élevés qu'en région parisienne, la moyenne des salaires de 38 professions masculines donne $0,46 \mathrm{~F}$ de l'heure en 1911 et $2,31 \mathrm{~F}$ en 1921 , soit 1,20 à $1,40 \mathrm{~F}$ en $1916^{49}$. Le pouvoir d'achat ouvrier subit un retard sur les prix pendant le conflit, sauf pour certains produits subventionnés, comme le pain ${ }^{50}$.

51 Du côté français, pour résoudre le déséquilibre de compétence entre les bons interprètes chinois et les médiocres, en considération d'un salaire jugé limité, le 
général Famin met en place des règles uniformes pour assurer aux interprètes chinois, quel que soit l'établissement où ils sont employés, une situation correspondant à leur valeur professionnelle, pour éviter que l'interprète se trouve en cas de changement dans une situation moins favorable que celle qu'il occupait précédemment. Les règles de rémunération uniforme prévoient l'embauche des interprètes au salaire minimum de $200 \mathrm{~F}$ par mois, avec des facilités pour arriver à un salaire de $250 \mathrm{~F}^{51}$ et, pour ceux qui étaient recrutés au salaire de $150 \mathrm{~F}$, la possibilité d'élever autant que possible le salaire à $200 \mathrm{~F}$ par mois, et ainsi de suite. Une année de salaire à $200 \mathrm{~F}$ mensuels représente théoriquement $2400 \mathrm{~F}$, ce qui équivaut en 1916-1917 à la rémunération d'un ouvrier qualifié $^{52} ; 250 \mathrm{~F}$ mensuels donnent $3000 \mathrm{~F}$ par an, sensiblement moins qu'une solde de sous-officier en zone de conflit (environ $5000 \mathrm{~F}$ ).

52 Au niveau de la rémunération, l'armée anglaise adapte la grille des emplois, avec l'ajout d'un grade d'interprète de $3^{\mathrm{e}}$ classe à la fin de l'année $1917^{53}$. Du côté français, le SOTC développe une nouvelle mesure d'équité salariale par rapport à la hausse constante des prix de détail de 20 à $30 \%$ par an, en élevant uniformément le salaire des interprètes

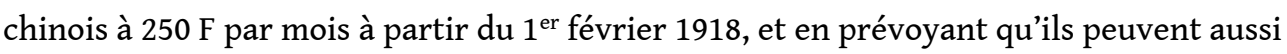
bénéficier d'une augmentation pour la cherté de vie, fixée dans chaque région pour les ouvriers français et chinois. Dans le cas où les directeurs d'établissements se trouvent dans l'incapacité d'adopter ces nouvelles conditions de salaire, il est prévu qu'ils remettent ces personnels à la disposition du SOTC pour une autre affectation ${ }^{54}$.

Sur le plan de la formation, le séjour prolongé en France des travailleurs du SOTC a permis à la plupart d'entre eux d'acquérir quelques notions de langue française, et même de se familiariser avec elle. En février 1918, pour mesurer leurs progrès linguistiques, le SOTC demande aux établissements de préciser les différents niveaux de compétence de chaque ouvrier pour parler, lire et écrire (dans sa langue maternelle et en français), d'abord à leur arrivée en France et ensuite au moment de l'enquête ${ }^{55}$.

Le SOTC rappelle aux établissements l'intérêt d'organiser dans chaque groupement, quel qu'en soit l'effectif, des cours réguliers de français pendant les heures de loisir, pour satisfaire le désir de s'instruire. L'argument avancé est, comme souvent, lié à la productivité : l'effort de chacun réduit le nombre d'illettrés et rend la tâche des établissements plus facile. Le rappel de cette nécessité laisse entendre que tous les établissements ne parviennent pas à mettre sur pied ou à faire fonctionner correctement ce dispositif d'enseignement.

Les Anglais n'organisent pas de cours pour leurs ouvriers, mais les volontaires de l'influente association Youg Men's Christian Association (YMCA), assez présente dans les unités américaines, fait beaucoup d'efforts pour animer la vie quotidienne des travailleurs chinois. La YMCA organise aussi des cours de chinois, de calcul, d'anglais et de zhuyin $^{56}$, ce dernier recueillant le meilleur taux d'assiduité de la part des apprentis ${ }^{57}$.

Cette transmission de savoir-faire aux ouvriers chinois en France semble avoir suivi deux directions différentes et complémentaires. Côté britannique, elle s'est effectuée plutôt par le recrutement et l'amélioration des compétences professionnelles et linguistiques des officiers et sous-officiers du Chinese Labour Corps. Côté français, elle semble majoritairement réalisée par l'augmentation du nombre d'interprètes chinois de qualité très inégale, avec une tentative de développer leur maitrise linguistique. 
L'objectif de ces deux processus est de développer le plus de communications directes possibles entre les employeurs et les ouvriers étrangers.

La vie des travailleurs chinois a été étroitement liée à celle des Anglais et des Français dans ce cadre historique particulier, où la capacité d'échanger verbalement pour produire était indispensable. Comme la plupart des ouvriers chinois étaient des paysans, dépourvus d'instruction dans leur propre culture, beaucoup d'efforts ont été déployés de part et d'autre pour leur assurer une adaptabilité minimale et opérationnelle à la culture européenne. L'aide des interprètes s'est révélée indispensable pour cette transmission de savoir-faire technique dans un cadre militaire; mais les interprètes chinois n'ont jamais pu accéder au statut d'interprètes militaires professionnels avec rang de sous-officiers, pour un ensemble de raisons pratiques et culturelles qui ont créé des barrières à leur ascension dans la hiérarchie.

L'évolution de la Grande Guerre étant en partie imprévisible, un certain nombre de décisions ont été prises sous la pression de l'urgence et pour répondre aux exigences journalières les plus immédiates, surtout dans les premiers mois. Avec la pérennisation du conflit en 1915-1916, l'entrée dans une guerre plus longue a favorisé des choix de moyen terme. La décision de recruter puis de transmettre des savoir-faire en partie militaires aux ouvriers chinois s'est déployée dans ce contexte, mais l'idée restait de limiter l'expérience à une dimension contractuelle; le transfert de compétences n'était pas programmé au-delà de la fin de la guerre.

59 En tenant compte des difficultés de départ, les solutions choisies ont consisté en un mélange empirique de décisions de bon sens et d'improvisations progressivement corrigées. Le fossé culturel entre la main-d'œuvre chinoise et l'encadrement européen a freiné l'adaptation rapide des ouvriers asiatiques aux contraintes initiales de productivité, mais un processus d'ajustement progressif a permis d'améliorer les rendements et les rémunérations de ces ouvriers. La décision d'utiliser la main-d'œuvre chinoise a été une certaine réussite au point de vue militaire, un renfort important à un moment très difficile de la guerre, et elle a constitué une dette de gratitude pour les Alliés après le conflit.

\section{BIBLIOGRAPHIE}

CHEN San Jing [uniquement en chinois], «Les travailleurs chinois et la guerre européenne, Chang Sha, Yuelu, 2013, 221 p.» CHEN Ta, Chinese Migration, with special reference to labor conditions, Washington, Government Printing Office, 1923.

DORNEL Laurent et REGNARD Céline, Les Chinois dans la Grande Guerre : des bras au service de la France, Paris, Les Indes Savantes, 2018.

GRIFFIN N. J., " The use of Chinese labour by the British army, 1916-1920: the "raw importation", its scope and problems », thèse, Norman, University of Oklahoma Graduate College, 1973. 
KLEIN Daryl, With the Chinks, Londres / New York, John Lane Company, 1919.

LESPINET-MORET Isabelle, MACHU Laure, VIET Vincent (dir.), Mains-d'œuvre en guerre, 1914-1918, Paris, Documentation française, 2018.

LI Nan Qiu [uniquement en chinois], «L'histoire de l'interprétariat, Qing Dao, Qing Dao chu ban she, $2002 »$.

STARLING John et LEE Ivor, No labour, no battle: military labour during the First World War, Gloucestershire, Spellmount, 2014.

SUMMERSKILL Michael, China on the Western Front: Britain's Chinese work force in the First World War, Londres, édité par l'auteur, 1982.

SUN Gan [uniquement en chinois], («Carnet de notes d'un travailleur chinois pendant la guerre

européenne, texte répertorié par Qi De Zhi, Tianjin, Institut socio-scientifique de Tianjin, 2013 »).

VAN Hoof Henri, « De l'identité des interprètes au cours des siècles ", Hieronymus Complutensis, 3, 1996, p. 9-19.

ZANCARINI-FOURNEL Michelle, « Genre et travail : les mains-d'œuvre en France au prisme de l'histoire des femmes et du genre », dans Lespinet-Moret Isabelle, Machu Laure, Viet Vincent (dir.), Mains-d'œuvre en guerre, 1914-1918, Paris, Documentation française, 2018, p. 167-174.

ZHANG Jian Guo (dir.) [une partie en chinois et une partie en anglais], « Chinese Labourers and the First World War, Jinan, Shandong University Press, $2009 »$.

\section{NOTES}

1. N. Q. Li, L'histoire de l'interprétariat; H. Van Hoof, « De l'identité des interprètes au cours des siècles ».

2. M. Summerskill, China on the Western front.

3. Service historique de la Défense, Centre des archives de l'armement et du personnel civil, Châtellerault (dorénavant: SHD CAAPC), et Centre de Vincennes, Service historique de la Défense, département de l'armée de terre, ex SHAT (dorénavant SHD DAT).

4. National Archives, site de Kew (dorénavant NA Kew), séries FO 228 pour l'embauche des interprètes et WO 107/37 pour le fonctionnement des organismes d'encadrement de la main-d'œuvre chinoise, mais aussi des documents déposés à l'Imperial War Museum (K99/945, livret de phrases bilingues anglo-chinoises) ou à la British Library (dossier BL F288 110 pour le fonctionnement du dépôt chinois de Noyelles-sur-Mer). À comparer avec les dossiers français du SHD cités supra.

5. S. J. Chen, Les travailleurs chinois et la guerre européenne; G. Sun, Carnet de notes d'un travailleur chinois pendant la guerre européenne; M. Summerskill, China on the Western front; J. Starling et I. Lee, No labour, no battle: military labour during the First World War.

6. D. Klein, With the Chinks.

7. T. Chen, Chinese migration, with special reference to labor conditions.

8. Ibid. 
9. S. J. Chen, Les travailleurs chinois et la guerre européenne; J. G. Zhang (dir.), Chinese Labourers and the First World War; L. Dornel et C. Regnard, Les Chinois dans la Grande Guerre.

10. NA Kew, 107/37, rapport du général de brigade Edward Wace, « The work of labour with the British Expeditionary Force, B.E.F. during the war », 14/10/1919, 207 p.

11. N. J. Griffin, The Use of Chinese labour by the British army, 1916-1920, annexe A.

12. NA Kew, WO 32/5094, minutes du courrier adressé au CIGS (Chief of the Imperial General Staff) et aux military members of Council, et remarques sur la proposition de " substitution of coloured for white fighting troops », 20 et 24 janvier 1917.

13. Ibid., « Substitution of coloured for white fighting troops (1917/1918)». Le Premier ministre britannique propose les chiffres de substitution suivants: Royal Artillery, 100000 dans des colonnes de munitions ; 35000 pour les Royal Engineers ; 53000 pour l'Army Service Corps ; 35000 pour le Royal Army Medical Corps, soit un total de 223000 hommes.

14. Pour le même processus de substitution en France, voir M. Zancarini-Fournel, «Genre et travail: les mains-d'œuvre en France au prisme de l'histoire des femmes et du genre ».

15. NA Kew, WO 32/5094, War Office, « Memorandum from the military members of the army council on a proposal that certain of the personnel of artillery ammunition columns and of Royal Engineer, Army Service Corps and Royal Army Medical Corps units might be replaced by coloured troops ", 06/02/1917, 15 p. L'Army Council est le conseil supérieur de l'armée, distinct du War Cabinet, cabinet de Guerre.

16. M. Summerskill, China on the Western Front. Depuis longtemps, les syndicats anglais protestaient contre l'emploi de main-d'œuvre chinoise en Angleterre; pendant la guerre, il n'était possible d'introduire des ouvriers chinois qu'en France.

17. NA Kew, WO 32/5094, réponse du chef de l'armée britannique en France au War Office, "Employment of coloured personnel in substitution of white personnel in certain services ", 04/03/1917, et WO 32/11346, tableau « Return of labour being raised for service in France », 03/02/1917. Le recrutement de 15000 « coolies » chinois par le War Office avait déjà commencé à Wei-Hai-Wei. Pour le Director General of transportation, le pourcentage des ouvriers qualifiés prévu est seulement de $5 \% ; 4000$ sont déjà arrivés en France.

18. NA Kew, WO 107/37, rapport du général de brigade Edward Wace, «The work of labour with the British Expeditionary Force, B.E.F. during the war", annexe RR "Technical course for labour company officers»: les cours prévus portent sur la manipulation des différents outils de travail, l'avantage d'appliquer le travail à la tâche, l'organisation et la qualité du travail, les méthodes d'aplanissement des terrains, la lecture d'un plan d'ingénieur, la construction des routes et chemins de fer, les techniques de construction de bâtiments dans des zones avancées, etc.

19. Par exemple, la guerre de tranchées et la pénurie de transport maritime entraînaient un besoin croissant de main-d'œuvre dans le groupement logistique LoC (Line of Communication).

20. S. J. Chen, Les travailleurs chinois et la guerre européenne; J. G. Zhang (dir.), Chinese Labourers and the First World War. 
21. NA Kew, WO 107/37, rapport du général de brigade Edward Wace, «The work of labour with the British Expeditionary Force, B.E.F. during the war ", annexe U, "Distribution of labour companies by employments and formations ".

22. Dans les textes administratifs et les rapports d'archives, le SOTC utilise le qualificatif de main-d'œuvre "indigène » ou "exotique», le War office emploie les prédicats de «coloured» ou «coolie»; sinon, le terme couramment adopté est «Chinois» (substantif ou adjectif).

23. NA Kew, WO 31/11346, télégramme du War Office à Sir John Jordan à Pékin, 20/10/1916 : le War Office l'a interrogé sur les perspectives de recruter des Européens qualifiés en langue chinoise. WO 106/33, dépêche de l'attaché militaire à Pékin au War Office, au sujet de la candidature de M. Tuckey pour le CLC, 04/12/1917 : quand le candidat ne résidait pas en Chine, il devait postuler directement auprès du service du War Office, ou par le biais de l'attaché militaire à Pékin.

24. NA Kew, WO 106/33, télégramme de Sir Jordan de la légation britannique à Pékin au Foreign Office, 22/10/1916: quand le projet est déclenché, en septembre 1916, le chef de la légation estimait que pour les 15000 embauches, la majorité des capitaines et des lieutenants peuvent être obtenus en Chine.

25. NA Kew, WO 106/33, lettre du lieutenant-colonel attaché militaire Robertson, "Supply of officers in Tiensin \&c. », 03/11/1916, 3 p.

26. NA Kew, FO 228/3322, rapport du révérend Hopkyn Rees, D. D., directeur de l'école linguistique rattachée à la British Chamber of Commerce, «Report for term ending December 22/17 », 02/02/1918.

27. NA Kew, WO 106/33, télégramme de la légation à Pékin.

28. NA Kew, FO 228/3322 : ce document inclut des résultats d'enquête sur les «facilities for study of Chinese by young Britains » en Chine ; ont été seulement échantillonnées dans la présente étude les réponses de l'année 1918.

29. https://archive.org/details/northchinaunion00nort

30. NA Kew, Wo 106/33, télégramme du Foreign Office, 23/041917, indiquant que le War Office a refusé de nommer des officiers consulaires à un grade supérieur à celui de lieutenant.

31. NA Kew, WO 106/33, rapport du lieutenant-colonel commandant du CLC au Director of Labour du GHQ, 25/12/1917, 6 p.

32. NA Kew, WO 107/37, rapport du général de brigade Edward Wace, «The work of labour with the British Expeditionary Force, B.E.F. during the war ", chap. X.

33. Imperial War Museums, K99/945: R. I. Purdon, A Chinese phrase book for Chinese Labour, [s.n, s.d.].

34. J. Starling et I. Lee, No labour, no battle...

35. H. A. Giles (éd.), A Chinese-English Dictionary, Londres / Shanghai, Quaritch, 1892.

36. NA Kew, 107/37 : rapport du général de brigade Edward Wace, « The work of labour with the British Expeditionary Force, B.E.F. during the war », p. 87-89.

37. G. Sun, Carnet de notes d'un travailleur chinois pendant la guerre européenne.

38. NA Kew, WO 106/33; ce projet a été proposé par l'attaché militaire anglais à Pékin.

39. NA Kew, WO 106/33, télégramme du Foreign Office au War Office, 14/12/1917.

40. Art. 25 du contrat Huimin (ou Truptil pour les francophones) signé le 14 mai 1916. 
41. SHD CAAPC, 232 2H2, carton $1668,7984-5 / 8$, dépêche du général Famin, Paris, 02/04/1917.

42. SHD DAT, GR $17 \mathrm{~N} 156$, tableau de répartition des travailleurs sur l'emploi des troupes auxiliaires italiennes et des travailleurs coloniaux, GQG, direction des Étapes, 16/06/1918. Le territoire d'opération des armées françaises était divisé en trois zones : zone de l'arrière, zone des étapes et zone de l'avant; la zone des étapes était placée sous l'autorité des généraux commandants de groupes d'armées, chaque groupe d'armées était doté d'une direction des étapes.

43. SHD DAT, GR $17 \mathrm{~N}$ 156, dépêche du directeur des Étapes nord du groupe d'armées de l'Est, 04/04/1918.

44. SHD DAT, GR $17 \mathrm{~N} 156$.

45. SHD CAAPC, $2322 \mathrm{H} 2$, carton $1668, n^{\circ} 8.103-5 / 8$, dépêche du général Famin au commandant du Groupement de travailleurs chinois de la manufacture d'armes de Châtellerault, Paris, 31/10/1916.

46. SHD CAAPC, $2322 \mathrm{H} 2$, carton $1668, \mathrm{n}^{\circ} 8.103-5 / 8$ : tous les interprètes français du groupement devaient participer au cours de français; c'est en raison de cette participation obligatoire que la décision est prise le 6 octobre 1916 d'accorder à ces interprètes une indemnité journalière de $5 \mathrm{~F}$.

47. SHD CAAPC, 232 2H2, carton 1668, copie d'une minute, 16/08/1917.

48. Statistique générale de la France, Annuaire statistique de la France, Paris, 1937, p. $168-170$.

49. Dans le département du Nord, les salaires oscillaient effectivement entre 0,30 et $0,50 \mathrm{~F}$ de l'heure en 1911 selon la qualification et l'agglomération et 2,20 à 3,30 F en 1920-1921: INSEE, Direction régionale de Lille, Annuaire statistique régional, Lille (rétrospectif 1789-1950), 1951, p. 314.

50. INSEE, Annuaire rétrospectif de la France, Paris, 1966, p. 410-420. Le prix du pain reste à peu près stable (environ $0,5 \mathrm{~F} \mathrm{le} \mathrm{kg}$ ) à Paris pendant la guerre, car il s'agit d'un produit plafonné et subventionné; il augmente un peu dans les autres grandes villes $(0,3 \mathrm{~F}$ à Lille). Cependant, les autres prix évoluent rapidement et triplent pendant le conflit, le kg de viande de bœuf passe de 2,80 F à Paris en 1913 à $8 \mathrm{~F}$ en 1918, et le kg de savon de Marseille de 0,75 F en 1913 à $3 \mathrm{~F}$ en 1918.

51. SHD CAAPC, $2322 \mathrm{H} 2$, carton $1668,8828-5 / 8$, dépêche du général Famin aux directeurs d'établissements, Paris, 13/04/1917.

52. Il n'existe pas de données salariales annuelles homogènes en France avant 1950.

53. NA Kew, FO 228/2892, lettre du British Emigration Bureau de Tsingtao à Johnstone Bourne, représentant du département de l'armée de terre à Wei-Hai-Wei pour recruter des travailleurs chinois, Wei-Hai-Wei, 29/12/1917.

54. SHD DAT, GR 7 N 161, "Dépêche au sujet des salaires des interprètes chinois du ministre de la Guerre aux services concernés », Paris, 31/01/1918.

55. Le rapport d'enquête figure vraisemblablement dans les séries archivistiques du SHD CAAPC, mais sa localisation exacte n'a pas encore été identifiée à ce stade de la recherche.

56. Le zhuyin fuhao a été officialisé en Chine par le gouvernement républicain dans les années 1910. Composé de 37 caractères et de quatre marques de tonalité, il transcrit 
tous les sons possibles en mandarin, d'autres variétés de chinois standard et des dialectes mandarins apparentés.

57. NA Kew, WO 107/37, rapport du général de brigade Edward Wace, «The work of labour with the British Expeditionary Force, B.E.F. during the war »; G. Sun, Carnet de notes d'un travailleur chinois pendant la guerre européenne, p. 112.

\section{RÉSUMÉS}

Entre 1917 et 1919, 40000 ouvriers chinois travaillent sur le front français pour les Français, et 100000 pour les Britanniques dans le cadre de travaux militaires liés à la Grande Guerre. Les employeurs français et britanniques ont rapidement constaté que la barrière de la langue constituait un obstacle à la productivité, notamment pour la main-d'œuvre non qualifiée. La communication propose d'examiner le rôle des interprètes auprès de la main-d'œuvre chinoise dans cette transmission des ordres et instructions émanant de l'employeur ou de ses préposés. De manière plus large, ces interprètes ne sont pas seulement chargés de traduire, mais aussi de favoriser l'esprit d'équipe et d'aider à classer les tâches par degrés d'urgence. Pour améliorer la communication avec ces ouvriers, on organise des réunions d'information et des cours. On s'interrogera sur le choix de la langue enseignée et les outils de travail choisis, notamment un livret de phrases bilingues anglais-chinois élaboré pour aider les officiers anglais. Comme la plupart des ouvriers chinois sont des paysans dépourvus d'instruction, beaucoup d'efforts sont déployés de part et d'autre pour assurer la coexistence de valeurs culturelles différentes. Cette étude est issue de recherches menées dans le cadre de la préparation d'une thèse de doctorat sous la direction de Michel-Pierre Chélini à l'université d'Artois, "Travailler pour les Alliés en France pendant la Grande Guerre : les salariés chinois et l'économie militaire, 1916-1919 ».

\section{AUTEUR}

\section{YUAN HUA LIU-HONVAULT}

Doctorante à l'université d'Artois, Centre de recherches et d'études histoire et sociétés (CREHS) 


\title{
Entre transmission des savoirs et propagande politique : Jules Patouillet et l'Institut français de Pétrograd à l'époque de la Grande Guerre
}

\author{
Manuel Geist
}

\begin{abstract}
«Vous savez vous-même que nous avons une propagande à faire même parmi nos amis et nos alliés : 1) pour leur faire mieux connaître la valeur de notre effort, qu'ils ignorent souvent, et parfois méconnaissent ; 2) pour lutter contre un parti existant, agissant, qui souhaite la paix. Nous devons lutter sur ce terrain avec l'immense majorité des Russes ${ }^{1}$. »
\end{abstract}

1 Ainsi Jules Patouillet, directeur de l'Institut français de Pétrograd (IFP), souligne-t-il, dans une lettre du 15 décembre $1915^{2}$, la nouvelle tâche qui incombait à lui-même et à l'institut dans le contexte d'une guerre persistante et épuisante. Contre les soupçons et malentendus circulant dans l'opinion publique en Russie envers l'effort militaire français, il fallait mettre en marche un service capable d'influencer systématiquement la presse et le public russes. La propagande ne devait plus être destinée uniquement à persuader l'opinion publique en France et dans les pays neutres de la légitimité morale, de la supériorité culturelle et du succès certain de l'effort militaire des Alliés. Il était grand temps d'étendre le travail de propagande aux pays alliés afin de consolider moralement l'alliance militaire.

2 C'est ainsi que l'Institut français de Pétrograd, fondé en 1911 en tant qu'établissement scientifique pour les études russes, s'est transformé en un foyer du service de la propagande française en temps de guerre. Comment ce changement apparent du profil de l'institut s'est-il opéré entre 1911 et 1915 ? Quel était son rôle concret, quelles étaient les compétences et fonctions précises de l'Institut au sein du service de la propagande française en Russie? Comment a-t-il interagi avec les acteurs diplomatiques et politiques? Quels étaient ses projets et objectifs pendant la guerre, et où ont-ils trouvé leurs limites et obstacles ? En répondant à ces questions, cet article se 
propose de mettre en lumière une phase jusqu'à présent négligée dans l'existence de l'Institut français de Pétrograd. Les travaux instructifs de Vladislav Rjéoutski et d'olga Medvedkova sur ce sujet se sont focalisés sur le début de son histoire au temps de son premier directeur, Louis Réau (1911-1913)³. En revanche, l'activité de l'institut pendant la Grande Guerre et la carrière de son deuxième directeur, Jules Patouillet, n'ont pas encore fait l'objet d'une analyse approfondie.

3 Cette étude est divisée en deux parties. La première partie questionne les intentions diverses des fondateurs de l'Institut français de Pétrograd, le caractère indéfini et les projets inachevés de son existence d'avant-guerre. La deuxième partie analyse les ambitions, fonctions et problèmes de l'institut au sein du service de la propagande française pendant la Grande Guerre.

\section{Un acteur de « l'expansion intellectuelle de la France » ? L'Institut français de Saint-Pétersbourg avant la guerre (1910-1914)}

4 Le 27 février 1911, Le Matin publiait en première page un long article intitulé «L'expansion intellectuelle de la France ». L'auteur en était Paul Doumer (1857-1932), député libéral expérimenté, qui avait été ministre des Finances de 1895 à 1896 et gouverneur général de l'Indochine française de 1897 à 1902. Il comptait alors parmi les hommes politiques de premier plan de la III ${ }^{e}$ République. C'est lors d'un voyage d'affaires en Russie et d'une audience accordée par l'empereur Nicolas II à la fin de 1910 que Paul Doumer avait proposé pour la première fois l'idée d'un Institut français à Saint-Pétersbourg (IFP). Quelques mois après, Doumer présentait dans ledit article le projet ambitieux de ce futur établissement. Pour lui, l'IFP devrait être l'instrument d'une expansion intellectuelle de la France, qui aspirait à défendre, dans le cadre global, la position de la culture française face à la compétition croissante des autres puissances impérialistes.

5 Dans le contexte de l'isolement diplomatique au lendemain de la guerre avec l'Allemagne (1870-1871), la France - affaiblie au niveau militaire, politique et économique - avait commencé, d'une manière compensatrice, à développer son action culturelle à l'étranger. La création de l'Alliance française en 1883, munie d'un réseau de filiales dans le monde entier, n'était que l'exemple principal d'une «diplomatie de la langue» qui promouvait l'enseignement du français à l'étranger ${ }^{4}$. La création d'établissements scientifiques à l'étranger devrait contribuer, de la même manière, au rayonnement de la civilisation française. En 1900, sous le gouvernement de Doumer en Indochine, fut créée l'École française de l'Extrême-Orient à Hanoï. En Europe, les instituts français de Florence (1908) et de Madrid (1909) étaient les pionniers d'un nouveau format de l'expansion scientifique à l'étranger. À cet égard, la France pouvait se vanter d'être le précurseur d'une diplomatie culturelle moderne, poursuivie sous la bannière d'une mission civilisatrice universelle : « Pour le bien de l'humanité, la France doit rester une des grandes éducatrices du monde ${ }^{5} »$. Cependant, cette expansion était loin d'être un projet impulsé et contrôlé par le gouvernement français. Les organes de l'expansion culturelle, alors qu'ils disposaient d'une réputation officielle, étaient, pour la plupart, le résultat d'initiatives autonomes et locales. C'est seulement en 1910 que 
s'installa au sein du ministère des Affaires étrangères un modeste Bureau des écoles et œuvres françaises à l'étranger, chargé de coordonner les différents projets individuels.

6 La fondation de l'Institut français de Saint-Pétersbourg devait remplir, d'ailleurs, une fonction bien spécifique au niveau bilatéral. L'alliance franco-russe, constituée sur un pacte militaire défensif, soutenue par une ample coopération financière et célébrée en grande pompe pendant des visites officielles entre 1891 et 1902, passait par une crise sérieuse au lendemain de la guerre russo-japonaise de 1904-1905. En France, on doutait de la force de l'armée russe, plusieurs fois vaincue par les Japonais; le gouvernement russe, en revanche, se méfiait du cabinet radical entourant Clémenceau et des sympathies françaises envers le mouvement révolutionnaire dans l'empire des tsars. Dans ce contexte, la fondation de l'Institut français de Saint-Pétersbourg pouvait être perçue comme une démarche vers un resserrement de l'alliance franco-russe et son extension au niveau des relations scientifiques et culturelles. Selon Doumer, ces domaines de l'influence française étaient largement négligés en Russie, où l'Allemagne semblait occuper un rôle prépondérant dans l'enseignement étranger.

7 En outre, Doumer attendait de l'IFP une impulsion positive sur les relations économiques entre la France et la Russie, pour contrebalancer la position dominante des négociants et industriels allemands. Grâce à ses contacts intimes dans le monde des affaires, il assurait de larges souscriptions des grands établissements financiers et industriels français (parmi lesquels figuraient la Société générale, la Banque de Paris et des Pays-Bas et la Banque d'Indochine), qui constituaient, au début, la majeure partie du budget annuel de l'Institut ${ }^{6}$. La liaison entre les intérêts scientifiques et économiques fut en quelque sorte matérialisée quand l'IFP s'installa à SaintPétersbourg dans le même immeuble que l'Alliance française et la Chambre de commerce franco-russe ${ }^{7}$.

\section{Un institut au caractère multiple}

8 De ce fait, Doumer était chargé des bases financières ainsi que de l'organisation politique de l'IFP. De son côté, Paul Boyer (1864-1949) était chargé d'élaborer son organisation scientifique. Titulaire de la première chaire de russe à l'École des langues orientales dès 1891, puis administrateur du même établissement (1908-1936), il était considéré comme l'autorité principale des études russes en France. Par ailleurs, il travaillait en tant que correspondant spécial du Temps pendant ses séjours en Russie, et entretenait des relations amicales avec les libéraux russes autour de Milioukov et de plusieurs hommes politiques en France ${ }^{8}$.

Boyer définit trois fonctions de l'IFP : il devrait être, premièrement, un centre des hautes études russes et un lieu d'accueil pour des russisants français. Ainsi, l'IFP envisageait d'attribuer des pensions et bourses pour des missions scientifiques. Parmi les premiers boursiers se trouvait André Mazon, élève de Boyer et éminent slavisant français du $\mathrm{Xx}^{\mathrm{e}}$ siècle. En outre, l'IFP allait créer une série de publications aux éditions Champion'. Deuxièmement, l'Institut devrait servir de bureau des renseignements scientifiques pour faciliter et encourager les échanges universitaires franco-russes et créer des liens personnels avec le monde académique russe. Troisièmement, il devrait offrir des cours d'études françaises (arts, littérature, histoire et géographie françaises) organisés par le personnel de l'IFP - à côté du directeur, deux ou trois maîtres de conférences ou pensionnaires - s'adressant au public russe francophone ${ }^{10}$. Outre ces 
trois fonctions explicites, l'IFP s'engageait à réaliser sa mission de rayonnement et à augmenter ainsi son prestige public à Saint-Pétersbourg.

10 L'inauguration solennelle de l'IFP en octobre 1911 réunit plus de 600 invités dans la salle de la Société impériale de géographie, parmi lesquels l'élite du monde diplomatique, politique et scientifique de la capitale russe. L'Exposition centennale de l'art français, organisée par l'IFP en coopération avec la revue d'art russe Apollon, montra au palais Ioussoupov, entre janvier et avril 1912, des œuvres de Caillebotte, Gauguin, Rodin et d'autres artistes célèbres, et attira l'intérêt de 30000 visiteurs russes $^{11}$.

11 Le caractère de l'IFP était alors, et dès ses débuts, multiple. Cependant, il n'y avait pas de hiérarchisation claire entre ses diverses fonctions, et le directeur avait beaucoup de liberté d'action pour son organisation concrète. D'autant plus que le conseil d'administration et le comité de direction de l'IFP à Paris, formellement chargés de surveiller et d'instruire l'activité de l'IFP, étaient restés très inactifs après son inauguration, fait encore renforcé par le déclenchement de la guerre. En règle générale, pour le meilleur ou pour le pire, le directeur de l'IFP ne pouvait compter que sur luimême. Ainsi, il était possible de modifier le profil de l'enseignement en priorisant, de plus en plus, selon la demande de la clientèle russe, les cours de langue française. Ce changement devait, naturellement, provoquer des animosités avec l'Alliance française, qui voyait en l'IFP plutôt un rival qu'un partenaire ${ }^{12}$.

12 Par ailleurs, l'IFP était confronté à deux entraves structurelles. La première concernait son statut non officiel. Bien qu'il fût constitué sous le patronage des universités de Paris, Nancy, Lille et Dijon, l'institut n'était formellement attaché à aucun établissement scientifique. Et alors que les ministres des Affaires étrangères et de l'Instruction publique apparaissaient en tant que présidents de son comité de direction, il n'était pas non plus un organe d'honneur de l'État français. Pour compenser ce défaut, le plan d'ériger un comité russe de patronage ne fut réalisé qu'en 1913. Cependant, le manque de reconnaissance officielle du statut de l'IFP par le gouvernement russe produisit des soucis tant juridiques que pratiques. Pendant des années, il fut interdit à l'institut de faire de la publicité, d'imprimer des affiches et d'émettre des diplômes ${ }^{13}$. Cette situation lui rendait plus difficile de gagner la réputation souhaitée ${ }^{14}$.

13 Le deuxième problème fondamental résidait dans l'irrégularité du budget de l'institut et la prompte pénurie de ses ressources. Déjà avant le début de la guerre, les souscriptions particulières s'étaient énormément réduites. La hausse continue du coût de la vie à partir de 1914 devait encore aggraver la situation financière de l'IFP. La demande d'un local plus grand et plus représentatif, formulée sans cesse par son directeur afin de faciliter l'expansion de l'Institut, demeurait toujours sans réponse ${ }^{15}$.

C'est dans ce contexte de désillusion croissante sur le développement trop lent de l'IFP qu'en octobre 1913, Louis Réau fut remplacé en tant que directeur par Jules Patouillet (1862-1942). Celui-ci avait commencé assez tard sa carrière de slavisant. Né dans un petit village de Bourgogne, agrégé de grammaire (1886) et de lettres (1890), il enseigna pendant douze ans dans différents lycées de province avant d'être muté au lycée Michelet en 1898. À Paris, Patouillet devint l'élève de Boyer à l'École des langues orientales et obtint un diplôme de russe en 1902. Étant parmi les premiers collaborateurs de l'institut, sa thèse sur "Le théâtre des mœurs russes des origines à Ostrovski (1672-1850)» fut le premier livre publié au sein de la bibliothèque de 
l'institut en $1912^{16}$. Et ses ambitions dans les fonctions de directeur récemment assumées n'étaient pas dissimulées quand il écrivait à son ami Émile Mâle en décembre 1913 qu'il était en train de faire de son mieux pour rendre l'institut « digne de ce [qu'il avait] toujours cru qu'il devait être ${ }^{17} »$.

\section{"Ce propagateur de pensée française en Russie »: I'Institut français de Pétrograd pendant la Grande Guerre (1914-1918)}

En février 1917, peu de semaines avant la chute du tsarisme, la Conférence interalliée se réunit à Pétrograd. Nicolas II y accueillait les délégations de la France, de la GrandeBretagne et de l'Italie afin de parler des problèmes les plus pressants de la guerre. Le côté français était représenté par le ministre des Colonies, Gaston Doumergue. Celui-ci avait reçu, en passant, une " Note sur l'Institut français de Pétrograd ", rédigée par le directeur du même établissement, Jules Patouillet. L'argument du message était clair : l'IFP aurait vécu, sous son premier directeur, "une période de tâtonnements et d'organisation un peu indécise», aurait toujours été une institution "très insuffisamment dotée et outillée » et notoirement négligée par son comité de direction. Malgré ces conditions difficiles, l'IFP aurait réussi, sous son directeur actuel, à devenir un véritable "propagateur de pensée française en Russie", qui aurait démontré sa capacité à rendre des "services nécessaires » à la France et à l'alliance franco-russe. Par conséquent, l'IFP devrait obtenir un statut officiel en tant qu'organe du ministère des Affaires étrangères et une "dotation digne » pour assurer le succès de ses efforts multiples. Patouillet soulignait spécialement le rôle exceptionnel que l'IFP aurait joué dans le domaine de la propagande française depuis janvier 1916:

\footnotetext{
«Par ce service de la propagande, qui présente des centaines d'articles insérés dans les journaux russes des capitales et de la province, l'Institut français est entré en contact avec les rédactions des journaux, les bureaux de l'état-major russe, le comité Skobélef, les unions des Zemstvos et des villes. On s'adresse à lui comme à une source de renseignements sur toute la vie actuelle de la France; et le nombre des personnes, officielles ou non, russes ou françaises, avec lesquelles il est maintenant en rapport est considérable. Ces rapports lui ont permis de recueillir de nombreuses et précieuses indications sur la véritable situation de l'influence française en Russie, sur le terrain perdu, sur les moyens et la nécessité de le reconquérir, sur les concours que l'on peut trouver du côté russe. Et ainsi l'Institut français apparaît comme pouvant être une sorte de consulat intellectuel et scientifique français en Russie, qui centraliserait et coordonnerait tout ce qui concerne, ici dans le pays, la diffusion de la science, des idées, des méthodes françaises ${ }^{18}$. "
}

Le langage exalté de la note et l'éloge exagéré de l'IFP étaient, sans doute, une stratégie rhétorique pour convaincre son destinataire et obtenir des allocations. Toutefois, le texte révélait en même temps l'ambition sincère de Patouillet de participer activement à la politique russe de son gouvernement et de s'approprier officiellement des fonctions diplomatiques. Avec ces prétentions, pourtant, son cas était loin d'être singulier. Le phénomène d'une mobilisation intellectuelle des écrivains, savants et journalistes dans les différentes sections de la propagande caractérisait la politique de tous les pays belligérants ${ }^{19}$. Concernant la propagande française en Russie, l'ensemble des savants en études russes (outre Patouillet, on trouvait aussi Jules Legras ou André Mazon) et des correspondants des journaux français en Russie (entre autres, Ludovic Naudeau et 
Claude Anet) était impliqués de manière variée ${ }^{20}$. Parmi tous ces experts des affaires russes, Patouillet avait l'avantage d'être pratiquement en permanence sur place et de représenter une institution, tout de même, établie à Pétrograd. Même s'il faut bien sûr relativiser l'impact si habilement attribué à l'IFP, sa collaboration au service de la propagande datait de la genèse de ce service.

\section{Le début du service de la propagande}

17 C'est dans les derniers mois de 1915 que Philippe Berthelot, à l'époque secrétaire général au Quai d'Orsay, avait créé la Maison de la presse, afin d'organiser systématiquement la propagande française dans les pays neutres et alliés. Dans ce contexte, il envoya l'un de ses intimes, le journaliste et orientaliste Robert de Caix, en mission d'enquête en Russie. Entre octobre et décembre, ce dernier passa plus de deux mois à Pétrograd et à Moscou pour observer la situation politique ainsi que l'opinion publique du pays et pour étudier les possibilités d'établissement d'un service de la propagande. Les diplomates français à Paris et à Pétrograd s'étaient rendu compte d'une méfiance des Russes envers l'effort militaire de leurs alliés sur le front occidental. Ils incriminaient, à côté des intrigues germanophiles de la cour, l'ignorance dominante en Russie des particularités de la guerre des tranchées. Il paraissait par conséquent indispensable d'influencer méthodiquement la presse russe en faveur des intérêts français et d'établir les moyens nécessaires afin « d'éclairer » le public militaire et civil en Russie ${ }^{21}$.

$18 \mathrm{Au}$ moment de l'arrivée de de Caix, le centre d'activité de l'Institut de Pétrograd l'enseignement - avait été laissé en friche. À l'exception de son directeur, âgé, tous les maitres de conférences avaient été mobilisés au début des hostilités ${ }^{22}$. Dans le même temps, la demande de cours français du côté des élèves russes avait aussi sensiblement baissé dans ce contexte de guerre. Faute d'une activité régulière d'enseignement, Patouillet chercha à intensifier le contact avec le monde universitaire russe, et devait réussir plus tard à être chargé des cours à l'université de Pétrograd ${ }^{23}$. En même temps, il s'engagea publiquement en faveur de la cohésion morale et militaire de l'Alliance franco-russe. Il donna des conférences sur l'effort français dans divers établissements culturels à Pétrograd et publia une brochure sur l'armée russe afin de renforcer la confiance mutuelle ${ }^{24}$.

Ainsi, il n'est pas surprenant que le projet de créer un service de propagande ait rencontré un écho très positif auprès de Patouillet et que de Caix ait trouvé en lui un collaborateur motivé. L'institut pouvait se passer sans problème d'une de ses pièces désertées, où s'installerait dorénavant le premier bureau de propagande. Celui-ci ne consista d'abord qu'en une traductrice, la secrétaire de l'institut, une dactylographe et un garçon de courses, tous travaillant sous la direction de Patouillet. Pour le bon fonctionnement de l'œuvre, une subvention mensuelle de 1000 francs fut, peu après, accordée à Patouillet. La mission du bureau était de traduire des extraits de la presse française et de les adapter à la manière russe afin de fournir aux journaux russes des articles favorables sur l'effort de la France. De Caix, pour sa part, se mit, dès son retour en France, à établir un bureau de propagande russe à Paris, qui devait être en communication permanente avec le bureau de Pétrograd pour recevoir des demandes et donner des instructions ${ }^{25}$. 

du bureau de la propagande à Pétrograd, Patouillet se montrait jusque-là content de son activité : tout récemment, le rédacteur en chef du bulletin des armées russes (Voennaja Letopis') - journal de front tirant à 800000 exemplaires - aurait sollicité les services du bureau. Patouillet remarquait : «Ce sera la plus vaste propagande dans les armées russes qu'il soit possible de souhaiter. » Par ailleurs, le bureau s'occuperait de faire des comptes rendus en russe de tous les brochures, albums et livres qui lui seraient envoyés par la Maison de la presse, afin de distribuer ce matériel adapté en Russie. Néanmoins, il serait nécessaire d'augmenter considérablement les envois à Pétrograd, car « Nous avons le fusil ou le canon, mais pas assez de munitions ». À part cela, la propagande semblait être en très bon chemin ${ }^{26}$.

Cependant, parmi les officiels français à Pétrograd, le jugement porté sur le bureau de propagande fut beaucoup moins optimiste. Le colonel Langlois, chef de l'état-major de la Mission militaire française en Russie, écrivait dans son rapport du 9 février : "Toute cette organisation est absolument insuffisante et ne peut donner les résultats que nous avons le devoir d'atteindre ». Au lieu de cela, il serait indispensable de créer un service de propagande établi sous le contrôle central de l'ambassade de France et dirigé par un agent professionnel ${ }^{27}$. Patouillet, en revanche, s'opposait à l'idée "d'attaché de propagande " pour la Russie. Au lieu d'un chef de mission sans expérience des choses russes, il plaidait pour qu'on lui envoie plutôt un ad latus susceptible de l'assister dans la tâche de l'expansion du service ${ }^{28}$. Pour cette fonction, il sollicitait l'affectation de Raoul Labry, un jeune slavisant attaché à l'époque à la mission médicale de l'armée d'Orient en Serbie ${ }^{29}$.

De Caix se décida, finalement, pour un compromis. D'un côté il approuvait l'arrivée de Labry et assurait l'augmentation de la mensualité de l'IFP à 3000 francs. D'un autre côté, il désignait le comte François d'Humilly de Chevilly (1870-1933) au poste d'agent de propagande pour coordonner, dès le mois de mars, la section cinématographique et photographique du service. Cet ancien officier et banquier, résidant depuis un grand nombre d'années à Pétrograd et pourvu d'un réseau de contacts auprès du monde des affaires et du monde militaire, lui parut être spécialement qualifié pour assumer, à long terme, les fonctions de chef du service de propagande en Russie. Cependant, faute d'un règlement officiel de la question de direction, cela ouvrait la voie à un conflit de compétence entre Patouillet et Chevilly, conflit qui se manifesta dans les mois suivants ${ }^{30}$.

23 Au lendemain du départ de Patouillet pour son voyage annuel à Paris, en juin 1916, Chevilly exprimait explicitement son ambition d'être officiellement chargé de la direction du service. Selon lui, cela serait le seul moyen de centraliser et d'harmoniser les initiatives disparates des nombreux individus impliqués dans ce domaine. En même temps, Chevilly considérait Patouillet comme peu susceptible d'assumer cette responsabilité à cause de «son amour-propre, le souci exagéré de l'importance de ses fonctions, le désir de ne sembler soumis à personne ${ }^{31}$ ».

24 C'est seulement au milieu de septembre 1916 que la question de la direction fut formellement résolue en faveur de Chevilly, qui fut chargé de coordonner toutes les activités de la propagande en Russie. Patouillet et ses collaborateurs de l'IFP demeuraient responsables du service de traduction et d'adaptation au sein du bureau de presse, alors que Chevilly assumait la tâche d'agent de liaison avec les rédactions des journaux russes. L'activité de l'IFP devait être ramenée à ses fonctions scientifiques 
originales. Pour ce faire, deux nouveaux maîtres de conférences furent envoyés à Pétrograd ${ }^{32}$.

\section{L'Institut français à l'époque de la révolution russe}

Mais la situation sociale en Russie ne facilitait pas le retour d'un enseignement régulier. Ainsi Patouillet remarquait-il rétrospectivement que « les cours n'ont été qu'une forme accessoire » de l'activité de l'IFP en temps de guerre ${ }^{33}$, chose qui ne changea guère dans le cadre de la révolution et de l'instabilité politique qui caractérisa l'année 1917 en Russie. Ainsi l'Institut français fut-il en quelque sorte contraint de demeurer un organe politique plutôt que scientifique. Des collaborateurs furent, de nouveau, recrutés pour remplir diverses tâches de la propagande: conférences, administration de l'agence interalliée d'informations télégraphiques, propagande personnelle auprès des différents camps politiques, etc. ${ }^{34}$.

Patouillet s'orienta alors vers la diplomatie scientifique et intensifia ses contacts avec l'historien libéral M. I. Rostovtsev et l'orientaliste renommé S.F. Oldenbourg, le nouveau ministre de l'Instruction publique au sein du gouvernement provisoire. Sous couvert d'une "union scientifique ", ils projetaient un service de promotion mutuelle des sciences russes et françaises au sein des revues scientifiques respectives, des échanges académiques réguliers et la création d'un Institut russe à Paris - pendant logique de l'IFP ${ }^{35}$. La prise du pouvoir bolchevique mit fin à ces projets.

Cependant, les efforts de la propagande française continuaient et devaient être élargis, selon le gouvernement français, afin d'éviter la conclusion d'une paix séparée entre l'empire allemand et la Russie des Soviets. En décembre 1917, le ministre des Affaires étrangères créa une Commission chargée de l'examen des questions russes, sous la présidence d'Henry Franklin-Bouillon. Parmi ses membres se trouvaient le comte de Chevilly, Robert de Caix et Paul Boyer. La tâche de la commission était d'élaborer une nouvelle stratégie d'action de la France en Russie, un plan de l'extension du service de la propagande et une liste de personnel français susceptible d'être envoyé en mission en Russie. Après plusieurs séances, la commission recommandait, entre autres, que le budget et le personnel du service de la propagande fussent largement augmentés. De plus, la coopération avec les services homologues de ses alliés devrait être sensiblement renforcée ${ }^{36}$.

L'Institut français avait déjà agi dans ce sens, appelant les représentants de la GrandeBretagne, des États-Unis, de l'Italie et de la Belgique à protester contre "les manœuvres bolchevistes" et à créer "l'entente intellectuelle et morale " entre la Russie et ses alliés ${ }^{37}$. Cependant, l'action de propagande devenait chaque jour plus difficile, à mesure que la dictature des Soviets s'installait et que la guerre civile se répandait. Par ailleurs, l'IFP se voyait toujours confronté aux problèmes financiers. Le ministère des Affaires étrangères n'avait jamais répondu de manière satisfaisante aux sollicitations de son directeur; le versement des subventions régulières se faisait attendre, et la situation de l'approvisionnement se détériorait à vue d'œil. Ainsi, Patouillet se plaignit plusieurs fois auprès de Boyer de ce que les collaborateurs de l'Institut souffraient de la faim. Labry devrait même chercher un emploi au sein de la Chambre de commerce franco-russe afin de pouvoir subvenir à ses besoins ${ }^{38}$.

En mars 1918, l'IFP - comme l'ambassade de France - était forcé de quitter Pétrograd, sous la menace d'une avancée de l'armée allemande, et s'installait à Moscou. Des 
subventions supplémentaires du côté du ministère des Affaires étrangères pouvaient, certes, assurer le maintien de l'Institut, mais son champ d'activité était chaque fois plus restreint et son impact marginalisé. À la fin de l'année 1918, Patouillet et ses collaborateurs rentraient en France.

L'Institut français de Pétrograd avait progressivement abandonné ses fonctions scientifiques en temps de guerre. Depuis décembre 1915, il avait en quelque sorte été absorbé par le service de propagande. Toutefois, dans la perspective contemporaine, cette transformation était moins radicale que le regard rétrospectif pourrait le suggérer. Dès sa création en 1911, l'IFP avait poursuivi une mission politique en vue du rayonnement intellectuel de la France à l'étranger. Étant un acteur de la diplomatie culturelle française, il employait déjà avant la guerre une propagande culturelle, au sens large du terme. Le caractère jamais strictement défini de l'institut et la surveillance presque inexistante de la part de son conseil d'administration permettaient au directeur une liberté d'action considérable. Prenant en compte ses grandes ambitions de transformer l'IFP en un "consulat intellectuel», Patouillet pouvait facilement utiliser cette marge de manœuvre pour assumer des fonctions de diplomate non officiel et de collaborateur de la propagande politique.

31 L'engagement de l'IFP au sein du service de la propagande ne peut être perçu que dans le contexte de ses problèmes financiers permanents. Les subventions de la Maison de la presse permettaient le maintien matériel de l'Institut. La référence à ses contributions actives à l'effort de la France servait, en plus, de moyen de pression auprès des potentiels bailleurs de fonds. Néanmoins, les tentatives répétées de Patouillet pour obtenir un financement correspondant à ses projets ambitieux n'ont jamais eu de succès complet.

L'analyse de l'activité de l'IFP pendant la guerre révèle aussi les défis et problèmes de la propagande française en Russie. Le service de la propagande devait être exercé, faute d'expérience historique, par des amateurs comme de Caix et Patouillet. Faisant de leur mieux selon leurs capacités personnelles, ils ne pouvaient pas s'appuyer sur des structures établies et étaient avant tout forcés d'improviser. La rivalité personnelle entre Patouillet et Chevilly n'était que l'expression du manque de direction centrale au niveau de l'ambassade de France et du ministère des Affaires étrangères. L'absence de coordination se transposait, de la même façon, aux relations interalliées. Le bureau de propagande anglais était plutôt perçu comme un concurrent dans la quête des sympathies russes que comme un collaborateur potentiel. Malgré plusieurs tentatives, la Triple Entente ne se réalisait donc guère au niveau de la propagande. Finalement, il est quand même douteux qu'un service de propagande plus professionnel, mieux doté et mieux coordonné aurait été capable d'éviter, au début de 1917, la désintégration politique et militaire d'un pays aussi las de la guerre que la Russie des tsars.

Dans les mémoires de son séjour en Russie, Raoul Labry reprochait au service de la propagande française de n'avoir pas réussi à s'adapter aux nouvelles conditions créées par la révolution russe. Se concentrant presque exclusivement sur les élites politiques et intellectuelles, la propagande aurait toujours négligé les milieux populaires ${ }^{39}$. Cette critique pouvait facilement être adressée, d'une manière particulière, à l'Institut français de Pétrograd, qui agissait avant tout parmi le monde universitaire. Néanmoins, 
l'engagement en faveur d'un rapprochement scientifique franco-russe était le seul objectif que l'institut expatrié pouvait poursuivre au lendemain de son retour en France. Ainsi, Patouillet allait intervenir à plusieurs reprises au profit des académiciens russes émigrés et devenir, en 1920, le secrétaire général auprès du Comité de secours aux écrivains et savants russes en France ${ }^{40}$. L'IFP se maintenait en exil, alors que son importance devait constamment diminuer, jusqu'à sa dissolution formelle dans les années 1950. Cependant, au début des années 1920, Jules Patouillet songeait toujours à un prochain retour de l'institut en Russie pour réaliser son grand projet de « consulat intellectuel ${ }^{41} »$.

\section{BIBLIOGRAPHIE}

CHAUBET François, La politique culturelle française et la diplomatie de la langue : L'Alliance française (1883-1940), Paris, L'Harmattan, 2006.

DMITRIEV Aleksandr N., « La mobilisation intellectuelle : la communauté académique internationale et la Première Guerre mondiale », Cahiers du monde russe, 2002, vol. 43, $n^{\circ} 4$, p. 617-644.

DOUMER Paul, Le Matin, 27 février 1911, p. 1.

EHRHARD Marcelle, « Jules Patouillet », Revue des études slaves, 1944, vol. 21, n 1-4, p. 179-183.

LABRY Raoul, Autour du bolchevisme, Cahors, chez l'auteur, 1921.

LEONHARD Jörn, Die Büchse der Pandora : Geschichte des Ersten Weltkriegs, Munich, C. H. Beck, 2014.

MEDVEDKOVA Olga, " "Scientifique” ou “intellectuel” ? Louis Réau et la création de l'Institut français de Saint-Pétersbourg », Cahiers du monde russe, 2002, vol. 42, nº 2-3, p. 411-422.

PATOUILLET Jules, L'armée et le soldat russes, Paris, Foi et Vie, 1915.

PATOUILLET Jules, « Les relations intellectuelles entre la France et la Russie », Revue de Paris, 15/03/1920, p. 429-448.

PONDOPOULo Anna, « Paul Boyer, ses liens avec la Russie et les enjeux politiques de la réforme de l'École des langues orientales dans les années 1910 », dans Charon Annie, Delmas Bruno, Le Goff Armelle (dir.), La France et les Français en Russie : nouvelles sources et approches (1815-1917), Paris, École nationale des chartes, 2011, p. 341-360.

RJÉOUTSKI Vladislav, « Francuzskij institut v Sankt-Petersburge i russko-francuzkoe kul'turnoe sbliženie » [L'Institut français de Saint-Pétersbourg et le rapprochement culturel russo-français], dans Čerkasov P. (dir.), Rossija i Francija, Moscou, Nauka, 2006, p. 293-322.

\section{NOTES}

1. Lettre de Jules Patouillet à Paul Boyer, 15/12/1915, Arch. nat., sous-série $62 \mathrm{AJ}$ : École nationale des langues orientales vivantes (INALCO), fonds 62, dossier Jules Patouillet. 
2. Les dates sont données selon le "nouveau style ", c'est-à-dire selon le calendrier grégorien, que la Russie n'a adopté qu'en 1918.

3. V. Rjéoutski, «Francuzskij institut v Sankt-Petersburge i russko-francuzkoe kul'turnoe sbliženie »; O. Medvedkova, " "Scientifique" ou "intellectuel" ? Louis Réau et la création de l'Institut français de Saint-Pétersbourg ".

4. Pour l'histoire de l'Alliance française, voir F. Chaubet, La politique culturelle française et la diplomatie de la langue : L'Alliance française (1883-1940).

5. P. Doumer, «L'expansion intellectuelle de la France », p. 1.

6. Les livres de comptes de l'Institut sont conservés aux Archives nationales: coll. 19820521 : laboratoire de slavistique (1918-80), carton 95/323 : «Institut français de Léningrad». Du côté des ministères des Affaires étrangères et de l'Instruction publique, l'IFP recevait une subvention annuelle de $30000 \mathrm{~F}$. Pour couvrir des dépenses annuelles d'environ $80000 \mathrm{~F}$, l'IFP était dépendant de souscriptions individuelles d'un montant de $50000 \mathrm{~F}$.

7. «Lettre de Louis Réau à Paul Boyer », 20/03/1911, Arch. nat., 62AJ/62, dossier Louis Réau.

8. A. Pondopoulo, «Paul Boyer, ses liens avec la Russie et les enjeux politiques de la réforme de l'École des langues orientales dans les années 1910 ».

9. Liste des publications: bibliothèque de l'IFP, Arch. nat., 62AJ/62, dossier IFP publications.

10. Avant la guerre, l'Institut accueillait jusqu'à 170 élèves. La plupart d'entre eux étaient des femmes. «Louis Réau : rapport sur le fonctionnement de l'Institut présenté au conseil d'administration. Année scolaire 1911-1912, Saint-Pétersbourg, 1913 », Arch. nat., sous-série AJ/16 : Académie de Paris, fonds 6953.

11. Ibid.

12. «Lettre de Gaston Caminade à Paul Boyer », $02 / 05 / 1913$; Lettre de Jules Patouillet à Paul Boyer, 15/12/1915, Arch. nat., 62AJ/62, dossiers Caminade / Patouillet.

13. Voir la correspondance entre Réau et Boyer, Arch. nat., 62AJ/62, dossier Réau.

14. "Lettre de Paul Boyer à Louis Réau », 16/10/1912, Arch. nat., 62AJ/62, dossier correspondance Boyer.

15. "Jules Patouillet, note sur l'Institut français de Pétrograd », Arch. nat., 62AJ/61, dossier Avenard / Malfitano.

16. M. Ehrhard, « Jules Patouillet »; « Dossier de carrière Jules Patouillet », Arch. nat., sous-série F/17, carton 24267.

17. «Lettre de Jules Patouillet à Émile Mâle », 01/12/1913, archives de l'Institut de France, fonds Émile Mâle, ms. 7656, fol. 19.

18. "Jules Patouillet, note sur l'Institut français de Pétrograd», Arch. nat., 62AJ/61, dossier Avenard / Malfitano.

19. A. N. Dmitriev, «La mobilisation intellectuelle: la communauté académique internationale et la Première Guerre mondiale »; J. Leonhard, Die Büchse der Pandora : Geschichte des Ersten Weltkriegs.

20. Voir les fonds suivants aux Archives diplomatiques: série 1 СРСОМ : guerre (1914-18), sous-série Russie, fonds 681-686; série Correspondance politique et commerciale (1914-40), sous-série 117CPCOM : URSS (1918-1929), fonds 378-389. 
21. "Note à M. Philippe Berthelot sur l'organisation de la propagande en Russie ", fin 1915, Arch. dipl., série papiers d'agents; arch. priv., 10PAAP : papiers de Philippe Berthelot, fonds 15, fol. 1-11.

22. «Jules Patouillet, note sur l'Institut français de Pétrograd », Arch. nat., 62AJ/61, dossier Avenard / Malfitano.

23. « Lettres de Jules Patouillet à Ernest Lavisse », 11/11/1914 et 17/11/1914, Arch. nat., 62AJ/61, dossier Rapports des directeurs, 1911-1916.

24. J. Patouillet, «L'armée et le soldat russes ».

25. "Note à M. Philippe Berthelot sur l'organisation de la propagande en Russie ", fin 1915, Arch. dipl., 10PAAP/15, fol. 1-11 ; «Lettre de Jules Patouillet à Robert de Caix ", 15/02/1916, Arch. dipl., 1CPCOM/681, fol. 8-14.

26. « Lettre de Jules Patouillet à Robert de Caix », 15/02/1916, Arch. dipl., 1CPCOM/681, fol. 8-14.

27. « Rapport Langlois », 09/02/1916, Arch. dipl., 10PAAP 10/15.

28. «Lettre de Jules Patouillet à Robert de Caix », 150/2/1916, Arch. dipl., 1CPCOM/681, fol. 8-14.

29. «Lettre de Paul Jean à Robert de Caix », 19/03/1916, Arch. dipl., série 1CPCOM/681, fol. 20-26.

30. "Lettre de Maurice Paléologue à Aristide Briand", 03/03/1916, Arch. dipl., 10PAAP/15.

31. «Lettre du comte de Chevilly à Robert de Caix », 25/07/1916, Arch. dipl., 1CPCOM/ 682, fol. 81-82.

32. « Lettre de Jules Patouillet à Robert de Caix », 03/01/1917, Arch. dipl., 1CPCOM/683, fol. 14-15.

33. «Lettre de Jules Patouillet à Paul Boyer », 07/09/1917, Arch. nat., 62AJ/62, dossier Jules Patouillet.

34. «Comte de Chevilly : note pour la direction de la propagande », 16/10/1917, Arch. dipl., 117CPCOM/378, fol. 2-14.

35. «Lettre de Jules Patouillet à Paul Boyer, 02/11/1917 », Arch. nat., 62AJ/62, dossier Jules Patouillet.

36. Pour la Commission chargée de l'examen des questions russes, voir Arch. dipl., 1 CPCOM/683bis.

37. «Lettre de Étienne Avenard et Giovanni Malfitano à Émile Borel », 17/12/1917 ", Arch. dipl., 1CPCOM/684, fol. 67-73.

38. «Lettre de Jules Patouillet à Paul Boyer ", 26/01/1918, Arch. nat., 62AJ/62, dossier Jules Patouillet.

39. R. Labry, Autour du bolchevisme.

40. Arch. dipl., série 417Q0 : service des Euvres français à l'étranger (1912-1940), fonds 39 : Russie (1912-1932) ; J. Patouillet, « Les relations intellectuelles entre la France et la Russie ».

41. «Lettre de Jules Patouillet à Paul Boyer », 07/05/1920, Arch. nat., sous-série 62AJ, fonds 62, dossier Jules Patouillet. 


\section{RÉSUMÉS}

L'Institut français de Pétrograd ne cherchait pas uniquement à promouvoir la coopération scientifique franco-russe. Dès sa fondation en 1911, il a été aussi un acteur de la diplomatie culturelle en vue d'améliorer l'image de la France à l'étranger. En temps de guerre, l'Institut se transforma en un organe de propagande politique. Sous l'égide de son ambitieux directeur, Jules Patouillet, l'institut aspirait à participer activement à la politique russe de la France. Son engagement au sein du service de la propagande française lui ouvrait de nouvelles possibilités, mais causait également des problèmes et rivalités. L'article s'interroge sur la genèse, les fonctions et les limites de l'activité de l'Institut français de Pétrograd entre 1914 et 1918. Se penchant sur un sujet jusqu'à présent peu étudié, il propose de contribuer de manière innovatrice à l'histoire des relations franco-russes ainsi qu'aux recherches sur la propagande à l'époque de la Grande Guerre.

\section{AUTEUR}

\section{MANUEL GEIST}

Doctorant en histoire, Albert-Ludwigs-Universität Freiburg, Allemagne 